
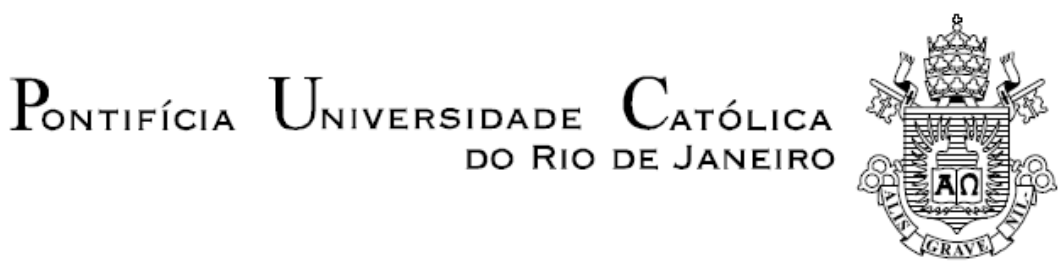

Rodrigo Pereira David

\title{
Detecção Distribuída em Canais Seletivos em Frequência e Algoritmos para Fusão Centralizada
}

\author{
Tese de Doutorado
}

Tese apresentada ao programa de Pós-Graduação em Engenharia Elétrica do Departamento de Engenharia Elétrica da PUC-Rio como parte dos requisitos parciais para obtenção do título de Doutor em Engenharia Elétrica.

Orientador: Prof. Raimundo Sampaio Neto Co-orientador: Cesar Augusto Medina Sotomayor

Rio de Janeiro

Outubro de 2014 


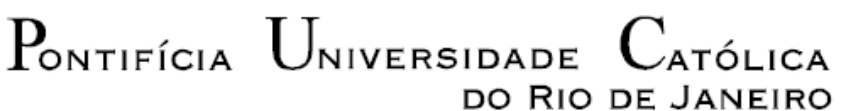

DO RIO DE JANEIRO

Rodrigo Pereira David

Detecção Distribuída em Canais Seletivos em Frequência e Algoritmos para Fusão Centralizada

Tese apresentada como requisito parcial para obtenção do grau de Doutor pelo Programa de Pós-Graduação em Engenharia Elétrica do Departamento de Engenharia Elétrica do Centro Técnico Científico da PUC-Rio. Aprovada pela Comissão Examinadora abaixo assinada.

Prof. Raimundo Sampaio Neto Orientador

Centro de Estudos em Telecomunicações /PUC-Rio

Prof. Cesar Augusto Medina Sotomayor Co-Orientador

Centro de Estudos em Telecomunicações /PUC-Rio

Prof. Rodrigo Caiado de Lamare Centro de Estudos em Telecomunicações /PUC-Rio

Prof. José Mauro Pedro Fortes Centro de Estudos em Telecomunicações /PUC-Rio

Prof. Marcello Luiz Rodrigues de Campos UFRJ

Prof. Moisés Vidal Ribeiro UFJF

Prof. Juraci Ferreira Galdino IME

Prof. José Eugenio Leal Coordenador Setorial do Centro

Técnico Científico - PUC-Rio

Rio de Janeiro, 31 de outubro de 2014 
Todos os direitos reservados. É proibida a reprodução total ou parcial do trabalho sem autorização da universidade, do autor e do orientador.

\section{Rodrigo Pereira David}

Graduou-se em Engenharia Elétrica com ênfase em Telecomunicações na Universidade do Estado do Rio de Janeiro(UERJ) em julho de 2002. Recebeu título de Mestre em Engenharia Elétrica na área de Sistemas de Comunicações pela PUC-Rio em 2004. Atualmente é Pesquisador-Tecnologista da Divisão de Metrologia em Tecnologia da Informação e Telecomunicações - Inmetro.

Ficha Catalográfica

David, Rodrigo Pereira

Detecção distribuída em canais seletivos em frequência e algoritmos para fusão centralizada / Rodrigo Pereira David; orientador: Raimundo Sampaio Neto; co-orientador: César Augusto Medina Sotomayor - 2014

130 f. ; $30 \mathrm{~cm}$

Tese (doutorado) - Pontifícia Universidade Católica do Rio de Janeiro, Departamento de Engenharia Elétrica, 2014.

Inclui bibliografia

1. Engenharia elétrica - Teses. 2. Detecção Distribuída. 3. Canais Seletivos em Frequência. 4. Fusão de Dados. I. Sampaio Neto, Raimundo. II. Sotomayor, Cesar Augusto Medina. III. Pontifícia Universidade Católica do Rio de Janeiro. Departamento de Engenharia Elétrica. IV. Título. 
Aos meus filhos Frederico e Arthur. 


\section{Agradecimentos}

Ao meu orientador, o professor Raimundo Sampaio Neto pela sua dedicação no ensino e por sua excelente orientação não apenas no doutorado, mas ao longo de toda minha vida acadêmica. Fica aqui todo meu respeito e admiração.

Ao co-orientador deste trabalho, o doutor César Augusto Medina Sotomayor, pelos enriquecedores conselhos que contribuíram para o desenvolvimento desta tese.

Aos professores que compuseram a minha banca de defesa, pelas suas valiosas contribuições na redação final desta tese.

Aos demais professores do CETUC e do Departamento de Engenharia Elétrica que contribuíram para o meu desenvolvimento profissional.

Ao colega João Cal Braz pelas discussões e contribuições para o desenvolvimento da minha tese.

Ao Inmetro, em especial ao Rodolfo Sabóia, pelo auxílio concedido, sem o qual este trabalho não poderia ser realizado.

À minha esposa Alessandra pelo companheirismo e compreensão nesta etapa de minha vida. 


\section{Resumo}

Pereira David, Rodrigo; Sampaio Neto, Raimundo (Orientador); Sotomayor, Cesar Augusto Medina (Co-orientador). Detecção Distribuída em Canais Seletivos em Frequência e Algoritmos para Fusão Centralizada. Rio de Janeiro, 2014. 130p. Tese de Doutorado - Departamento de Engenharia Elétrica, Pontifícia Universidade Católica do Rio de Janeiro.

Este trabalho estuda o problema de detecção de hipóteses binárias em sistemas distribuídos com centro de fusão operando em presença de canais seletivos em frequência. O uso de uma técnica de múltiplo acesso, referida aqui como CS-CDMA, é proposta para comunicação ortogonal entre os nós e o centro de fusão, assim como detector ótimo Bayesiano para fusão de dados em tais sistemas distribuídos é obtido. Como a complexidade do detector ótimo cresce exponencialmente com o número de nós sensores, um receptor sub-ótimo de baixa complexidade que realiza uma detecção casada multi-usuário seguida de decisão pela regra da maioria é proposto e examinado neste trabalho. Técnicas para estimação de canal, cega e assistida, necessárias para a implementação prática da detecção casada são também propostas. Simulações indicam que este receptor, de baixa complexidade, possui um desempenho próximo ao receptor ótimo. Com o objetivo de se ampliar o desempenho do detector casado do centro de fusão, é examinado o uso de cooperação na rede de sensores. Resultados de simulações mostraram que, como esperado, o uso de cooperação em sistema distribuídos utilizando o esquema de múltiplo acesso CS-CDMA melhora o desempenho do decisor do centro de fusão, entretanto esse ganho de desempenho mostrou-se mais significativo em ambientes com poucos multipercursos, uma vez que os sistemas distribuídos CS-CDMA não-cooperativos propostos exploram eficientemente a diversidade de multipercurso. Finalmente, este trabalho propõe um procedimento de fusão adaptativa não-assistida para sistemas distribuídos com fusão centralizada. Simulações mostram que a estratégia de fusão adaptativa possui desempenho muito próximo ao da regra de fusão ótima.

\section{Palavras-chave}

Detecção Distribuída; Canais Seletivos em Frequência; Fusão de Dados. 


\section{Abstract}

Pereira David, Rodrigo; Sampaio Neto, Raimundo (Advisor); Sotomayor, Cesar Augusto Medina (Co-Advisor). Distributed Detection in Frequency Selective Channels and Algorithms for Centralized Fusion. Rio de Janeiro, 2014. 130p. DSc. Thesis - Departamento de Engenharia Elétrica, Pontifícia Universidade Católica do Rio de Janeiro.

This work studies the problem of detecting binary hypotheses in distributed systems with a fusion center operating in frequency selective channels. The use of a multiple access technique, referred herein as Chip Spread-Code Division Multiple Access (CS-CDMA), is proposed for orthogonal communication between the nodes and the fusion center and the Bayesian optimum detector for data fusion for such distributed systems is obtained. As the complexity of the optimal detector grows exponentially with the number of sensor nodes, a sub-optimal lowcomplexity receiver that performs a multi-user matched detection followed by the majority rule is proposed and examined in this work. Blind and assisted techniques for channel estimation necessary for the practical implementation of the matched detection have also been proposed. Simulations indicate that this low complexity receptor has a performance close to the optimal receiver. In order to increase the performance of the matched detector of the fusion center, it was examined the use of cooperation in this sensor network. Simulation results showed that, as expected, the use of cooperation in the distributed system with a multiple access scheme CS-CDMA improves the performance of the fusion center, however, this performance increasing was more significant in environments with few multipath, since the non-cooperative CS-CDMA distributed systems proposed here, efficiently exploits the multipath diversity. Finally, this paper proposes a non-assisted adaptive fusion for distributed systems with centralized fusion. Simulations show that the adaptive fusion strategy has a performance very close to the optimal fusion rule.

\section{Keywords}

Distributed Detection; Frequency Selective Channels; Data Fusion 


\section{Sumário}

1. Introdução

1.1. Organização do texto __ 19

2. Modelagem, Transmissão e Fusão em Redes de Sensores CS-CDMA _ 21

2.1. Modelagem da Rede de Sensores __ 21

2.1.1. Detecção Distribuída em Canal Ideal __ 23

2.2. Esquema Proposto para Detecção Distribuída em Canal Seletivo em Frequência__ 26

2.2.1. Sistema CS-CDMA _ 26

2.2.2. Regra de Fusão Ótima para Redes de Sensores CS-CDMA__ 29

2.2.3. Regra de Fusão Sub-Ótima para Redes de Sensores CS-CDMA___ 31

2.3. Simulações e Resultados__ 35

2.3.1. Receptor Sub-ótimo CS-CDMA vs Receptor Ótimo CS-CDMA ___ 36

2.3.2. Desempenho dos Receptores Sub-Ótimos CS-CDMA e DS-CDMA __ 39

2.3.3. Desempenho dos Receptores Sub-Ótimos CS-CDMA e DS-CDMA com Códigos não Ortogonais e Transmissão Assíncrona___ 44

2.4. Conclusões __ 48

3. Desempenho de Redes de Sensores com Esquema de Transmissão CSCDMA Utilizando Estimação de Canal

3.1. Estimação Cega de Canal para Redes de Sensores CS-CDMA _ 49

3.2. Estimação Assistida de Canal para Redes de Sensores CS-CDMA___ 51

3.3. Simulações e resultados

3.3.1. Receptor Sub-ótimo CS-CDMA vs Receptor Sub-ótimo DS-CDMA __ 53

3.4. Estimação Cega de Canal em Redes de Sensores CS-CDMA em Ambientes Variantes no Tempo __ 59

3.5. Conclusões _ 61

4. Redes Cooperativas de Sensores _ 62

4.1. Redes Cooperativas de Sensores com Transmissão CS-CDMA __ 62

4.2. Simulações e resultados _ 67

4.2.1. Rede Sensores CS-CDMA Cooperativa vs Rede de Sensores CS-CDMA Não-Cooperativa__ 68

4.3. Conclusões _ 72

5. Fusão Adaptativa em Redes de Sensores _ 73

5.1. Formulação do Aprendizado Online___ 74

5.2. Processo Adaptativo de Estimação Conjunta dos Pesos e do Limiar de Decisão

5.2.1. Fusão Adaptativa Baseado no Algoritmo LMS:

5.2.2. Fusão Adaptativa Baseada no Algoritmo RLS: ___ 81

5.3. Simulações e Resultados___ 82

5.3.1. Desempenho da Fusão Adaptativa vs Fusão Ótima ___ 83

5.4. Análise de Convergência dos Algoritmos Propostos ___ 88

5.4.1. Análise da Evolução do Erro Médio Quadrático Relativo ao Sinal de Referência 
5.5. Avaliação da Probabilidade de Erro de Decisão no Centro de Fusão

5.5.1. Análise de Probabilidade de Erro

5.6. Algoritmo de Gradiente para minimização da DER __ 105

5.7. Conclusões _ 109

6. Conclusões e Trabalhos Futuros

Referências bibliográficas

Apêndice A 


\section{Lista de figuras}

Figura 2. 1: Esquema de detecção distribuída

Figura 2. 2: Estrutura da sequência de blocos transmitidos pelo sensor $k$ (CSCDMA)

Figura 2. 3: Canal binário equivalente sensor/canal

Figura 2. 4: DER vs número de sensores para uma SNR média do canal de $5 \mathrm{~dB}$ e $12 \mathrm{~dB}$

Figura 2. 5: DER vs SNR média do canal para uma SNR local de $0 \mathrm{~dB}$ e $\mathrm{K}=5$ sensores locais

Figura 2. 6: DER vs SNR do sensor local para uma SNR média do canal de $11 \mathrm{~dB}$ e $\mathrm{K}=5$ sensores locais

Figura 2. 7: Comparação das estruturas das sequências de blocos transmitidos pelo sensor $k$ no sistema proposto CS-CDMA e sistema DS-CDMA

Figura 2. 8: DER vs número de sensores para uma SNR média do canal de $11 \mathrm{~dB}$ e SNR local de $0 \mathrm{~dB}$

Figura 2. 9: DER vs SNR média de canal para uma SNR local de $0 \mathrm{~dB}$ e $\mathrm{K}=7$ sensores locais

Figura 2. 10: DER vs SNR local para uma SNR média de canal de $11 \mathrm{~dB}$ e $\mathrm{K}=7$ sensores locais

Figura 2. 11: DER vs SNR local para uma SNR média de canal de $11 \mathrm{~dB}$ e $\mathrm{K}=7$ sensores locais, utilizando códigos $\mathrm{PN}$ de comprimento 32

Figura 2. 12: DER vs SNR local para uma SNR média de canal de $11 \mathrm{~dB}$ e $\mathrm{K}=7$ sensores locais, utilizando códigos $\mathrm{PN}$ de comprimento 10

3: DER vs SNR local para uma SNR média de canal de $11 \mathrm{~dB}$ e $\mathrm{K}=7$ sensores locais, utilizando códigos PN de comprimento 32 e com assincronia na transmissão dos símbolos.

Figura 3. 1: Evolução do valor médio quadrático dos erros de estimação dos filtros de detecção para redes de sensores CS-CDMA e DS-CDMA com uma SNR média de canal de $10 \mathrm{~dB}$ e $\mathrm{K}=7$ sensores locais

Figura 3. 2: DER vs número de sensores para uma SNR média do canal de $11 \mathrm{~dB}$ e SNR local de $0 \mathrm{~dB}$

Figura 3. 3: DER vs SNR local para uma SNR média de canal de $10 \mathrm{~dB}$ e $\mathrm{K}=7$ sensores locais

Figura 3. 4: DER vs SNR médio de canal para uma SNR local de $0 \mathrm{~dB}$ e $\mathrm{K}=7$ sensores locais

Figura 3. 5: DER vs SNR local para uma SNR média de canal de $10 \mathrm{~dB}$ e $\mathrm{K}=7$ sensores locais-canal variante no tempo

Figura 4. 1: Diagrama de Bloco da Rede de Sensores Cooperativa

Figura 4. 2: Diagrama da transmissão para o centro de fusão na Fase I

Figura 4. 3: Diagrama da transmissão para o sensor relay na Fase I

Figura 4. 4: Diagrama da transmissão para o centro de fusão na Fase II

Figura 4. 5: DER vs SNR do sensor local para uma SNR média do canal multipercurso $\mathrm{SNR}_{w}=6 \mathrm{~dB}$ e $\mathrm{K}=7$ sensores locais

Figura 4. 6: DER vs número de sensores para uma SNR média do canal multipercurso $\mathrm{SNR}_{w}=6 \mathrm{~dB}$ e SNR local $=1 \mathrm{~dB}$ 
Figura 4. 7: DER vs SNR do sensor local para uma SNR média do canal plano $\mathrm{SNR}_{w}=6 \mathrm{~dB}$ e $\mathrm{K}=7$ sensores locais

Figura 4. 8: DER vs número de sensores para uma SNR média do canal plano $\mathrm{SNR}_{w}=6 \mathrm{~dB}$ e SNR local $=1 \mathrm{~dB}$

Figura 5. 1: Diagrama da regra de fusão geral ótima 76

Figura 5. 2: Regra de fusão adaptativa $\quad 78$

Figura 5. 3: DER vs SNR do sensor local para uma SNR média do canal de $8 \mathrm{~dB}, \mathrm{~K}=7$ sensores locais e probabilidades $a$ priori iguais

Figura 5. 4: DER vs SNR do sensor local para uma SNR média do canal de $8 \mathrm{~dB}, \mathrm{~K}=7$ sensores locais e probabilidades a priori $p_{0}=0,1$ e $p_{1}=0,9$

Figura 5. 5: DER vs SNR do sensor local para uma SNR média do canal de $2 \mathrm{~dB}, \mathrm{~K}=7$ sensores locais e probabilidades $a$ priori iguais

Figura 5. 6: DER vs SNR do sensor local para uma SNR média do canal de $2 \mathrm{~dB}, \mathrm{~K}=7$ sensores locais e probabilidades a priori $p_{0}=0,1 \mathrm{e}$ $p_{1}=0,9$

Figura 5. 7: DER vs SNR do sensor local, $K=7$ sensores locais, SNR média do canal dos sensores: 1 e $2=8 \mathrm{~dB}, 3$ a $5=-2 \mathrm{~dB}, 6$ e $7=7 \mathrm{~dB}$ e probabilidades a priori iguais

Figura 5. 8: DER vs SNR do sensor local, $K=7$ sensores locais, $S N R$ média do canal dos sensores: 1 e $2=8 \mathrm{~dB}, 3$ a $5=-2 \mathrm{~dB}, 6$ e $7=7 \mathrm{~dB}$ e probabilidades $a$ priori $p_{0}=0,1$ e $p_{1}=0,9$

Figura 5. 9: Evolução do erro médio quadrático do algoritmo LMS $(\delta=0,0001)$ e do algoritmo $\operatorname{RLS}(\lambda=0,9999), \mathrm{K}=7$ sensores locais, SNR média do canal de $8 \mathrm{~dB}$ e SNR local dos sensores iguais a $3 \mathrm{~dB}$ e probabilidades a priori $p_{0}=0,1$ e $p_{1}=0,9$

Figura 5. 10: Evolução do erro médio quadrático do algoritmo LMS $(\delta=0,0001)$ e do algoritmo $\operatorname{RLS}(\lambda=0,9999), \mathrm{K}=7$ sensores locais, SNR média do canal de $8 \mathrm{~dB}$ e SNR local dos sensores iguais a $-2 \mathrm{~dB}$ e probabilidades $a$ priori $p_{0}=0,1 \mathrm{e} p_{1}=0,9$

Figura 5. 11: Evolução do erro médio quadrático do algoritmo LMS $(\delta=0,0001)$ e do algoritmo $\operatorname{RLS}(\lambda=0,9999), \mathrm{K}=7$ sensores locais, sistema não homogêneo com $\mathrm{SNR}_{\text {ref }}=3 \mathrm{~dB}$ e probabilidades a priori $p_{0}=0,1 \mathrm{e} p_{1}=0,9$

Figura 5. 12: Evolução do erro médio quadrático do algoritmo LMS $(\delta=0,0001)$ e do algoritmo $\operatorname{RLS}(\lambda=0,9999), \mathrm{K}=7$ sensores locais, sistema não homogêneo com SNR $\mathrm{SN}_{\text {ref }}=-2 \mathrm{~dB}$ e probabilidades a priori $p_{0}=0,1$ e $p_{1}=0,9$

Figura 5. 13: Coeficiente de correlação entre a saída do algoritmo LMS $(\delta=0,0001)$ e do algoritmo $\operatorname{RLS}(\lambda=0,9999)$ com a regra ótima, para $\mathrm{K}=7$ sensores locais, sistema não homogêneo com $\mathrm{SNR}_{r e f}=3 \mathrm{~dB}$ e probabilidades a priori $p_{0}=0,1 \mathrm{e}$ $p_{1}=0,9$

Figura 5. 14: Evolução da DER do algoritmo LMS $(\delta=0,0001)$ e do algoritmo $\operatorname{RLS}(\lambda=0,9999), K=7$ sensores locais, sistema não homogêneo com $\mathrm{SNR}_{r e f}=3 \mathrm{~dB}$ e probabilidades a priori $p_{0}=0,1$ e $p_{1}=0,9$ 
Figura 5. 15: Evolução da DER do algoritmo LMS $(\delta=0,0001)$ e do algoritmo RLS $(\lambda=0,9999), K=7$ sensores locais, sistema não homogêneo com $\mathrm{SNR}_{\text {ref }}=-2 \mathrm{~dB}$ e probabilidades $a$ priori $p_{0}=0,1$ e $p_{1}=0,9$

Figura 5. 16: Coeficiente de correlação entre a saída do algoritmo LMS $(\delta=0,0001)$ e do algoritmo $\operatorname{RLS}(\lambda=0,9999)$ com a regra ótima, para $\mathrm{K}=7$ sensores locais, sistema não homogêneo com $\mathrm{SNR}_{r e f}=-2 \mathrm{~dB}$ e probabilidades $a$ priori $p_{0}=0,1$ e $p_{1}=0,9$

Figura 5. 17: Evolução da DER do algoritmo LMS $(\delta=0,0001)$ e do algoritmo $\operatorname{RLS}(\lambda=0,9999)$, sistema homogêneo, $K=7$ sensores locais, SNR média do canal de $8 \mathrm{~dB}$ e SNR local dos sensores iguais a $3 \mathrm{~dB}$ e probabilidades $a$ priori $p_{0}=0,1 \mathrm{e}$ $p_{1}=0,9$

Figura 5. 18: Evolução da DER do algoritmo LMS $(\mu=0,0001)$ e do algoritmo RLS $(\lambda=0,9999)$, sistema homogêneo, $K=7$ sensores locais, SNR média do canal de $8 \mathrm{~dB}$ e SNR local dos sensores iguais a $-2 \mathrm{~dB}$ e probabilidades a priori $p_{0}=0,1$ e $p 1=0,9 \quad 103$

Figura 5. 19: Coeficiente de correlação entre a saída do algoritmo LMS $(\delta=0,0001)$ e do algoritmo $\operatorname{RLS}(\lambda=0,9999)$, sistema homogêneo, $K=7$ sensores locais, SNR média do canal de $8 \mathrm{~dB}$ e SNR local dos sensores iguais a $3 \mathrm{~dB}$ e probabilidades a priori $p_{0}=0,1$ e $p_{1}=0,9$

Figura 5. 20: Evolução do erro médio quadrático do algoritmo LMS $(\delta=0,0001)$ e do algoritmo $\operatorname{RLS}(\lambda=0,9999), \mathrm{K}=7$ sensores locais, sistema não homogêneo com $\mathrm{SNR}_{r e f}=3 \mathrm{~dB}$ e probabilidades a priori $p_{0}=0,1 \mathrm{e} p_{1}=0,9$

Figura 5. 21: DER vs $\mathrm{SNR}_{\text {ref }}$ para os algoritmos LMS e gradiente. $\mathrm{K}=7$ sensores locais, sistema não homogêneo e probabilidades $a$ priori $p_{0}=0,1$ e $p_{1}=0,9$

Figura 5. 22: DER vs $\mathrm{SNR}_{\text {ref }}$ para os algoritmos LMS e gradiente. $\mathrm{K}=7$ sensores locais, sistema não homogêneo e probabilidades $a$ priori iguais 


\section{Introdução}

O interesse em detecção distribuída surgiu com aplicações de detecção de múltiplos alvos e estimação de fenômenos utilizando múltiplos sensores dispersos geograficamente. Sensores distribuídos foram originalmente motivados por suas aplicações militares, tais como vigilância e controle, e, recentemente, têm sido empregados em uma grande variedade de aplicações [1-3]. O baixo custo dos sensores, a inerente redundância disponível com o uso de redes multi-sensores, a disponibilidade de redes de comunicação com alta taxa de transmissão e o aumento da capacidade computacional têm estimulado um grande interesse neste tópico de pesquisa [1]. Com isso, o processamento distribuído de sinais vem ganhando importância nos últimos anos.

Na teoria clássica de detecção supõe-se que todos os sensores locais (tais como radar, sonar, sensores infravermelhos e outros) transmitem a informação dos dados coletados para um processador central que realiza a detecção ou estimação baseado em técnicas estatísticas convencionais. No sistema de detecção distribuída considerado nesta tese, é realizado um pré-processamento dos dados observados em cada sensor local (frequentemente compressão com perdas) e as informações processadas são transmitidas para um centro de processamento que é conhecido como centro de fusão [2,3].

Algumas das vantagens dos sistemas de processamento distribuído na detecção de sinais são a taxa de transmissão reduzida, maior confiabilidade e custos reduzidos. Além disso, uma arquitetura de sistema distribuído pode resultar em uma melhor resposta às rápidas mudanças no cenário observado. Diferentemente do processador central nos sistemas centralizados, o processador central de um sistema distribuído (chamado de centro de fusão) tem acesso somente às decisões (decisões binárias ou $m$-árias sobre a hipótese observada) transmitidas pelos sensores. Isto resulta em uma perda de desempenho nos sistemas distribuídos quando comparado ao sistema centralizado. Entretanto, essa perda pode ser pequena quando as informações dos sensores são processadas otimamente [4]. O objetivo da maioria dos estudos nesse campo é desenvolver 
algoritmos computacionalmente eficientes nos sensores e no centro de fusão. Em geral, uma rede de sensores distribuídos precisa abordar questões como escolha da topologia, capacidade de reconfigurar a estrutura no caso de falhas de sensores / enlace de comunicações, existência de canaç de retorno entre sensores e centro de fusão, e robustez de algoritmos de processamento de sinal em relação aos modelos estatísticos, jammers, e outras interferências externas.

Esta tese trata do problema de detecção distribuída com hipóteses binárias, em uma rede de sensores sem fio. Este problema tem sido tema de estudo desde o trabalho seminal em [5] com uma longa lista de contribuições desde então [6-12]. É considerado também que os sensores enviam as versões quantizadas de suas observações para um centro de fusão que realiza a decisão final a partir das informações recebidas. Com essa formulação, o escopo de aplicação das redes de sensores pode ser ampliado das aplicações originais, como detecção de evento, vigilância e aplicações militares. Por exemplo, um sistema de comunicação detect and forward com relays, onde um nó de comunicação utiliza $\mathrm{K}$ relays que detectam a informação transmitida pelo nó de comunicação e a retransmitem para um nó destino a fim de explorar a diversidade espacial, pode ser considerado como um caso particular de rede de sensores em uma topologia paralela. Nesse caso, os sensores locais são representados pelos $\mathrm{K}$ relays, o evento de interesse observado pelos sensores locais é o estado do símbolo transmitido pelo nó de comunicação e o centro de fusão é representado pelo nó destino. Outro exemplo de aplicação pode ser o de um sistema de comunicação multiple-input multipleoutput (MIMO), onde as múltiplas antenas transmitem a mesma informação para um receptor de modo a explorar a diversidade espacial. Novamente, esse cenário pode ser enquadrado em uma rede de sensores onde os nós sensores são representados pelas antenas de transmissão, o evento de interesse observado pelos sensores locais é a própria informação dirigida a cada antena (neste caso específico a probabilidade de erro de detecção dos sensores locais seria nula) e o centro de fusão é representado pelo receptor. Verifica-se com esses dois exemplos que o escopo de aplicação de redes de sensores pode ser estendido à sistemas de comunicação que utilizam diversidade espacial. Assim, o modelamento das redes de sensores utilizada nesta tese é ampliado a fim de englobar sistemas clássicos de sensoriamento bem como sistemas de comunicação cooperativa. 
A maioria dos trabalhos encontrados na literatura científica considera as observações dos sensores como sendo condicionalmente independentes. Além de ser razoável na prática, a ausência desta suposição leva a uma estratégia de decisão ótima cuja complexidade computacional para obter uma resposta é $N P$ hard $[4,6]$. Com essa suposição, um resultado fundamental é que o quantizador binário, ótimo em cada sensor, é implementado por um teste de razão de verossimilhança utilizando limiar que depende das decisões dos outros sensores [4,6,8]. Entretanto, a determinação desses limiares é, geralmente, difícil por causa da existência de múltiplos ótimos locais [8] e os algoritmos propostos para a busca numérica dos limiares não garantem um mínimo global [8].

No caso especial das observações dos sensores serem consideradas identicamente distribuídas, é razoável admitir que o uso de sensores com o mesmo limiar de decisão (sensores idênticos) leve à solução ótima, porém, contraintuitivamente, os autores em [4] apresentaram exemplos em que a solução ótima é obtida com o uso de sensores não idênticos. Em muitos casos, porém, o uso de sensores idênticos apresenta uma perda de desempenho pequena com relação à escolha ótima de sensores não idênticos, perda essa que desaparece à medida que o número de sensores cresce indefinidamente [4].

O uso de sensores idênticos simplifica enormemente o problema e a regra de fusão ótima para $\mathrm{K}$ sensores é a regra $n$-out-of-K (em uma rede de $\mathrm{K}$ sensores se $n$ ou mais sensores decidem por uma hipótese esta é considerada a hipótese verdadeira pelo centro de fusão) com o uso de um limiar $\mu$ comum a todos os sensores [13-14]. Assim, a busca pela solução ótima se resume a achar o par $(n, \mu)$ que minimiza a probabilidade de erro média final do detector (critério de Bayes). Entretanto, a determinação do par $(n, \mu)$ ótimo exige o conhecimento da distribuição de probabilidade das observações nos sensores. É mostrado em [13] que para observações independentes e identicamnete distribuídas (i.i.d), com função densidade de probabilidade simétrica e com média nula, a regra de fusão ótima se torna a regra da maioria (onde em uma rede de $\mathrm{K}$ sensores se mais de $\mathrm{K} / 2$ sensores decidem por uma hipótese esta é considerada a hipótese verdadeira pelo centro de fusão) e o limiar $\mu$ ótimo dos sensores é igual a zero.

Recentemente, foram apresentados estudos de esquemas de detecção distribuída universais [15-16] em que as observações dos sensores são corrompidas por um ruído aditivo com distribuição de probabilidade desconhecida 
[16]. Este fato torna estes esquemas atraentes para serem implementados em redes de sensores reais, já que as estatísticas do ruído ambiente podem variar. Este esquema necessita apenas do conhecimento do momento de segunda ordem do ruído e a probabilidade de erro média resultante tem uma taxa de decaimento exponencial.

Um artigo comparando o esquema de detecção distribuída que utiliza a regra n-out-of-K, cuja optimalidade depende da distribuição de probabilidade do ruído aditivo que corrompe a observação no sensor, com o assim chamado detector distribuído universal que requer apenas o conhecimento do momento de segunda ordem do ruído foi publicado em [17], no qual foi verificada a superioridade de desempenho da regra $n$-out-of-K para observações Gaussianas.

Após uma revisão da literatura dos algoritmos de detecção distribuída, foi observado que os estudos clássicos focam em regras de fusão que supoem canais de transmissão ideais entre os sensores e o centro de fusão [4-12]. Entretanto, , o problema de detecção distribuída em ambientes com canais com desvanescimento plano entre os sensores e o centro de fusão tem despertado grande interesse [1820]. Além disso, esses estudos consideram que as mensagens enviadas pelos sensores acessam o meio através de transmissão ortogonal (TDMA - time division multiple access ou FDMA - frequence division multilpe access), sem interferência mútua entre os sinais.

Em aplicações envolvendo uma rede densa de sensores de baixo custo é desejável que os sensores compartilhem o canal simultaneamente de modo que os mesmos possam ir para um modo de economia de energia mais rápido ao invés de esperar um longo período de tempo em um modo ativo como em um método de acesso como TDMA. Trabalhos considerando transmissão simultânea utilizando Direct-Sequence Code Division Multiple Access (DS-CDMA) dos sensores para o centro de fusão foram publicados [21-22], porém supondo canais com desvanescimento plano, quando canais seletivos em frequencia seriam mais apropriados para o esquema DS-CDMA.

Ressalte-se ainda que a regra de fusão ótima obtida nesses trabalhos consideram o conhecimento prévio da probabilidade de detecção e falso alarme de cada sensor pelo centro de fusão, o que pode não ser uma suposição realística em casos práticos. 
Essa tese enfoca estruturas de transmissão em canais de múltiplo acesso passíveis de serem utilizados pelas redes de sensores em ambientes seletivos em frequência, bem como algoritmos adaptativos não assistidos (sem sequência de treinamento), para recepção das informações transmitidas pelos sensores e realização da decisão final, a partir das informações recebidas no centro de fusão.

$\mathrm{Na}$ presença de canais seletivos em frequência, o desempenho do sistema DS-CDMA degrada substancialmente devido a perda de ortogonalidade entre as sequências de espalhamento usadas pelos sensores com a resultante interferência de múltiplo acesso (IMA).

A fim de mitigar esses efeitos esse trabalho propõe o uso de uma variação de uma técnica CDMA chamada de Chip Spread-Code Division Multiple Access (CS-CDMA) [23-24] como método de acesso da rede de sensores na presença de canais seletivos em frequência. A técnica CS-CDMA tem a propriedade de evitar a IMA em canais seletivos em frequência, o que permite que as mensagens dos sensores sejam separadas idealmente no centro de fusão. Essa parte do trabalho foi publicada em [25]. Como a complexidade deste fusor ótimo possui aumento exponencial com o número de sensores, foi também proposto em [25] um esquema sub-ótimo, porém prático, de recepção no centro de fusão. $\mathrm{O}$ desempenho do esquema de recepção sub-ótimo para redes de sensores utilizando CS-CDMA foi comparado com redes de sensores utilizando um esquema subótimo para esquemas DS-CDMA tradicionais com detecção linear MMSE (minimum mean square error).

Além disso, com base na estrutura simples do sinal CS-CDMA de cada sensor que é recebido pelo centro de fusão, uma técnica simples para estimação cega de canal é proposto. Esse método cego é baseado na busca do autovetor associado ao maior autovalor da matriz de autocorrelação do vetor de observação. Esta busca pode ser feita eficientemente pelo método das potências [26,47]. Métodos de estimação de canal assistida (utilizando pilotos) também são propostos. O desempenho do esquema de recepção sub-ótimo para redes de sensores utilizando CS-CDMA, em que o receptor realiza estimação cega e assistida do canal multipercurso, foram comparados com o esquema de recepção sub-ótimo utilizando DS-CDMA e cujo receptor realiza detecção baseada no método RLS também foram apresentadas. Resultados desta parte do trabalho também aparecem em [25]. 
A confiabilidade da decisão final feita no centro de fusão depende da qualidade das decisões dos sensores e da qualidade dos canais que conectam esses sensores ao centro de fusão. Uma maneira, examinada neste trabalho, para aumentar a confiabilidade das mensagens recebidas no centro de fusão é a inclusão de relays na rede de sensores [27-28]. Neste esquema, nós relays são empregados para retransmitir os dados dos nós sensores, e, consequentemente, melhorar o desempenho de transmissão pelo aumento de diversidade espacial. Assim, essa tese contempla uma rede de sensores CS-CDMA cooperativa que é investigada em ambientes com desvanecimento plano e seletivo em frequência com o objetivo de explorar o compromisso natural de complexidade e desempenho de detecção. No esquema proposto cada nó da rede atua como sensor e relay simultaneamente. Cada nó sensor transmite seus próprios dados e retransmite os dados do nó sensor vizinho, formando assim um par sensor cooperativo, através de uma cooperação detect-and-forward (DEF). Um artigo resultante dessa parte do trabalho foi publicado em [29].

A estrutura de transmissão proposta nesse trabalho para rede de sensores tem como objetivo mitigar os efeitos do canal entre os sensores e o centro de fusão. Desse modo, estimativas de boa qualidade das mensagens dos sensores podem ser obtidas no receptor do centro de fusão, estimativas estas que são utilizadas na detecção final da hipótese observada pelos sensores através de uma regra de fusão.

A regra de fusão ótima, dada às decisões dos sensores, foi desenvolvida em [7] para uma média ponderada destas decisões, ponderadas de acordo com sua confiabilidade que é função da probabilidade de falso alarme e misdetection de cada sensor, é comparada com um limiar que, por sua vez, é função da probabilidade a priori das hipóteses (considerando hipóteses binárias). Entretanto, as probabilidades de falso alarme e misdetection de cada sensor e a probabilidade a priori da observação não são, em geral, conhecidas. Além disso, os sensores são, geralmente, expostos a ambientes variantes no tempo fazendo com que o desempenho de cada sensor individual não permaneça constante. Isto torna complexa a aplicação da regra de fusão ótima em redes de sensores.

Em [30] foi proposto um algoritmo para a estimação das probabilidades envolvidas em um sistema de detecção distribuída de hipóteses binárias. Contudo como o algoritmo necessita resolver um sistema de K-1 equações não lineares: em 
que K é igual ao número de sensores, sua complexidade aumenta demasiadamente com o aumento do número de sensores. Algoritmos iterativos foram propostos [31-33] para estimar as probabilidades envolvidas, entretanto o tempo de convergência destes algoritmos pode ser demasiadamente longo, tornando-os pouco adequados para ambientes variantes no tempo. Em [34] um algoritmo simples de fusão que faz uma aproximação da solução maximum likelihood (ML) foi proposta para um cenário onde os sensores locais possuem probabilidade de detecção desconhecida, contudo suas probabilidades de falso alarme são supostamente conhecidas pelo centro de fusão. Já em [35], foi proposto um algoritmo para estimar adaptativamente os pesos associados à confiabilidade das decisões de cada sensor, que são utilizados na média ponderada da regra de fusão. Contudo o limiar de decisão não é estimado, mas sim suposto como zero, o que torna este limiar de decisão ótimo apenas no caso de hipóteses binárias equiprováveis e sub-ótimo no caso geral. No presente trabalho, algoritmos adaptativos são propostos a fim de estimar conjuntamente os pesos e o limiar de decisão da regra de fusão. A implementação dessa regra de fusão adaptativa é baseada em algoritmos least mean square (LMS) e recursive least squares (RLS) que utilizam decisões sub-ótimas geradas pelo receptor do centro de fusão como referência nesses algoritmos. Análises de desempenho e convergência desta regra de fusão adaptativa são apresentadas nessa tese. Esta parte do trabalho foi publicado em [60].

\section{1}

\section{Organização do texto}

No capítulo 2 são apresentados a topologia e o modelo de comunicação da rede de sensores adotados, bem como a formulação matemática geral do problema de detecção distribuída com fusão centralizada em rede de sensores. O esquema de múltiplo acesso CS-CDMA é proposto para uso na rede de sensores em canais seletivos em frequência. O receptor ótimo e o receptor sub-ótimo, com processamento em dois estágios, são obtidos e resultados do desempenho desses receptores são apresentados. Comparações entre redes de sensores utilizando o esquema de transmissão tradicional DS-CDMA e o esquema proposto CS-CDMA também são apresentados. 
No Capítulo 3 são propostos técnicas de estimação cega e assistida de canais para redes de sensores utilizando o esquema de transmissão CS-CDMA. São apresentados resultados de simulações comparando o desempenho dos receptores sub-ótimos para redes de sensores CS-CDMA utilizando as estimativas de canal cega e assistida, com o receptor para redes de sensores DS-CDMA utilizando equalização RLS.

O Capítulo 4 examina o uso de cooperação na rede de sensores CS-CDMA a fim de explorar a diversidade espacial e, consequentemente, prover robustez aos efeitos do canal. O modelo de cooperação proposto é apresentado para redes de sensores utilizando esquema de transmissão CS-CDMA. Resultados de simulações, comparando os desempenhos das redes de sensores CS-CDMA cooperativa e não-cooperativa, são apresentados.

No capítulo 5 a regra de fusão ótima para redes de sensores, com receptores de dois estágios, é reescrita de forma que algoritmos de estimação linear possam ser aplicados na estimação dos parâmetros desconhecidos. Dois algoritmos adaptativos, do tipo least mean square (LMS) e recursive least squares (RLS), para estimação adaptativa conjunta linear dos pesos e do limiar de decisão da regra de fusão ótima. Resultados de simulação são apresentados, considerando uma rede de sensores CS-CDMA, comparando os desempenhos dos esquemas adaptativos com os desempenhos associados à regra de fusão ótima e à regra da maioria. Uma análise de convergência do erro médio quadrático das estimativas geradas pelos algoritmos LMS e RLS são apresentados bem como uma análise da evolução da probabilidade de erro de decisão resultante do uso de estimadores LMS e RLS nos receptores. Finalmente, uma versão modificada do algoritmo LMS cuja função custo é diretamente relacionada à probabilidade de erro de decisão, é apresentada.

Conclusões finais e propostas de trabalhos futuros são apresentadas no Capítulo 6.

Complementam o texto os apêndice A e B. No apêndice A é desenvolvido a formulação do algoritmo adaptativo RLS, enquanto no apêndice B são obtidas expressões analíticas relacionadas ao desempenho dos algoritmos adaptativos propostos. 


\section{2 \\ Modelagem, Transmissão e Fusão em Redes de Sensores CS-CDMA}

No presente capítulo são apresentados o modelo de comunicação adotado para a rede de sensores com fusão centralizada de dados.

A formulação matemática geral do problema de detecção distribuída em rede de sensores é apresentado na Seção 2.1., considerando um canal de transmissão ideal. Na Seção 2.2 são considerados canais seletivos em frequência, e o esquema de múltiplo acesso CS-CDMA é proposto para uso na rede de sensores. O receptor ótimo e receptores sub-ótimos também são desenvolvidos nessa seção.

$\mathrm{Na}$ Seção 2.3, são apresentados resultados do desempenho dos receptores ótimos e sub-ótimos em uma rede de sensores utilizando o esquema de transmissão CS-CDMA. Comparações entre redes de sensores, utilizando o esquema de transmissão tradicional DS-CDMA e o esquema proposto CS-CDMA, foram realizadas e os resultados são apresentados no fim dessa seção.

As conclusões desse capítulo são apresentadas na Seção 2.4.

\section{1}

\section{Modelagem da Rede de Sensores}

O presente trabalho considera o problema de teste binário de hipóteses por uma rede de sensores conectada ao centro de fusão em uma arquitetura distribuída paralela, ou seja, os sensores não se comunicam entre si.

Sejam $H_{0}$ e $H_{1}$, a hipótese nula e a hipótese alternativa de um evento com probabilidade a priori $P\left(H_{0}\right)=p_{0}$ e $P\left(H_{1}\right)=p_{1}$, respectivamente. Uma rede de $\mathrm{K}$ sensores é empregada na área do evento, sendo que cada sensor local $k=1, \ldots, \mathrm{K}$, decide por uma das hipóteses, independentemente dos demais sensores em cada período de observação. As hipóteses binárias adotadas nesta tese são modeladas como: 


$$
\begin{aligned}
& H_{1}: u=+1 \\
& H_{0}: u=-1
\end{aligned}
$$

em que $u$ é uma variável aleatória representando a hipótese binária.

Quando as observações em cada sensor são condicionalmente independentes, os detectores ótimos dos sensores são implementados como testes de razão de verossimilhança utilizando diferentes limiares [4]. Assim sendo, a tomada de decisão em cada sensor local é independente das decisões realizadas pelos demais sensores, através de sua observação local ruidosa $y_{k}$ de modo a gerar a sua decisão local que é a saída de um teste de razão verossimilhança (likelihood ratio test - LRT):

$$
\frac{p_{y_{k} \mid H_{1}}}{p_{y_{k} \mid H_{0}}} \underset{H_{0}}{\gtreqless} \mu_{k}
$$

em que $p_{y_{k} \mid H_{i}}$ representa a função densidade de probabilidade $(f d p)$ da observação $y_{k}$ condicionada à hipótese $H_{i}$ e $\mu_{k}$ é o limiar de decisão do $k$-ésimo sensor. Entretanto, o uso de limiares idênticos simplifica significativamente o problema e em muitos casos, a perda de optimalidade é muito pequena [9]. Desse modo, neste trabalho os limiares dos K sensores são iguais.

Assumindo uma modulação binária, supõe-se sem perda de generalidade, que as decisões binárias locais são mapeadas em símbolos $b_{k}(i) \in\{-1,+1\}$ que são codificados em um esquema de transmissão de múltiplo acesso (TDMA, CDMA, etc) e transmitidos para o centro de fusão que realiza a decisão final $\hat{u}$ por meio de uma regra de fusão que é função das mensagens $b_{k}(i)$ enviadas pelos sensores.

A Figura 2.1 ilustra o esquema de detecção distribuída para hipóteses binárias utilizando uma rede de $\mathrm{K}$ sensores em uma topologia paralela. 


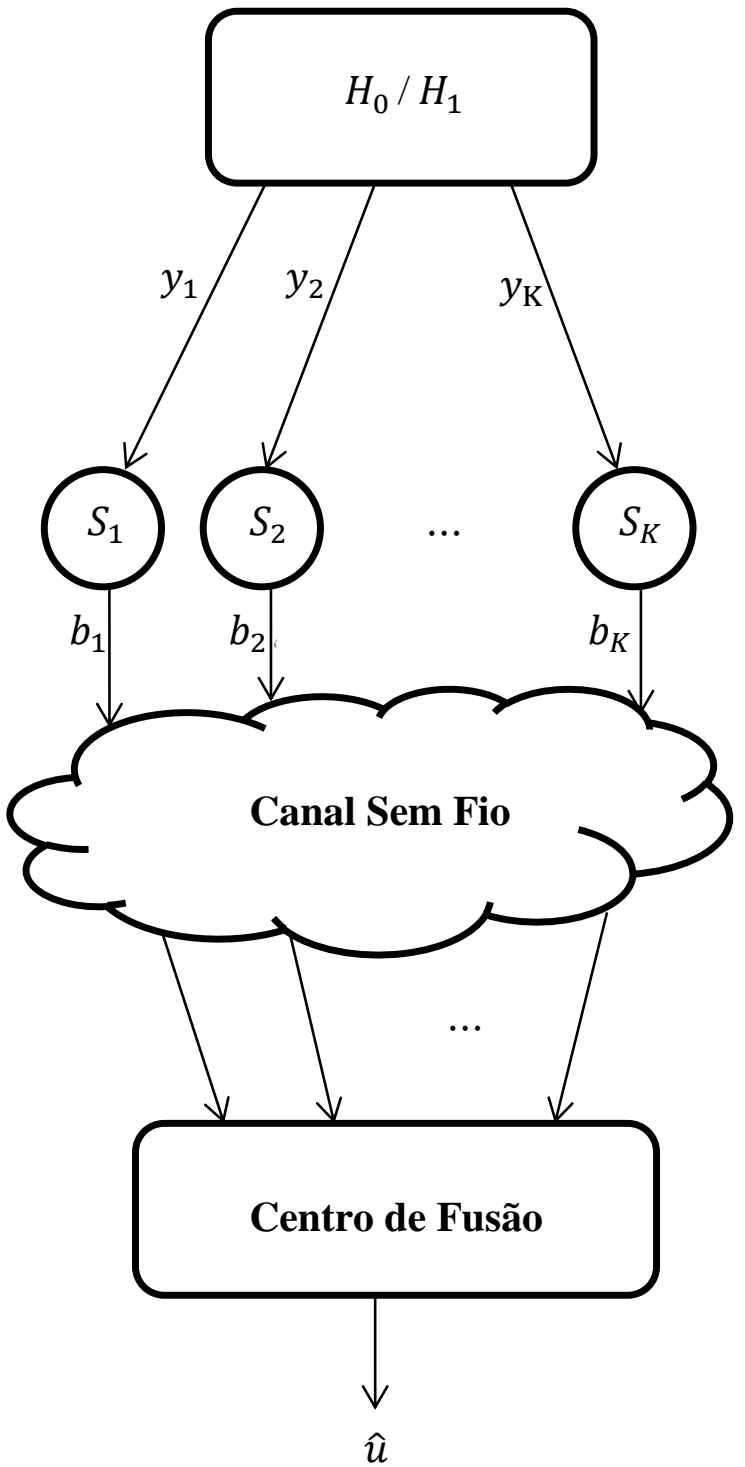

Figura 2.1: Esquema de detecção distribuída

\subsection{1}

\section{Detecção Distribuída em Canal Ideal}

Para o caso de canal ideal, e assumindo que o centro de fusão recebe independentemente cada mensagem $b_{k}$, podemos interpretar o problema de fusão dos dados (realização da tomada de decisão final pelo centro de fusão) recebidos pelo centro de fusão como um teste binário de hipóteses baseado no vetor $\mathbf{b}=\left[b_{1} \ldots b_{\mathrm{K}}\right]^{T}$. A regra de fusão Bayesiana ótima é dada pelo teste de razão de verossimilhança (LRT) [4]: 


$$
L(\mathbf{b})=\frac{P\left(\mathbf{b} \mid H_{1}\right)}{P\left(\mathbf{b} \mid H_{0}\right)} \underset{H_{0}}{H_{1}}
$$

em que $\tau$ é o limiar do centro de fusão que depende das probabilidades a priori $p_{0}$ e $p_{1}$ e da função custo a otimizar. A função $P\left(\mathbf{b} \mid H_{i}\right)$ representa a probabilidade de ocorrência do vetor b condicionado à hipótese $H_{i}$. Para teste de máxima probabilidade a posteriori (MAP) o limiar é $\tau=\frac{p_{0}}{p_{1}}$.

Assumindo que as observações locais são condicionalmente independentes as probabilidades condicionais $P\left(\mathbf{b} \mid H_{i}\right)$ para $i=1,0$ podem ser expressas como:

$$
P\left(\mathbf{b} \mid H_{i}\right)=\prod_{k=1}^{K} P\left(b_{k} \mid H_{i}\right)
$$

na qual

$$
P\left(b_{k} \mid H_{1}\right)=\left\{\begin{array}{cl}
1-P_{M_{k}}^{S} & ; b_{k}=1 \\
P_{M_{k}}^{S} & ; b_{k}=-1
\end{array}\right.
$$

e

$$
P\left(b_{k} \mid H_{0}\right)=\left\{\begin{array}{c}
1-P_{F_{k}}^{S} ; b_{k}=-1 \\
P_{F_{k}}^{S} ; b_{k}=1
\end{array}\right.
$$

sendo $P_{M_{k}}^{S}$ e $P_{F_{k}}^{S}$ são as probabilidades de misdetection e falso alarme do $k$-ésimo sensor, respectivamente.

Deste modo substituindo (2-4) em (2-3) o teste MAP é escrito como:

$$
L(\mathbf{b})=\frac{\prod_{k=1}^{K} P\left(b_{k} \mid H_{1}\right)}{\prod_{k=1}^{K} P\left(b_{k} \mid H_{0}\right)} \underset{H_{0}}{H_{1}} \tau
$$

Em [7] é mostrado que a regra MAP, dado o vetor $\mathbf{b}$, pode ser escrita, manipulando (2-7), como uma soma ponderada das decisões dos sensores locais $b_{k}$ :

$$
\hat{u}=\left\{\begin{aligned}
1 & ; \text { se } a_{0}+\sum_{k=1}^{K} a_{k} b_{k}>0 \\
-1 ; & \text { caso contrário }
\end{aligned}\right.
$$


sendo que os pesos ótimos são dados por:

$$
\begin{aligned}
& a_{0}=\log \frac{p_{1}}{p_{0}} \\
& a_{k}=\log \frac{1-P_{M_{k}}^{S}}{P_{F_{k}}^{S}}, \text { se } b_{k}=1, \\
& a_{k}=\log \frac{1-P_{F_{k}}^{S}}{P_{M_{k}}^{S}}, \text { se } b_{k}=-1 .
\end{aligned}
$$

Se os sensores possuem regras de detecção idênticas e, além disso, as observações $y_{k}$ de cada sensor $k$ são identicamente distribuídas, as probabilidades misdetection e falso alarme se tornam idênticas, ou seja, $P_{M_{k}}^{S}=P_{M}^{S}$ e $P_{F_{k}}^{S}=P_{F}^{S}$. Nesse caso, é mostrado em [4,7] que a regra de fusão ótima, dado o vetor $\mathbf{b}$, se reduz a regra $n$-out-of-K:

$$
\hat{u}=\left\{\begin{aligned}
1 & \text { se } b_{1}+\cdots+b_{\mathrm{K}} \geq 2 n-\mathrm{K} \\
-1 & \text { caso contrário }
\end{aligned}\right.
$$

onde $n$ é função das probabilidades a priori e das probabilidades de misdetection e falso alarme dos sensores e K é o número total de sensores. Assim, a decisão global $\hat{u}$ é igual a 1 se $n$ ou mais sensores decidem por 1 .

Se as probabilidades a priori são idênticas e $P_{M}^{S}=P_{F}^{S}$, é mostrado em [7] que a regra de fusão ótima se torna a regra da maioria e o centro de fusão faz decisão final $\hat{u}$ de acordo com:

$$
\widehat{u}=\left\{\begin{aligned}
1 & \text { se } b_{1}+\cdots+b_{\mathrm{K}}>0 \\
-1 & \text { caso contrário }
\end{aligned}\right.
$$

Vale ressaltar aqui que a regra da maioria dada em (2-13) é um caso especial da regra geral $n$-out-of-K. 


\section{2}

\section{Esquema Proposto para Detecção Distribuída em Canal Seletivo em Frequência}

$\mathrm{Na}$ seção anterior foram apresentadas regras de fusão em uma rede de sensores, nas quais as mensagens dos sensores eram recebidas sem erro pelo centro de fusão. Nesta sub-seção serão apresentadas técnicas de transmissão e algoritmos de detecção para redes de sensores em canais seletivos em frequência. Aqui serão enfocadas estruturas de múltiplo acesso CDMA para que em redes densas, os sensores possam acessar o canal simultaneamente.

O uso do esquema DS-CDMA tradicional para transmissão das mensagens $b_{k}$ em um ambiente seletivo em frequência introduz termos de IMA no receptor do centro de fusão. A fim de mitigar esse efeito este trabalho propõe o uso de uma variação do esquema CS-CDMA, descrito na próxima seção.

\subsection{1}

\section{Sistema CS-CDMA}

No esquema CS-CDMA $[23,24]$ os $\mathrm{N}$ chips de uma sequência de código $\mathbf{c}_{k}=\left[c_{k, 0} \ldots c_{k, \mathrm{~N}-1}\right]^{T}$, com $\left\|\mathbf{c}_{k}\right\|^{2}=1$, são multiplicados pelo mesmo vetor de dados $\mathbf{b}_{k}(i)$ de comprimento $\mathrm{P}$, conforme ilustrado na Figura 2.2.

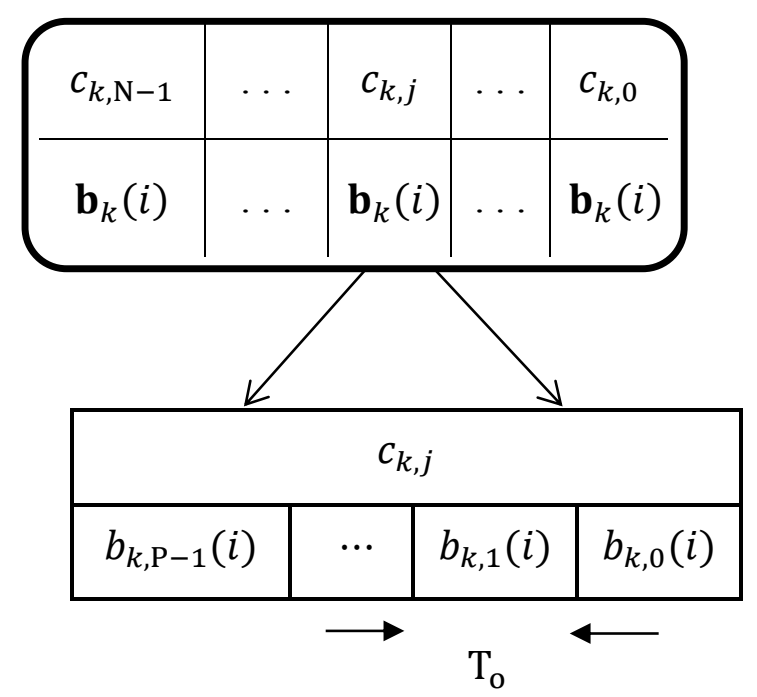

Figura 2.2: Estrutura da sequência de blocos transmitidos pelo sensor $k$ (CS-CDMA) 
O bloco de dados transmitido pelo sensor $k$ no $j$-ésimo período de símbolo, $j=0,1, \ldots, \mathrm{N}-1$, é dado por $\mathbf{b}_{k}(i) c_{k, j}$, sendo $c_{k, j}$ o $j$-ésimo chip da sequência de código do $k$-ésimo sensor. As $\mathrm{P}$ componentes de $\mathbf{b}_{k}(i) c_{k, j}$ são transmitidas serialmente através do canal multipercurso.

O equivalente discreto do canal entre o sensor $k$ e o centro de fusão é modelado como um filtro FIR (finite impulse response) $\mathbf{h}_{k}(i)$ de comprimento L:

$$
\mathbf{h}_{k}(i)=\left[h_{k, 0}(i) \ldots h_{k, \mathrm{~L}-1}(i)\right]^{T}
$$

cujos coeficientes são amostras do equivalente passa-baixa da resposta ao impulso do canal tomadas a taxa de $1 / \mathrm{T}_{\mathrm{o}}$, em que $\mathrm{T}_{\mathrm{o}}$ é a duração associada às componentes do bloco $\mathbf{b}_{k}(i) c_{k, j}$.

Para conveniência de notação, o índice de tempo do símbolo $i$ será omitido no restante do texto

O bloco de dados $\mathbf{b}_{k} c_{k, j}$ é, então, transmitido através do canal multipercurso e o sinal recebido no centro de fusão, assumindo sincronismo perfeito de símbolo e relógio e $\mathrm{P} \geq \mathrm{L}-1$, é dado por:

$$
\mathbf{x}_{k}(j)=\mathbf{H}_{T_{k}} \mathbf{b}_{k} c_{k, j}+\mathbf{H}_{k}^{p} \mathbf{b}_{k}^{p} c_{k}^{p}+\mathbf{H}_{k}^{s} \mathbf{b}_{k}^{s} c_{k}^{s}+\mathbf{n}_{w}^{o}(j)
$$

em que $\mathbf{H}_{T_{k}}$ é uma matriz Toeplitz de convolução $(\mathrm{P}+\mathrm{L})$ x $\mathrm{P}$, cuja primeira coluna é a resposta ao impulso do equivalente discreto do canal completada com $\mathrm{P}$ zeros $\quad\left[\mathbf{h}_{k}^{T} 0 \ldots 0\right]^{T}, \mathbf{H}_{k}^{p}$ é uma matriz Toeplitz triangular superior $(\mathrm{P}+\mathrm{L}) \mathrm{x}$ P representando a interferência do bloco prévio $\mathbf{b}_{k}^{p} c_{k}^{p}$ do sensor $k$ no bloco atual $\mathbf{b}_{k} c_{k, j}, \mathbf{H}_{k}^{s}$ é uma matriz Toeplitz triangular inferior $(\mathrm{P}+\mathrm{L}) \times \mathrm{P}$ representando a interferência do bloco subsequente $\mathbf{b}_{k}^{s} c_{k}^{s}$ do sensor $k$ no bloco atual e $\mathbf{n}_{w}^{o}(j)$ o vetor de ruído branco do centro de fusão de média zero e matriz covariância $\mathbb{E}\left[\mathbf{n}_{w}^{o}(j) \mathbf{n}_{w}^{o}(j)^{\mathcal{H}}\right]=\sigma_{w}^{2} \mathbf{I}_{\mathrm{P}+\mathrm{L}}$, em que $\mathbf{I}_{\mathrm{P}+\mathrm{L}}$ representa a matriz identidade de dimensão $(P+L)$.

A fim de evitar a interferência entre blocos no sinal recebido, $\mathbf{x}_{k}(j)$, é proposto nesse trabalho que o vetor $\mathbf{b}_{k}$ seja constituído com a mensagem $b_{k}$ do $k$ ésimo sensor concatenada com $\mathrm{L}-1$ zeros (admitindo aqui o conhecimento do 
comprimento do canal), assim $\mathrm{P}=\mathrm{L}$ e $\mathbf{b}_{k}=\left[b_{k} \mathbf{0}_{\mathrm{L}-1}^{T}\right]^{T}$. Com esta estrutura para $\mathbf{b}_{k}$, o termo $\mathbf{H}_{k}^{\boldsymbol{p}} \mathbf{b}_{k}^{\boldsymbol{p}} c_{k}^{\boldsymbol{p}}$ da interferência entre blocos é suprimido.

Além disso, como as L últimas componentes de $\mathbf{x}_{k}(\mathrm{j})$ não contêm elementos do sinal desejado, essas componentes podem ser removidas, ou seja, o termo $\mathbf{H}_{k}^{S} \mathbf{b}_{k}^{\boldsymbol{S}} C_{k}^{\boldsymbol{S}}$ da interferência entre blocos é também removido de (2-15). O vetor de observação resultante $\mathbf{r}_{k}(j)$ de dimensão L x 1 é dado por:

$$
\mathbf{r}_{k}(j)=b_{k} \mathbf{h}_{k} c_{k, j}+\mathbf{n}_{w}(j), j=0,1, \ldots, \mathrm{N}-1
$$

$\mathbf{n}_{w}(j)$ corresponde ao vetor $\mathbf{n}_{w}^{\boldsymbol{o}}(j)$ com as últimas L componentes removidas.

Considerando as transmissões de todos os sensores, o sinal composto recebido pelo centro de fusão é dado por:

$$
\mathbf{r}(j)=\sum_{k=1}^{K} b_{k} \mathbf{h}_{k} c_{k, j}+\mathbf{n}_{w}(j), j=0,1, \ldots, \mathrm{N}-1
$$

Coletando $\mathrm{N}$ consecutivos sinais $\mathbf{r}(j)$ recebidos, a matriz $\mathbf{R}=[\mathbf{r}(0) \ldots \mathbf{r}(\mathrm{N}-1)]$ de dimensão L x N é formada e pode ser escrita como:

$$
\mathbf{R}=\sum_{k=1}^{K} b_{k} \mathbf{h}_{k} \mathbf{c}_{k}^{T}+\mathbf{N}
$$

onde a matriz $\mathbf{N}=\left[\mathbf{n}_{w}(0) \ldots \mathbf{n}_{w}(\mathrm{~N}-1)\right]$.

A partir de (2-18) resulta que a ortogonalidade entre as sequências de códigos de cada sensor é preservada, a despeito da transmissão através do canal multipercurso (desde que o comprimento do código seja maior ou igual a K). Adicionalmente, diferentemente do tradicional esquema DS-CDMA, a IMA pode ser eliminada antes da estimação do canal, equalização e outros procedimentos de detecção no receptor do centro de fusão. O sinal correspondente do sensor $k$ é obtido a partir de:

$$
\widetilde{\mathbf{r}}_{k}=\mathbf{R c}_{k}=b_{k} \mathbf{h}_{k}+\widetilde{\mathbf{n}}_{k} \quad k=1,2, \ldots, \mathrm{K}
$$


em que vetor de ruído $\widetilde{\mathbf{n}}_{k}=\mathbf{R} \mathbf{c}_{k}$ é complexo Gaussiano com média zero e matriz de covariância $\mathbb{E}\left[\widetilde{\mathbf{n}}_{k} \widetilde{\mathbf{n}}_{k}^{\mathcal{H}}\right]=\sigma_{w_{k}}^{2} \mathbf{I}_{\mathrm{L}}$.

Assim, o uso do esquema CS-CDMA apresentado nessa tese, permite ao receptor do centro de fusão separar as $\mathrm{K}$ mensagens transmitidas pelos sensores locais para o centro de fusão.

\subsection{2}

\section{Regra de Fusão Ótima para Redes de Sensores CS-CDMA}

As estatísticas suficientes para determinar a regra de fusão são dadas pelos vetores de saída $\mathbf{r}_{k}$ em (2-16). Os vetores podem ser agrupados a fim de formar o vetor conjunto de saída $\tilde{\mathbf{r}}=\left[\tilde{\mathbf{r}}_{1}{ }^{T} \tilde{\mathbf{r}}_{2}{ }^{T} \ldots \tilde{\mathbf{r}}_{\mathrm{K}}{ }^{T}\right]^{T}$ modelado como:

$$
\widetilde{\mathbf{r}}=\mathbf{H b}+\widetilde{\mathbf{n}}
$$

onde $\mathbf{H}=\left[\begin{array}{cccc}\mathbf{h}_{1} & \mathbf{0}_{\mathrm{Lx} 1} & \ldots & \mathbf{0}_{\mathrm{Lx} 1} \\ \vdots & \mathbf{h}_{2} & \ldots & \vdots \\ \vdots & \vdots & \ddots & \vdots \\ \mathbf{0}_{\mathrm{Lx} 1} & \ldots & \ldots & \mathbf{h}_{\mathrm{K}}\end{array}\right], \mathbf{b}=\left[b_{1} b_{2} \cdots b_{\mathrm{K}}\right]^{T}$ e $\widetilde{\boldsymbol{n}}=\left[\widetilde{\boldsymbol{n}}_{1}{ }^{\boldsymbol{T}} \widetilde{\boldsymbol{n}}_{2}{ }^{\boldsymbol{T}} \cdots \widetilde{\boldsymbol{n}}_{\mathrm{K}}{ }^{T}\right]^{T}$

e a matriz $\mathbf{H}$ possui dimensão $K L$ x K, b é o vetor de dimensão $K$ x 1 contendo as K decisões dos sensores e $\widetilde{\boldsymbol{n}}$ é o vetor de ruído Gaussiano de dimensão KL x 1 com matriz autocorrelação $\mathbf{K}_{\widetilde{\boldsymbol{n}}}=\sigma_{w_{k}}^{2} \mathbf{I}_{\mathrm{KL}}$.

Podemos interpretar o problema de fusão dos dados da rede de sensores CSCDMA como um teste binário de hipóteses baseados no vetor de observação $\tilde{\mathbf{r}}$ e a matriz de coeficientes do canal $\mathbf{H}$. A regra de fusão Bayesiana ótima é dada pelo teste de razão de verossimilhança (LRT) [1-4]:

$$
L(\tilde{\mathbf{r}})=\frac{p\left(\tilde{\mathbf{r}} \mid H_{1}, \mathbf{H}\right)}{p\left(\tilde{\mathbf{r}} \mid H_{0}, \mathbf{H}\right)} \underset{H_{0}}{\gtreqless} \tau,
$$

em que, novamente, $\tau$ é o limiar no centro de fusão que depende das probabilidades a priori $p_{0}$ e $p_{1}$ e a função custo. A função $p\left(\tilde{\mathbf{r}} \mid H_{i}, \mathbf{H}\right)$ representa a função densidade de probabilidade $(f d p)$ do vetor de saída $\tilde{\mathbf{r}}$ condicionado à 
hipótese $H_{i}$ e à matriz de coeficientes de canal $\mathbf{H}$. Para o teste de máxima probabilidade a posteriori (MAP), o limiar é $\tau=\frac{p_{0}}{p_{1}}$ [4].

Utilizando o modelo de sinal recebido $\tilde{\mathbf{r}}$ dado em (2-21) a função razão de verossimilhança $L(\tilde{\mathbf{r}})$ pode ser escrito como:

$$
L(\tilde{\mathbf{r}})=\frac{\sum_{\mathbf{b} \in\{-1,+1\}^{\mathrm{K}}} \exp \left\{\frac{2}{\sigma_{w}^{2}} \mathbb{R}\left(\tilde{\mathbf{r}}^{\mathcal{H}} \mathbf{H b}\right)\right\} P\left(\mathbf{b} \mid H_{1}\right)}{\sum_{\mathbf{b} \in\{-1,+1\}^{\mathrm{K}}} \exp \left\{\frac{2}{\sigma_{w}^{2}} \mathbb{R}\left(\tilde{\mathbf{r}}^{\mathcal{H}} \mathbf{H b}\right)\right\} P\left(\mathbf{b} \mid H_{0}\right)},
$$

na qual operador $\mathbb{R}($.$) representa a parte real. Os somatórios englobam todas$ as $2^{\mathrm{K}}$ possibilidades para o vetor $\mathbf{b}$ transmitido, cujas componentes são as mensagens $b_{k}$ dos sensores.

Devido às premissas assumidas na Seção 2.1, nas equações (2-4) e (2-5), de observações locais condicionalmente independentes e considerando um limiar zero $(\mu=0)$ para a LRT dos sensores locais em (2-2), ou seja, os sensores realizam uma decisão ML (admitimos que os sensores não possuem conhecimento prévio das probabilidades a priori de suas observações), as probabilidades $P_{M_{k}}^{S}$ and $P_{F_{k}}^{S}$ são idênticas. Admitindo-se ainda o mesmo valor de razão sinal-ruído (SNR) para os sensores, nesse caso as probabilidades $P_{M}^{S}$ e $P_{F}^{S}$ se tornam idênticas e são aqui chamadas de $P_{e}$. Assim as probabilidades condicionais $P\left(\mathbf{b} \mid H_{i}\right)$ podem ser expressas como:

$$
P\left(\mathbf{b} \mid H_{i}\right)=P_{e}^{d_{i}(\mathbf{b})}\left(1-P_{e}\right)^{K-d_{i}(\mathbf{b})}
$$

em que $d_{i}(\mathbf{b})$ é a distância de Hamming entre o vetor $\mathbf{b}$ e o vetor correspondente a hipótese verdadeira $H_{i}$ (vetor com todas as componentes iguais a 1 para $H_{1} \mathrm{e}$ iguais a -1 para $H_{0}$ ).

Assumindo que o receptor do centro de fusão não tenha conhecimento da probabilidade a priori da hipótese binária testada, o limiar se torna $\tau=1$, ou seja o receptor realiza um teste de razão de máxima verossimilhança (ML). Nesse caso o receptor ótimo da rede de sensores CS-CDMA realiza a decisão global $\hat{u}$ de acordo com: 


$$
\frac{\sum_{\mathbf{b} \in\{-1,+1\}^{\mathrm{K}}} \exp \left\{\frac{2}{\sigma_{w}^{2}} \mathbb{R}\left(\tilde{\mathbf{r}}^{\mathcal{H}} \mathbf{H b}\right)\right\} P_{e}^{d_{1}(\mathbf{b})}\left(1-P_{e}\right)^{K-d_{1}(\mathbf{b})}}{\sum_{\mathbf{b} \in\{-1,+1\}^{\mathrm{K}}} \exp \left\{\frac{2}{\sigma_{w}^{2}} \mathbb{R}\left(\tilde{\mathbf{r}}^{\mathcal{H}} \mathbf{H b}\right)\right\} P_{e}^{d_{0}(\mathbf{b})}\left(1-P_{e}\right)^{K-d_{0}(\mathbf{b})} \hat{u}=-1} \stackrel{\gtreqless}{\gtreqless} 1 .
$$

\subsection{3}

\section{Regra de Fusão Sub-Ótima para Redes de Sensores CS-CDMA}

Definindo o número de multiplicações requeridas (NoM) como a complexidade computacional de um receptor, então pode ser observado de (2-24) que o decisor ML para o problema de detecção distribuída binário utilizando redes de sensores em um esquema CS-CDMA em canais multipercurso possui uma complexidade exponencial com o número de sensores K. Assim, o uso do receptor que realiza a fusão dos dados ótima em redes com um número de sensores razoavelmente elevado é de difícil implementação. Entretanto, o desempenho do decisor ótimo apresentado em (2-24) fornece um limitante para o desempenho de redes de sensores utilizando esquema CS-CDMA.

Assim para reduzir a complexidade computacional do receptor é proposto um receptor sub-ótimo com complexidade que cresce linearmente com o número de sensores K. Nessa abordagem, a detecção coerente é realizada em um primeiro estágio de forma a estimar os símbolos $b_{k}$ transmitidos pelos sensores locais. O vetor de estimativas dado por

$$
\hat{\mathbf{b}}=\left[\hat{b}_{1} \hat{b}_{2} \ldots \hat{b}_{\mathrm{K}}\right]^{T},
$$

em que $\hat{b}_{k}$ é a estimativa do símbolo $b_{k}$ transmitido pelo sensor $k$ é, então, utilizado pelo receptor para a fusão dos dados.

O primeiro estágio realiza a estimação dos símbolos $b_{k}$ com base no vetor de saída do filtro casado ao $k$-ésimo código $\mathbf{c}_{k}$, dado em (2-19). Como o uso do esquema de transmissão CS-CDMA elimina os termos da IMA, a estimação se torna um problema de detecção de vetores antipodais na presença de AWGN. Desta forma, o detector ótimo de máxima verossimilhança (ML) para o vetor $\widetilde{\mathbf{r}}_{k}$ é um filtro casado ao vetor de canal $\mathbf{h}_{k}$ seguido por um detector de polaridade: 


$$
\widehat{b}_{k}=\operatorname{sgn}\left\{\mathbb{R}\left(\mathbf{h}_{k}^{\mathcal{H}} \widetilde{\mathbf{r}}_{k}\right)\right\}, k=1,2, \ldots, \mathrm{K},
$$

em que o operador $\operatorname{sgn}($.$) é a função sign.$

A complexidade computacional da filtragem casada em (2-26) é proporcional ao comprimento do canal $\mathbf{h}_{k}$ e a complexidade do primeiro estágio de detecção cresce linearmente com o número $\mathrm{K}$ de sensores locais.

Pode-se observar que o filtro casado em (2-26) explora a diversidade de multipercurso tendo em vista (ver (2-19)) que as L componentes de $\widetilde{\mathbf{r}}_{k}$ contêm a mesma informação multiplicada pelos diferentes coeficientes do canal.

Admitindo-se que os canais de transmissão dos diferentes sensores são estatisticamente independentes, tem-se que as estimativas $\hat{b}_{k}$ são condicionalmente independentes, assim as probabilidades condicionais $P\left(\hat{\mathbf{b}} \mid H_{i}\right)$ podem ser expressas como:

$$
P\left(\hat{\mathbf{b}} \mid H_{i}\right)=\prod_{k=1}^{K} P\left(\hat{b}_{k} \mid H_{i}\right) ; i=1,0
$$

Para inserir o efeito de erros na detecção de símbolo provocado pela presença de canal multipercurso no receptor do centro de fusão, as probabilidades de falso alarme e misdetection são substituídas pelas probabilidades condicionais de erro associadas à combinação sensor-canal.

A combinação sensor-canal pode ser visualizada como dois canais binários em série, onde o primeiro canal representa o $k$-ésimo sensor (com probabilidades de transição $P_{M_{k}}^{S}$ e $P_{F_{k}}^{S}$ ) e o segundo canal representa o canal multipercurso entre o $k$-ésimo sensor e o receptor do centro de fusão, com probabilidades de transição $P_{M_{k}}^{c}=P\left(\hat{b}_{k}=-1 \mid b_{k}=+1\right) \quad$ e $\quad P_{F_{k}}^{c}=P\left(\hat{b}_{k}=+1 \mid b_{k}=-1\right) . \quad$ Assim, essa combinação em série de canais binários pode ser representada como um canal equivalente, conforme ilustrado na Figura 2.3: 

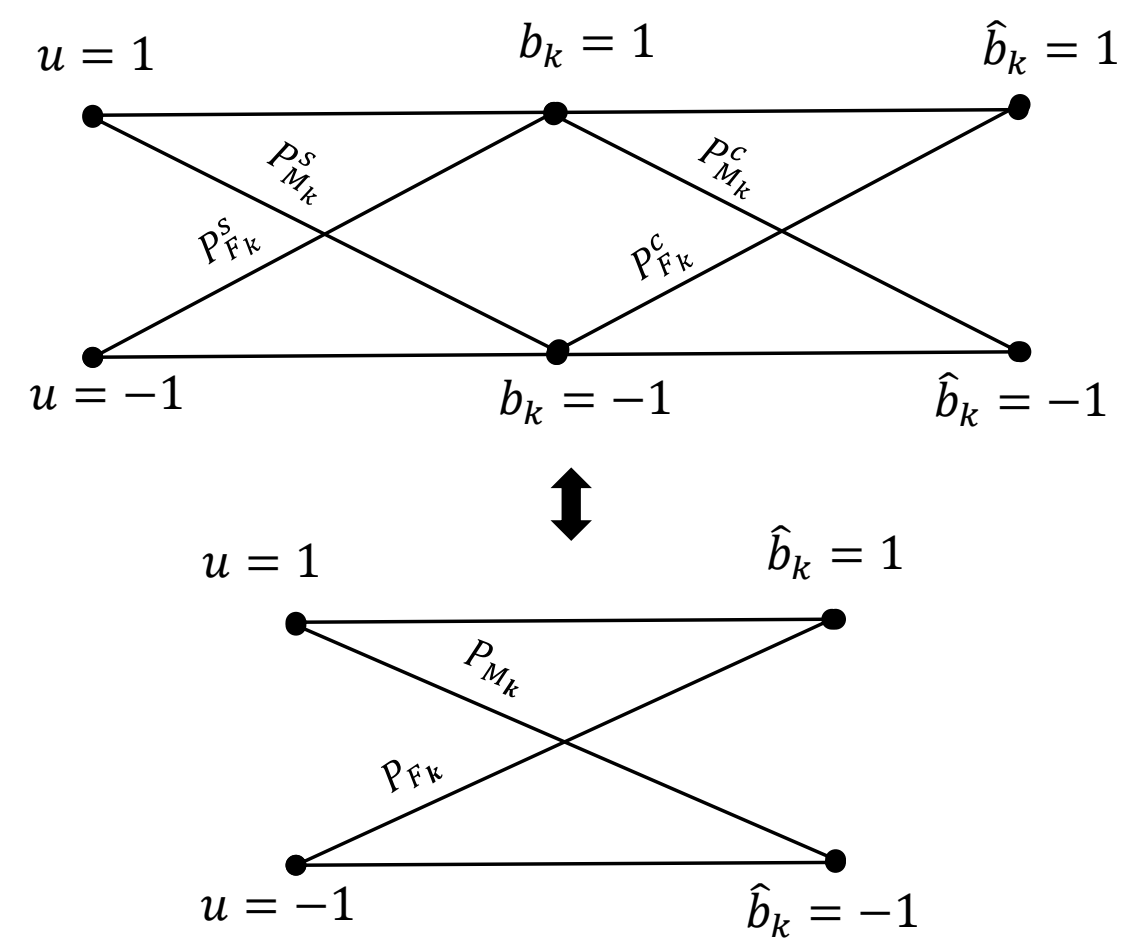

Figura 2.3: Canal binário equivalente sensor/canal.

As probabilidades de erro condicionais associadas à combinação sensorcanal (as probabilidades de transição do canal binário equivalente indicadas na Figura 2.3) são, portanto, dadas por:

$$
\begin{gathered}
P_{M_{k}}=P\left(\hat{b}_{k}=-1 \mid u=+1\right)=P_{M_{k}}^{c}\left(1-P_{M_{k}}^{S}\right)+\left(1-P_{F_{k}}^{c}\right) P_{M_{k}}^{S} \\
P_{F_{k}}=P\left(\hat{b}_{k}=+1 \mid u=-1\right)=P_{F_{k}}^{c}\left(1-P_{F_{k}}^{S}\right)+\left(1-P_{M_{k}}^{c}\right) P_{F_{k}}^{S}
\end{gathered}
$$

Tem-se, assim que:

$$
P\left(\hat{b}_{k} \mid H_{1}\right)=\left\{\begin{array}{cl}
1-P_{M_{k}} ; & \hat{b}_{k}=1 \\
P_{M_{k}} ; & \hat{b}_{k}=-1
\end{array}\right.
$$

$\mathrm{e}$

$$
P\left(\hat{b}_{k} \mid H_{1}\right)=\left\{\begin{array}{cc}
1-P_{F_{k}} ; & \hat{b}_{k}=1 \\
P_{F_{k}} ; & \hat{b}_{k}=-1
\end{array}\right.
$$

No segundo estágio o receptor realiza a fusão de dados de acordo com o teste de razão de máxima verossimilhança dado por: 


$$
L(\hat{\mathbf{b}})=\frac{P\left(\hat{\mathbf{b}} \mid H_{1}\right)}{P\left(\hat{\mathbf{b}} \mid H_{0}\right)}=\prod_{k=1}^{K} \frac{P\left(\hat{b}_{k} \mid H_{1}\right)}{P\left(\hat{b}_{k} \mid H_{0}\right)} \underset{\hat{u}=-1}{\hat{u}=1} \tau
$$

Assim, em total analogia com as expressões (2-3)-(2-11), tem-se que a regra de fusão ótima considerando-se os canais de transmissão é dada por:

$$
\hat{u}=\left\{\begin{aligned}
1 ; & \text { se } a_{0}+\sum_{k=1}^{K} a_{k} \hat{b}_{k}>0 \\
-1 ; & \text { caso contrário }
\end{aligned}\right.
$$

em que

$$
\begin{aligned}
& a_{0}=\log \frac{p_{1}}{p_{0}} \\
& a_{k}=\beta_{k}=\log \frac{1-P_{M_{k}}}{P_{F_{k}}}, \text { se } \hat{b}_{k}=1, \\
& a_{k}=\gamma_{k}=\log \frac{1-P_{F_{k}}}{P_{M_{k}}}, \text { se } \hat{b}_{k}=1,
\end{aligned}
$$

com $P_{M_{k}}$ e $P_{F_{k}}$ definidos em (2-28) e (2-29) respectivamente.

Supõe-se que os canais de transmissão dos sensores são igualmente distribuídos, resultando que $P_{M_{k}}^{c}=P_{M}^{c}$ e $P_{F_{k}}^{c}=P_{F}^{c}, k=1,2, \ldots, \mathrm{K}$ e, devido a detecção ML em (2-26), tem-se que $P_{M}^{c}=P_{F}^{c}$. Supondo que $P_{M}^{S}=P_{F}^{S}$ para os sensores, usada em (2-23) resulta, finalmente, de (2-28) e (2-29) que $P_{M_{k}}=$ $P_{F_{k}}, k=1, \ldots, \mathrm{K}$.

Assim sendo, para o caso de probabilidades a priori idênticas a regra de fusão ótima é dada pela regra da maioria de acordo com (2-13):

$$
\hat{u}=\left\{\begin{array}{rl}
1 & \text { se } \hat{b}_{1}+\cdots+\hat{b}_{\mathrm{K}}>0 \\
-1 \text { caso contrário }
\end{array} .\right.
$$

Esse receptor sub-ótimo tem o mesmo princípio do receptor chamado de receptor Chair-Varshney (CV) que foi desenvolvido para redes de sensores em canais com desvanecimento plano em [7], onde primeiro se estima os símbolos transmitidos e depois utiliza estas estimativas na regra da maioria a fim de realizar 
a decisão final. Além da presente proposta de considerar canais com desvanecimento seletivo em frequência, o uso do esquema CS-CDMA, aqui proposto, permite que a detecção feita no primeiro estágio seja bastante simples, podendo ser realizada otimamente símbolo a símbolo, conforme (2-26), tendo uma complexidade linear com o número de sensores $\mathrm{K}$, para detectar as $\mathrm{K}$ mensagens. Ao passo que no receptor $\mathrm{CV}$ a estimativa ótima do primeiro estágio é o receptor multi-usuário ML demandando $2^{\mathrm{K}}$ testes, ou seja, tem complexidade exponencial com o número de sensores K. Uma estimativa sub-ótima, utilizando o filtro MMSE como detector no primeiro estágio também foi proposta em [32] a fim de se reduzir a complexidade, porém, além da perda da optimalidade, o algoritmo requer o conhecimento das correlações existentes entre as mensagens dos sensores tendo em vista que os mesmos observam o mesmo fenômeno. Outro ponto é que o receptor CV não explora diversidade nos detectores do primeiro estágio, devido à suposição de canal plano.

Assim sendo, nessa tese é desenvolvido um receptor sub-ótimo para redes de sensores em canais seletivos em frequência utilizando o esquema CS-CDMA que possui uma complexidade linear com o número de sensores $\mathrm{K}$.

\section{3}

\section{Simulações e Resultados}

Nas simulações a observação $y_{k}$ do sensor $k$ é modelada como $y_{k}=u . d+$ $n_{k}, k=1,2, \ldots, \mathrm{K}$, em que $u$ é definida em (2-1), $d$ é uma constante conhecida e $n_{k}$ são variáveis aleatórias Gaussianas i.i.d, com média zero e variâncias iguais a $\sigma^{2}$. As probabilidades $a$ priori $p_{0}$ e $p_{1}$ são supostas idênticas. $\mathrm{O}$ sensor $k$ realiza uma detecção ML na observação $y_{k}$ a fim de estimar $u$. As probabilidades $P_{M_{k}}^{S}$ e $P_{F_{k}}^{S}$ resultantes são, portanto, iguais e a probabilidade $P_{e}$ que aparece em (2-24) é dada por $P_{e}=\mathcal{Q}\left(\sqrt{\frac{d^{2}}{\sigma^{2}}}\right)$ em que $\mathcal{Q}($.$) representa o complemento da função de$ distribuição Gaussiana $\left(Q(\alpha)=\int_{\alpha}^{\infty} \frac{1}{\sqrt{2 \pi}} e^{-\frac{x^{2}}{2}} d x\right)$. As mensagens são mapeadas em símbolos BPSK e então transmitidas para o centro de fusão usando o esquema CS-CDMA descrito na seção 2.2.1, com códigos de Hadamard com comprimento $\mathrm{N} \geq \mathrm{K}$. Os canais multipercurso entre os sensores e o centro de fusão são 
independentes e identicamente distribuídos e são modelados por um filtro FIR invariante no tempo contendo $\mathrm{L}=4$ coeficientes. A sequência de coeficientes do $k$-ésimo canal é dada por $h_{k, l}=q_{l} \alpha_{k, l}$, na qual $\alpha_{k, l}, l=0,1, \ldots, \mathrm{L}-1$, são variáveis aleatórias complexas Gaussianas estatisticamente independentes, com média nula e $\mathbb{E}\left[\left|\alpha_{k, l}\right|^{2}\right]=1$ em que o operador $\mathbb{E}[$.$] representa o valor esperado.$ Os valores de $\alpha_{k, l}$ são gerados aleatoriamente e mantidos fixos durante cada rodada de simulação. Os pesos $q_{l}$ satisfazem $\sum_{\mathrm{i}=0}^{\mathrm{L}-1}\left|q_{i}\right|^{2}=1$, e, portanto, $\mathbb{E}\left[\left\|\mathbf{h}_{k}\right\|^{2}\right]=1$, com $q_{0}=0,8671, q_{1}=0,4346, q_{2}=0,2178$ e $q_{3}=0,1092$. Os resultados são dados pela média de 10000 experimentos independentes, com 100 símbolos enviados por sensor em cada realização. É admitido o conhecimento perfeito dos canais pelos receptores.

\subsection{1}

\section{Receptor Sub-ótimo CS-CDMA vs Receptor Ótimo CS-CDMA}

Esta subseção apresenta resultados e compara os desempenhos, obtidos via simulação, do receptor sub-ótimo de baixa complexidade CS-CDMA e do receptor ótimo para a rede de sensores CS-CDMA. Aqui os códigos de Hadamard utilizados possuem comprimento $\mathrm{N}=4$, para valores de $\mathrm{K}=3$ e $\mathrm{N}=8$, para valores de $K=5,7$.

A Figura 2.4 compara os desempenhos de uma rede de sensores utilizando o receptor sub-ótimo de baixa complexidade, proposto na sub-seção 2.2.3, e o receptor ótimo, obtido na subseção 2.2.2, em termos de taxa de erro de decisão (decision error rate - DER) em função do número de sensores para diferentes valores de razão sinal-ruído $\mathrm{SNR}=d^{2} / \sigma^{2}$ do sensor local e da razão sinal-ruído média $\mathrm{SNR}=b_{k}^{2} / \sigma_{w_{k}}^{2}$ do canal (ambas SNR são consideradas iguais para todos os sensores, representando um sistema homogêneo). A figura indica que para canais com SNR de $12 \mathrm{~dB}$, os desempenhos dos receptores são essencialmente idênticos para SNR locais variando de $0 \mathrm{~dB}$ a $8 \mathrm{~dB}$. Isto era esperado, pois em canais com valores altos de SNR o primeiro estágio do receptor sub-ótimo produz mensagens detectadas próximas as do canal ideal (sem erros). Nessa situação, o desempenho é limitado pela SNR do sensor local. Para valores baixos de SNR do canal, o primeiro estágio do receptor sub-ótimo tem uma probabilidade maior de 
produzir estimativas errôneas, de forma que mais erros são cometidos pelo centro de fusão degradando assim o desempenho do detector de baixa complexidade. Isto pode ser observado para uma SNR do canal de $5 \mathrm{~dB}$, na qual a diferença de desempenho entre os detectores ótimos e sub-ótimos são mais evidentes. Quando a SNR dos sensores locais decai para $0 \mathrm{~dB}$ ambos detectores apresentam um desempenho similarmente pobre.

A DER do receptor do centro de fusão é ilustrada na Figura 2.5 como função da SNR do canal, mantendo-se uma SNR de $0 \mathrm{~dB}$ para todos $\mathrm{K}=5$ sensores. Os resultados nessa figura indicam que os desempenhos dos receptores ótimo e sub-ótimo são muito próximos, mesmo para canais com valores baixos de SNR. Além disso, os desempenhos destes receptores convergem para o mesmo valor à medida em que a SNR do canal aumenta.

A DER de fusão versus a SNR dos sensores locais é ilustrada na Figura 2.6 para um número $\mathrm{K}=5$ de sensores e canais com SNR média de $11 \mathrm{~dB}$. Os resultados ilustrados nesta figura e aqueles obtidos com diferentes valores de SNR do canal indicam que para valores práticos de SNR do sensor local (valores baixos) o receptor sub-ótimo tem um desempenho muito próximo ao do receptor ótimo.

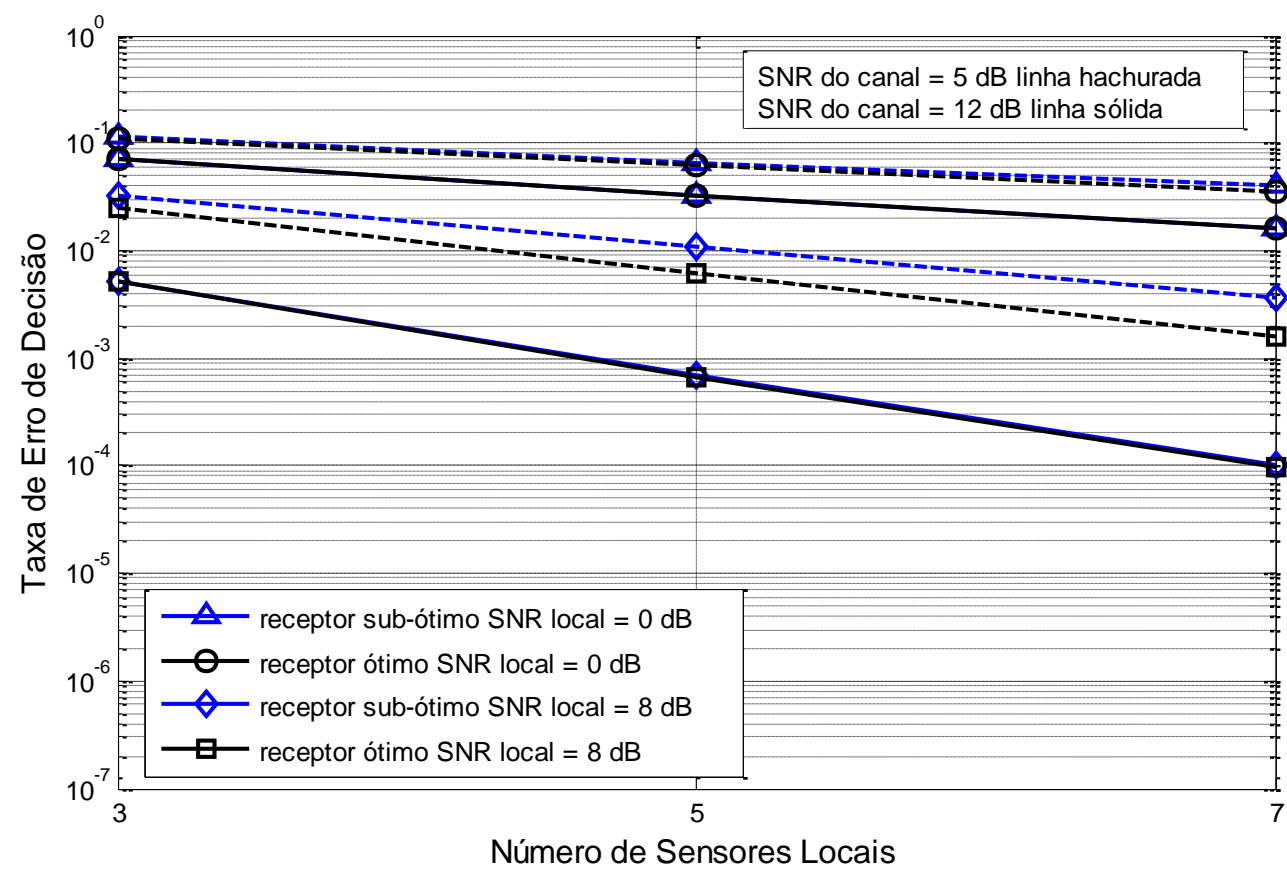

Figura 2.4: DER vs número de sensores para uma SNR média do canal de $5 \mathrm{~dB}$ e $12 \mathrm{~dB}$. 


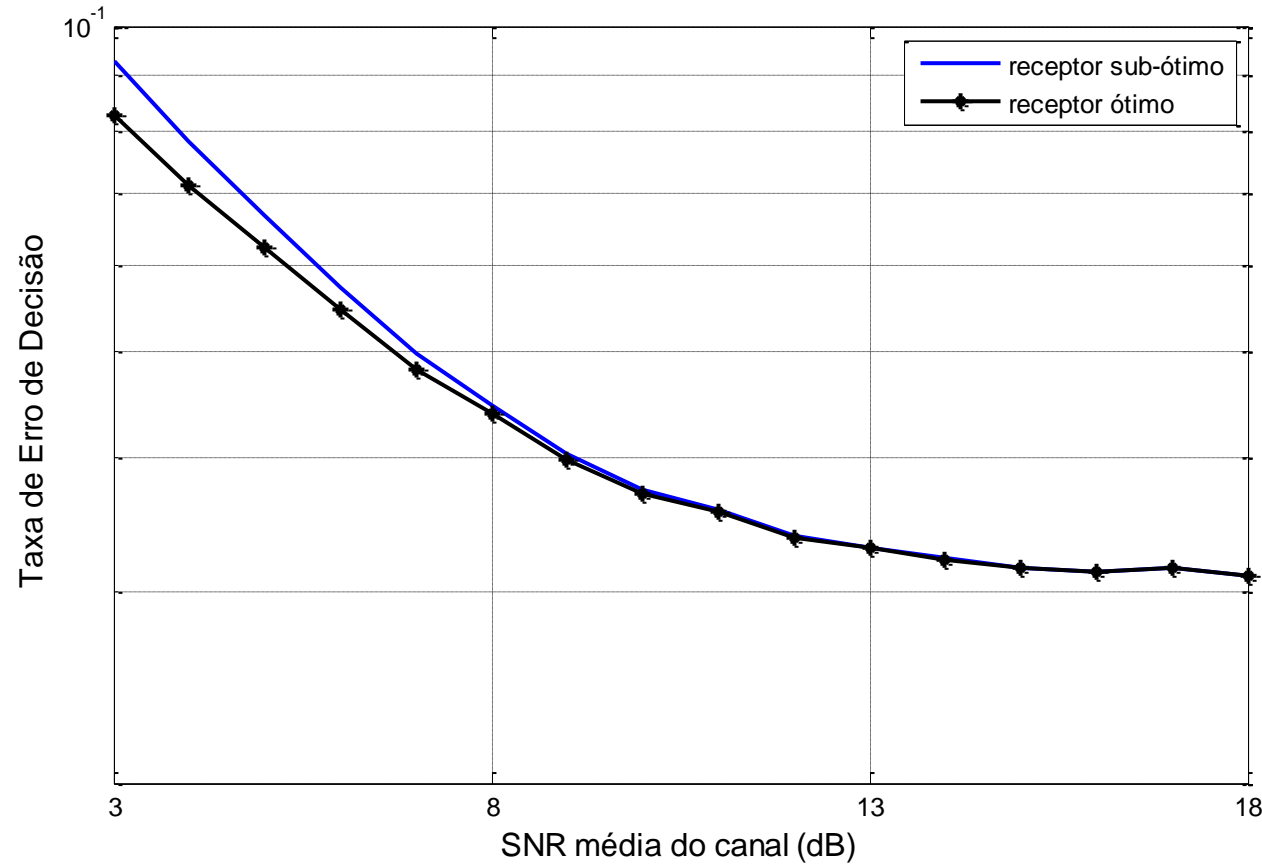

Figura 2.5: DER vs SNR média do canal para uma SNR local de $0 \mathrm{~dB}$ e $\mathrm{K}=5$ sensores locais.

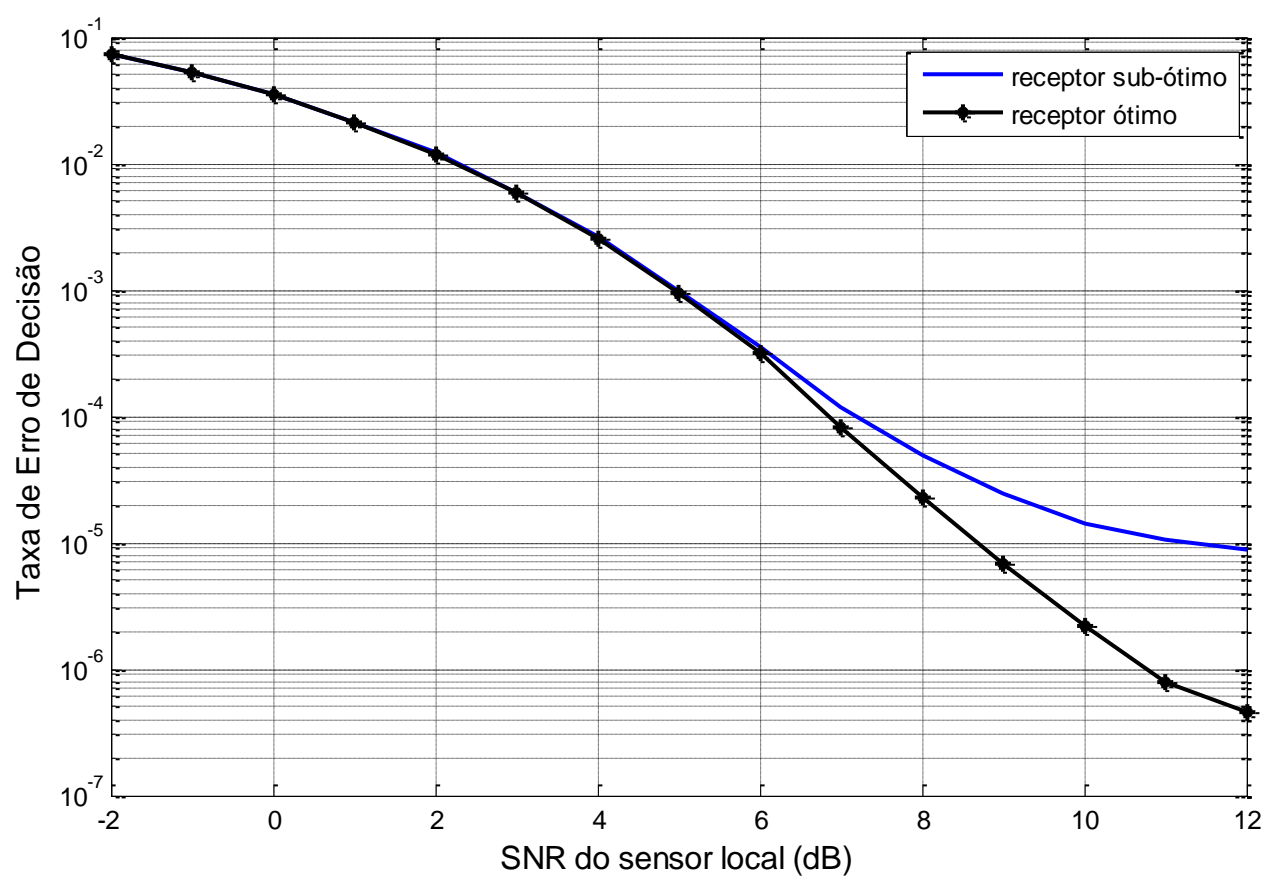

Figura 2.6: DER vs SNR do sensor local para uma SNR média do canal de $11 \mathrm{~dB}$ e $\mathrm{K}=5$ sensores locais. 


\subsection{2}

\section{Desempenho dos Receptores Sub-Ótimos CS-CDMA e DS-CDMA}

Esta subseção apresenta resultados de simulações comparando o desempenho de uma rede de sensores utilizando o esquema de transmissão CSCDMA com o receptor sub-ótimo de baixa complexidade proposto e uma rede de sensores utilizando o esquema de transmissão DS-CDMA com um receptor subótimo similar ao proposto em [21].

$\mathrm{Na}$ transmissão em bloco DS-CDMA o símbolo de transmissão $b_{k}$ transmitido pelo sensor $k$ é multiplicado por uma sequência de $\mathrm{N}^{\prime}$ chips, $\mathbf{c}_{k}$. Um intervalo de guarda utilizando zero padding de comprimento $\mathrm{L}-1$ é inserido no fim de cada bloco $\mathbf{c}_{k} b_{k}$ antes da transmissão resultando em um bloco de transmissão com comprimento $\mathrm{M}=\mathrm{N}^{\prime}+\mathrm{L}-1$. A fim de simplificar o processo de equalização, a equalização no domínio da frequência (FDE) é utilizada no receptor do centro de fusão. Assim depois da aplicação de uma DFT de M pontos, o vetor de observação de comprimento $\mathrm{M} \mathrm{x} 1$ pode ser expresso como [37]:

$$
\mathbf{r}=\sum_{k=1}^{K} \mathbf{H}_{D_{k}} \mathbf{V} \mathbf{c}_{k} b_{k}+\widehat{\mathbf{n}}_{w}
$$

em que $\mathbf{H}_{D_{k}}=\operatorname{diag}\left(\hat{\mathbf{h}}_{k}\right), \hat{\mathbf{h}}_{k}=\sqrt{P} \mathbf{F}_{\mathrm{M}, \mathrm{L}} \mathbf{h}_{k}$ e $\mathbf{F}_{\mathrm{M}, \mathrm{L}}$ é uma matriz normalizada de dimensão $\mathrm{M}$ x L contendo as L primeiras colunas da matriz que implementa uma DFT de dimensão $\mathrm{M}$. A matriz $\mathbf{V}$ de dimensão $\mathrm{M} \times \mathrm{N}^{\prime}$ é definida por $\mathbf{V}=\mathbf{F}_{\mathrm{M}, \mathrm{N}}, \mathrm{O}$ vetor de ruído $\widehat{\mathbf{n}}_{w}=\mathbf{F}_{\mathrm{M}} \mathbf{n}_{w}$ é complexo Gaussiano com média zero e matriz de covariância $\mathbb{E}\left[\widehat{\mathbf{n}}_{w} \widehat{\mathbf{n}}_{w}{ }^{\mathcal{H}}\right]=\sigma_{w}^{2} \mathbf{I}_{\mathrm{M}}$.

O receptor sub-ótimo do centro de fusão da rede de sensores que utiliza transmissão DS-CDMA procede de maneira similar ao que é feito no caso CSCDMA: o primeiro estágio estima os símbolos $b_{k}$ transmitidos pelos sensores e o segundo estágio implementa a decisão final pela regra da maioria.

Dois detectores para o primeiro estágio do receptor da rede de sensores DSCDMA são utilizados na comparação. O detector coerente mais simples utiliza um filtro casado ao sinal de um único sensor, o assim chamado receptor convencional. 
A saída do filtro casado ao sinal correspondente ao $k$-ésimo sensor local é dado por:

$$
\begin{gathered}
\hat{b}_{k}=\operatorname{sgn}\left\{\mathbb{R}\left(\mathbf{c}_{k}^{T}\left(\mathbf{H}_{D_{k}} \mathbf{V}\right)^{\mathcal{H}} \mathbf{r}\right)\right\} \\
\hat{b}_{k}=\operatorname{sgn}\left\{\mathbb{R}\left(\mathbf{s}_{k}^{\mathcal{H}} \mathbf{r}\right)\right\}
\end{gathered}
$$

O detector acima tem uma complexidade computacional mais alta do que o do detector do primeiro estágio utilizado nas redes de sensores CS-CDMA dado em (2-26), visto que o vetor $\mathbf{s}_{k}$ possui dimensão $\mathrm{M}$ x 1 , sendo que em geral $\mathrm{M}>>$ L, além da necessidade da aplicação de uma matriz DFT. Além disso, diferentemente do esquema CS-CDMA, seu desempenho é degradado pela presença de termos de interferência de múltiplo acesso (IMA).

A fim de tentar reduzir os efeitos da IMA, considerou-se também o detector linear MMSE na obtenção das estimativas do primeiro estágio:

$$
\begin{gathered}
\hat{b}_{k}=\operatorname{sgn}\left\{\mathbb{R}\left(\left[\mathcal{R}^{-1} \mathbf{p}_{k}\right]^{\mathcal{H}} \mathbf{r}\right)\right\} \\
=\operatorname{sign}\left\{\mathbb{R}\left(\boldsymbol{w}_{k}^{\mathcal{H}} \mathbf{r}\right)\right\},
\end{gathered}
$$

em que $\mathcal{R}$ é a matriz de auto-correlação do vetor de observação $\mathbf{r}$ em (2-38) dada por:

$$
\mathcal{R}=\mathbb{E}\left[\mathbf{r} \mathbf{r}^{\mathcal{H}}\right]=\sum_{k=1}^{K} \mathbf{H}_{D_{k}} \mathbf{V} \mathbf{c}_{k} \mathbf{c}_{k}^{\mathcal{H}} \mathbf{V}^{\mathcal{H}} \mathbf{H}_{D_{k}}^{\mathcal{H}}+\sigma_{w}^{2} \mathbf{I}_{\mathrm{M}}
$$

e $\mathbf{p}_{k}$ é o vetor de correlação cruzada expresso por:

$$
\mathbf{p}_{k}=\mathbb{E}\left[b_{k} \mathbf{r}\right]=\mathbf{H}_{D_{k}} \mathbf{V c}_{k}
$$

O detector MMSE atinge um melhor desempenho, à custa de uma maior complexidade computacional, quando comparado ao receptor convencional (filtro casado), uma vez que o mesmo requer a inversão de uma matriz de dimensão $\mathrm{M} \mathrm{x}$ $\mathrm{M}, \mathrm{M}=\mathrm{N}^{\prime}+\mathrm{L}-1$, e a multiplicação de duas matrizes com dimensão $\mathrm{M} \times \mathrm{M}$ e $\mathrm{M}$ $\mathrm{x} \mathrm{N}^{\prime}$, respectivamente. 
O segundo estágio do receptor da rede de sensores DS-CDMA é similar ao do receptor do esquema CS-CDMA, i.e., os símbolos estimados no primeiro estágio são utilizados no centro de fusão a fim de determinar a decisão final $\hat{u}$ pela regra da maioria.

Seja $\mathrm{T}_{\mathrm{o}}$ a duração de cada um dos $\mathrm{L}$ componentes transmitidos no bloco $\mathbf{b}_{k} c_{k, j}$ no sistema CS-CDMA e $\mathrm{T}_{\mathrm{c}}$ a duração dos chips do código DS-CDMA. Para que os dois sistemas tenham a mesma resposta ao impulso do canal discreto equivalente e mesma banda ocupada no canal, é necessário que $\mathrm{T}_{\mathrm{o}}=\mathrm{T}_{\mathrm{c}}$. A Figura 2.8 apresenta uma comparação entre as estruturas das sequências de blocos transmitidos pelo sensor $k$ no sistema CS-CDMA modificado proposto e no sistema DS-CDMA.

DS-CDMA

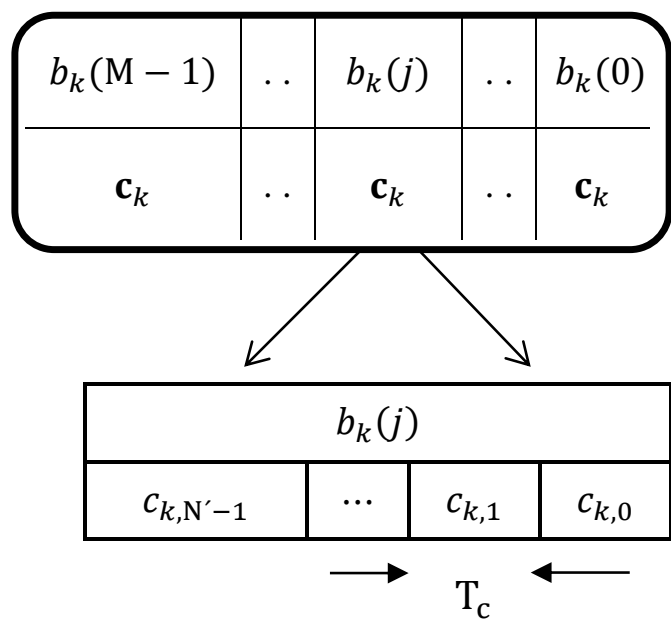

CS-CDMA

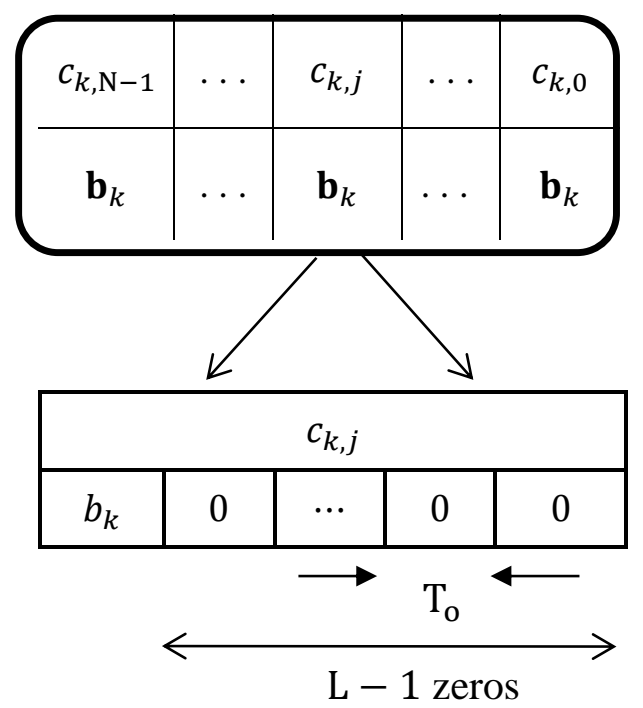

Figura 2.7: Comparação das estruturas das sequências de blocos transmitidos pelo sensor $k$ no sistema CS-CDMA proposto e no sistema DS-CDMA.

Por outro lado, o intervalo de tempo necessário para a transmissão de uma dada mensagem do sensor $k$ é (NL) $\mathrm{T}_{\mathrm{o}}$ para o sistema CS-CDMA considerado nesta tese, e $\left(\mathrm{N}^{\prime}+\mathrm{L}-1\right) \mathrm{T}_{\mathrm{c}}$ no esquema DS-CDMA. Consequentemente, fazendo $\mathrm{T}_{\mathrm{o}}=\mathrm{T}_{\mathrm{c}}$ resulta que a razão entre as eficiências espectrais dos sistemas CS-CDMA e DS-CDMA é dada por $\eta=\frac{\mathrm{N}^{\prime}+\mathrm{L}-1}{\mathrm{LN}}$. Assim, para uma comparação justa ( $\eta=$ $1)$, temos a condição $\mathrm{N}^{\prime}=(\mathrm{N}-1) \mathrm{L}+1$. Note que idealmente o desempenho da detecção CS-CDMA não depende do código ortogonal, contanto que $\mathrm{N} \geq \mathrm{K}$. 
Para fins de comparação dos receptores CS-CDMA e DS-CDMA, os resultados apresentados a seguir utilizaram códigos de Hadamard de comprimento $\mathrm{N} \geq \mathrm{K}$ no sistema CS-CDMA e um comprimento $\mathrm{N}^{\prime}$ no sistema DS-CDMA de tal forma que a razão de eficiência espectral $\eta$ fique o mais próximo possível da unidade. Os valores utilizados nas comparações estão sumarizados na Tabela 2.1.

Tabela 2.1: Relação entre o comprimento dos códigos de Hadamard utilizados no sistema CS-CDMA e DS-CDMA e respectiva razão entre eficiências espectrais.

\begin{tabular}{cccc}
\hline $\mathbf{K}$ & $\mathbf{N}$ & $\mathbf{N}^{\prime}$ & $\boldsymbol{\eta}$ \\
\hline 3 & 4 & 16 & 1,1875 \\
5 & 8 & 32 & 1,09375 \\
7 & 8 & 32 & 1,09375 \\
9 & 16 & 64 & 1,046875 \\
11 & 16 & 64 & 1,046875 \\
13 & 16 & 64 & 1,046875 \\
15 & 16 & 64 & 1,046875 \\
\hline
\end{tabular}

A Figura 2.8 ilustra o desempenho em termos de DER dos receptores do centro de fusão em função do número $\mathrm{K}$ de sensores, para canais com SNR de 11 $\mathrm{dB}$ e SNR local de $0 \mathrm{~dB}$ para todos os sensores. Note que além de uma eficiência espectral superior $(\eta>1)$, o esquema CS-CDMA utilizando uma filtragem casada no primeiro estágio do receptor fornece um melhor desempenho quando comparado aos dois detectores utilizados no primeiro estágio do receptor do esquema DS-CDMA, como era de se esperar devido à eliminação dos termos da IMA no esquema CS-CDMA. Esta diferença de desempenho aumenta com o número de sensores devido ao aumento da IMA no esquema DS-CDMA.

A Figura 2.9 mostra o desempenho do centro de fusão versus a SNR média dos canais para uma SNR local fixa de $0 \mathrm{~dB}$ e $\mathrm{K}=7$ sensores. Os resultados de DER indicam que para valores elevados de SNR, o desempenho do centro de fusão é limitado pela qualidade das decisões dos sensores locais. O desempenho do detector MMSE do esquema DS-CDMA só se aproxima do detector (muito menos complexo) do esquema CS-CDMA para valores elevados de SNR do canal.

Finalmente, a Figura 2.10 apresenta a probabilidade de erro do centro de fusão como função da SNR local para um número $K=7$ de sensores e uma SNR do canal de $11 \mathrm{~dB}$ para todos os sensores. Como esperado, o desempenho do centro de fusão melhora com a SNR dos sensores locais. Entretanto, eles exibem 
um patamar de erro a partir da SNR local de $10 \mathrm{~dB}$. Os receptores do esquema DS-CDMA apresentam um patamar de erro mais elevado devido à presença dos termos de IMA que é determinado pelo número de sensores.

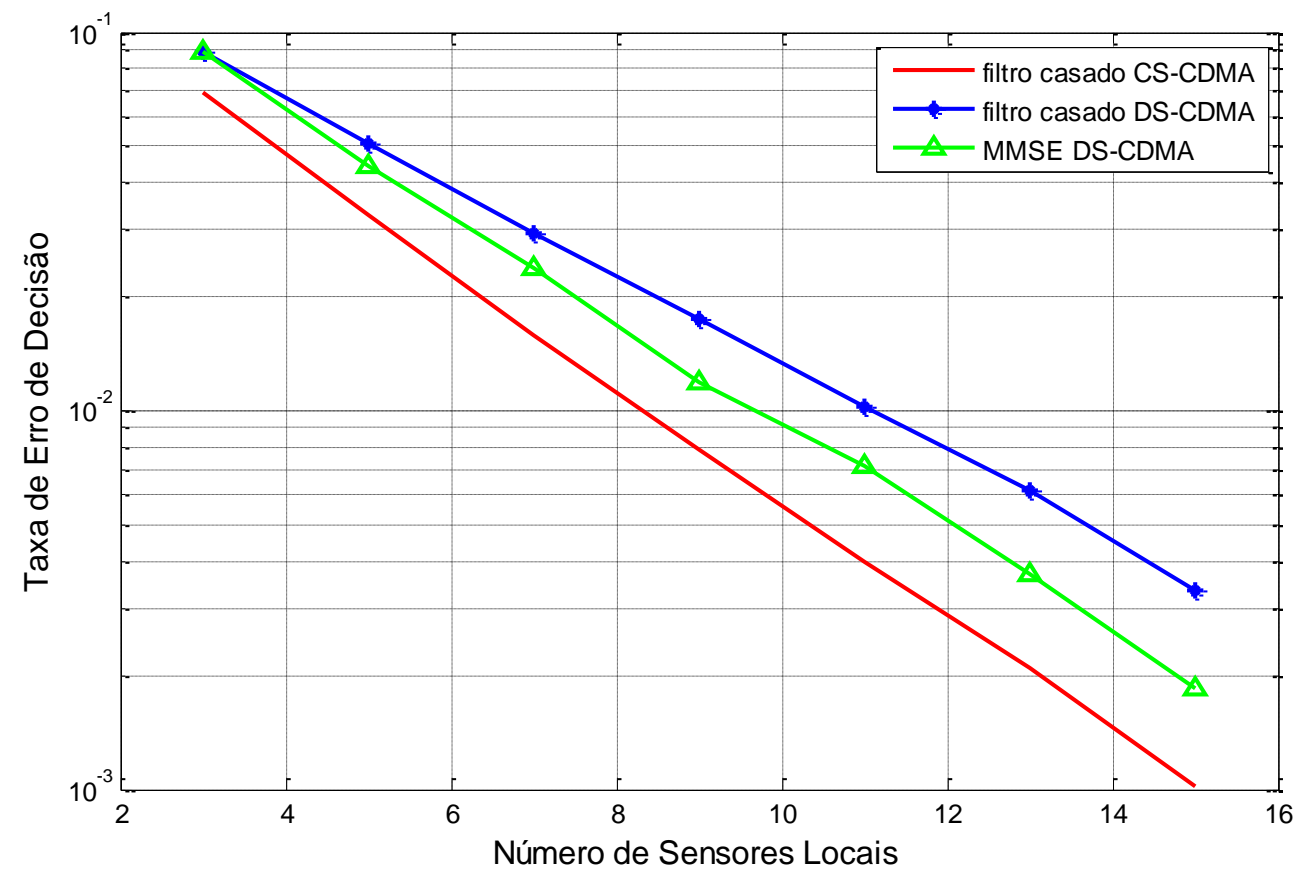

Figura 2.8: DER vs número de sensores para uma SNR média do canal de $11 \mathrm{~dB}$ e SNR local de $0 \mathrm{~dB}$.

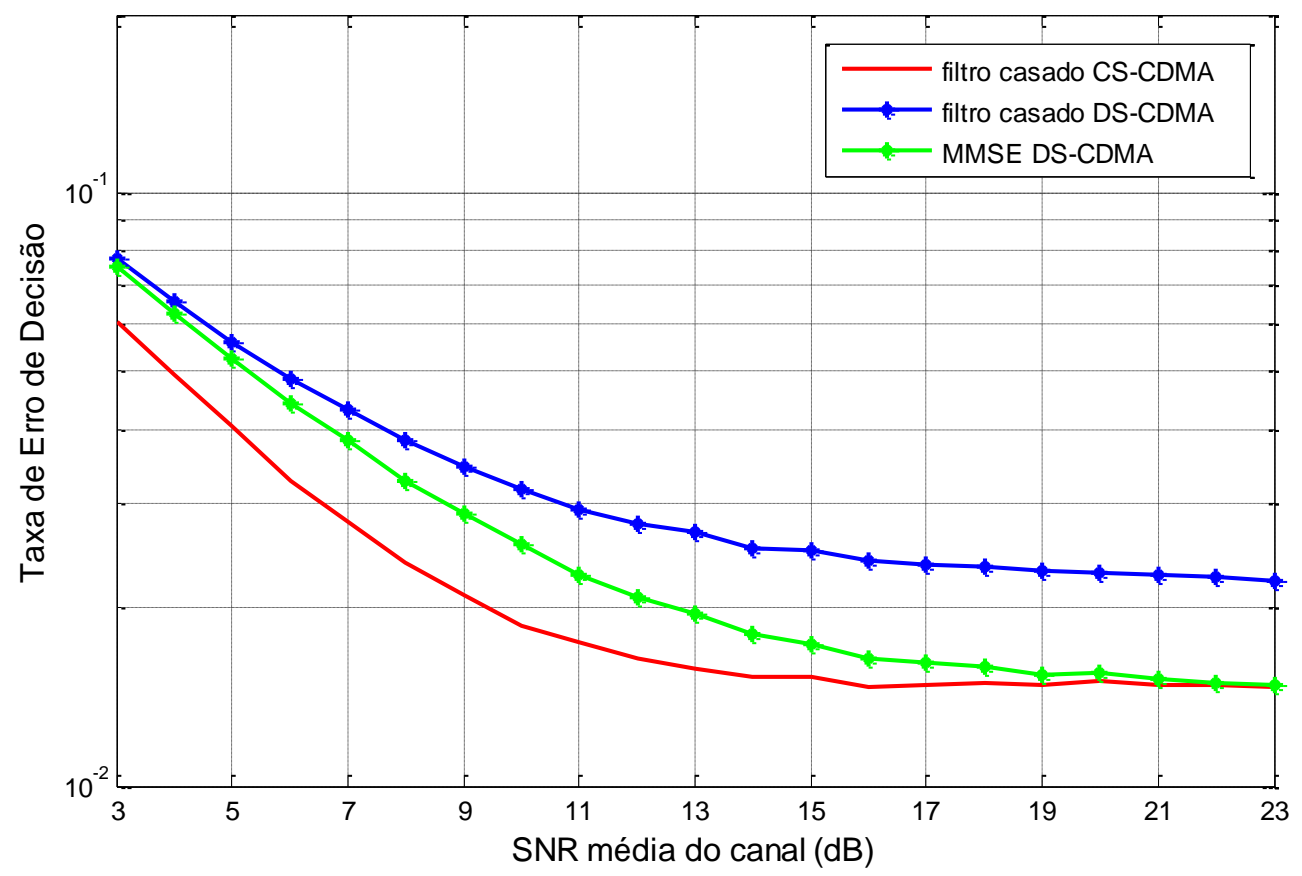

Figura 2.9: DER vs SNR média de canal para uma SNR local de $0 \mathrm{~dB}$ e $\mathrm{K}=7$ sensores locais. 


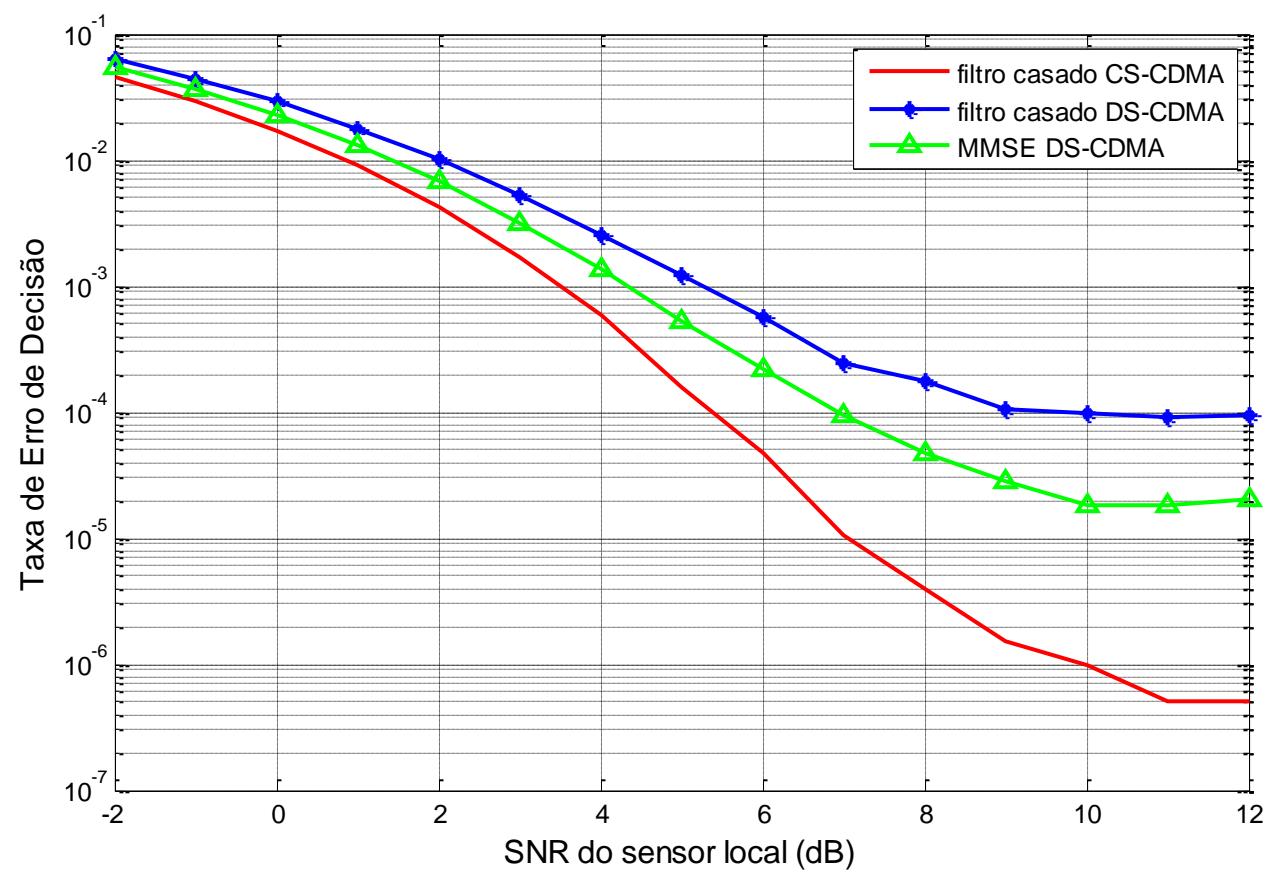

Figura 2.10: DER vs SNR local para uma SNR média de canal de $11 \mathrm{~dB}$ e $\mathrm{K}=7$ sensores locais.

\subsection{3}

\section{Desempenho dos Receptores Sub-Ótimos CS-CDMA e DS-CDMA com Códigos não Ortogonais e Transmissão Assíncrona}

Na subseção 2.3.2 foram feitas comparações entre os sistemas CS-CDMA e DS-CDMA que indicaram uma superioridade de desempenho para o CS-CDMA devido, principalmente, à ausência de IMA, uma vez que o sistema CS-CDMA proposto mantém idealmente a ortogonalidade dos códigos em canais seletivos em frequência.

Como, na prática, o uso de códigos perfeitamente ortogonais não é factível em uma rede de muitos sensores, nesta sub-seção será avaliado o impacto do uso de códigos não ortogonais, ou seja, códigos que possuem coeficiente de correlação cruzada diferente de zero, no desempenho do sistema de recepção CS-CDMA estudado neste capítulo.

Utilizando a mesma configuração das simulações da Subseção 2.3.2, códigos pseudoaleatórios (pseudorandom - PN), que possuem correlação diferente de zero, serão utilizados nos sistemas CS-CDMA (utilizando filtro casado no 
receptor) e DS-CDMA (utilizando o equalizador MMSE no receptor) a fim de avaliar a perda de desempenho entre devido a não-ortogonalidade dos códigos.

No primeiro experimento são utilizados códigos PN de comprimento fixo de 32 chips em ambos os sistemas, de modo que não será levado em conta a razão entre as eficiências espectrais dos sistemas considerados pois o objetivo deste experimento é avaliar a perda de desempenho resultante do uso de códigos não ortogonais no sistema CS-CDMA. Com um comprimento de 32, o coeficiente de correlação entre os códigos resultou nos valores $0, \pm 0,125$ e $\pm 0,25$.

A Figura 2.11 apresenta a DER como função da SNR local para um número $\mathrm{K}=7$ de sensores e uma SNR do canal de $11 \mathrm{~dB}$ para todos os sensores. Quando a SNR de canal é alta, a perturbação predominante no sistema é a IMA causada pela não ortogonalidade entre os códigos.

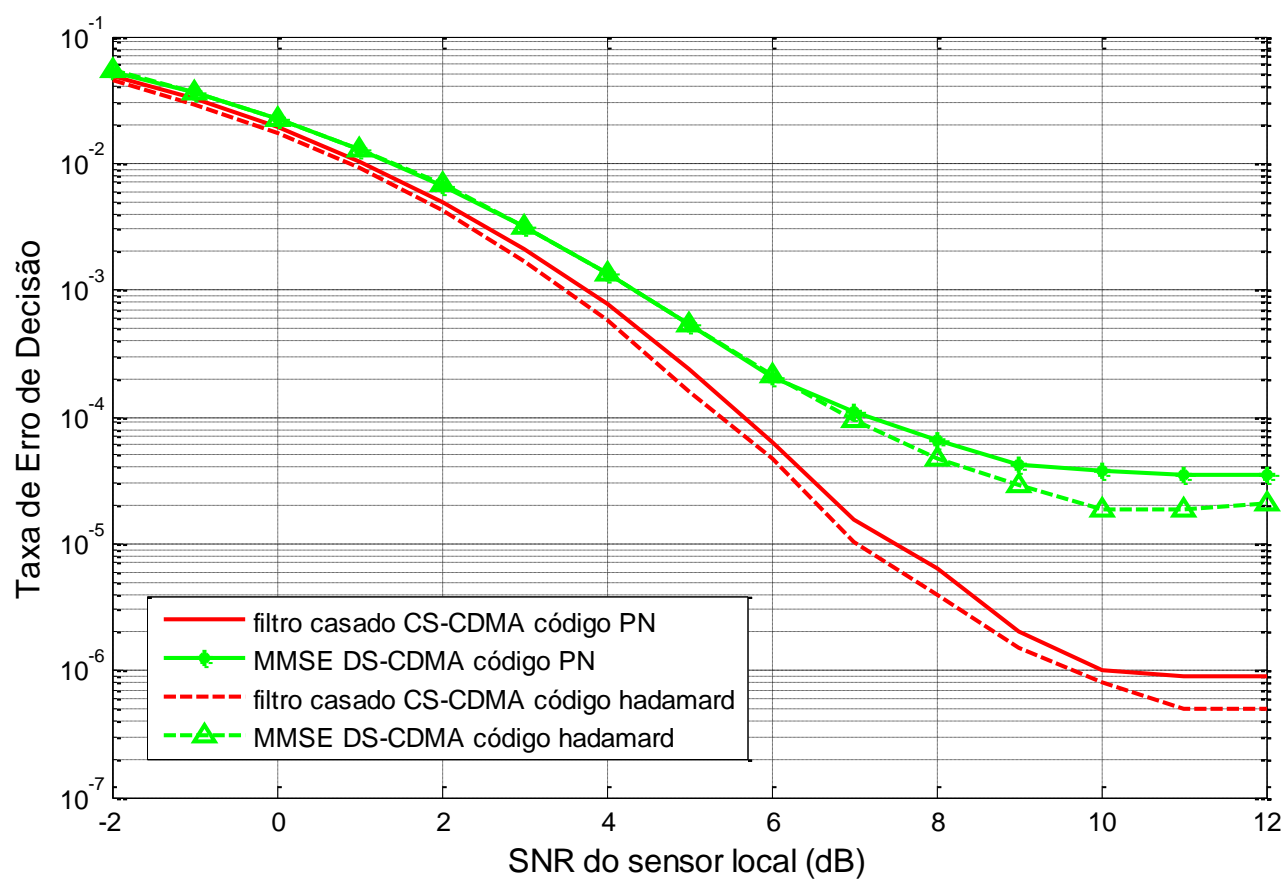

Figura 2.11: DER vs SNR local para uma SNR média de canal de $11 \mathrm{~dB}$ e $\mathrm{K}=7$ sensores locais, utilizando códigos PN de comprimento 32.

Para o código PN de comprimento 32, apesar do filtro casado não ser mais o filtro ótimo para o CS-CDMA, a perda de desempenho deste sistema utilizando um filtro casado é muito pequena, praticamente mantendo a diferença de desempenho em relação ao equalizador MMSE do sistema DS-CDMA. 
Os resultados ilustrados na Figura 2.12 são para um código PN de comprimento 10. Nesse caso, o coeficiente de correlação entre os códigos assume valores 0,2 e 0,6 .

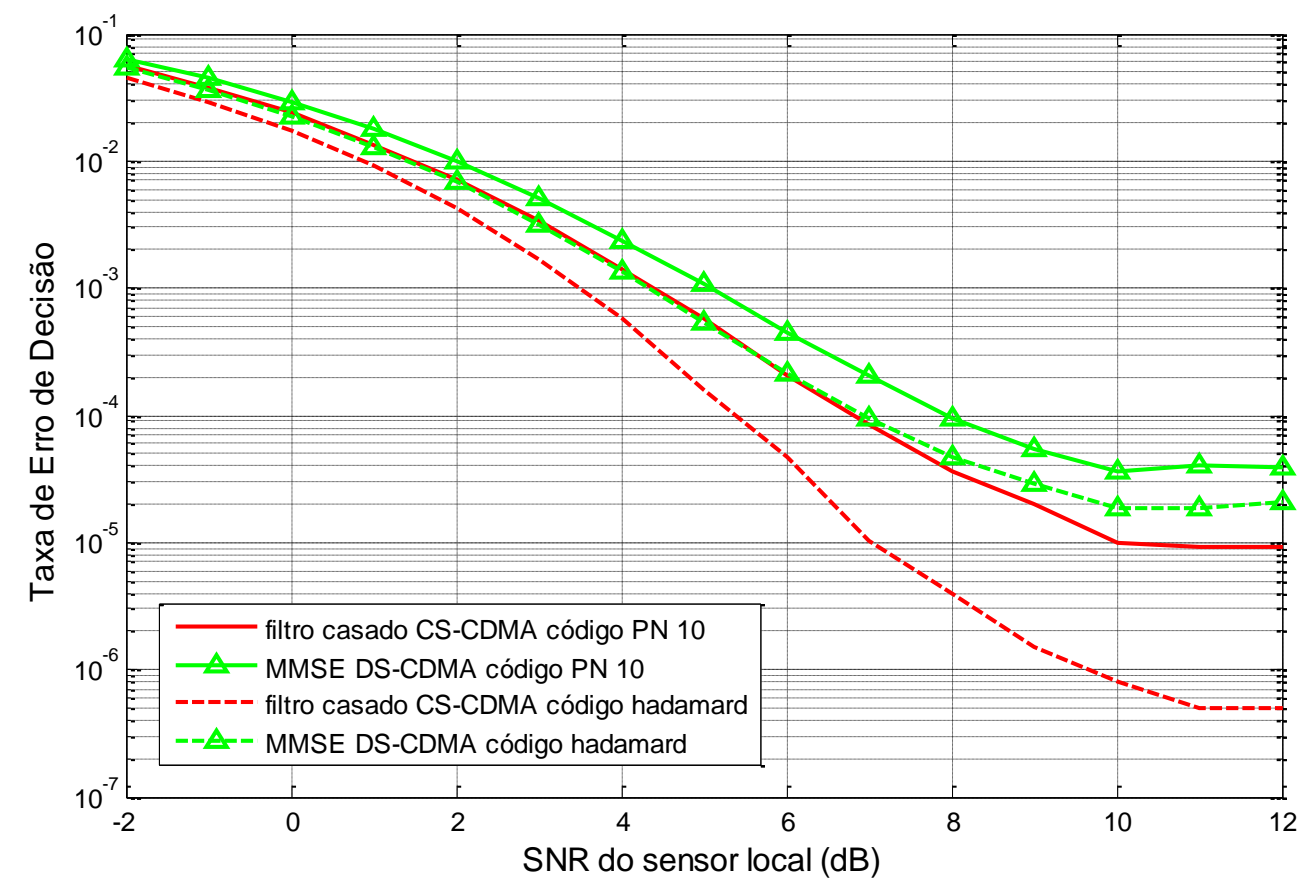

Figura 2.12: DER vs SNR local para uma SNR média de canal de $11 \mathrm{~dB}$ e $\mathrm{K}=7$ sensores locais, utilizando códigos PN de comprimento 10.

Aqui a perda de desempenho do sistema CS-CDMA é mais significativa, da ordem de 3 a 4 dB para valores médios (entre 6 a $10 \mathrm{~dB}$ ) da SNR do sensor local. Como todos os códigos são correlatados e existem códigos com correlação bastante alta $(0,6)$, a IMA é bastante significativa com o uso de um filtro casado o que justifica a degradação nos sistema. No sistema DS-CDMA a perda desempenho é menor (aproximadamente $1 \mathrm{~dB}$ ), pois o uso do equalizador MMSE tende a mitigar o efeito da IMA. Ainda assim, o sistema CS-CDMA utilizando filtro casado apresentou um desempenho de aproximadamente $1 \mathrm{~dB}$ superior ao do sistema DS-CDMA. Além de uma complexidade inferior.

Uma possibilidade de melhora para o desempenho do sistema CS-CDMA em casos de correlação alta entre os códigos seria a utilização de um equalizador MMSE ao invés do filtro casado. Porém isso aumentaria a complexidade do sistema, e um dos objetivos do sistema CS-CDMA aqui proposto é o de ser o menos complexo possível. Vale ressaltar que a situação de correlação alta entre os 
códigos é aqui considerada extrema, pois na prática o comprimento dos códigos não ortogonais deve ser razoavelmente superior ao número de sensores.

Outra suposição feita nas sub-seções anteriores desse capítulo foi a perfeita sincronia entre os símbolos transmitidos pelos diferentes sensores. No próximo experimento essa condição será relaxada com a introdução de assincronia em uma rede de $\mathrm{K}=7$ sensores utilizando código PN de comprimento 32. Essa assincronia temporal é simulada por meio de uma variável aleatória que varia uniformemente entre 0 e 31 unidades de chips, em cada iteração, de modo que a assincronia máxima não exceda a duração de 1 símbolo. Esta é uma suposição razoável para se avaliar o efeito da degradação de desempenho em sistemas onde os sensores não estão sincronizados entre si.

A Figura 2.13 ilustra o efeito da assincronia em termos de probabilidade de erro de decisão como função da SNR local para um número $K=7$ de sensores e uma SNR do canal de $11 \mathrm{~dB}$ para todos os sensores. Nesse caso ambos os sistemas CS-CDMA e DS-CDMA apresentam uma perda de desempenho equivalente, e, portanto, mantendo a superioridade de desempenho do sistema CSCDMA.

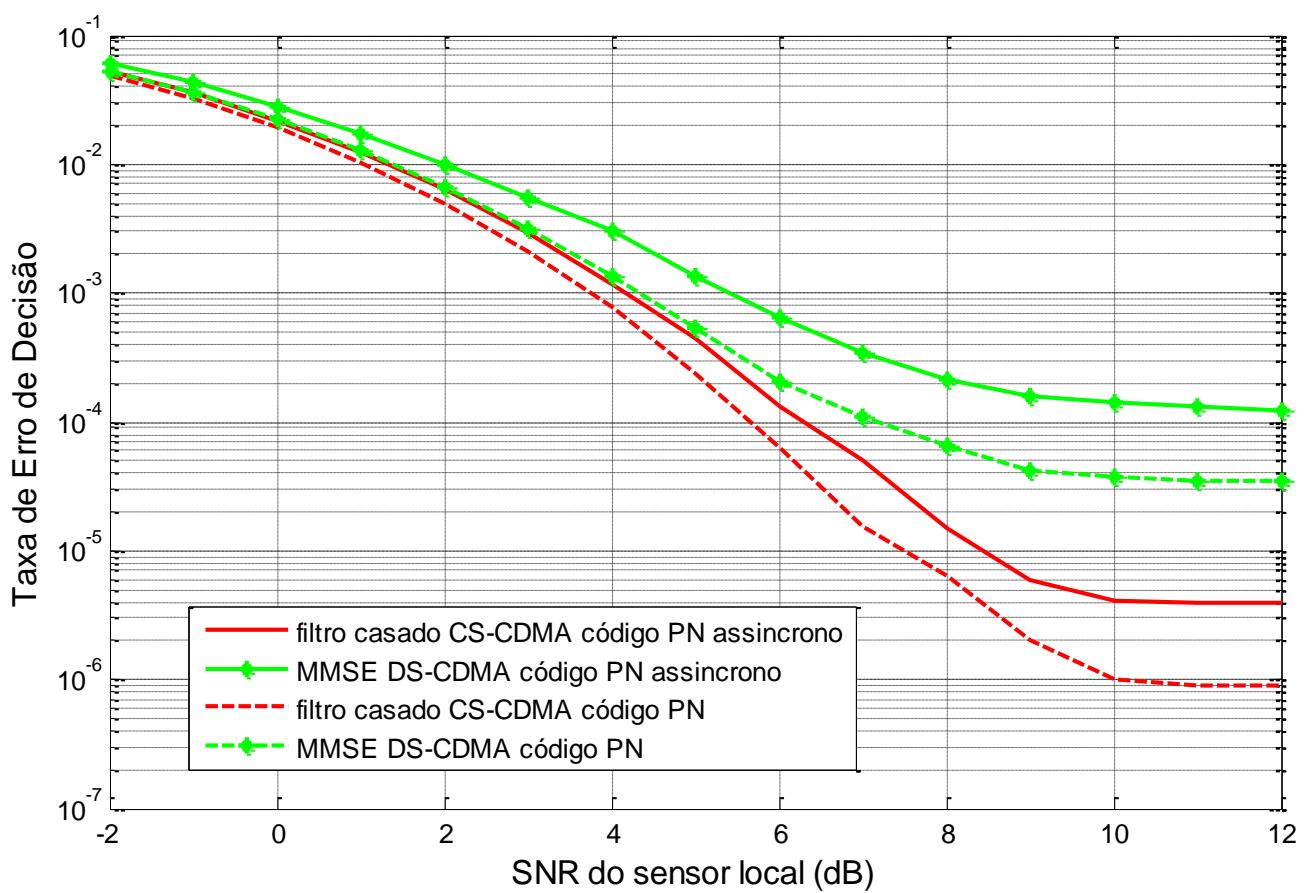

Figura 2.13: DER vs SNR local para uma SNR média de canal de $11 \mathrm{~dB}$ e $\mathrm{K}=7$ sensores locais, utilizando códigos PN de comprimento 32 e com assincronia na transmissão dos símbolos. 


\section{4}

\section{Conclusões}

No presente capítulo foi proposto o uso de um esquema de múltiplo acesso CS-CDMA para ser utilizado em redes de sensores distribuídos em canais seletivos em frequência. No esquema CS-CDMA proposto, a ortogonalidade entre os sinais transmitidos pelos sensores é preservada no receptor, a despeito da propagação através de canais multipercursos seletivos em frequência.

Um procedimento de decisão sub-ótimo de baixa complexidade foi proposto para ser utilizado no centro de fusão e foi mostrado que seu desempenho é bem próximo do decisor ótimo no centro de fusão, o qual também foi desenvolvido nessa tese. Comparações de desempenho foram feitas com uma rede de sensores utilizando o esquema de transmissão DS-CDMA e mostrou-se que a rede de sensores com esquema proposto CS-CDMA possui complexidade computacional menor, podendo operar com maior eficiência espectral e desempenho superior.

Foi mostrado também que a introdução de imperfeições na ortogonalidade dos códigos e/ou a ausência de sincronia nos sinais transmitidos pelos diferentes sensores degrada o desempenho do esquema CS-CDMA proposto. Apesar dessa degradação, o desempenho deste esquema se mantem superior ao do sistema DSCDMA nas mesmas condições de imperfeições na transmissão. 


\section{3 \\ Desempenho de Redes de Sensores com Esquema de Transmissão CS-CDMA Utilizando Estimação de Canal}

O conhecimento da resposta ao impulso no tempo discreto dos canais conectando os sensores ao centro de fusão foi considerado na descrição do receptor ótimo e sub-ótimo (Capítulo 2) para redes de sensores utilizando o esquema de transmissão CS-CDMA. Entretanto, esta informação não está disponível sem uma estimação prévia de canal. Com base na estrutura simples do vetor de observação $\tilde{\mathbf{r}}_{k}$ correspondente a cada sensor $k$, dado em (2-16), este trabalho propõe dois esquemas de estimação de canal: um esquema cego e outro assistido. Vale ressaltar que, como o vetor de observação $\tilde{\mathbf{r}}_{k}$ não possui termos de IMA, no esquema CS-CDMA a tarefa de estimação é simplificada quando comparada com o esquema DS-CDMA.

A Seção 3.1 apresenta o esquema de estimação cega de canal proposto para redes de sensores utilizando o esquema de transmissão CS-CDMA.

Na Seção 3.2 é apresentado o esquema tradicional de estimação assistida a fim de ser utilizado como comparação ao método de estimação cega proposto.

A Seção 3.3 apresenta o resultado de simulações comparando o desempenho dos receptores sub-ótimos para redes de sensores CS-CDMA utilizando as estimativas de canal cega e assistida, obtidas nas seções 3.1 e 3.2, respectivamente, com o receptor sub-ótimo para redes de sensores DS-CDMA utilizando detecção RLS.

Conclusões do capítulo são apresentadas na Seção 3.4.

\section{1}

\section{Estimação Cega de Canal para Redes de Sensores CS-CDMA}

Existem vários esquemas para estimação cega de canal e talvez os mais populares sejam as baseadas no critério de variância mínima [38-40] e de módulo constante [41-45]. As soluções de variância mínima e módulo constante incluem 
operações custosas computacionalmente como, por exemplo, inversão de matrizes.

Entretanto, a estrutura do vetor $\tilde{\mathbf{r}}_{k}$ em (2-16), onde um múltiplo do equivalente discreto da resposta impulso do canal $\mathbf{h}_{k}$ é somado a um vetor complexo Gaussiano, permite uma estimação cega muito mais simples [46]:

$$
\begin{array}{r}
\hat{\mathbf{h}}_{k}=\operatorname{argmax}_{\omega} \boldsymbol{\omega}^{\mathcal{H}} \mathbf{R}_{k} \boldsymbol{\omega} \\
\text { sujeito à }\|\boldsymbol{\omega}\|^{2}=1
\end{array}
$$

em que $\mathbf{R}_{k}$, a matriz de autocorrelação do vetor $\tilde{\mathbf{r}}_{k}$ e é dada por:

$$
\mathbf{R}_{k}=\mathbf{h}_{k} \mathbf{h}_{k}^{\mathcal{H}}+\sigma_{w_{k}}^{2} \mathbf{I}_{\mathrm{L}}
$$

Podemos observar que de fato (3-1) fornece uma solução normalizada $\left(\left\|\hat{\mathbf{h}}_{k}\right\|=1\right)$ para o problema de maximização dado em (3-1), pois:

$$
\begin{aligned}
\boldsymbol{\omega}^{\mathcal{H}} \mathbf{R}_{k} \boldsymbol{\omega} & =\boldsymbol{\omega}^{\mathcal{H}}\left(\mathbf{h}_{k}^{\mathcal{H}} \mathbf{h}_{k}+\sigma_{w_{k}}^{2} \mathbf{I}_{\mathrm{L}}\right) \boldsymbol{\omega}= \\
& =\left\|\boldsymbol{\omega}^{\mathcal{H}} \mathbf{h}_{k}\right\|^{2}+\sigma_{w_{k}}^{2} \mathbf{I}_{\mathrm{L}}\|\boldsymbol{\omega}\|^{2}
\end{aligned}
$$

Logo o vetor $\boldsymbol{\omega}$ que maximiza (3-3), sob a restrição $\|\boldsymbol{\omega}\|^{2}=1$, é da forma $\hat{\mathbf{h}}_{k}=\alpha \frac{\mathbf{h}_{k}}{\left\|\mathbf{h}_{k}\right\|}$, sendo $\alpha \in \mathbb{C}$ e $|\alpha|=1$. Este escalar é responsável pelo problema de ambiguidade de fase comum aos métodos de estimação cega. Como $\alpha$ é complexo, tem o efeito de produzir uma rotação no símbolo complexo a ser detectado quando $\hat{\mathbf{h}}_{k}$ é usado como filtro de detecção, interferindo no processo de decisão do receptor. Existem técnicas para solucionar este problema de ambiguidade. Nessa tese, supõe-se o conhecimento exato da fase do escalar $\alpha$ pelo estimador.

O problema de maximização descrito em (3-1) tem solução conhecida. O vetor $\boldsymbol{\omega}$ que com norma unitária maximiza a forma quadrática $\boldsymbol{\omega}^{\mathcal{H}} \mathbf{R}_{k} \boldsymbol{\omega}$ é o autovetor associado ao maior autovalor de $\mathbf{R}_{k}$. Assim, o método utilizado para estimar $\mathbf{h}_{k}$ é composto de duas etapas. Primeiramente, a matriz de autocorrelação 
$\mathbf{R}_{k}$ pode ser estimada através da aproximação da média estatística pela média aritmética:

$$
\widehat{\mathbf{R}}_{k}(i)=\frac{1}{i} \sum_{i=0}^{i-1} \tilde{\mathbf{r}}_{k}(i) \widetilde{\mathbf{r}}_{k}(i)^{\mathcal{H}}
$$

Esta aproximação pode ser computada recursivamente através de:

$$
\widehat{\mathbf{R}}_{k}(i+1)=\widehat{\mathbf{R}}_{k}(i)+\frac{1}{i+1}\left[\tilde{\mathbf{r}}_{k}(i) \tilde{\mathbf{r}}_{k}(i)^{\mathcal{H}}-\widehat{\mathbf{R}}_{k}(i)\right]
$$

na qual $\tilde{\mathbf{r}}_{k}$ é o vetor recebido no $i$-ésimo intervalo de sinalização. A estimativa de $\widehat{\mathbf{R}}_{k}(i)$ será tão boa quanto maior for o número de símbolos $i$, utilizados para computar (3-4).

$\mathrm{Na}$ segunda etapa, se atribui a $\hat{\mathbf{h}}_{k} \mathrm{o}$ autovetor normalizado para o comprimento unitário, correspondente ao maior autovalor de $\widehat{\mathbf{R}}_{k}(i)$. A busca pelo autovetor pode ser eficientemente computada recursivamente pelo método das potências [26,47]:

$$
\begin{aligned}
& \mathbf{g}(i)=\widehat{\mathbf{R}}_{k}(i) \mathbf{g}(i-1) \\
& \mathbf{g}_{u}(i)=\mathbf{g}(i) /\|\mathbf{g}(i)\|
\end{aligned}
$$

sendo $\mathbf{g}_{u}(i)$ é a aproximação do autovetor associado ao maior autovalor de $\widehat{\mathbf{R}}_{k}(i) \cdot$

\section{2}

\section{Estimação Assistida de Canal para Redes de Sensores CS-CDMA}

No esquema de estimação assistida os sensores enviam pilotos durante um período de treinamento, de forma que o vetor de observação $\widetilde{\mathbf{r}}_{k}^{p}$ associado aos pilotos pode ser escrito como: 


$$
\widetilde{\mathbf{r}}_{k}^{p}=\mathbf{R c}_{k}=b_{k}^{p} \hat{\mathbf{h}}_{k}+\widetilde{\mathbf{n}}_{k}, \quad k=1,2, \ldots, \mathrm{K},
$$

em que $b_{k}^{p}$ são os símbolos piloto enviados por cada sensor $k$ para o receptor do centro de fusão na fase de treinamento e $\mathbf{R}$ é a matriz definida em (2-18).

Uma das soluções para o receptor do centro de fusão estimar $\mathbf{h}_{k}$ com o uso de pilotos é através da correlação cruzada de $\tilde{\mathbf{r}}_{k}^{p}$ e $b_{k}^{p}$, ou seja,

$$
\hat{\mathbf{h}}_{k}=\mathbb{E}\left[\widetilde{\mathbf{r}}_{k}^{p} b_{k}^{p}\right]
$$

para cada vetor de observação $\tilde{\mathbf{r}}_{k}^{p}$.

Um método prático para encontrarmos $\hat{\mathbf{h}}_{k}$, a aproximação da solução dada em (3-8), consiste em aproximarmos a média estatística pela média aritmética, ou seja,

$$
\hat{\mathbf{h}}_{k}=\frac{1}{\mathrm{~N}_{p}} \sum_{i=0}^{N_{p}-1} \tilde{\mathbf{r}}_{k}^{p}(i) b_{k}^{p}(i)
$$

na qual $\mathrm{N}_{p}$ é o número total de símbolos piloto enviados por cada sensor, $\hat{\mathbf{h}}_{k}$ é a estimativa do canal $\mathbf{h}_{k}$ após o recebimento de $\mathrm{N}_{p}$ vetores de observação $\tilde{\mathbf{r}}_{k}^{p}$. A estimativa $\hat{\mathbf{h}}_{k}$ se aproxima do equivalente discreto da resposta ao impulso do canal $\hat{\mathbf{h}}_{k}$ à medida que o número de pilotos $\mathrm{N}_{p}$ aumenta.

O esquema de estimação assistida tem a desvantagem de reduzir a vazão de comunicação de dados do sistema.

\section{3}

\section{Simulações e resultados}

Nas simulações, a observação $y_{k}$ do sensor $k$, dado em (2-2), é modelada como $y_{k}=u . d+n_{k}, k=1,2, \ldots, \mathrm{K}, \quad$ sendo $u$ é definida em (2-1), $d$ é uma constante conhecida e $n_{k}$ são variáveis aleatórias Gaussianas independentes com média zero e variâncias iguais a $\sigma^{2}$. As probabilidades a priori $p_{0}$ e $p_{1}$ são supostas idênticas. As mensagens são mapeadas em símbolos BPSK e, então, 
transmitidas para o centro de fusão usando o esquema CS-CDMA descrito na seção 2.2.1, com códigos Hadamard de tamanho $\mathrm{N}$ dado pela Tabela 2.1. Os canais entre os sensores e o centro de fusão são mutuamente independentes e modelados por um filtro FIR invariante no tempo contendo $\mathrm{L}=4$ coeficientes. A sequência de coeficientes do $k$-ésimo canal é dada por $h_{k, l}=q_{l} \alpha_{k, l}$, onde $\alpha_{k, l}$, $\mathrm{l}=0,1, \ldots, \mathrm{L}-1$, são variáveis aleatórias complexas Gaussianas estatisticamente independentes, com média nula e $\mathbb{E}\left[\left|\alpha_{k, l}\right|^{2}\right]=1$. Os valores de $\alpha_{k, l}$ são gerados aleatoriamente e mantidos fixos durante cada rodada de simulação. Os pesos $q_{l}$ satisfazem $\sum_{\mathrm{i}=0}^{\mathrm{L}-1}\left|q_{i}\right|^{2}=1$ com $q_{0}=0,8671, q_{1}=0,4346, q_{2}=0,2178$ e $q_{3}=$ 0,1092. Os resultados são dados pela média de 10000 experimentos independentes, com 200 símbolos enviados por sensor em cada realização, sendo os primeiros 100 símbolos utilizados como etapa treinamento.

\subsection{1}

\section{Receptor Sub-ótimo CS-CDMA vs Receptor Sub-ótimo DS-CDMA}

Esta subseção apresenta resultados de simulações comparativas de desempenho entre o receptor sub-ótimo de baixa complexidade da rede de sensores CS-CDMA com o receptor sub-ótimo para rede de sensores DS-CDMA. O sistema DS-CDMA opera com códigos ortogonais de tamanho $\mathrm{N}^{\prime}$ dado pela Tabela 2.1, ambos receptores utilizam estimação dos filtros de detecção.

O primeiro estágio do receptor da rede de sensores CS-CDMA em (2-26) é modificado para:

$$
\hat{b}_{k}=\operatorname{sgn}\left\{\mathbb{R}\left(\hat{\mathbf{h}}_{k}^{\mathcal{H}} \widetilde{\mathbf{r}}_{k}\right)\right\}, k=1,2, \ldots, \mathrm{K}
$$

sendo que $\hat{\mathbf{h}}_{k}$ representa a estimativa cega (3-1) ou assistida (3-7) do canal.

Para a rede de sensores DS-CDMA utilizaremos o receptor sub-ótimo quando o primeiro estágio é formado pelo detector MMSE, dado em (2-34), tendo em vista que este apresentou um melhor desempenho que o detector em (2-33). Como o detector do sistema CS-CDMA é um filtro casado ao canal, a estimação deste é o próprio detector. No caso DS-CDMA, o uso do filtro casado, utilizando uma estimativa de canal, tem um desempenho degradado devido aos termos de 
IMA. O detector MMSE tenta reduzir os efeitos desta interferência e apresenta um melhor desempenho que o filtro casado, conforme foi verificado nas curvas de desempenho apresentadas na Seção 2.3.2. Assim para o esquema DS-CDMA será feita a estimativa do detector MMSE dado em (2-40), ou seja,:

$$
\begin{aligned}
\hat{b}_{k} & =\operatorname{sgn}\left\{\mathbb{R}\left(\left[\hat{\mathcal{R}}^{-1} \widehat{\mathbf{p}}_{k}\right]^{\mathcal{H}} \mathbf{r}\right)\right\}= \\
& =\operatorname{sgn}\left\{\mathbb{R}\left(\widehat{\boldsymbol{w}}_{k}^{\mathcal{H}} \mathbf{r}\right)\right\}
\end{aligned}
$$

onde $\widehat{\mathcal{R}}$ é uma aproximação da matriz autocorrelação $\mathcal{R}$, em (2-41), e é obtida por:

$$
\widehat{\mathcal{R}}(i)=\frac{1}{\mathrm{~N}_{p}} \sum_{i=0}^{N_{p}-1} \mathbf{r}(i) \mathbf{r}(i)^{\mathcal{H}}
$$

e $\widehat{\mathbf{p}}_{k}$ é uma aproximação do vetor $\mathbf{p}_{k}$, em (2-42), e é determinada por:

$$
\widehat{\mathbf{p}}_{k}(i)=\frac{1}{\mathrm{~N}_{p}} \sum_{l=0}^{N_{p}-1} \mathbf{r}(i) b_{k}^{p}(i)
$$

onde $\mathrm{N}_{p}$ é o total de amostras do vetor de observação $\mathbf{r}$ e $b_{\mathrm{k}}^{p}(i)$ são os símbolos piloto enviados por cada sensor durante o período de treinamento. Alternativamente aproximações $\mathcal{R}(i)$ e $\mathbf{p}_{k}(i)$ podem ser obtidas recursivamente através de:

$$
\begin{gathered}
\hat{\mathcal{R}}(i)=\frac{1-\lambda}{1-\lambda^{l+1}} \widehat{\mathcal{R}}^{o}(i) \\
\widehat{\mathcal{R}}^{o}(i)=\lambda \widehat{\mathcal{R}}^{o}(i-1)+\mathbf{r}(i) \mathbf{r}(i)^{\mathcal{H}} ; i=1,2, \ldots, \mathrm{N}_{p} \\
\widehat{\mathbf{p}}_{k}(i)=\frac{1-\lambda}{1-\lambda^{i+1}} \widehat{\mathbf{p}}_{k}^{o}(i) \\
\widehat{\mathbf{p}}_{k}{ }^{o}(i)=\lambda \widehat{\mathbf{p}}_{k}^{o}(i-1)+\mathbf{r}(i) b_{k}^{p}(i) ; i=1,2, \ldots, \mathrm{N}_{p}
\end{gathered}
$$

$\operatorname{com} 0 \ll \lambda<1$.

As aproximações em (3-14) e (3-15) quando utilizadas em (3-11) correspondem ao algoritmo bem conhecido recursive least squares (RLS) [52-55], onde o fator de esquecimento $\lambda$ é unitário para canais invariantes no tempo (neste caso tem-se 
$\lim _{\lambda \rightarrow 1} \frac{1-\lambda}{1-\lambda^{i+1}}=\frac{1}{i+1}$ ). Após a sequência de treinamento, os símbolos piloto $b_{k}^{p}(i)$ podem ser substituídos pelas estimativas das mensagens dos sensores $\hat{b}_{k}(i-1)$ de forma que o algoritmo RLS trabalhe no modo decision directed. Vale ressaltar que o modo decision directed pode também ser utilizado no estimador assistido para o sistema CS-CDMA dado em (3-9).

Em termos de complexidade computacional os estimadores cegos em (3-1) e assistido em (3-9) do esquema CS-CDMA necessitam de multiplicações e somas de vetores de dimensão L x 1 e matrizes de dimensão L x L. Já a abordagem de estimação do receptor MMSE do esquema DS-CDMA em (3-11), (3-14) e (3-15), requer uma inversão de uma matriz de dimensão $\mathrm{M} \times \mathrm{M}, \mathrm{M}=\mathrm{N}^{\prime}+\mathrm{L}-1$, multiplicação de uma matriz de dimensão $\mathrm{M} \times \mathrm{M}$ com um vetor $\mathrm{M} \times 1$, e multiplicação e somas de um vetor $\mathrm{M}$ x 1, sendo que em geral, $\mathrm{M} \gg \mathrm{L}$ ( o comprimento do canal $\mathbf{h}_{k}$ ). Assim. os dois esquemas de estimação do filtro de detecção propostos para redes de sensores CS-CDMA possuem complexidade computacional significantemente menor do que o esquema de estimação RLS utilizada para redes de sensores DS-CDMA.

A Figura 3.1 apresenta a evolução do valor médio quadrático do erro normalizado (NMSE) da estimativa do canal, E $\left[\left(\frac{\left\|\mathbf{h}_{k}-\hat{\mathbf{h}}_{k}\right\|}{\left\|\mathbf{h}_{k}\right\|}\right)^{2}\right]$, que é utilizada como filtro de detecção no receptor CS-CDMA em (3-10). A figura apresenta também a evolução do valor médio quadrático do erro normalizado da estimativa $\widehat{\boldsymbol{w}}_{k}$, $\mathrm{E}\left[\left(\frac{\left\|\widehat{\boldsymbol{w}}_{k}-\boldsymbol{w}_{k}\right\|}{\left\|\boldsymbol{w}_{k}\right\|}\right)^{2}\right]$, utilizada como filtro de detecção no receptor MMSE do sistema DS-CDMA (ver (3-11)). Os resultados são para uma SNR média do canal de 10 $\mathrm{dB}, \mathrm{K}=7$ sensores e $\lambda=0,9999$. Pode ser observado que o NMSE das estimativas cega e assistida do método CS-CDMA está bem próximo de zero após 100 símbolos piloto transmitidos. Já no caso DS-CDMA, a convergência se dá mais lentamente, o que pode ser explicado pelas grandes dimensões das matrizes e vetores envolvidas na aproximação do filtro MMSE em (3-11), além da presença de termos de IMA no vetor de observação $\mathbf{r}$ dado em (2-38). Esta convergência lenta justifica o uso do método decison directed no estimador RLS após a sequência de treinamento. Vale ressaltar que a estimação cega no esquema CSCDMA pode ser efetuada recursivamente durante toda a transmissão. 
A Figura 3.2 ilustra a DER dos receptores sub-ótimos CS-CDMA e DSCDMA utilizando os métodos de estimação apresentados versus o número $\mathrm{K}$ de sensores para uma SNR média do canal de $11 \mathrm{~dB}$ e uma SNR local de 0 dB para todos os sensores. A DER é calculada após uma sequência de treinamento de 100 símbolos piloto.

O receptor sub-ótimo para redes de sensores CS-CDMA utilizando os métodos de estimação cega e assistido apresentam praticamente o mesmo desempenho que o receptor sub-ótimo com conhecimento completo das informações dos estados do canal (receptor "gênio"), o que era esperado tendo em vista que o NMSE da estimativa de canal $\hat{\mathbf{h}}_{\mathrm{k}}$ é muito próximo de zero após 100 símbolos piloto para os dois métodos de estimação. O receptor sub-ótimo para rede de sensores DS-CDMA, utilizando o método de estimação RLS, apresenta uma perda de desempenho em relação ao receptor sub-ótimo com conhecimento pleno do canal tendo em vista que neste caso o estimador apresenta ainda um NMSE residual de valor significativo após 100 símbolos de treinamento.

O mesmo comportamento é observado na Figura 3.3, na qual a DER é ilustrada em função da SNR local dos sensores para uma SNR média do canal de $10 \mathrm{~dB}$ e $\mathrm{K}=7$ sensores. Novamente, os métodos de estimação cega e assistida propostos para o receptor sub-ótimo CS-CDMA apresentam praticamente o mesmo desempenho do receptor sub-ótimo CS-CDMA com conhecimento pleno do canal enquanto o receptor sub-ótimo DS-CDMA com equalização RLS apresenta uma perda de desempenho.

Para valores fixos da SNR local e do número de sensores, é esperado que para baixos valores de SNR do canal a qualidade da estimativa $\hat{\mathbf{h}}_{k}$, deteriore, refletindo em perda de desempenho dos receptores sub-ótimos das redes de sensores. Isto é visto na Figura 3.4, na qual a DER dos receptores é avaliada em função da SNR média do canal para uma SNR local de 0 dB e K $=7$ sensores. É observado que para valores de SNR do canal abaixo de $5 \mathrm{~dB}$, os receptores subótimos CS-CDMA utilizando os métodos de estimação cego e assistido apresentam uma pequena perda de desempenho em relação ao receptor "gênio" sub-ótimo.

Assim, verificou-se que os métodos de estimação de canal para rede de sensores CS-CDMA, tanto cego quanto assistido, apesar de obtidos com 
algoritmos de baixa complexidade computacional fornecem estimativas de canal muito próximas ao canal verdadeiro $\mathbf{h}_{k}$ após um número reduzido de símbolos transmitidos. Comparativamente, o método de estimação RLS do filtro de detecção do receptor MMSE para redes de sensores DS-CDMA apresenta alta complexidade computacional e convergência mais lenta.

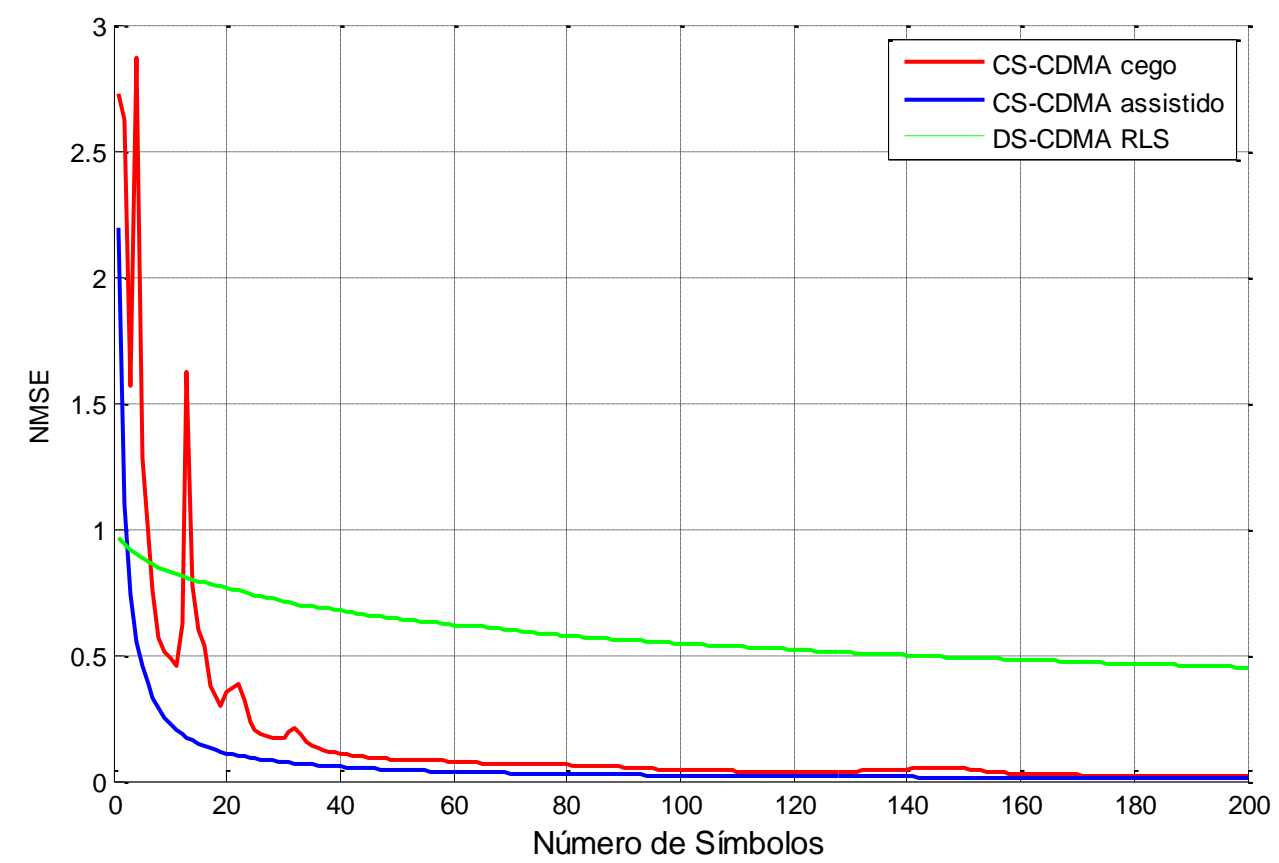

Figura 3.1: Evolução do valor médio quadrático dos erros de estimação dos filtros de detecção para redes de sensores CS-CDMA e DS-CDMA com uma SNR média de canal de $10 \mathrm{~dB}$ e $\mathrm{K}=7$ sensores locais. 


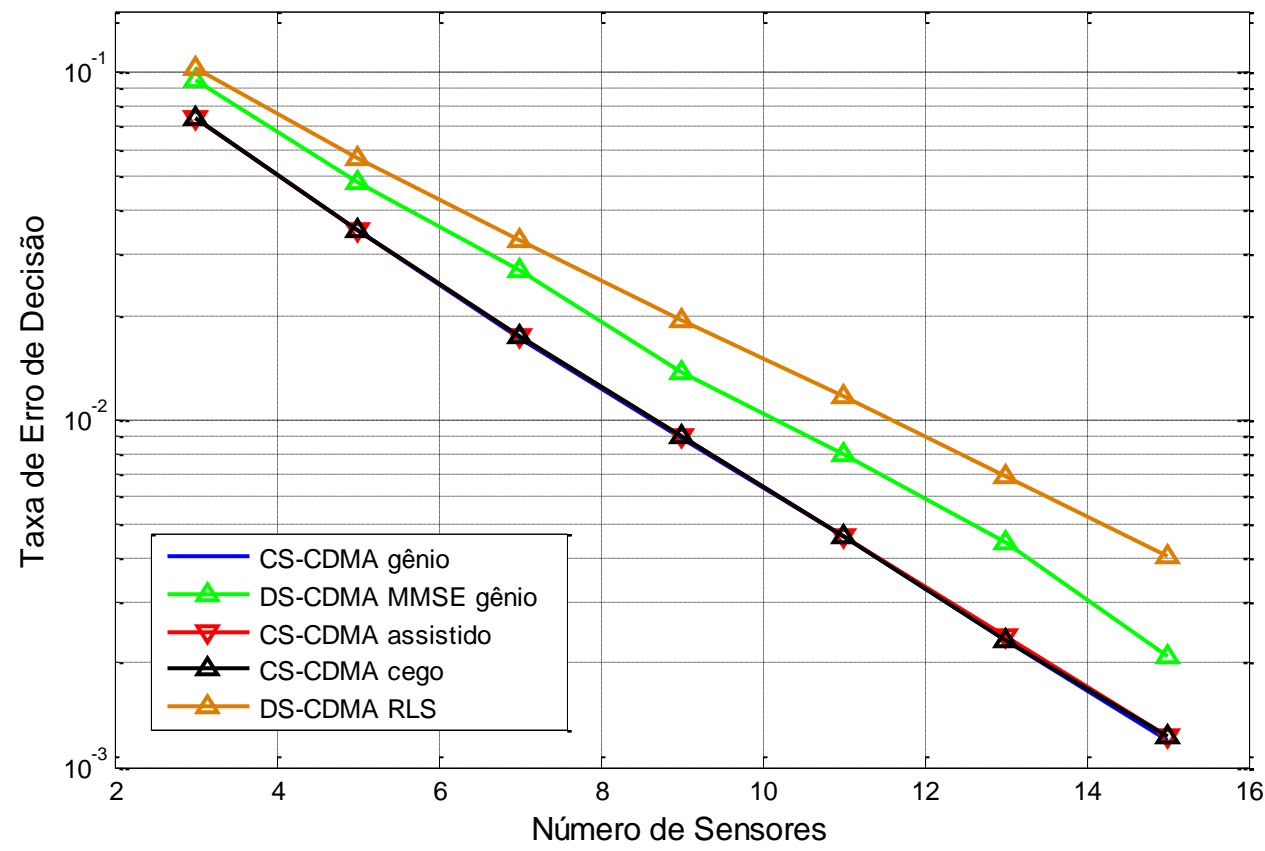

Figura 3.2: DER vs número de sensores para uma SNR média do canal de $11 \mathrm{~dB}$ e SNR local de $0 \mathrm{Db}$.

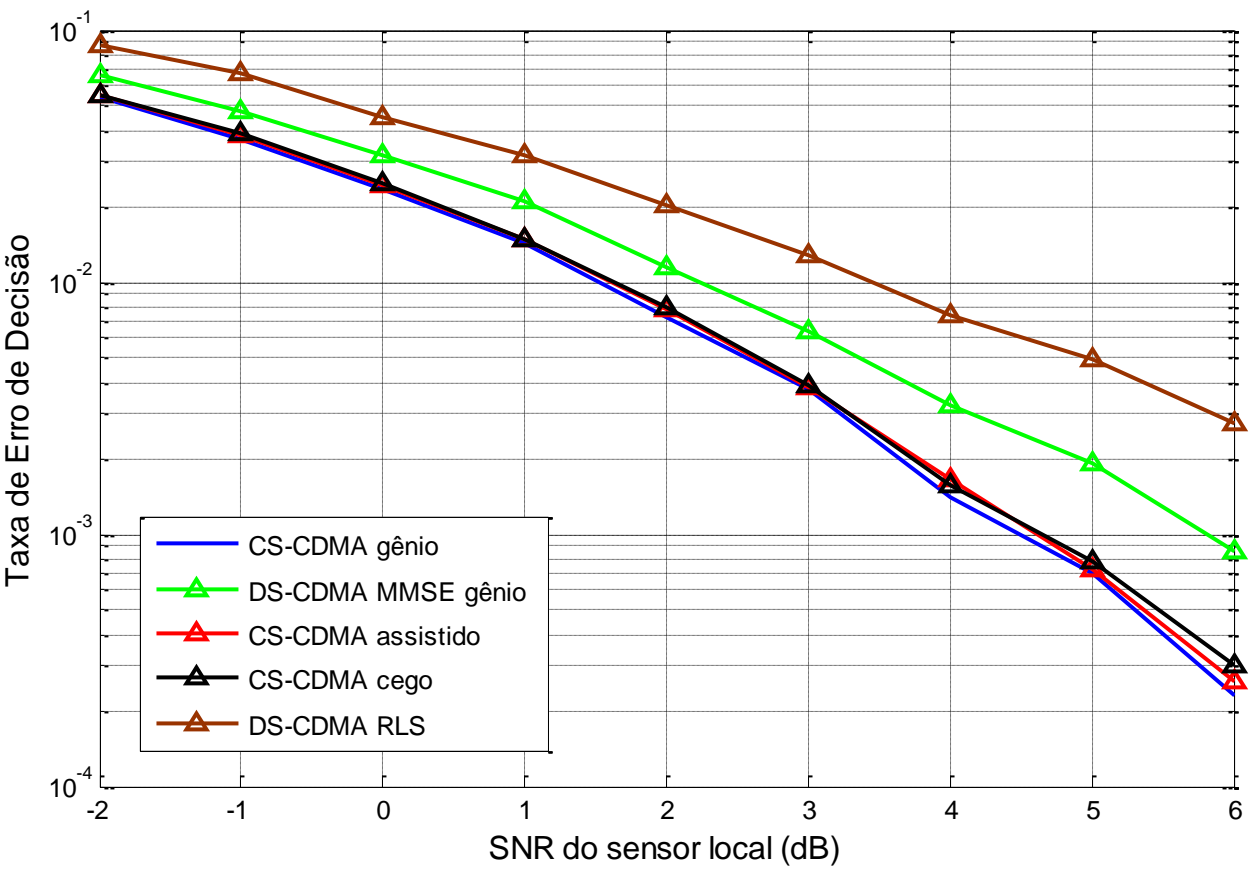

Figura 3.3: DER vs SNR local para uma SNR média de canal de $10 \mathrm{~dB}$ e $\mathrm{K}=7$ sensores locais. 


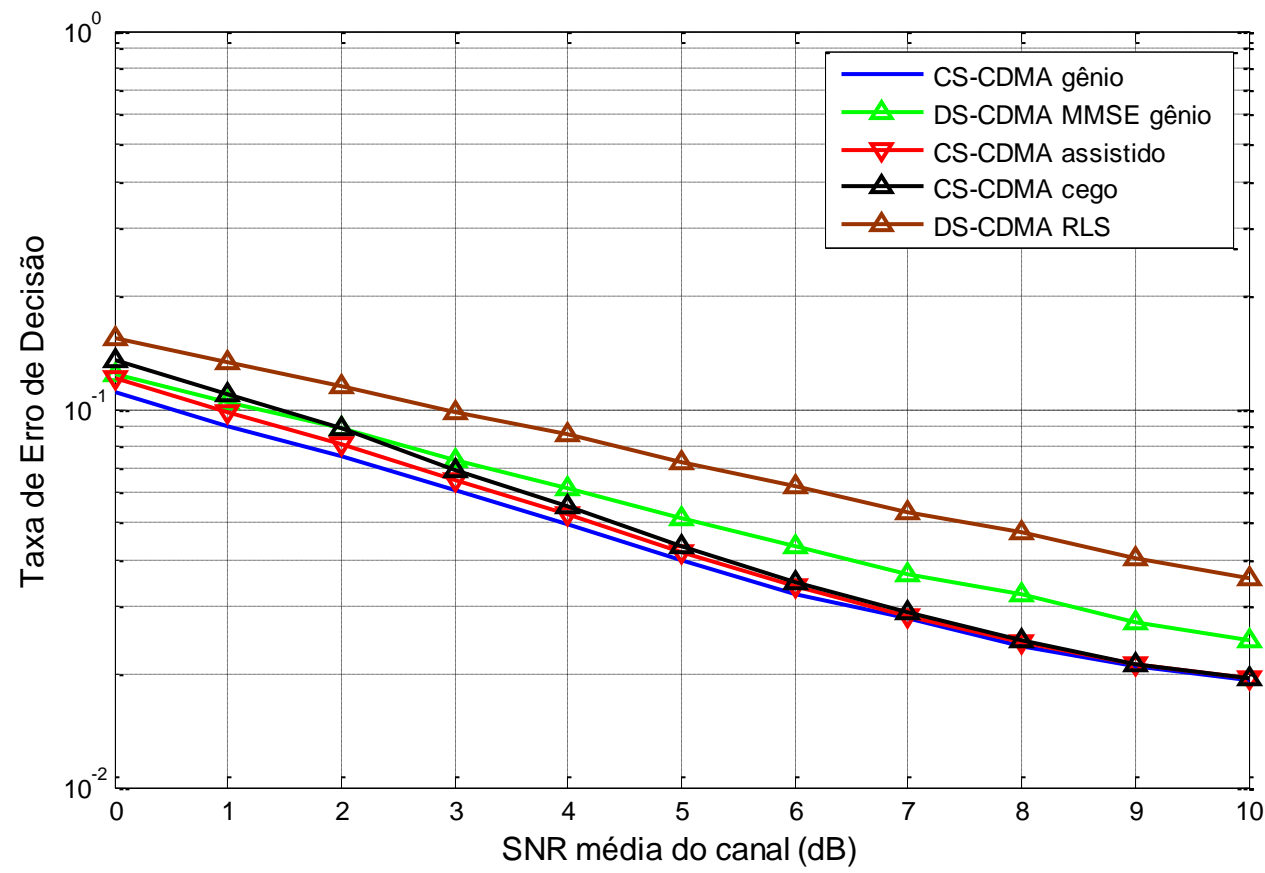

Figura 3.4: DER vs SNR médio de canal para uma SNR local de $0 \mathrm{~dB}$ e $\mathrm{K}=7$ sensores locais.

\section{4}

\section{Estimação Cega de Canal em Redes de Sensores CS-CDMA em Ambientes Variantes no Tempo}

Nas seções anteriores as técnicas de estimação de canal para redes de sensores CS-CDMA foram avaliados em ambientes invariantes no tempo. Entretanto, ambientes variantes no tempo podem ocorrer em situações práticas como sensoriamento veicular.

A fim de avaliar a robustez do método de estimação cega das redes de sensores CS-CDMA em ambientes variantes no tempo, os ganhos do canal $\alpha_{k, l}$, $\mathrm{l}=0,1, \ldots, \mathrm{L}-1$, serão modelados com uma correlação temporal $\mathbb{E}\left[\alpha_{k, l}(i+\right.$ $\left.\tau) \alpha_{k, l}^{*}(i)\right]=\sigma^{2} \mathcal{J}_{0}\left(2 \pi f_{d} \mathrm{~T} \tau\right)$ dado pelo modelo de Clark [49-51] em que $\mathcal{J}_{0}($.$) é a$ função de Bessel de primeiro tipo e ordem zero, $f_{d}$ é a frequência Doppler dos canais e T é o intervalo de tempo entre os vetores de observação $\tilde{\mathbf{r}}_{k}(i), \tilde{\mathbf{r}}_{k}(i+1)$ e $\mathbf{r}(i), \mathbf{r}(i+1)$ para as redes CS-CDMA e DS-CDMA respectivamente. A frequência Doppler $f_{d}$ é considerada a mesma para todos os canais. Assim, cada canal $\mathbf{h}_{k}$ possui a mesma relação $f_{d}$ T, ou seja, a mesma "velocidade" do canal. 
A Figura 3.5 mostra a DER em função da SNR local, para o receptor subótimo da rede de sensores CS-CDMA com estimação cega (nesse caso a estimativa $\widehat{\mathbf{R}}_{k}(i)$ utilizada em (3-6) é calculada recursivamente de forma análoga a empregada em (3-4) (utilizando um fator de esquecimento $\lambda$ ) e para o receptor sub-ótimo da rede de sensores DS-CDMA com equalização RLS. O produto $f_{d} \mathrm{~T}$ varia de 0 a $10^{-2}$ e o fator de esquecimento $\lambda$ é mantido fixo em 0,999 para ambos os esquemas.

Vale ressaltar que nesse experimento o fator de esquecimento $\lambda$ não é ajustado para rastrear o canal variante no tempo, pois o objetivo é verificar a perda de desempenho do esquema de estimação cego do CS-CDMA e do detector RLS do DS-CDMA quando o canal varia com o tempo.

Pela Figura 3.5 fica evidente que o método de estimação cega para a rede de sensores CS-CDMA é mais robusto em relação à variação da velocidade do canal quando comparado ao método de estimação RLS da rede de sensores DS-CDMA. A perda de desempenho do receptor da rede de sensores CS-CDMA, para um dado aumento da velocidade de variação $\left(f_{d} \mathrm{~T}\right)$ do canal, é menor que a perda de desempenho sofrida pela rede de sensores DS-CDMA para o mesmo aumento na velocidade do canal $\left(f_{d} \mathrm{~T}\right)$.

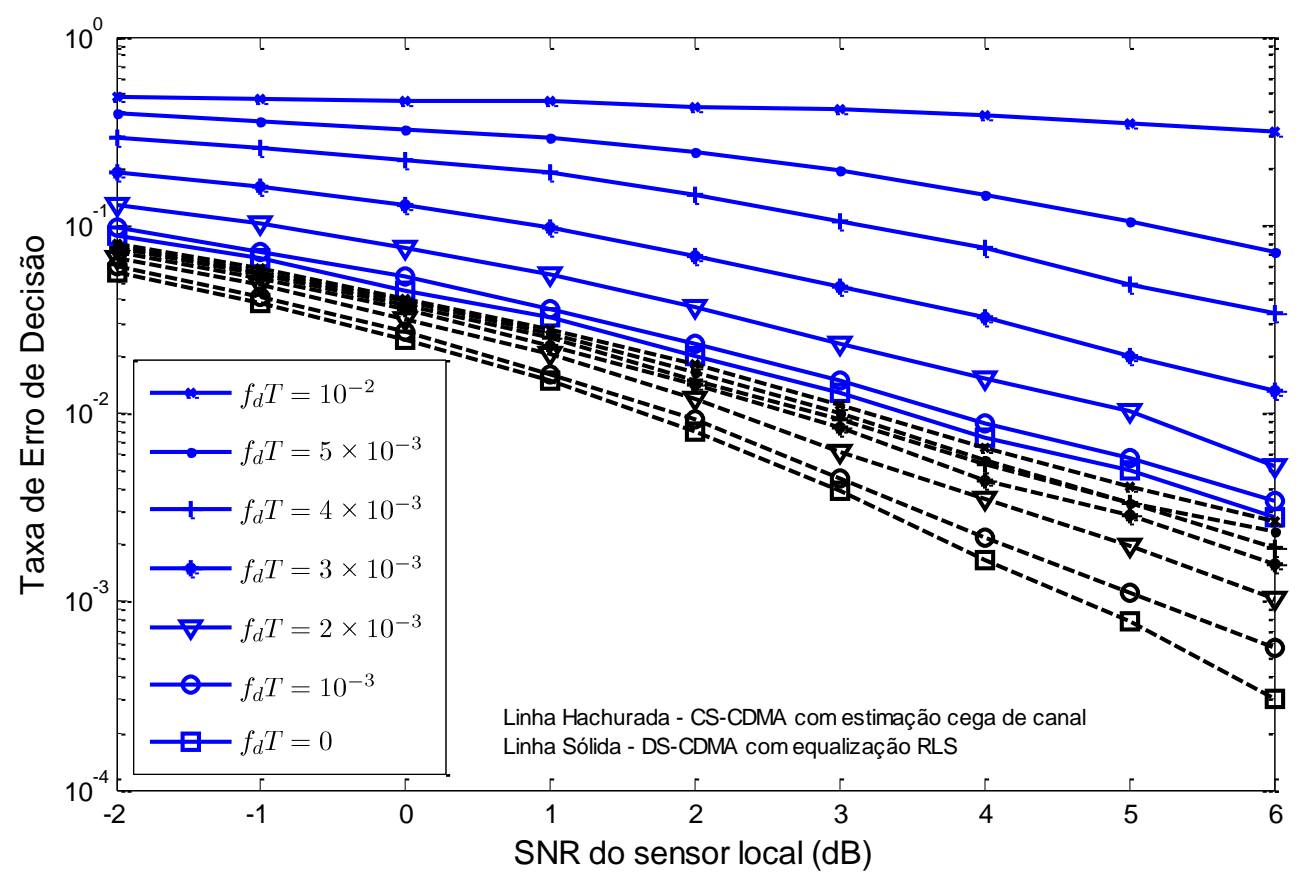

Figura 3.5: DER vs SNR local para uma SNR média de canal de $10 \mathrm{~dB}$ e $\mathrm{K}=7$ sensores locais-canal variante no tempo. 


\section{5}

Conclusões

Foi proposto o uso de dois métodos simples de estimação de canal, um cego e outro assistido, para utilização em redes de sensores CS-CDMA. Foi visto que a estrutura do vetor de observação $\tilde{\mathbf{r}}_{k}$ da rede de sensores CS-CDMA favorece a tarefa de estimação do canal (tanto cega quanto assistida) e que os receptores CSCDMA utilizando a estimativa de canal possuem um desempenho superior (com uma complexidade computacional mais baixa) ao do receptor DS-CDMA com equalização RLS, tanto em ambientes invariantes quanto variantes no tempo. 


\section{Redes Cooperativas de Sensores}

A confiabilidade da decisão final $\hat{u}$, para um número $\mathrm{K}$ de sensores, feita no centro de fusão depende da qualidade das decisões dos sensores e da qualidade dos canais que conectam estes sensores ao centro de fusão, medida em termos de SNR. Este capítulo examina o uso de cooperação [27-28] na rede de sensores CSCDMA a fim de explorar diversidade espacial e consequentemente prover robustez aos efeitos inerentes do canal de comunicação.

Na Seção 4.1 é apresentado o modelo de cooperação proposto para redes de sensores utilizando esquema de transmissão CS-CDMA.

Na Seção 4.2 são apresentados resultados de simulações comparando os desempenhos das redes de sensores CS-CDMA cooperativa e não-cooperativa.

Conclusões do capítulo são apresentadas na Seção 4.3.

\section{1}

Redes Cooperativas de Sensores com Transmissão CS-CDMA

$\mathrm{Na}$ rede de sensores CS-CDMA cooperativa aqui proposta, cada nó da rede trabalha como sensor e como relay, conforme é mostrado na Figura 4.1 


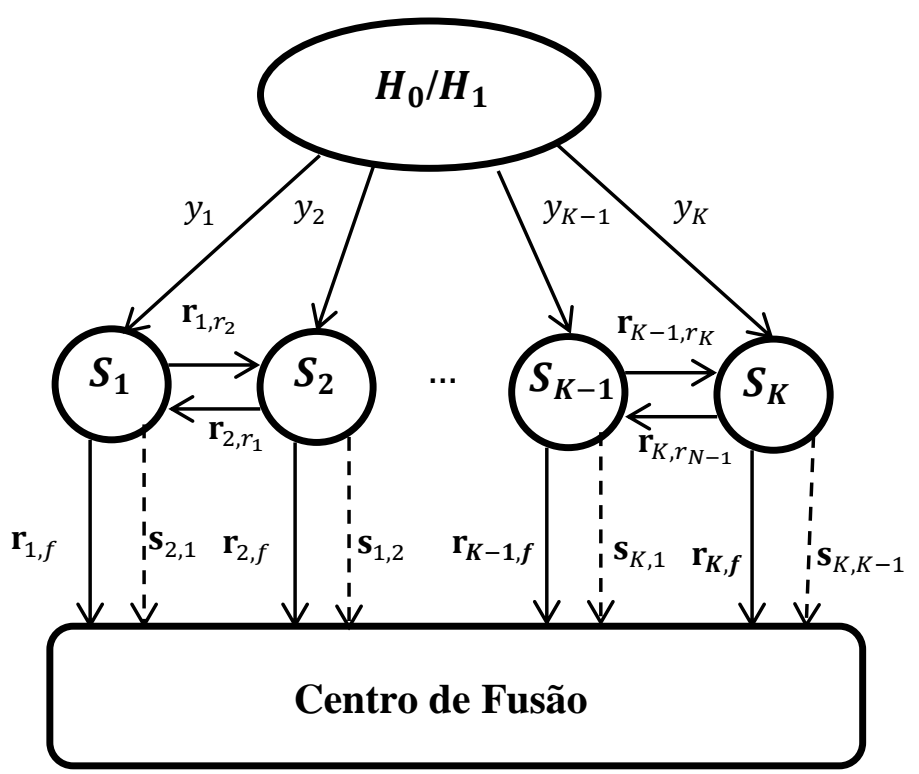

Figura 4.1: Diagrama de Bloco da Rede de Sensores Cooperativa.

De acordo com a Figura 4.1, a rede de sensores compreende um centro de fusão e um conjunto de sensores formado por nós cooperativos, onde cada nó sensor é pareado com um nó sensor vizinho. Nesse esquema cada sensor transmite seus próprios dados e retransmite as mensagens do sensor vizinho aplicando o método de cooperação detect-and-forward (DEF) [48]. As transmissões dos sinais de cada nó cooperativo ocorrem em dois intervalos de tempo disjuntos. Na Fase I, cada sensor trabalha como sensor e como relay, transmitindo seu sinal CS-CDMA diretamente para o centro de fusão e também para o seu respectivo nó sensor vizinho atuando como relay. As Figuras 4.2 e 4.3 detalham a transmissão do sinal na fase I para o centro de fusão e para o nó relay, respectivamente.

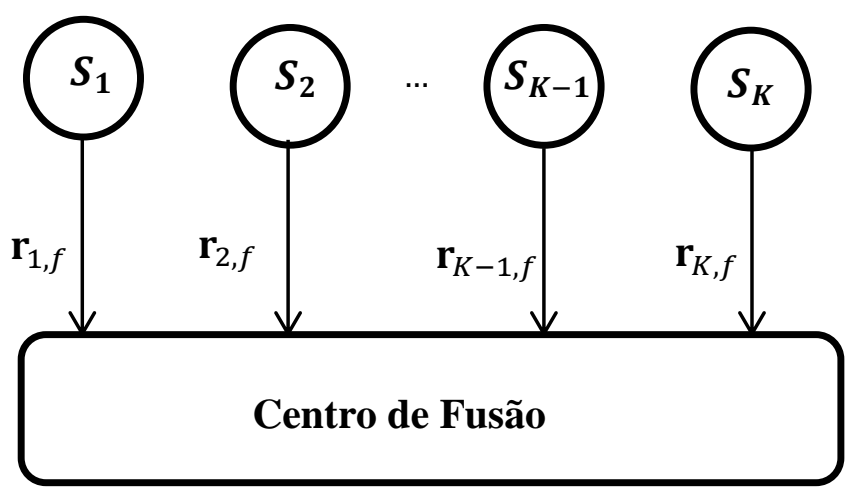

Figura 4.2: Diagrama da transmissão para o centro de fusão na Fase I. 
O sinal composto recebido pelo receptor do centro de fusão durante a Fase I é representado por:

$$
\mathbf{r}_{\text {PhaseI }}(j)=\sum_{k=1}^{K} \mathbf{r}_{k, f}(j)+\mathbf{n}_{w}, j=0,1, \ldots, \mathrm{N}-1,
$$

sendo $\mathbf{r}_{k, f}(j)=\sqrt{P_{k}} b_{k} \mathbf{h}_{k} c_{k, j}$ o sinal transmitido por cada sensor $k$ e $P_{k}$ a sua potência média de transmissão e $\mathbf{h}_{k}$ representa o canal discreto conectando o sensor $k$ ao centro de fusão. O receptor do centro de fusão coleta $\mathrm{N}$ consecutivos sinais $\mathbf{r}_{\text {PhaseI }}(j)$ e obtém o vetor $\widetilde{\mathbf{r}}_{k, f}$, correspondente a transmissão do sensor $k$, conforme (2-20).

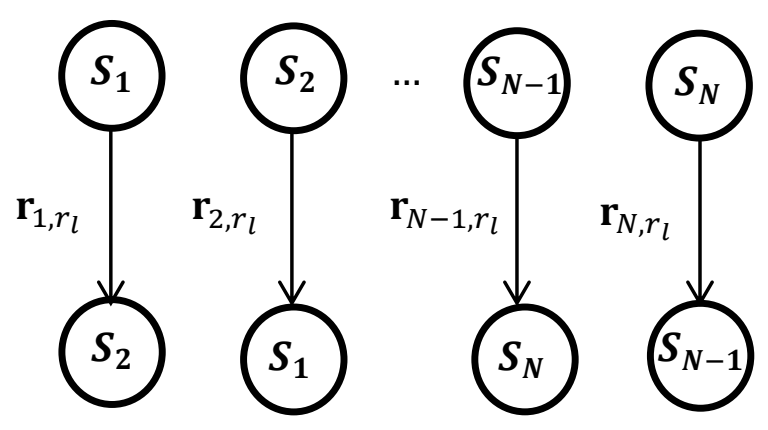

Figura 4.3: Diagrama da transmissão para o sensor relay na Fase I.

Similarmente, o sinal que chega no sensor relay $l$ na fase I é dado por:

$$
\mathbf{r}_{r_{l}}(j)=\sum_{k=1}^{K} r_{k, r_{l}}(j)+\mathbf{n}_{w, l}(j), j=0,1, \ldots, \mathrm{N}-1
$$

em que $\mathrm{r}_{k, r_{l}}(j)=\sqrt{P_{k}} b_{k} \mathbf{h}_{k, l} c_{k, j}$ é o sinal transmitido por cada sensor $k$ que chega no sensor relay $l, \mathbf{h}_{k, l}$ é o equivalente discreto da resposta ao impulso do canal e $\mathbf{n}_{w, l}(j)$ é o vetor de ruído branco do receptor do sensor relay $l$ com média zero e matriz covariância $\mathbb{E}\left[\mathbf{n}_{w, l}(j) \mathbf{n}_{w, l}(j)^{\mathcal{H}}\right]=\sigma_{l}^{2} \mathbf{I}_{\mathrm{L}}$. Após coletar $\mathrm{N}$ consecutivos sinais $\mathrm{r}_{k, r_{l}}(j)$, o receptor do sensor relay $l$ forma a matriz de observação $\mathbf{R}_{l}$ :

$$
\mathbf{R}_{r_{l}}=\sum_{k=1}^{K} \sqrt{P_{k}} b_{k} \mathbf{h}_{k, l} \mathbf{c}_{k}^{T}+\mathbf{N}_{l}
$$


onde $\mathbf{N}_{l}=\left[\mathbf{n}_{w, l}(0) \ldots \mathbf{n}_{w, l}(\mathrm{~N}-1)\right]$. Da mesma forma que o receptor do centro de fusão, o receptor do sensor relay $l$ obtém o vetor $\tilde{\mathbf{r}}_{k, l}$ correspondente à mensagem transmitida pelo sensor $k$ resultando em:

$$
\tilde{\mathbf{r}}_{k, r_{l}}=\sqrt{P_{k}} b_{k} \mathbf{h}_{k, l}+\widetilde{\mathbf{n}}_{l} \quad k=1,2, \ldots, \mathrm{K},
$$

o vetor de ruído $\widetilde{\mathbf{n}}_{l}=\mathbf{N}_{l} \mathbf{c}_{k}$ é Gaussiano complexo com média zero e matriz covariância $\mathbb{E}\left[\widetilde{\mathbf{n}}_{l} \widetilde{\mathbf{n}}_{l}{ }^{H}\right]=\sigma_{l}^{2} \mathbf{I}_{\mathrm{L}}$.

$\mathrm{Na}$ Fase II, cada sensor relay $l$ detecta coerentemente a mensagem do seu sensor pareado $k$ com um filtro casado a $\mathbf{h}_{k, l}$ seguido de um detector de polaridade:

$$
\tilde{b}_{k}=\operatorname{sign}\left\{\mathbb{R}\left(\mathbf{h}_{k, l}{ }^{H} \tilde{\mathbf{r}}_{k, r_{l}}\right)\right\}, k=1,2, \ldots, \mathrm{K} .
$$

Em seguida, codifica $\tilde{b}_{k}$, a estimativa da mensagem $b_{k}$ do sensor $k$, no esquema de transmissão CS-CDMA, conforme descrito no Capítulo 2.

Na Fase II, o sensor relay $l$, então, retransmite a nova mensagem CS-CDMA para o centro de fusão, conforme representado na Figura 4.4:

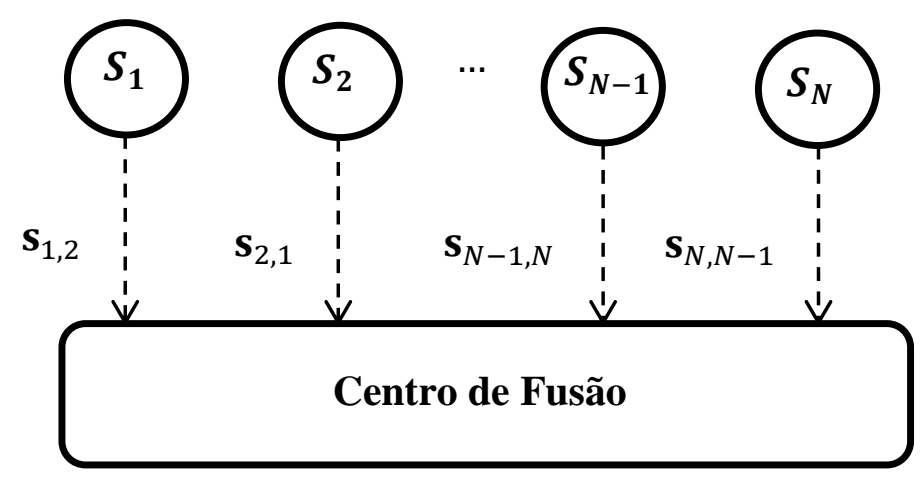

Figura 4.4: Diagrama da transmissão para o centro de fusão na Fase II. 
O sinal composto recebido pelo receptor do centro de fusão na Fase II é dado por:

$$
\mathbf{r}_{\text {PhaseII }}(j)=\sum_{l=1}^{K} \mathbf{s}_{l, k}(j)+\mathbf{n}_{w}, j=0,1, \ldots, N-1
$$

onde $\mathbf{s}_{l, k}(j)=\sqrt{P_{l}} \widetilde{b}_{k} \mathbf{h}_{l} c_{l, j}$ é o sinal recebido pelo centro de fusão correspondente ao sinal transmitido pelo sensor relay $l$ contendo a estimativa da mensagem enviada pelo sensor $k$ na Fase I, $P_{l}$ é a potência média do sinal transmitido pelo sensor relay $l$ e $\mathbf{h}_{l}$ representa o canal discreto conectando o sensor relay $l$ ao centro de fusão.

É importante ressaltar que cada transmissão dos sensores cooperativos satisfaz a restrição de potência média total $P_{T}=P_{k}+P_{l}$.

Analogamente à Fase I, após o receptor do centro de fusão coletar N sinais $\mathbf{r}_{\text {PhaseII }}(j)$ consecutivos, são obtidos no centro de fusão o vetor $\tilde{\mathbf{s}}_{l, f}$ correspondente a transmissão do sensor relay $l$.

Finalmente, o receptor do centro de fusão agrupa o sinal recebido do sensor $k$ na Fase I, $\widetilde{\mathbf{r}}_{k, f}$, e o sinal recebido do seu respectivo sensor relay $l$ na Fase II, $\widetilde{\mathbf{s}}_{l, k}$, para forma um vetor conjunto de observação $\mathbf{x}_{k}=\left[\tilde{\mathbf{r}}_{k, f}{ }^{T} \tilde{\mathbf{s}}_{l, k}{ }^{T}\right]^{T}$ modelado por:

$$
\mathbf{x}_{k}=\mathbf{H b}_{k}+\mathbf{n}
$$

em que $\mathbf{H}=\left[\begin{array}{cc}\sqrt{P_{k}} \mathbf{h}_{k} & 0 \\ 0 & \sqrt{P_{l}} \mathbf{h}_{l}\end{array}\right], \mathbf{b}_{k}=\left[\begin{array}{l}b_{k} \\ \tilde{b}_{k}\end{array}\right]$ e $\mathbf{n}=\left[\begin{array}{c}\mathbf{n}_{k} \\ \mathbf{n}_{l}\end{array}\right]$.

O receptor do centro de fusão então emprega uma detecção de máxima razão de verossimilhança (ML) no vetor $\mathbf{x}_{k}$. A densidade de probabilidade condicional de $\mathbf{x}_{k}, p\left(\mathbf{x}_{k} \mid b_{k}, \mathbf{H}\right)$ pode ser expressa como:

$$
\begin{aligned}
p\left(\mathbf{x}_{k} \mid b_{k}, \mathbf{H}\right)= & p\left(\mathbf{x}_{k} \mid b_{k}, \mathbf{H}, \tilde{b}_{k}=1\right) \operatorname{Pr}\left(\tilde{b}_{k}=1 \mid b_{k}\right)+ \\
& +p\left(\mathbf{x}_{k} \mid b_{k}, \mathbf{H}, \tilde{b}_{k}=-1\right) \operatorname{Pr}\left(\tilde{b}_{k}=-1 \mid b_{k}\right)
\end{aligned}
$$

Usando o modelo do vetor de observação (4-7) e a $f d p$ (4-8) , a função de máxima razão de verossimilhança $L\left(\mathbf{x}_{k}\right)$ é expressa por: 


$$
L\left(\mathbf{x}_{k}\right)=\frac{\sum_{\tilde{b}_{k} \in\{-1,+1\}} \exp \left\{\frac{2}{\sigma_{w}^{2}} \operatorname{Re}\left(\mathbf{x}_{k}^{H} \mathbf{H} \mathbf{b}_{k}^{+}\right)\right\} \operatorname{Pr}\left(\tilde{b}_{k} \mid b_{k}=1\right)}{\sum_{\tilde{b}_{k} \in\{-1,+1\}} \exp \left\{\frac{2}{\sigma_{w}^{2}} \operatorname{Re}\left(\mathbf{x}_{k}^{H} \mathbf{H} \mathbf{b}_{k}^{-}\right)\right\} \operatorname{Pr}\left(\tilde{b}_{k} \mid b_{k}=-1\right)}
$$

em que $\mathbf{b}_{k}^{+}=\left[\begin{array}{c}1 \\ \tilde{b}_{\mathrm{k}}\end{array}\right], \mathbf{b}_{k}^{-}=\left[\begin{array}{c}-1 \\ \tilde{b}_{k}\end{array}\right]$ e as probabilidades condicionais $\operatorname{Pr}\left(\tilde{b}_{k} \mid b_{k}=i\right)$ resultantes de (4-4) e (4-5) são expressas por:

$$
\operatorname{Pr}\left(\tilde{b}_{k} \mid b_{k}=i\right)=\left\{\begin{array}{l}
P_{e} ; \tilde{b}_{k} \neq i \\
1-P_{e} ; \tilde{b}_{k}=i
\end{array}\right.
$$

sendo $P_{e}=Q\left(\sqrt{\frac{\left\|\mathbf{h}_{\mathbf{k}, 1}\right\|^{2} \mathbf{P}_{\mathbf{k}}}{\boldsymbol{\sigma}_{\mathbf{l}}^{2}}}\right)$.

Assim, o primeiro estágio do receptor do centro de fusão realiza a detecção ML da mensagem $b_{k}$ enviada por cada sensor $k$ :

$$
\begin{gathered}
\hat{b}_{k}=1 \\
L\left(\mathbf{x}_{k}\right) \stackrel{\gtreqless}{\gtreqless} 1 \\
\hat{b}_{k}=-1
\end{gathered}
$$

e as estimativas das mensagens dos sensores, $\hat{b}_{k}$, são utilizadas no centro de fusão para a tomada da decisão global, $\hat{u}$, aplicando a regra de fusão dada em (2-31).

\section{2}

\section{Simulações e resultados}

Nas simulações, a observação $y_{k}$ do sensor $k$, dado em (2-2), é modelada como $y_{k}=u . d+n_{k}, k=1,2, \ldots, \mathrm{K}$, onde $u$ é definida em (2-1), $d$ é uma constante conhecida e $\mathrm{n}_{\mathrm{k}}$ são variáveis aleatórias Gaussianas mutuamente independentes com média zero e variâncias iguais a $\sigma^{2}$. As probabilidades $a$ priori $p_{0}$ e $p_{1}$ são supostas idênticas. As mensagens são mapeadas em símbolos BPSK e então transmitidas para o centro de fusão usando o esquema CS-CDMA, 
descrito na Subseção 2.2.1. Os canais discretos, $\mathbf{h}_{k}$ entre os sensores $k$ e o centro de fusão na Fase I e $\mathbf{h}_{l}$ entre os sensores atuando como relay $l$ e o centro de fusão na Fase II, são ambos mutuamente independentes e modelados por um filtro FIR invariante no tempo contendo L coeficientes. A sequência de coeficientes do $k$ ésimo canal é dada por $h_{k, l}=q_{l} \alpha_{k, l}$, onde $\alpha_{k, l}, \mathrm{l}=0,1, \ldots, \mathrm{L}-1$, são variáveis aleatórias complexas Gaussianas estatisticamente independentes, com média nula e $\mathbb{E}\left[\left|\alpha_{k, l}\right|^{2}\right]=1$. Os valores de $\alpha_{k, l}$ são gerados aleatoreamente e mantidos fixos durante cada rodada de simulação. Os pesos $q_{l}$ satisfazem $\sum_{\mathrm{i}=0}^{\mathrm{L}-1}\left|q_{i}\right|^{2}=1 \operatorname{com} q_{0}=$ $0,8671, q_{1}=0,4346, q_{2}=0,2178$ e $q_{3}=0,1092$. O canal discreto $\mathbf{h}_{k, l}$ entre o sensor $k$ e seu respectivo pareado sensor relay $l$ é modelado por um filtro FIR invariante no tempo contendo $\mathrm{L}=1$ coeficiente (simulando um ambiente com desvanecimento plano), com o coeficiente $h_{k, l}$ sendo uma variável aleatória complexa Gaussiana. Cada sensor cooperativo usa metade de sua potência média total normalizada $P_{T}$ para transmitir sua própria mensagem e a outra metade para retransmitir a estimativa da mensagem recebida de seu sensor pareado, i.e, $P_{k}=$ $P_{l}=1 / 2$. A SNR média $\left(\operatorname{SNR}_{w}=b_{k}^{2} / \sigma_{w_{k}}^{2}\right)$ associada ao canal $\mathbf{h}_{k}$ e $\mathbf{h}_{l}$ é considerada $10 \mathrm{~dB}$ mais baixa que a SNR média $\left(\mathrm{SNR}_{l}=b_{k}^{2} / \sigma_{l}^{2}\right)$ de $\mathbf{h}_{k, l}$. A SNR média local dos sensores é $\mathrm{SNR}=d^{2} / \sigma^{2}$. Os resultados são dados pela média de 10000 experimentos independentes, com 100 símbolos enviados por sensor em cada realização. É admitido o conhecimento pleno dos canais pelos receptores.

\subsection{1}

\section{Rede Sensores CS-CDMA Cooperativa vs Rede de Sensores CS- CDMA Não-Cooperativa}

Nessa subseção é feita a comparação do desempenho da rede de sensores CS-CDMA cooperativa com a rede de sensores CS-CDMA não cooperativa, (descrita no capítulo 2), na qual os sensores transmitem suas mensagens com $P_{T}=$ 1 (potência total).

A DER de ambas as redes de sensores é ilustrada na Figura 4.5, como função da SNR média local dos sensores, para $\mathrm{K}=7$ sensores/relays e SNR média do canal de comprimento $\mathrm{L}=4$ fixada em $6 \mathrm{~dB}\left(\mathrm{SNR}_{w}=6 \mathrm{~dB}\right)$. Os resultados apresentados na figura indicam que para valores baixos da SNR local do sensor há 
pouca diferença entre o desempenho das redes de sensores cooperativa e nãocooperativa. Nesta região de SNR, o desempenho global de ambas as redes de sensores é fortemente influenciado pelos erros das decisões feitas pelos sensores e o ganho de diversidade obtido através da cooperação tem influência limitada. À medida que a SNR local aumenta os erros oriundos do canal de transmissão são mais pronunciados que os erros das decisões locais dos sensores e, consequentemente, o desempenho da rede de sensores CS-CDMA cooperativa é superior devido ao ganho de diversidade espacial que reduz os efeitos do canal.

A Figura 4.6 ilustra a DER de ambas as redes de sensores em função do número $\mathrm{K}$ de sensores, para uma $\mathrm{SNR}_{w}=6 \mathrm{~dB}$ e uma SNR local fixa em $1 \mathrm{~dB}$ para todos os sensores. O pequeno ganho de desempenho da rede de sensores cooperativa é explicado pelo fato que a rede de sensores não-cooperativa já possuir um ganho de diversidade vinda do receptor do centro de fusão, dado em (2-26), que combina coerentemente as componentes de multipercurso do canal $\mathbf{h}_{k}$. Assim, a rede de sensores CS-CDMA não-cooperativa já opera próximo ao limite teórico de desempenho onde o canal é ideal (sem erros no canal).

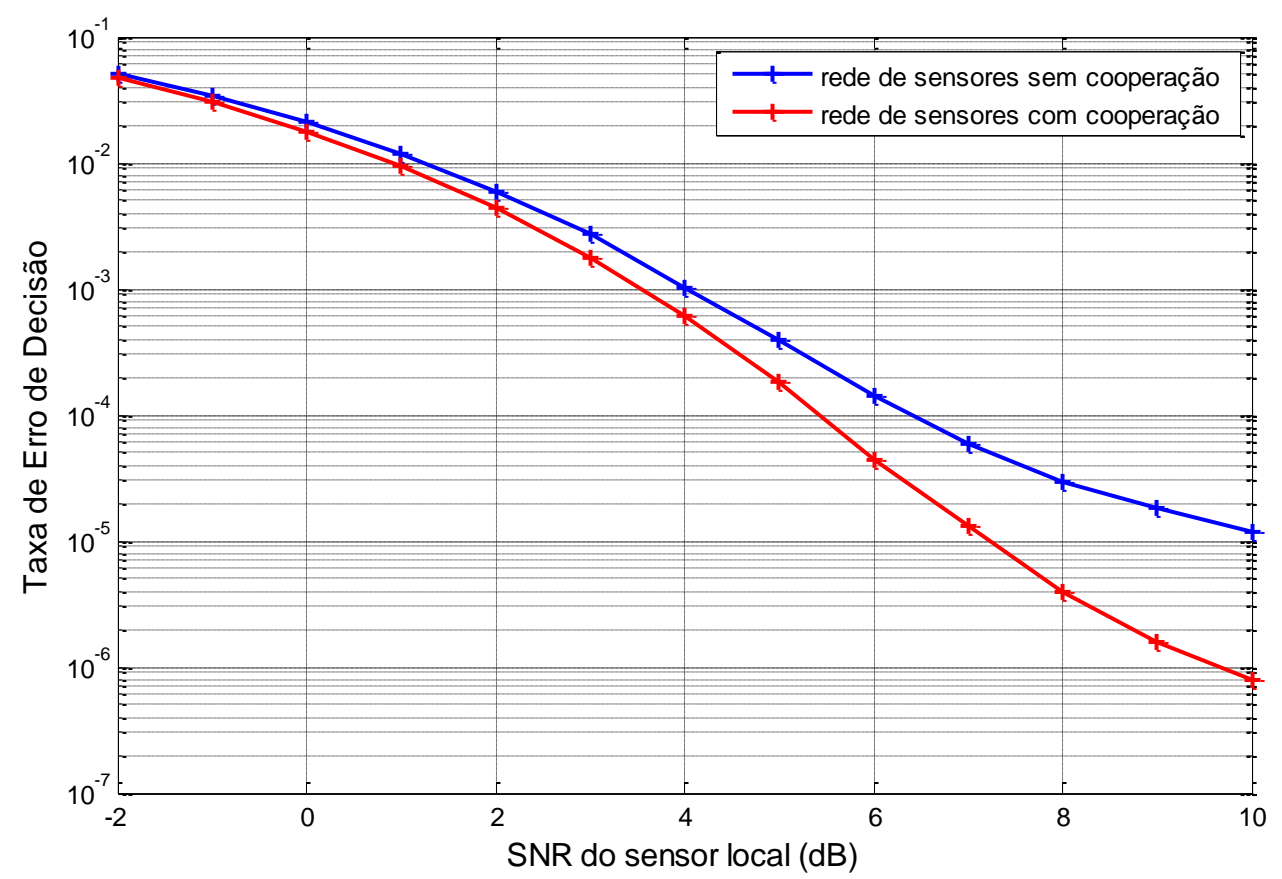

Figura 4.5: DER vs SNR do sensor local para uma SNR média do canal multipercurso $\mathrm{SNR}_{w}=6 \mathrm{~dB}$ e $\mathrm{K}=7$ sensores locais. 


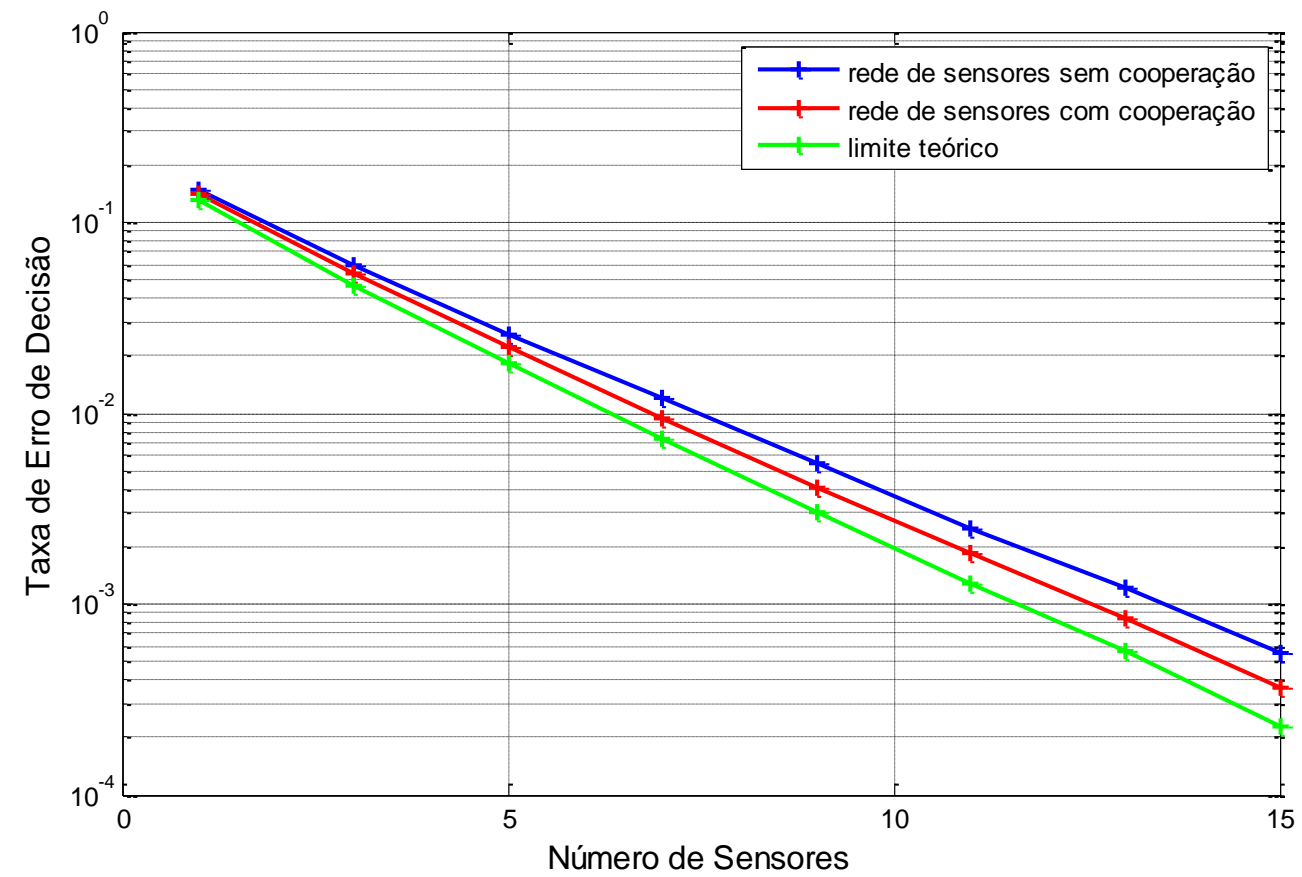

Figura 4.6: DER vs número de sensores para uma SNR média do canal multipercurso $\mathrm{SNR}_{w}=6 \mathrm{~dB}$ e SNR local $=1 \mathrm{~dB}$.

A fim de avaliar o ganho vindo oferecido pela cooperação, na próxima simulação os canais $\mathbf{h}_{k}$ e $\mathbf{h}_{l}$ são modelados com $\mathrm{L}=1$ coeficiente, simulando um desvanecimento plano entre os sensores e o centro de fusão, para ambas as redes de sensores cooperativa e não-cooperativa (nesse caso, existe apenas o canal discreto $\mathbf{h}_{k}$ ). Assim a DER de ambas as redes de sensores ilustrada na Figura 4.7, como função da SNR média local dos sensores, para $\mathrm{K}=7$ sensores/relays e SNR média do canal de comprimento $\mathrm{L}=1$ fixada em $6 \mathrm{~dB}\left(\mathrm{SNR}_{w}=6 \mathrm{~dB}\right)$, evidencia que, como esperado, os desempenhos individuais são inferiores ao caso multipercuso da Figura 4.5. Entretanto, para valores médios e altos de SNR local, a diferença no desempenho entre as redes de sensores cooperativa e nãocooperativa é maior que no caso de ambiente seletivo em frequência.

A Figura 4.8 mostra a DER versus o número de sensores $\mathrm{K}$, para uma $\mathrm{SNR}_{w}$ $=6 \mathrm{~dB}$ e uma SNR local de $1 \mathrm{~dB}$ para todos os sensores. Comentários similares aos que foram feitos em relação aos resultados mostrados nas Figuras 4.5 e 4.7 se aplicam na comparação entre os resultados apresentados nas Figuras 4.6 e 4.8.

Em canais planos a maior diferença de desempenho entre as redes de sensores cooperativas e não-cooperativas ocorre devido à capacidade de explorar a diversidade espacial provida pela rede de sensores cooperativa, enquanto que a 
rede de sensores não-cooperativa dispõe de uma diversidade de multipercurso para ser explorada.

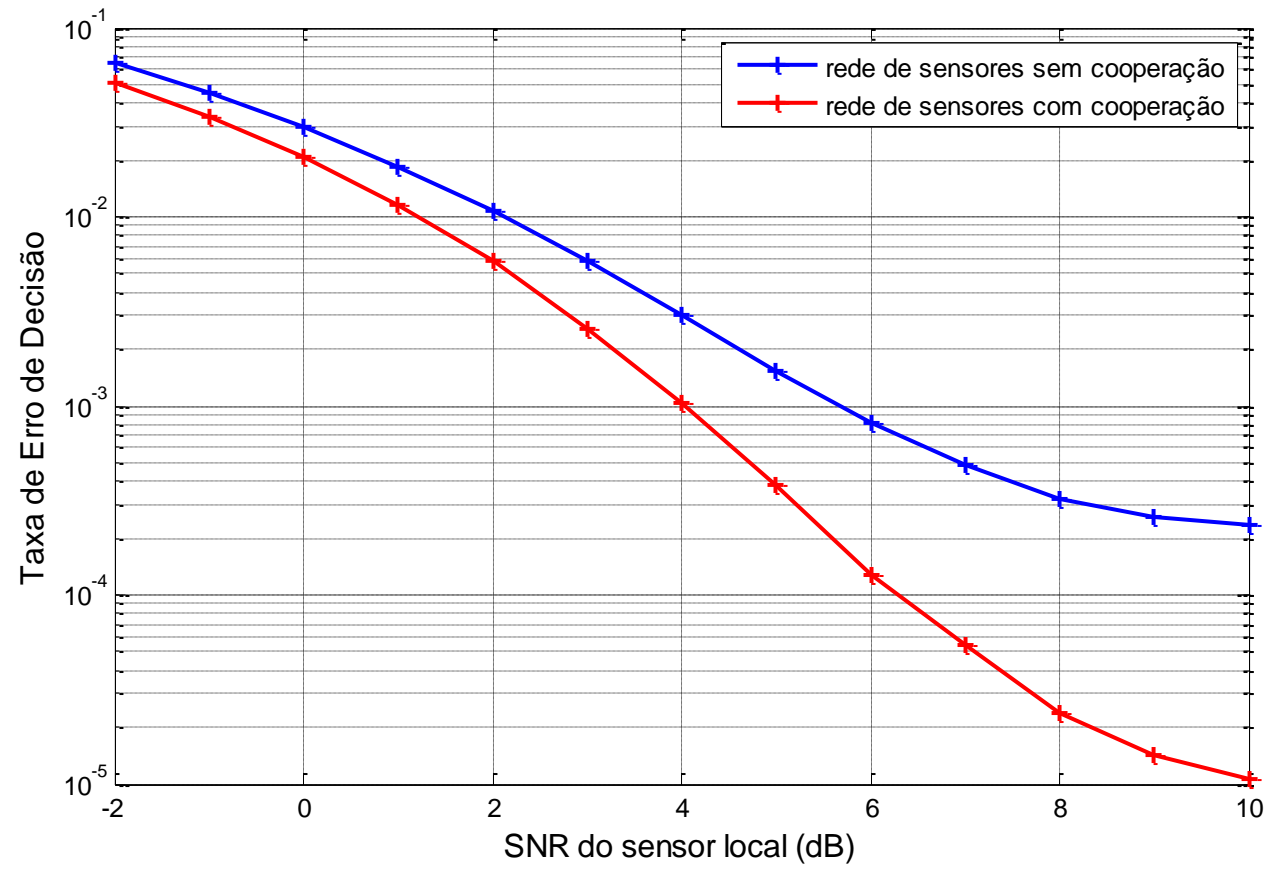

Figura 4.7: DER vs SNR do sensor local para uma SNR média do canal plano $\mathrm{SNR}_{w}=6 \mathrm{~dB}$ e $\mathrm{K}=7$ sensores locais.

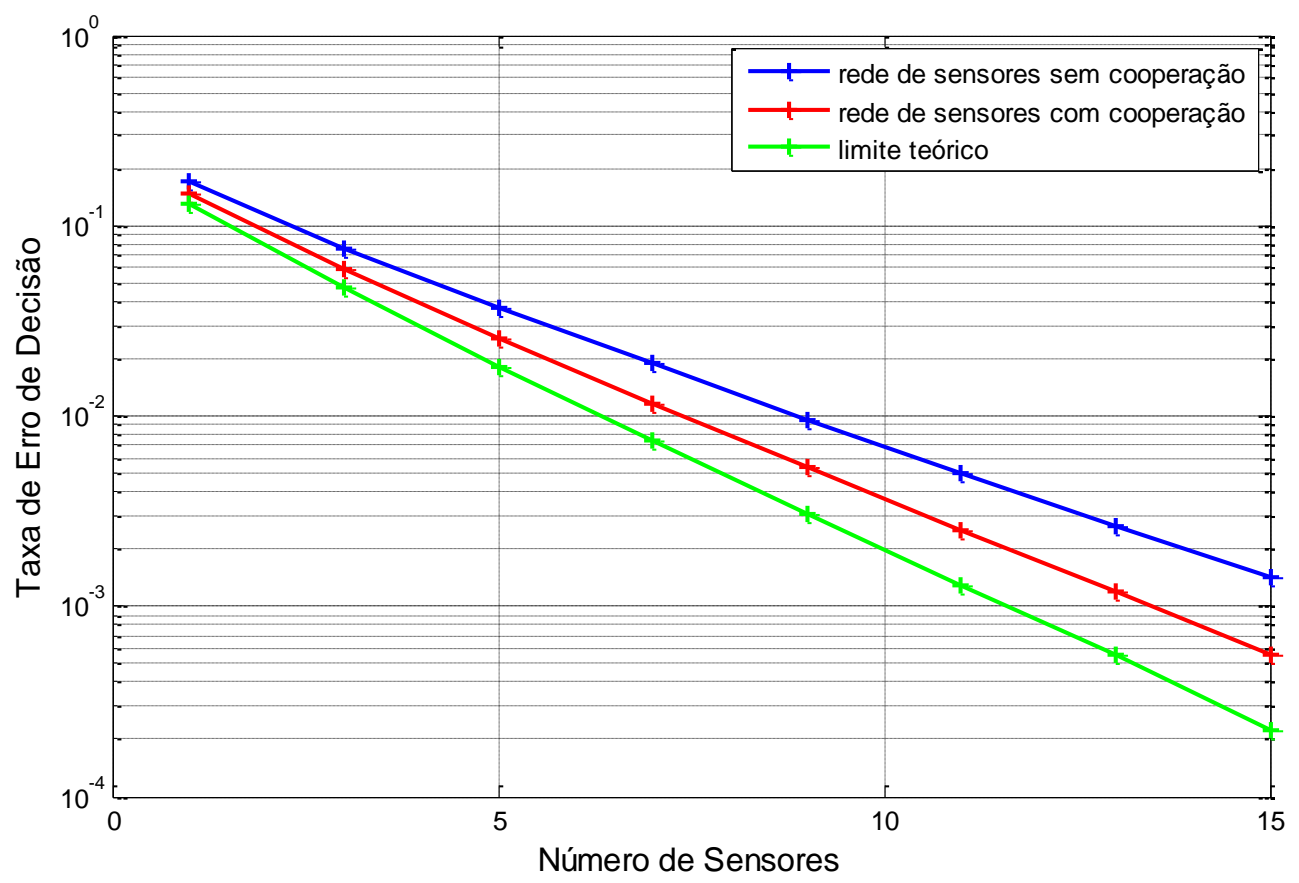

Figura 4. 8: DER vs número de sensores para uma SNR média do canal plano $\mathrm{SNR}_{w}=6 \mathrm{~dB}$ e SNR local $=1 \mathrm{~dB}$. 


\section{3}

\section{Conclusões}

No presente capítulo foi proposta uma rede de sensores cooperativa utilizando o esquema de transmissão CS-CDMA. Nesta rede, cada sensor é pareado com um sensor vizinho formando um sensor cooperativo que transmite sua mensagem e retransmite uma estimativa da mensagem do sensor pareado a partir do protocolo de cooperação DEF. Resultados numéricos indicaram que, como esperado, a rede de sensores cooperativa possui um melhor desempenho que a rede se sensores não-cooperativa. Entretanto, o ganho de desempenho é mais significativo em ambientes com desvanecimento plano. Em ambientes seletivos em frequência, a rede de sensores CS-CDMA não-cooperativa já explora eficientemente a diversidade de multipercurso, e o ganho decorrente da diversidade espacial provida pelo uso da cooperação não resulta em uma melhora substancial no desempenho final. Isto indica que o uso de cooperação em redes de sensores utilizando o esquema de transmissão CS-CDMA é mais vantajoso em ambientes com poucos componentes de multipercurso. 


\section{Fusão Adaptativa em Redes de Sensores}

A regra de fusão adotada nos capítulos anteriores foi a regra da maioria. Contudo, conforme mencionado no Capítulo 2, ponderar igualmente as decisões binárias dos sensores e verificar a polaridade da combinação só é um procedimento ótimo quando os sensores operam nas mesmas condições, as hipóteses são equiprováveis a priori, e, além disso, os detectores dos sensores possuem a mesma relação sinal ruído.

Conforme mostrado em [7], a regra de fusão ótima para o caso geral, pondera as decisões dos sensores levando em conta o nível de confiança de suas decisões e compara a soma ponderada das decisões com um limiar que depende das probabilidades de ocorrência das hipóteses consideradas. Os fatores de ponderação devem refletir a variabilidade das condições de operação da rede de sensores, bem como a eficiência de detecç̧ão e a confiabilidade dos sensores.

Assim, para implementar a regra geral de fusão ótima, o peso associado a cada sensor e as probabilidades das hipóteses consideradas devem ser conhecidos a priori. Em [30], foi proposto um algoritmo para a estimação das probabilidades envolvidas em um sistema de detecção distribuída de hipóteses binárias. Contudo, como o algoritmo necessita resolver um sistema de K-1 equações não lineares, onde $\mathrm{K}$ é igual ao número de sensores, sua complexidade aumenta demasiadamente com o número de sensores. Algoritmos iterativos foram propostos em [31-33] para estimar as probabilidades de falso alarme e misdetection as quais são utilizadas no cálculo dos pesos e as probabilidades $a$ priori das hipóteses na obtenção do limiar de decisão. Entretanto, o tempo de convergência destes algoritmos pode ser demasiadamente longo, tornando-os pouco adequados para ambientes variantes no tempo. Já em [35], foi proposto um algoritmo para estimar adaptativamente os pesos associados à confiabilidade das decisões de cada sensor. Contudo, o limiar de decisão não é estimado, suposto como zero, de forma que a regra de fusão estimada não corresponde à regra ótima geral de fusão. Ressalta-se ainda que nos artigos supracitados supõem-se a ausência de erros na transmissão dos sensores para o centro de fusão (canal ideal). 
Assim, a fim de se buscar uma solução generalizada para o problema de fusão, este capítulo propõe um algoritmo adaptativo que, assim como em [35], considera as variações no cenário por meio do uso ponderado das decisões do centro de fusão, no entanto, neste novo esquema os pesos são estimados de forma conjunta com o limiar de decisão ótima. Desta forma, a regra de fusão resultante contempla a situação geral de sensores com confiabilidades diferentes e hipóteses não equiprováveis.

Na Seção 5.1 é apresentada a formulação da regra de decisão ótima para redes de sensores, na qual a regra de fusão é reescrita de forma que algoritmos de estimação linear possam ser aplicados na estimação dos parâmetros desconhecidos.

Na Seção 5.2 são apresentados os algoritmos do tipo LMS e RLS propostos para a estimação conjunta dos pesos e do limiar da regra de fusão ótima, para serem utilizados no segundo estágio do receptor.

Considerando uma rede de sensores CS-CDMA, a Seção 5.3 apresenta resultados de simulações comparando os desempenhos dos esquemas adaptativos com os desempenhos associados à regra de fusão ótima e à regra da maioria

$\mathrm{Na}$ Seção 5.4 é realizada uma análise de convergência do erro médio quadrático das estimativas geradas pelos algoritmos LMS e RLS.

Na Seção 5.5 é realizada uma análise da evolução da probabilidade de erro de decisão resultante do uso de estimadores LMS e RLS nos receptores.

Na Seção 5.6 é analisada uma versão modificada do algoritmo LMS, cuja função custo é a probabilidade de erro de decisão.

Conclusões do capítulo são apresentadas na Seção 5.7.

\section{1}

\section{Formulação do Aprendizado Online}

Considera-se aqui o teste binário de hipóteses em uma rede de sensores sem fio, com probabilidade a priori $p_{0}$ e $p_{1}$, modelada na Seção 2.1.1, onde as decisões binárias locais dos sensores $u_{k}$ são mapeadas em símbolos antipodais $b_{k}(i) \in$ $\{-1,+1\}$, transmitidos para o centro de fusão, cujo receptor do primeiro estágio faz a estimativa $\hat{b}_{k}(i)$ dos símbolos transmitidos pelo sensor $k$. Para esse cenário 
onde o canal não ideal, temos que a regra de fusão ótima (decisão MAP) é dada pelas expressões (2-33) a (2-36), repetidas aqui por conveniência:

$$
\hat{u}=\left\{\begin{array}{r}
1 ; \text { se } a_{0}+\sum_{k=1}^{K} a_{k} \hat{b}_{k}>0 \\
-1 ; \text { caso contrário }
\end{array}\right.
$$

na qual os pesos ótimos são dados por:

$$
\begin{aligned}
& a_{0}=\log \frac{p_{1}}{p_{0}} \\
& a_{k}=\beta_{k}=\log \frac{1-P_{M_{k}}}{P_{F_{k}}}, \text { se } \hat{b}_{k}=1, \\
& a_{k}=\gamma_{k}=\log \frac{1-P_{F_{k}}}{P_{M_{k}}}, \text { se } \hat{b}_{k}=1,
\end{aligned}
$$

e $P_{M_{k}}$ e $P_{F_{k}}$ são definidos em (2-28) e (2-29), respectivamente.

Como os coeficientes $a_{k}(k=1, \ldots, \mathrm{K})$ em (5-3) e (5-4) depende do valor de $\hat{b}_{k}$, é necessário uma estimação não linear para estimar os valores de $a_{k}$. Entretanto, a regra ótima pode ser reescrita de forma que os coeficientes não dependam do valor de $\hat{b}_{k}$, ou seja, a regra ótima pode ser expressa por uma combinação linear das decisões do primeiro estágio do receptor. Para isso, o coeficiente $a_{k}$ é expresso de forma unificada como:

$$
\begin{gathered}
a_{k}=\beta_{k}\left(\frac{1+\hat{b}_{k}}{2}\right)+\gamma_{k}\left(\frac{1-\hat{b}_{k}}{2}\right) \\
=\frac{1}{2}\left(\beta_{k}-\gamma_{k}\right) \hat{b}_{k}+\frac{1}{2}\left(\beta_{k}+\gamma_{k}\right)
\end{gathered}
$$

Assim, se $\hat{b}_{k}=1$ tem-se $a_{k}=\beta_{k}$ e para $\hat{b}_{k}=-1$ tem-se $a_{k}=\gamma_{k}$. Continuando o desenvolvimento de (5-1), e lembrando que $\hat{b}_{k}^{2}=1$, tem-se:

$$
a_{k} \hat{b}_{k}=\frac{1}{2}\left(\beta_{k}+\gamma_{k}\right) \hat{b}_{k}+\frac{1}{2}\left(\beta_{k}-\gamma_{k}\right)
$$


Substituindo (5-5) em (5-1), observa-se que a regra ótima pode ser expressa por:

$$
\hat{u}=\left\{\begin{array}{rl}
1 ; & \text { se } c_{0}+\sum_{k=1}^{K} c_{k} \hat{b}_{k}>0 \\
-1 ; & \text { caso contrário }
\end{array},\right.
$$

em que os novos coeficientes $c_{k}$ são independentes de $\hat{b}_{k}$ e, portanto,

$$
\begin{gathered}
c_{0}=a_{0}+\sum_{k=1}^{K} \frac{1}{2}\left(\beta_{k}-\gamma_{k}\right)= \\
=\log \frac{p_{1}}{p_{0}}+\frac{1}{2} \sum_{k=1}^{K} \log \frac{\left(1-P_{M_{k}}\right) P_{F_{k}}}{\left(1-P_{F_{k}}\right) P_{M_{k}}} \\
c_{k}=\frac{1}{2}\left(\beta_{k}+\gamma_{k}\right)=\frac{1}{2} \log \frac{\left(1-P_{M_{k}}\right)\left(1-P_{F_{k}}\right)}{P_{F_{k}} P_{M_{k}}} .
\end{gathered}
$$

Note que, diferentemente de (5-2), o termo independente (limiar) não depende apenas de $p_{0}$ e $p_{1}$ e não se anula quando $p_{0}=p_{1}$.

A regra de fusão ótima em (5-6) é ilustrada na Figura 5.1:

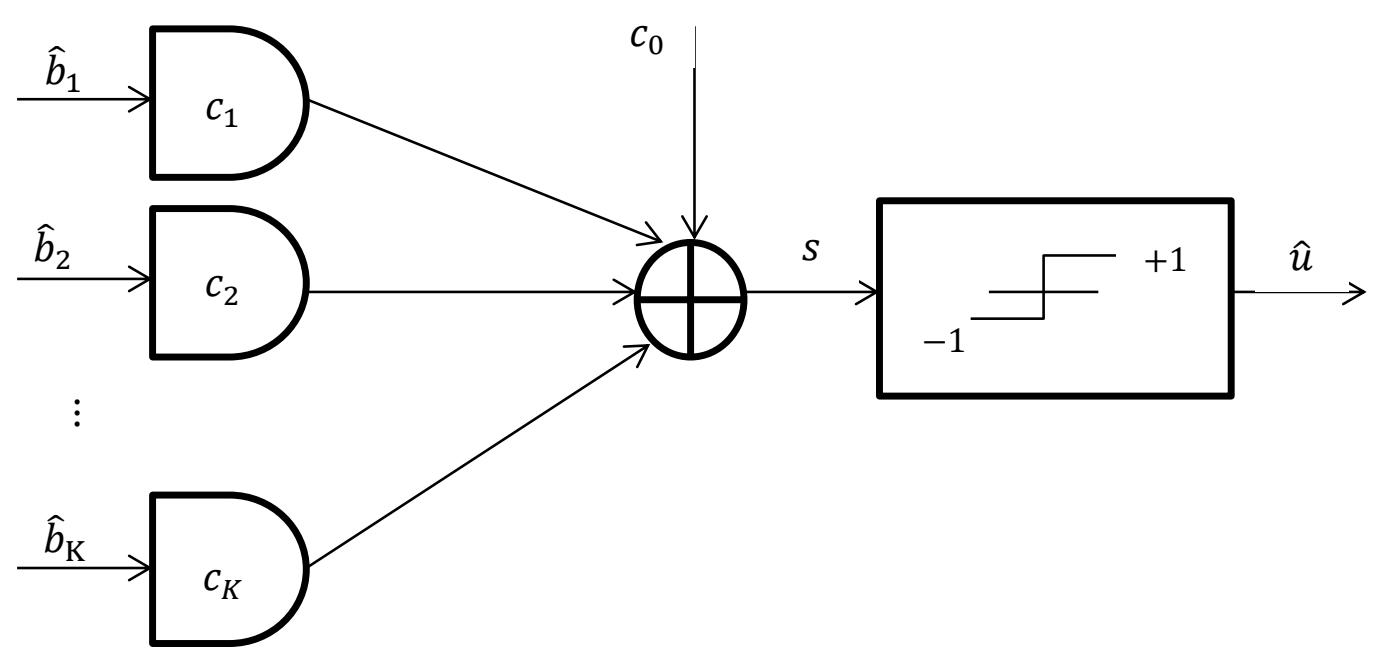

Figura 5.1: Diagrama da regra de fusão geral ótima. 
em que $s=c_{0}+\sum_{k=1}^{K} c_{k} \hat{b}_{k}$

Técnicas cooperativas de detecção, incluindo os testes de razão de verossimilhança (Teste de Bayes [5,41] utilizado para desenvolver (5-1), Teste Neyman-Person [5,41], etc) correspondem a uma adequada ponderação das decisões dos sensores. Contudo, conforme evidenciado em (5-6), as expressões dos pesos pressupõem o conhecimento da probabilidade de detecção e a probabilidade de falso-alarme de cada sensor e do receptor do centro de fusão, além do conhecimento das probabilidades a priori de ocorrência das hipóteses, requerido em (5-7) para o limiar de decisão.

A técnica de estimação das probabilidades de detecção, falso-alarme e $a$ priori apresentada em [31] não considera o efeito do canal, além de necessitar de um período de treinamento longo (respondendo lentamente a ambientes variantes no tempo). A estrutura proposta requer sinais de referência para que os valores estimados convirjam para o valor ótimo, permitindo fazer a melhor decisão. Como uma referência não está disponível, em geral, uma vez que em redes de sensores práticos nenhuma informação a priori é dada sobre os sensores e sobre as hipóteses observadas.

Em [35], a decisão feita por uma regra de fusão particular (nesse esquema a regra OR) é utilizada como sinal de referência no período de treinamento do algoritmo de estimação dos pesos, tendo em vista que a decisão feita por uma regra de fusão é mais confiável do que as decisões dos sensores. O trabalho em [35] considera ainda que o limiar de detecção é sempre 0 .

A estrutura linear da regra de fusão ótima apresentada em (5-6), motivou a proposição neste trabalho de um algoritmo adaptativo linear cego (sem necessidade de pilotos conhecidos pelo receptor) para a estimação dos pesos $c_{k} \mathrm{e}$ do limiar $c_{0}$ e fusão de dados em redes sensores sem fio, quando os efeitos do canal são levados em consideração. 


\section{2}

Processo Adaptativo de Estimação Conjunta dos Pesos e do Limiar de Decisão

O esquema proposto para estimação adaptativa dos pesos e limiar de decisão é ilustrado na Figura 5.2:

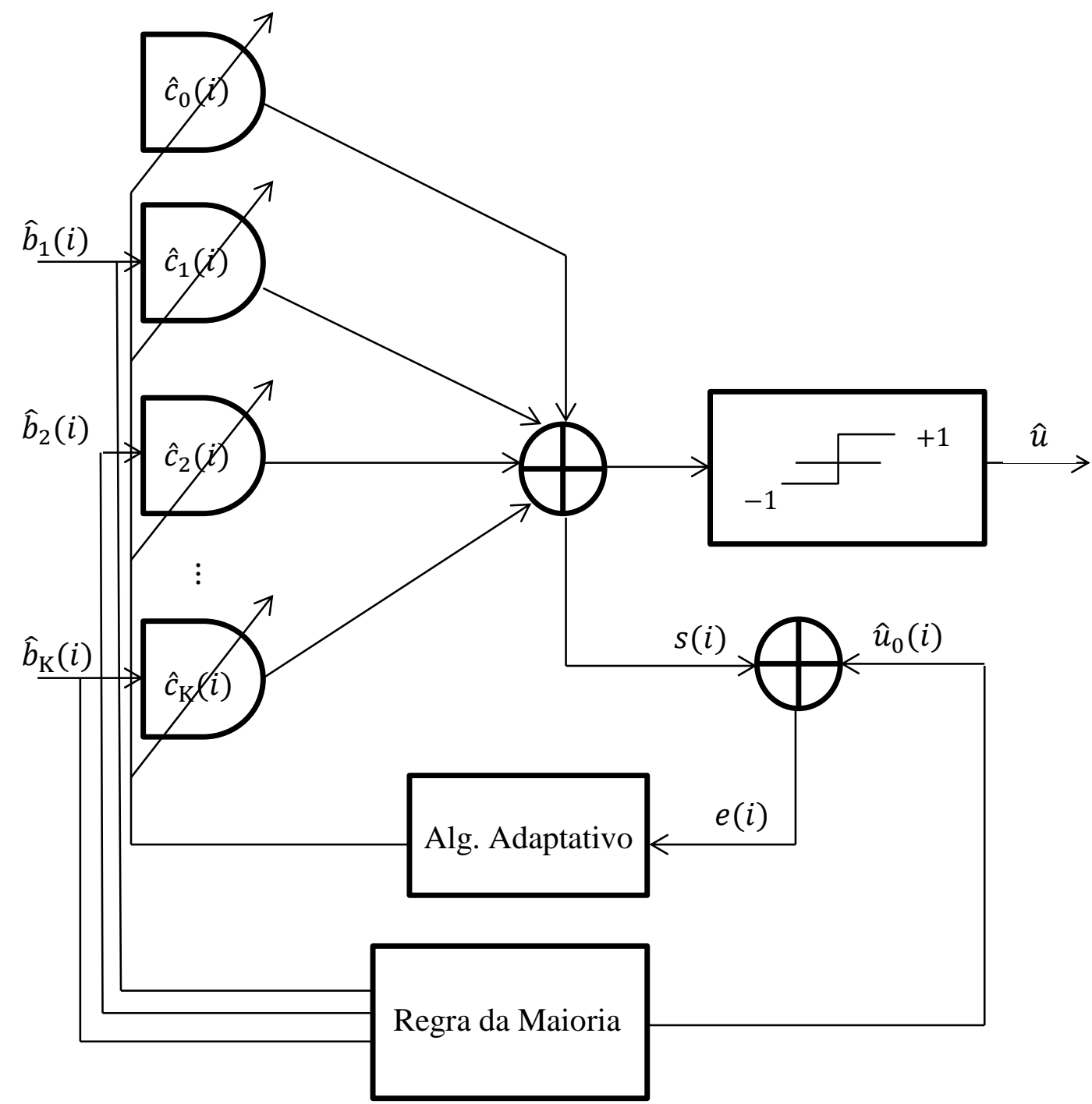

Figura 5.2: Regra de fusão adaptativa. 
Nessa figura, $\hat{u}_{0}(i) \in\{-1,+1\}$ representa uma decisão intermediária, obtida combinando as estimativas das decisões dos sensores $\hat{\mathbf{b}}(i)=\left[\hat{b}_{1}(i) \hat{b}_{2}(i) \cdots \hat{b}_{\mathrm{K}}(i)\right]^{T}$, utilizando a regra da maioria. De acordo com $(5-$ 2)-(5-4), essa regra é ótima quando as probabilidades de erros condicionais, $P_{M_{k}} \mathrm{e}$ $P_{F_{k}}$, associadas às decisões do primeiro estágio do receptor forem iguais entre si e idênticas para todos os sensores, e ainda as probabilidades a priori $p_{0}=p_{1}$, ou seja, essa regra considera todas as decisões com o mesmo nível de confiabilidade e não favorece alguma hipótese previamente. Como o algoritmo não tem conhecimento a priori das probabilidades, a regra da maioria foi proposta para gerar estimativas intermediárias $\hat{u}_{0}(i)$ que são utilizadas como sinal de referência para o algoritmo adaptativo que busca a regra ótima de fusão.

A saída do algoritmo na amostra $i, s(i)$, é dada pela combinação linear das estimativas das decisões dos sensores adicionada a um termo de limiar de decisão:

$$
s(i)=\hat{\mathbf{c}}(i)^{T} \hat{\mathbf{b}}(i)+\hat{c}_{0}(i)
$$

na qual $\hat{\mathbf{c}}(i)=\left[\hat{c}_{1}(i) \hat{c}_{2}(i) \cdots \hat{c}_{\mathrm{K}}(i)\right]^{T}$ é o vetor de pesos utilizado na combinação linear das componentes de $\hat{\mathbf{b}}(i)$ e $\hat{c}_{0}(i)$, é o termo um termo de limiar de decisão. Assim, como $s(i)$ é real, a decisão final $\hat{u}(i)$ é baseada na polaridade de $s(i)$.

O sinal custo de atualização $e(i)$ é dado por:

$$
e(i)=\hat{u}_{0}(i)-s(i)
$$

A fim de se adaptar os pesos $\hat{\mathbf{c}}(i)$ e o limiar de decisão $\hat{c}_{0}(i)$, é adotada a minimização do erro médio quadrático $\left(\mathrm{MSE}_{\widehat{u}_{0}}\right), \mathbb{E}\left[e^{2}(i)\right]=\mathbb{E}\left[\left|\hat{u}_{0}(i)-s(i)\right|^{2}\right]$, em relação à referência intermediária $\hat{u}_{0}(i)$.

$\mathrm{O}$ vetor $\mathbf{c}^{\boldsymbol{w}}$ e o escalar $c_{0}^{w}$ que minimizam o valor médio quadrático, $\mathbb{E}\left[e^{2}(i)\right]$, são obtidos igualando o seu gradiente de a zero. Resolvendo para $c_{0}^{w}$ obtem-se:

$$
c_{0}^{w}=m_{\widehat{u}_{0}}-\mathbf{c}^{\boldsymbol{w}^{T}} \boldsymbol{m}_{\hat{\mathbf{b}}}
$$


em que $m_{\widehat{u}_{0}}=\mathbb{E}\left[\hat{u}_{0}(i)\right]$ e $\boldsymbol{m}_{\hat{\mathbf{b}}}=\mathbb{E}[\hat{\mathbf{b}}(i)]$. Substituindo (5-11) em $\mathbb{E}\left[e^{2}(i)\right]$ e minimizando para $\mathbf{c}^{\boldsymbol{w}}$, resulta:

$$
\mathbf{c}^{\boldsymbol{w}}=\mathbf{K}_{\hat{\mathbf{b}}}^{-1} \boldsymbol{p}_{\bar{u}_{0} \overline{\mathbf{b}}}
$$

em que a matriz de covariância $\mathbf{K}_{\hat{\mathbf{b}}}=\mathbb{E}\left[\left(\hat{\mathbf{b}}(i)-\boldsymbol{m}_{\hat{\mathbf{b}}}\right)\left(\hat{\mathbf{b}}(i)-\boldsymbol{m}_{\hat{\mathbf{b}}}\right)^{T}\right]$ e o vetor de covariância cruzada $\boldsymbol{p}_{\bar{u}_{0} \overline{\mathbf{b}}}=\mathbb{E}\left[\left(\hat{u}_{0}(i)-m_{\widehat{u}_{0}}\right)\left(\hat{\mathbf{b}}(i)-\boldsymbol{m}_{\mathfrak{b}}\right)\right]$. As expressões em (5-11) e (5-12) resultantes da minimização de $\mathbb{E}\left[e^{2}(i)\right]$ correspondem a solução de Wiener com referência $\hat{u}_{0}(i)$ (referido como solução de Wiener $\widehat{u}_{0}$ ).

Algoritmos de filtragem adaptativa podem ser utilizados para aproximar (511) e (5-12). Neste trabalho serão examinados algoritmos do tipo LMS e o do tipo RLS, apresentados nas próximas sub-seções.

\section{2 .1}

\section{Fusão Adaptativa Baseado no Algoritmo LMS}

O algoritmo LMS, que é baseado no método steepest descent, é comumente utilizado para reduzir o erro quadrático instantâneo [52-55]. Este algoritmo pode ser utilizado para atualizar as estimativas dos pesos $\hat{\mathbf{c}}(i)$ conjuntamente com a estimativa do limiar $\hat{c}_{0}(i)$ :

$$
\begin{aligned}
& \hat{\mathbf{c}}(i+1)=\hat{\mathbf{c}}(i)-\delta_{\hat{\mathbf{c}}} \nabla_{\hat{\mathbf{c}}}|e(i)|^{2} \\
& \hat{c}_{0}(i+1)=\hat{c}_{0}(i)-\delta_{\hat{\mathbf{c}}} \nabla_{\hat{c}_{0}}|e(i)|^{2}
\end{aligned}
$$

em que $\nabla$ é o operador gradiente e $\delta_{\hat{\mathbf{c}}}$ e $\delta_{\hat{\mathbf{c}}}$ são os passos de atualização.

Resolvendo a diferenciação em (5-13) chega-se as equações de recursão:

$$
\begin{array}{r}
\hat{\mathbf{c}}(i+1)=\hat{\mathbf{c}}(i)+\delta_{\hat{\mathbf{c}}} e(i) \hat{\mathbf{b}}(i) \\
\hat{c}_{0}(i+1)=\hat{c}_{0}(i)+\delta_{\hat{c}_{0}} e(i)
\end{array}
$$

Uma desvantagem do algoritmo LMS é o fato dele ser sensível a variações da amplitude de seu sinal de entrada, o que dificulta o dimensionamento 
apropriado dos passos $\delta_{\hat{\mathbf{c}}}$ e $\delta_{\hat{\mathbf{c}}}$ [52]. O algoritmo LMS normalizado (NMLS) é a forma do algoritmo LMS que minora esse problema normalizando o passo $\delta$ em relação à potência instantânea do sinal de observação. No presente caso, esta potência não sofre flutuações e o passo é normalizado por $\hat{\mathbf{b}}^{T}(i) \hat{\mathbf{b}}(i)=\mathrm{K}$.

\section{2 .2}

\section{Fusão Adaptativa Baseada no Algoritmo RLS}

O algoritmo RLS obtém recursivamente os coeficientes que minimizam a função custo de mínimos quadrados lineares ponderados $J_{\hat{\mathbf{c}}, \hat{c}_{0}}(i)$, relacionada com o vetor de decisões de entrada onde:

$$
J_{\hat{\mathbf{c}}, \hat{c}_{0}}(i)=\sum_{l=0}^{i} \lambda^{i-l} e^{2}(l)
$$

em que $\lambda$ é o fator de esquecimento que fornece um compromisso entre a capacidade de rastreamento do algoritmo e o desempenho no estado estacionário e tem valores $0<\lambda<1$.

O vetor de pesos $\hat{\mathbf{c}}(i)$ e o limiar $\hat{c}_{0}(i)$ são dados pela resolução da seguinte equação de minimização:

$$
\left.\nabla J_{\hat{\mathbf{c}}, \hat{c}_{0}}(i)\right|_{\hat{\mathbf{c}}=\hat{\mathbf{c}}(i), \hat{c}_{0}=\hat{c}_{0}(i)}=0
$$

Resolvendo (5-16) pode-se mostrar, vide Apêndice A, que o limiar $\hat{c}_{0}(i)$ é dado por:

$$
\hat{c}_{0}(i)=m_{\widehat{u}_{0}}(i)-\hat{\mathbf{c}}(i)^{T} \boldsymbol{m}_{\hat{\mathbf{b}}}(i)
$$

no qual $\quad m_{\widehat{u}_{0}}=\left(\frac{1-\lambda}{1-\lambda^{i+1}}\right) \sum_{l=0}^{i} \lambda^{i-l} \hat{u}_{0}(l)$ e $\quad \boldsymbol{m}_{\hat{\mathbf{b}}}=\left(\frac{1-\lambda}{1-\lambda^{i+1}}\right) \sum_{l=0}^{i} \lambda^{i-l} \hat{\mathbf{b}}(l)$ representam uma média ponderada dos valores de $\hat{u}_{0}(i)$ e de $\hat{\mathbf{b}}(i)$, respectivamente. $\mathrm{O}$ vetor de pesos $\hat{\mathbf{c}}(i)$ é dado pela formulação RLS, ou seja, 


$$
\hat{\mathbf{c}}(i)=\hat{\mathbf{c}}(i-1)+\mathbf{K}(i)\left(\bar{u}_{0 m}(i)-\hat{\mathbf{c}}^{T}(i-1) \hat{\mathbf{b}}_{m}(i)\right)
$$

em qual $\bar{u}_{0 m}(i)=\hat{u}_{0}(i)-m_{\widehat{u}_{0}}(i), \hat{\mathbf{b}}_{m}(i)=\hat{\mathbf{b}}(i)-\boldsymbol{m}_{\hat{\mathbf{b}}}(i)$ e o vetor $\mathbf{K}(i)$ é o ganho de Kalman descrito na equação (A-13) do Apêndice A.

Substituindo o vetor de pesos $\hat{\mathbf{c}}(i)$ e o limiar $\hat{c}_{0}(i)$ em (5-9) obtêm-se a estimativa RLS de $s(i)$ :

$$
s(i)=\hat{\mathbf{c}}^{T}(i) \hat{\mathbf{b}}_{m}(i)+m_{\widehat{u}_{0}}(i)
$$

\section{3}

\section{Simulações e Resultados}

Nesta subseção são apresentados resultados de desempenho obtidos com uma rede de sensores CS-CDMA utilizando o receptor sub-ótimo de dois estágios proposto no Capítulo 2, sendo que no segundo estágio é implementada a regra de fusão adaptativa proposta neste capítulo. Nas simulações a observação $y_{k}$ do sensor $k$ é modelada como $y_{k}=u . d+n_{k}, k=1,2, \ldots, \mathrm{K}$, em que $u$ é definida em (2-1), $d$ é uma constante conhecida e $n_{k}$ são variáveis aleatórias Gaussianas mutuamente independentes com média zero e variâncias iguais a $\sigma^{2}$. O sensor $k$ realiza uma detecção ML na observação $y_{k}$ a fim de estimar $u$. As probabilidades $P_{M_{k}}^{S}$ e $P_{F_{k}}^{S}$ que aparecem em (2-28) e (2-29) são, portanto, iguais a $P_{e}=$ $\mathcal{Q}\left(\sqrt{\frac{d^{2}}{\sigma^{2}}}\right)$. As mensagens são mapeadas em símbolos BPSK que são transmitidas para o centro de fusão usando o esquema CS-CDMA, com códigos ortogonais de tamanho $\mathrm{N}$ dado pela Tabela 2.1. Os canais entre os sensores e o centro de fusão são mutuamente independentes e modelados por um filtro FIR invariante no tempo contendo $\mathrm{L}=4$ coeficientes. A sequência de coeficientes do $k$-ésimo canal é dada por $h_{k, l}=q_{l} \alpha_{k, l}$, onde $\alpha_{k, l}, l=0,1, \ldots, \mathrm{L}-1$, são variáveis aleatórias complexas Gaussianas estatisticamente independentes, com média nula e $\mathbb{E}\left[\left|\alpha_{k, l}\right|^{2}\right]=1$. Os valores de $\alpha_{k, l}$ são sorteados aleatoreamente e mantidos fixos durante cada rodada de simulação. Os pesos $q_{l}$ satisfazem $\sum_{\mathrm{i}=0}^{\mathrm{L}-1}\left|q_{i}\right|^{2}=1 \operatorname{com} q_{0}=$ 
$0,8671, q_{1}=0,4346, q_{2}=0,2178$ e $q_{3}=0,1092$. Considerando que os detectores do primeiro estágio realizam uma detecção ML de acordo com (2-26) e (2-19), tem-se que as probabilidades $P_{F_{k}}^{c}$ e $P_{M_{k}}^{c}$, de acordo com (2-28) e (2-29) são dadas por $\mathcal{Q}\left(\sqrt{\frac{\left\|\mathbf{h}_{k}\right\|^{2}}{\sigma_{w_{k}}^{2}}}\right)$. Os resultados são dados pela média de 10000 experimentos independentes, com 700 símbolos enviados por sensor em cada realização. O desempenho foi computado após a convergência dos algoritmos. É admitido o conhecimento ideal dos canais pelos receptores

\subsection{1}

\section{Desempenho da Fusão Adaptativa vs Fusão Ótima}

Nesta subseção é apresentado os resultados das simulações nas quais as regras de fusão adaptativas (LMS e RLS) são comparadas com a regra de fusão ótima dada em (5-6)-(5-8) e com a regra da maioria dada em (2-37). Para o algoritmo LMS foi utilizado um passo normalizado $\delta_{\hat{\mathbf{c}}}=\delta_{\hat{c}_{0}}=\delta=0,0001$ e para o algoritmo RLS foi utilizado um fator de esquecimento $\lambda=0,9999$. Apesar das estimativas geradas pela regra da maioria poderem ser usadas ininterruptamente como sinal de referência, visando uma provável melhora de desempenho após a convergência dos algoritmos LMS e RLS, os mesmos podem ser utilizados no modo decision-directed (não explorado aqui) onde os pesos $\hat{\mathbf{c}}(i-1)$ e o limiar $\hat{c}_{0}(i-1)$ na amostra $i-1$ são utilizados para obter o sinal de referência $\hat{u}_{0}(i)$ na amostra $i$ por meio de:

$$
\hat{u}_{0}(i)=\operatorname{sign}\left\{\operatorname{Re}\left(\hat{\mathbf{c}}(i-1)^{T} \hat{\mathbf{b}}(i)+\hat{c}_{0}(i-1)\right)\right\} .
$$

A Figura 5.3 ilustra o desempenho das estratégias de fusão, expresso pela DER, em função da SNR média local dos sensores para $K=7$ sensores, SNR média do canal de $8 \mathrm{~dB}$ para todos os sensores, e probabilidades a priori $p_{0}$ e $p_{1}$ idênticas. Os resultados apresentados na figura indicam que os algoritmos LMS e RLS têm desempenho praticamente idêntico ao da regra ótima de fusão. Conforme pode ser observado na figura, a regra da maioria obteve um desempenho muito próximo ao da regra ótima de fusão apesar dos canais de cada 
sensor não serem iguais em cada iteração (são aleatórios) e consequentemente $P_{F_{k}}^{c}$ e $P_{M_{k}}^{c}$ são diferentes para cada sensor $k$ em cada iteração. Isto indica que, na média, o desempenho da regra da maioria é igual à regra ótima quando os canais aleatórios possuem valor médio quadrático iguais, para o cenário utilizado nesta simulação.

A fim de avaliar os desempenhos dos algoritmos com probabilidades $a$ priori diferentes, a Figura 5.4 ilustra a DER das regras de fusão em função da SNR média dos sensores locais, para $K=7$ sensores, SNR média do canal de $8 \mathrm{~dB}$ para todos os sensores e probabilidades a priori $p_{0}=0,1$ e $p_{1}=0,9$. Pode ser observado na Figura 5.4 que o desempenho da fusão adaptativa LMS e o da fusão RLS mantém-se muito próximo do desempenho da regra de fusão ótima. A regra da maioria, por ser sub-ótimo no caso de hipóteses não equiprováveis, apresenta um desempenho inferior.

As Figuras 5.5 e 5.6 ilustram o desempenho dos algoritmos adaptativos em regimes de SNR do canal baixas, $2 \mathrm{~dB}$ para todos os sensores, em função da SNR média dos sensores locais, com $\mathrm{K}=7$ sensores, com probabilidades a priori $p_{0}=0,1$ e $p_{1}=0,9$, respectivamente. Como observado nas figuras, para ambos os casos, não há degradação considerável, em relação à regra de fusão ótima, no desempenho dos algoritmos LMS e RLS mesmo para valores baixos da SNR do canal. Este resultado comprova a robustez dos esquemas propostos, pois a quase ausência de degradação ocorre apesar do sinal de referência, formado pela regra da maioria, apresentar uma sensível degradação de qualidade, conforme é mostrado na Figura 5.6.

Os experimentos realizados até aqui consideraram redes de sensores com a mesma SNR local e mesma SNR média do canal, de forma que todos os sensores eram "idênticos" do ponto de vista do receptor do centro de fusão.

O próximo experimento ilustra o comportamento dos algoritmos adaptativos em redes de sensores com diferentes valores de SNR local e valores diferentes de SNR média dos canais (sistema não homogêneo), ou seja, simulando redes de sensores práticas, nas quais os sensores estão dispostos em diferentes distâncias do centro de fusão. Nesse experimento, $K=7$ sensores foram distribuídos em 3 grupos onde os sensores de um mesmo grupo possuem a mesma SNR local média relacionada a uma SNR de referência $\left(\mathrm{SNR}_{r e f}\right)$. Assim, os sensores 1 a 3 foram 
configurados com SNR local $=\mathrm{SNR}_{r e f}$, o sensor 4 com SNR local $=0,6 \times \mathrm{SNR}_{r e f}$ e os sensores 5 a 7 com SNR local $=1,5 \times$ SNR $_{\text {ref }}$. Procedimento similar foi feito para a SNR dos canais, onde os canais associados aos sensores 1 a 2 possuem SNR média igual a $8 \mathrm{~dB}$, os canais associados aos sensores 3, 4 e 5 possuem SNR média de $-2 \mathrm{~dB}$ e os demais têm SNR média de $7 \mathrm{~dB}$.

As Figuras 5.7 e 5.8 ilustram o desempenho dos algoritmos adaptativos em função da $\mathrm{SNR}_{\text {ref }}$ para probabilidades a priori iguais e probabilidades a priori $p_{0}=0,1$ e $p_{1}=0,9$, respectivamente. Neste cenário há uma ligeira perda de desempenho dos algoritmos LMS e RLS em relação à regra de fusão ótima, devido ao aumento dos erros nas estimativas $\hat{b}_{k}$. Essa perda de desempenho é pequena e indica que neste sentido os esquemas adaptativos propostos são robustos às variações de SNR nos sensores e no canal.

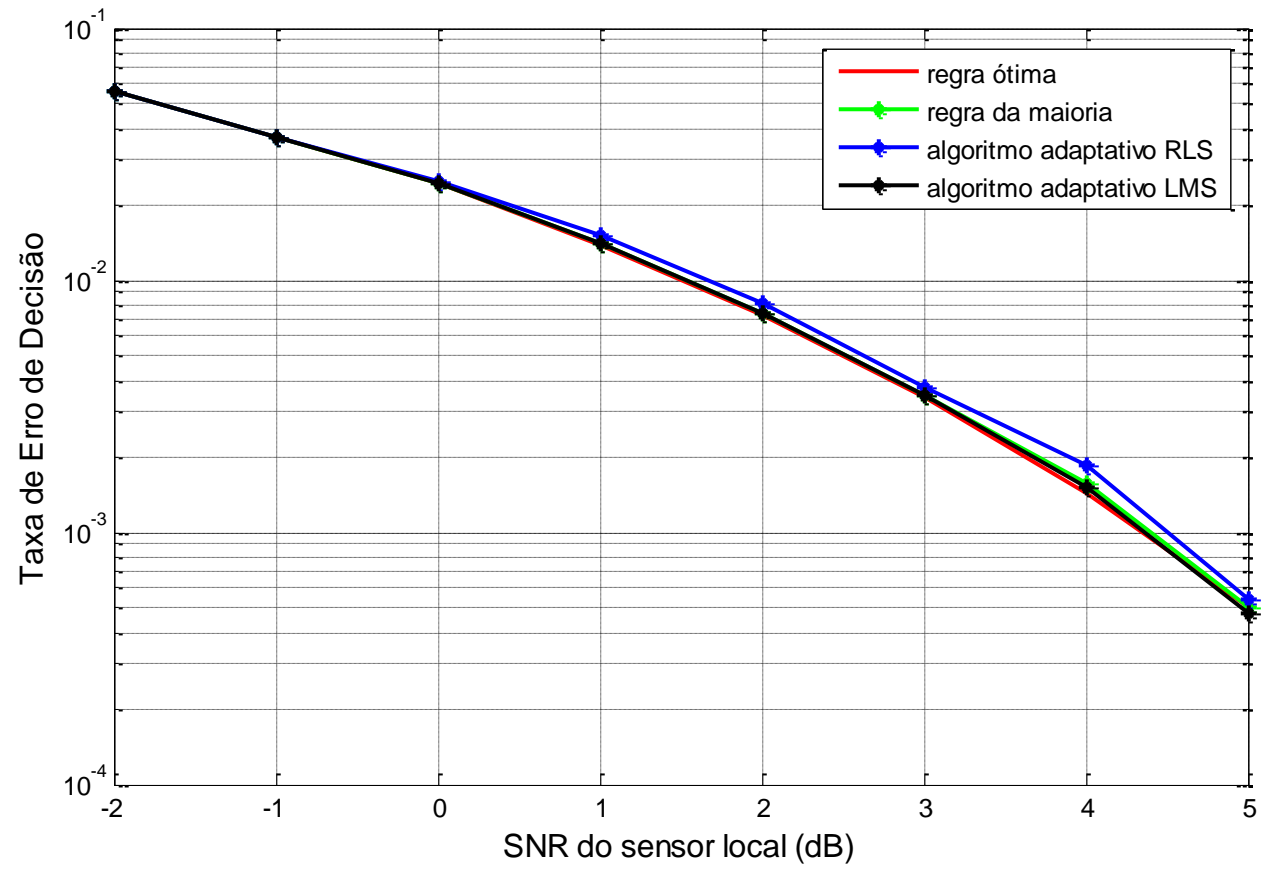

Figura 5.3: DER vs SNR do sensor local para uma SNR média do canal de $8 \mathrm{~dB}$, $\mathrm{K}=7$ sensores locais e probabilidades a priori iguais. 


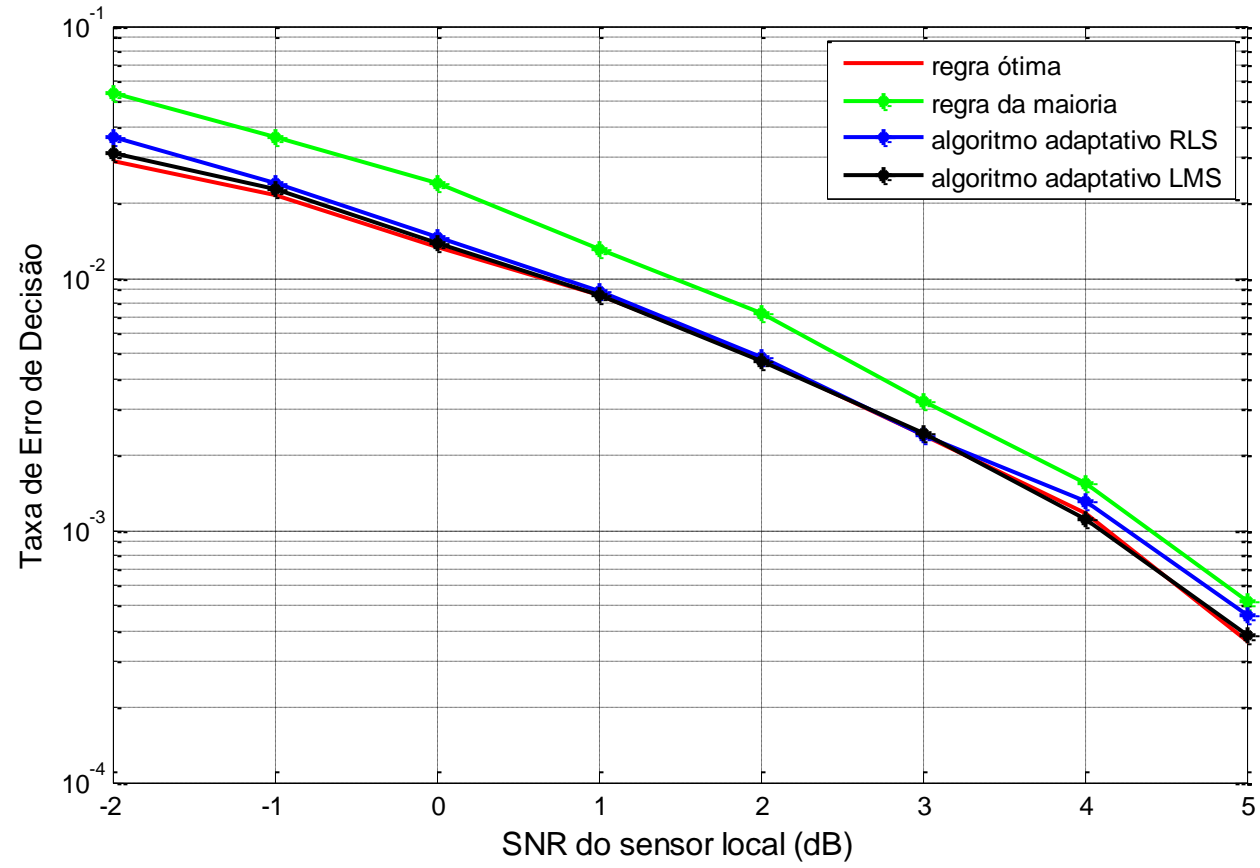

Figura 5.4: DER vs SNR do sensor local para uma SNR média do canal de $8 \mathrm{~dB}$, $\mathrm{K}=7$ sensores locais e probabilidades a priori $p_{0}=0,1$ e $p_{1}=0,9$.

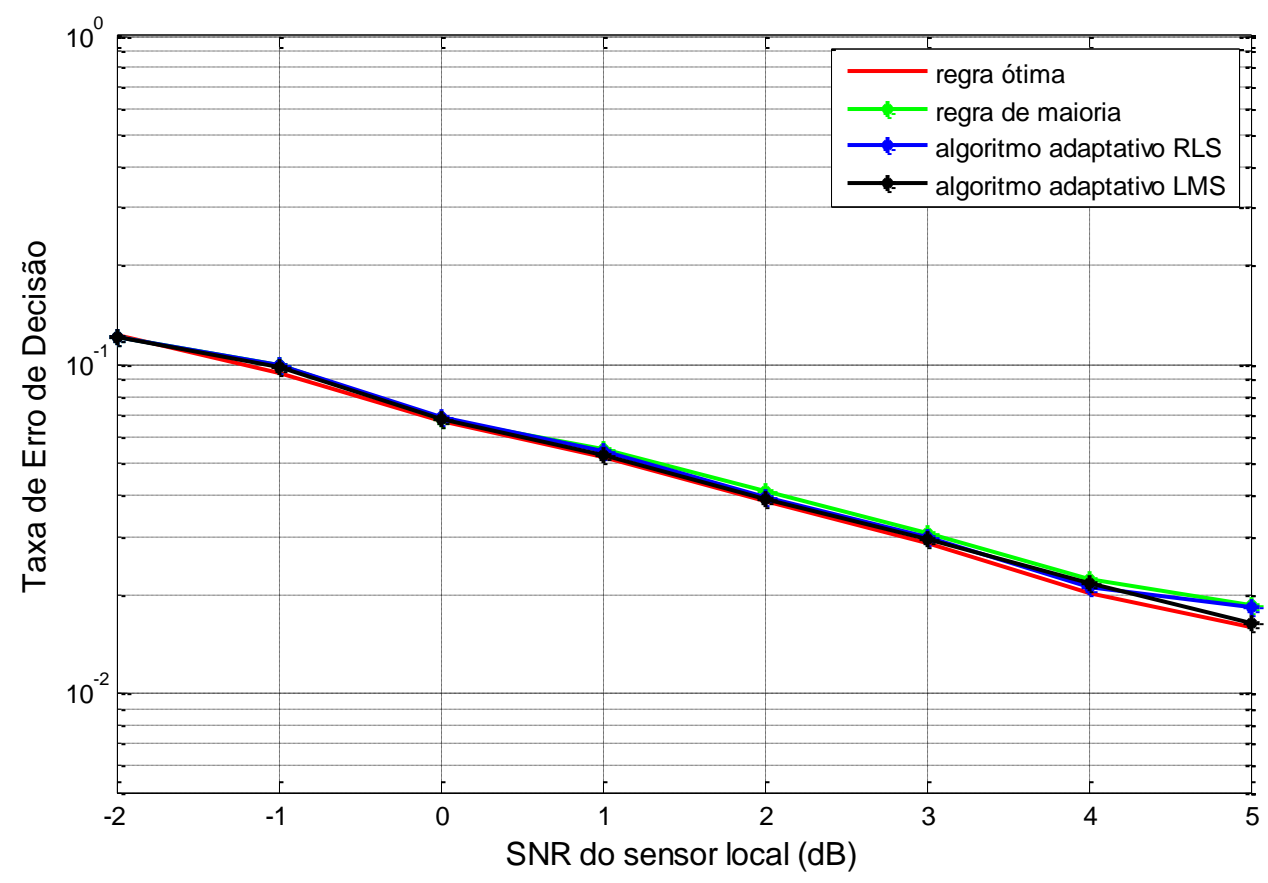

Figura 5.5: DER vs SNR do sensor local para uma SNR média do canal de $2 \mathrm{~dB}$, $\mathrm{K}=7$ sensores locais e probabilidades a priori iguais. 


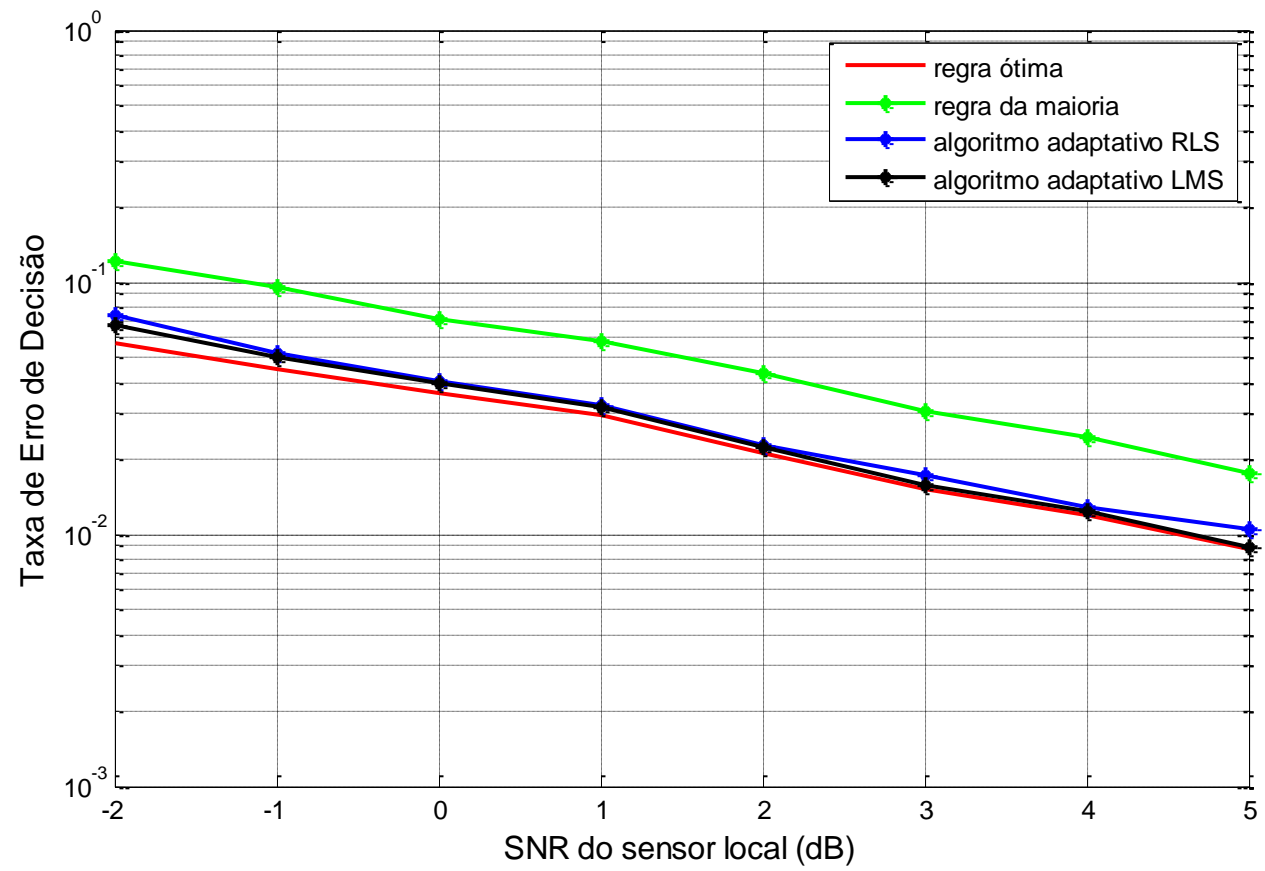

Figura 5. 6: DER vs SNR do sensor local para uma SNR média do canal de $2 \mathrm{~dB}$, $\mathrm{K}=7$ sensores locais e probabilidades a priori $p_{0}=0,1$ e $p_{1}=0,9$.

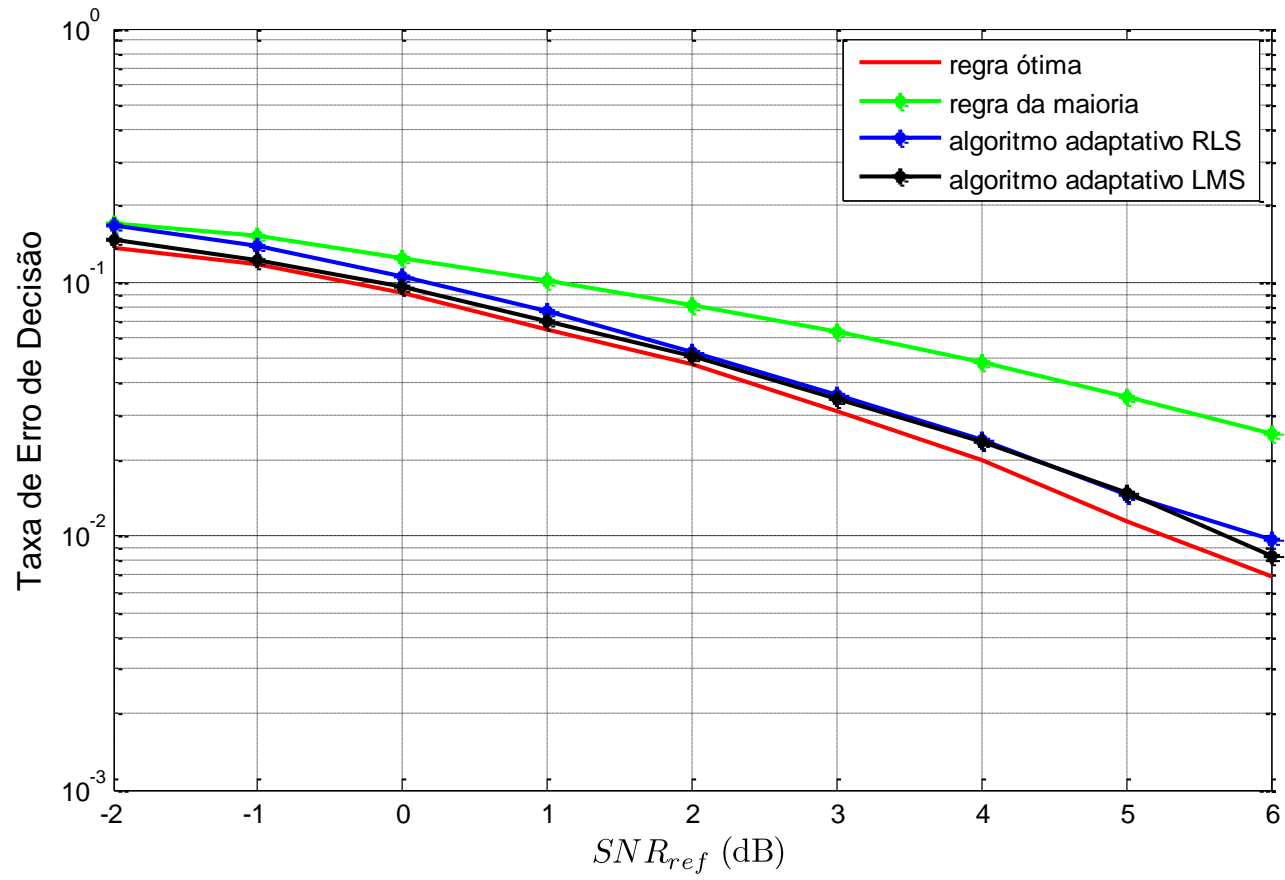

Figura 5.7: DER vs SNR do sensor local, $K=7$ sensores locais, SNR média do canal dos sensores: 1 e $2=8 \mathrm{~dB}, 3$ a $5=-2 \mathrm{~dB}, 6$ e $7=7 \mathrm{~dB}$ e probabilidades a priori iguais. 


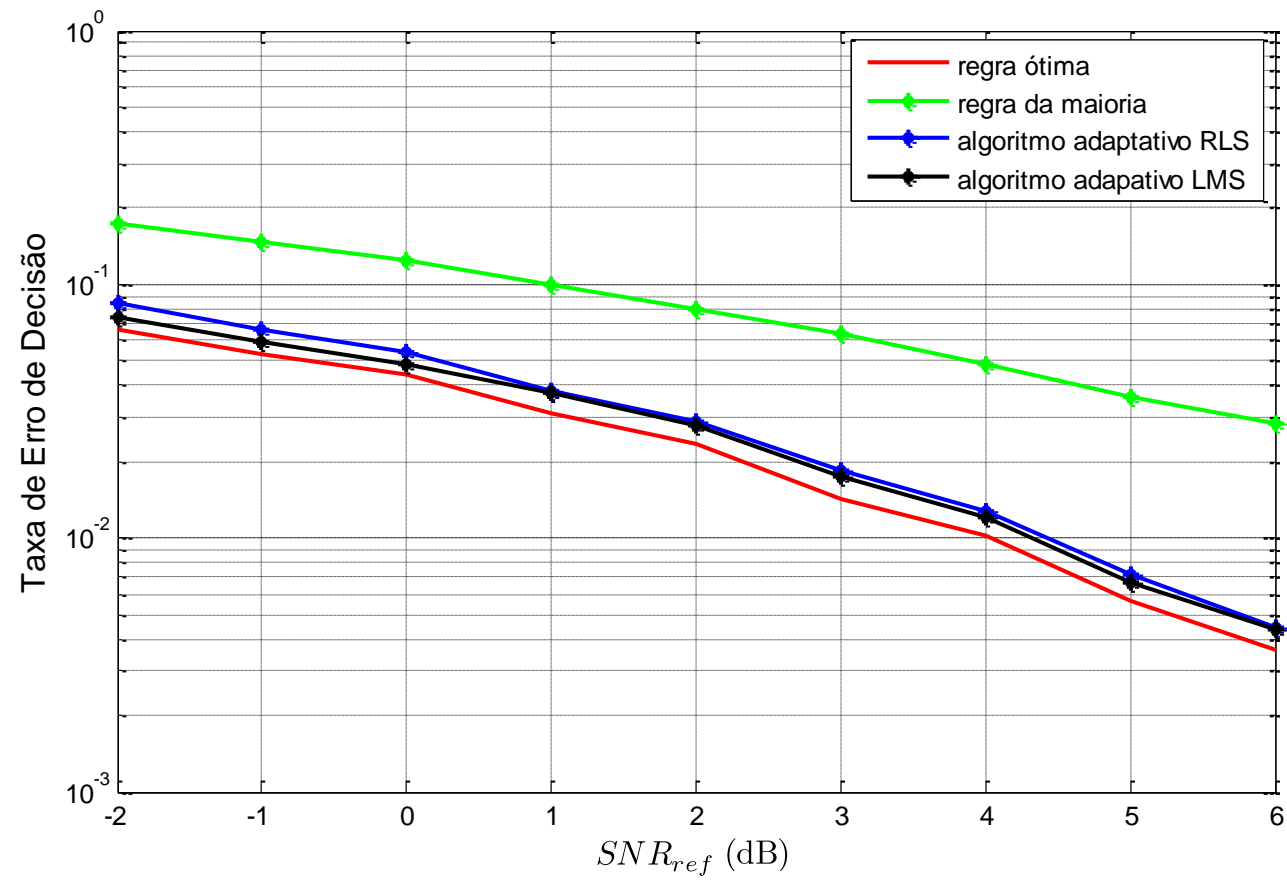

Figura 5. 8: DER vs SNR do sensor local, $K=7$ sensores locais, SNR média do canal dos sensores: 1 e $2=8 \mathrm{~dB}, 3 \mathrm{a} 5=-2 \mathrm{~dB}, 6$ e $7=7 \mathrm{~dB}$ e probabilidades a priori $p_{0}=0,1$ e $p_{1}=0,9$.

\section{4}

\section{Análise de Convergência dos Algoritmos Propostos}

$\mathrm{Na}$ seção anterior foram propostos dois algoritmos para realização da estimação adaptativa conjunta dos pesos e do limiar de decisão da regra de fusão ótima no centro de fusão. Geralmente, o desempenho de um filtro adaptativo é medido geralmente em termos de seu comportamento transitório e pelo seu comportamento em estado estacionário [51-54].

Nesta seção é discutido o comportamento de convergência do estado transitório para o estado estacionário para ambos os algoritmos. Primeiramente será avaliada a curva de aprendizado dos algoritmos. Isto é feito realizando a média temporal do erro quadrático $e^{2}(i)=\left|\hat{u}_{0}(i)-s(i)\right|^{2}$ associado aos algoritmos LMS e RLS de modo a avaliar seus comportamentos de convergência média.

A minimização do erro médio quadrático com relação à $\hat{u}_{0}(i)\left(\operatorname{MSE}_{\widehat{u}_{0}}\right)$ foi utilizada como a métrica de atualização dos algoritmos RLS e LMS por ser pouco complexa e seu tratamento matemático ser amplamente conhecido. A fim de avaliar o quanto o uso dessa métrica resulta em resultados próximos aos valores 
ótimos teóricos em (5-7) e (5-8), será avaliada a correlação entre os pesos c $\mathbf{c}(i)$ e o limiar $c(i)$ da regra ótima de fusão, dados em (5-7) e (5-8) e os pesos $\hat{\mathbf{c}}(i)$ e o limiar $\hat{c}_{0}(i)$ resultantes de ambos os algoritmos LMS e RLS. É esperado que quanto mais correlacionado os pesos $\hat{\mathbf{c}}(i)$ e o limiar $\hat{c}_{0}(i)$ estiverem de $\mathbf{c}(i)$ e $c(i)$, mais próximos serão os desempenhos dos algoritmos em relação à regra ótima.

\subsection{1}

\section{Análise da Evolução do Erro Médio Quadrático Relativo ao Sinal de Referência}

É bem conhecido que o algoritmo RLS possui uma taxa de convergência mais rápida e um menor erro médio quadrático em estado estacionário que o algoritmo LMS para observações contínuas. No presente caso o vetor de observação $\hat{\mathbf{b}}(i)$ possui componentes discretas com probabilidades dadas por:

$$
\begin{gathered}
P\left(\hat{b}_{k}=1\right)=\left(1-P_{M_{k}}\right) p_{1}+P_{F_{k}} p_{0} \\
P\left(\hat{b}_{k}=-1\right)=P_{M_{k}} p_{1}+\left(1-P_{F_{k}}\right) p_{0}
\end{gathered}
$$

Assim, a fim de se verificar o comportamento da convergência dos algoritmos LMS e RLS neste cenário de observações discretas, as curvas de aprendizado serão comparadas com o mínimo erro médio quadrático da solução de Wiener com referência $\hat{u}_{0}\left(\mathrm{MMSE}_{\widehat{u}_{0}}\right)$, dada por (5-11) e (5-12). Neste caso, o $\operatorname{MMSE}_{\widehat{u}_{0}}$ é dado por:

$$
\operatorname{MMSE}_{\widehat{u}_{0}}=\left(1-m_{\widehat{u}_{0}}^{2}\right)-\boldsymbol{p}_{\bar{u}_{0} \overline{\mathbf{b}}^{T}}^{T} \mathbf{K}_{\hat{\mathbf{b}}}^{-1} \boldsymbol{p}_{\bar{u}_{0} \overline{\mathbf{b}}}
$$

com a média $m_{\widehat{u}_{0}}$ dada por (ver Apêndice B):

$$
m_{\widehat{u}_{0}}=\left(1-2 P_{M 0}\right) p_{1}+\left(2 P_{F 0}-1\right) p_{0}
$$

onde $P_{F 0}$ e $P_{M 0}$ são as probabilidades de falso alarme e misdetection associados a estimativa $\hat{u}_{0}$ dadas por (B-46) e (B-47) do Apêndice B. Expressões para a matriz de covariância $\mathbf{K}_{\hat{\mathbf{b}}}$ e para o vetor de covariância cruzada $\boldsymbol{p}_{\bar{u}_{0} \overline{\mathbf{b}}}$ foram também obtidas no Apêndice B. 
Assim, para avaliar a convergência dos algoritmos LMS e RLS serão computados os erros quadráticos, ao longo do índice $i$, para ambos os algoritmos e para a solução de Wiener $\widehat{u}_{0}$ :

$$
\begin{gathered}
e_{L M S}^{2}(i)=\left|\hat{u}_{0}(i)-\hat{\mathbf{c}}^{L M S}(i)^{T} \hat{\mathbf{b}}(i)-\hat{c}_{0}^{L M S}(i)\right|^{2} \\
e_{R L S}^{2}(i)=\left|\hat{u}_{0}(i)-\hat{\mathbf{c}}^{R L S}(i-1)^{T} \hat{\mathbf{b}}(i)-\hat{c}_{0}^{R L S}(i-1)\right|^{2} \\
e_{w}^{2}(i)=\left|\hat{u}_{0}(i)-c^{w^{T}} \hat{\mathbf{b}}(i)-c_{0}^{w}\right|^{2}
\end{gathered}
$$

em que $e_{L M S}^{2}(i)$ é o erro quadrático a posteriori para o algoritmo LMS, $e_{R L S}^{2}(i)$ é o erro quadrático a priori do algoritmo RLS. Já $e_{w}^{2}(i)$ é o erro quadrático resultante da solução de Wiener $\widehat{u}_{0}$.

A fim de se avaliar o comportamento de $e_{L M S}^{2}(i)$ e $e_{R L S}^{2}(i)$, ao longo do tempo, foram realizadas simulações cujos erros quadráticos foram obtidos com os mesmos parâmetros utilizados nas simulações da seção anterior $(\delta=0,0001$ e $\lambda=$ 0,9999), mesmo modelamento de canais em cada sensor, e calculados para 600 símbolos em cada experimento. As curvas de aprendizado para os algoritmos RLS e LMS foram obtidas através da média tomada ao longo de 10000 experimentos independentes. $\mathrm{O}$ valor teórico de $\mathrm{MMSE}_{\widehat{u}_{0}}$ é utilizado como figura de mérito para o estado estacionário dos valores médios de $e_{L M S}^{2}(i), e_{R L S}^{2}(i)$ e $e_{w}^{2}(i) \overline{\left(e_{L M S}^{2}\right.}(i)$, $\overline{e_{R L S}^{2}}(i)$ e $\overline{e_{w}^{2}}(i)$ respectivamente), onde $\overline{e_{w}^{2}}(i)$ é utilizado também para verificar a exatidão da expressão analítica de $\mathrm{MMSE}_{\widehat{u}_{0}}$ dada por (5-23) e pelos resultados do Apêndice B.

As Figuras 5.9 e 5.10 ilustram as curvas de aprendizado do algoritmo RLS e LMS para um sistema homogêneo (SNR média do canal e local iguais para todos os nós da rede de sensores) com $\mathrm{K}=7$ sensores, SNR média do canal de $8 \mathrm{~dB}$ para todos os sensores e probabilidades a priori $p_{0}=0,1$ e $p_{1}=0,9$. A Figura 5.9 considera uma SNR local de $3 \mathrm{~dB}$ e a Figura 5.10 é para uma SNR local de -2 dB. 


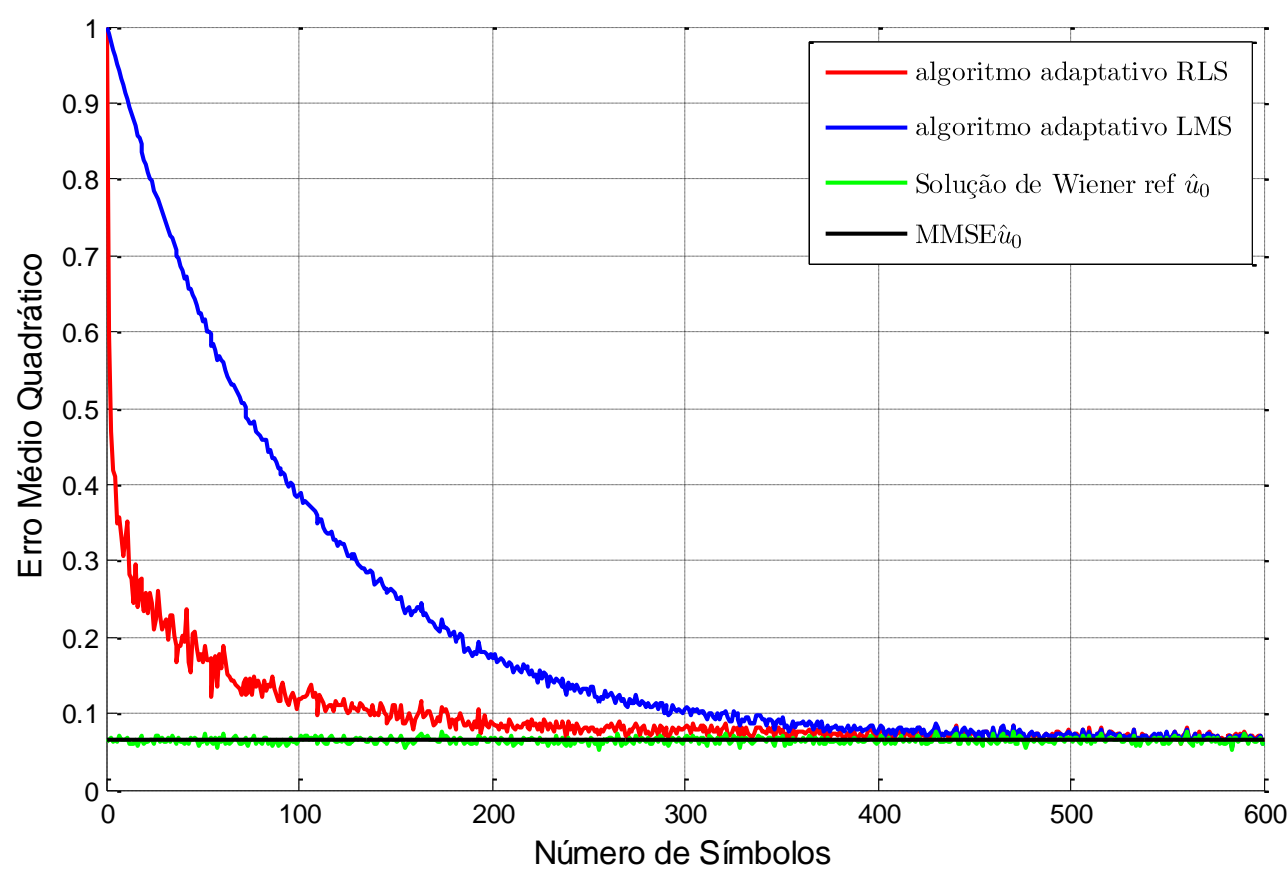

Figura 5.9: Evolução do erro médio quadrático do algoritmo LMS $(\delta=0,0001)$ e do algoritmo $\operatorname{RLS}(\lambda=0,9999), K=7$ sensores locais, SNR média do canal de $8 \mathrm{~dB}$ e SNR local dos sensores iguais a $3 \mathrm{~dB}$ e probabilidades a priori $p_{0}=0,1$ e $p_{1}=0,9$.

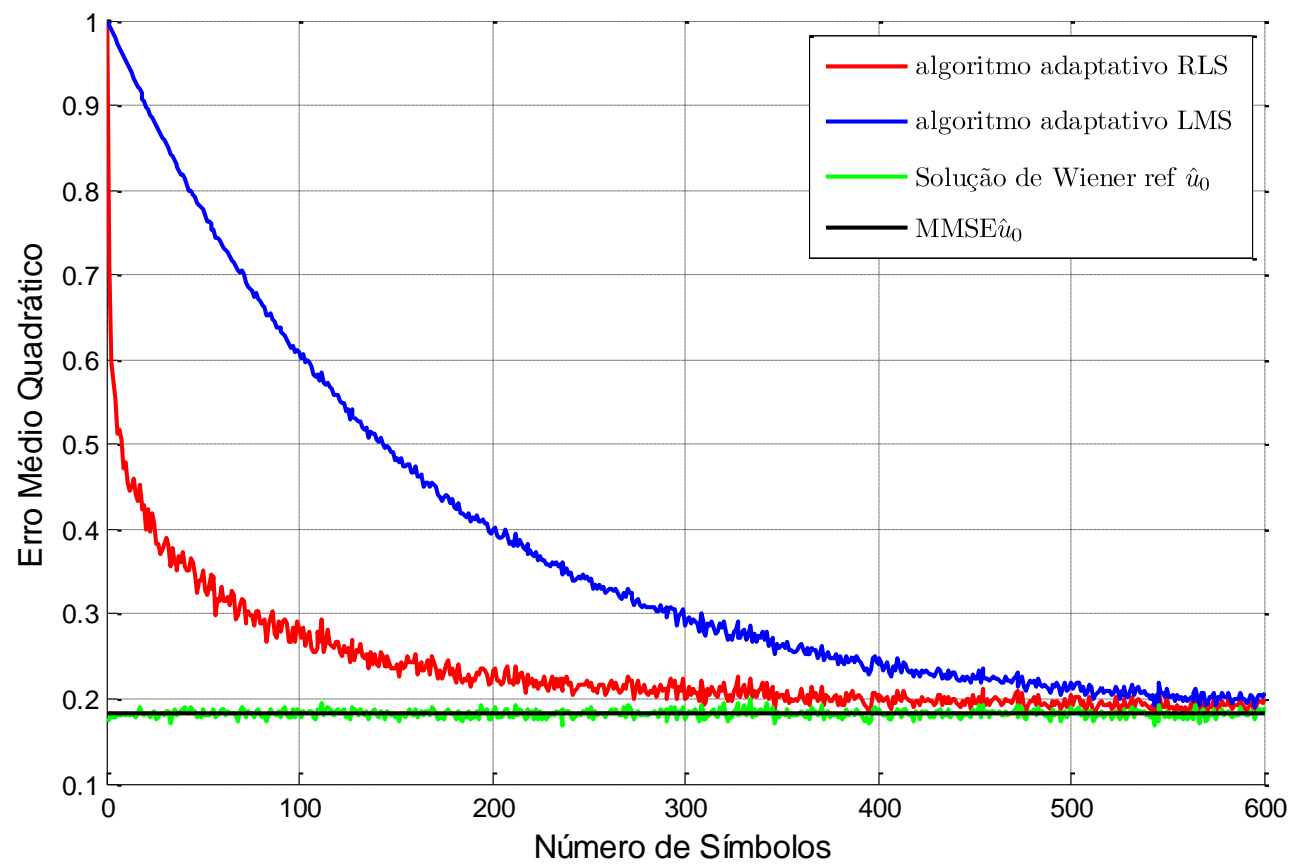

Figura 5.10: Evolução do erro médio quadrático do algoritmo LMS $(\delta=0,0001)$ e do algoritmo RLS $(\lambda=0,9999), K=7$ sensores locais, SNR média do canal de $8 \mathrm{~dB}$ e SNR local dos sensores iguais a $-2 \mathrm{~dB}$ e probabilidades a priori $p_{0}=0,1$ e $p_{1}=0,9$. 
Conforme indicado pelas Figuras 5.9 e 5.10, o mínimo erro médio quadrático teórico da solução de Wiener $\widehat{u}_{0}, M \mathrm{MSE}_{\widehat{u}_{0}}$, e o valor estimado de $\overline{e_{w}^{2}}(i)$, são praticamente idênticos. O valor de $\overline{e_{w}^{2}}(i)$ apresenta um comportamento ruidoso tendo aparente valor médio igual ao valor de $\mathrm{MMSE}_{\widehat{u}_{0}}$, confirmando assim o resultado em (5-23). Para uma SNR local de $3 \mathrm{~dB}$, o algoritmo RLS converge para o valor $\mathrm{MMSE}_{\widehat{u}_{0}}$ de 0,064 em aproximadamente 150 símbolos enquanto que o algoritmo LMS converge para o mesmo valor em 350 símbolos.

Quando a SNR local diminui, os erros na decisão do sensor local aumentam e, consequentemente, a correlacão entre as componentes do vetor de observação $\hat{\mathbf{b}}(i)$ diminui. Com isso, o termo $\boldsymbol{p}_{\bar{u}_{0} \overline{\mathbf{b}}^{T}} \mathbf{K}_{\hat{\mathbf{b}}}^{-1} \boldsymbol{p}_{\bar{u}_{0} \overline{\mathbf{b}}}$ de (5-23) diminui enquanto o termo $\left(1-m_{\widehat{u}_{0}}^{2}\right)$ aumenta com consequente aumento do valor de $\operatorname{MMSE}_{\widehat{u}_{0}}$. Assim, quando a SNR local e de canal são mais baixas é esperado que os algoritmos convirjam para um valor de $\mathrm{MMSE}_{\widehat{u}_{0}}$ maior.

Uma forma de avaliar a correlação entre as componentes do vetor $\hat{\mathbf{b}}(i)$ é calculando o eigenspread (razão entre o maior e menor autovalor de uma matriz) de sua matriz de covariância $\mathbf{K}_{\hat{\mathbf{b}}}$. Quando menor for o eigenspread menor será a correlação das componentes do vetor. A título de comparação, o valor médio do eigenspread de $\mathbf{K}_{\hat{\mathbf{b}}}\left(\boldsymbol{\chi}_{\text {med }}\left(\mathbf{K}_{\hat{\mathbf{b}}}\right)\right)$, tomado ao longo dos experimentos, para uma SNR local de $-2 \mathrm{~dB}$ foi $\boldsymbol{\chi}_{\text {med }}\left(\mathbf{K}_{\hat{\mathbf{b}}}\right)=2,12$ e para SNR local de $3 \mathrm{~dB}$ foi $\boldsymbol{\chi}_{\text {med }}\left(\mathbf{K}_{\hat{\mathbf{b}}}\right)=7,16$. Uma comparação entre as Figuras 5.9 e 5.10 comprova esse comportamento, onde para uma SNR local de $-2 \mathrm{~dB}$ (Figura 5.10), ambos os algoritmos convergem para um $\mathrm{MMSE}_{\widehat{u}_{0}}=0,18$ e para uma SNR local de $3 \mathrm{~dB}$ (Figura 5.9) ambos algoritmos convergem para um valor menor de $\mathrm{MMSE}_{\widehat{u}_{0}}=$ 0,064. O algoritmo RLS converge em aproximadamente 350 símbolos enquanto que o LMS converge em aproximadamente 550 símbolos com um erro residual um pouco maior que o do algoritmo RLS. Assim para sistemas homogêneos, o uso de 500 símbolos para convergência foi uma escolha razoável para o cálculo da DER na Seção 5.3.

A análise das curvas de convergência para o sistema não homogêneo com descrito na Seção 5.3, com probabilidades a priori $p_{0}=0,1$ e $p_{1}=0,9$ e $\mathrm{SNR}_{r e f}=3 \mathrm{~dB}$ e $\mathrm{SNR}_{r e f}=-2 \mathrm{~dB}$ são apresentadas nas Figuras 5.10 e 5.11, respectivamente. 


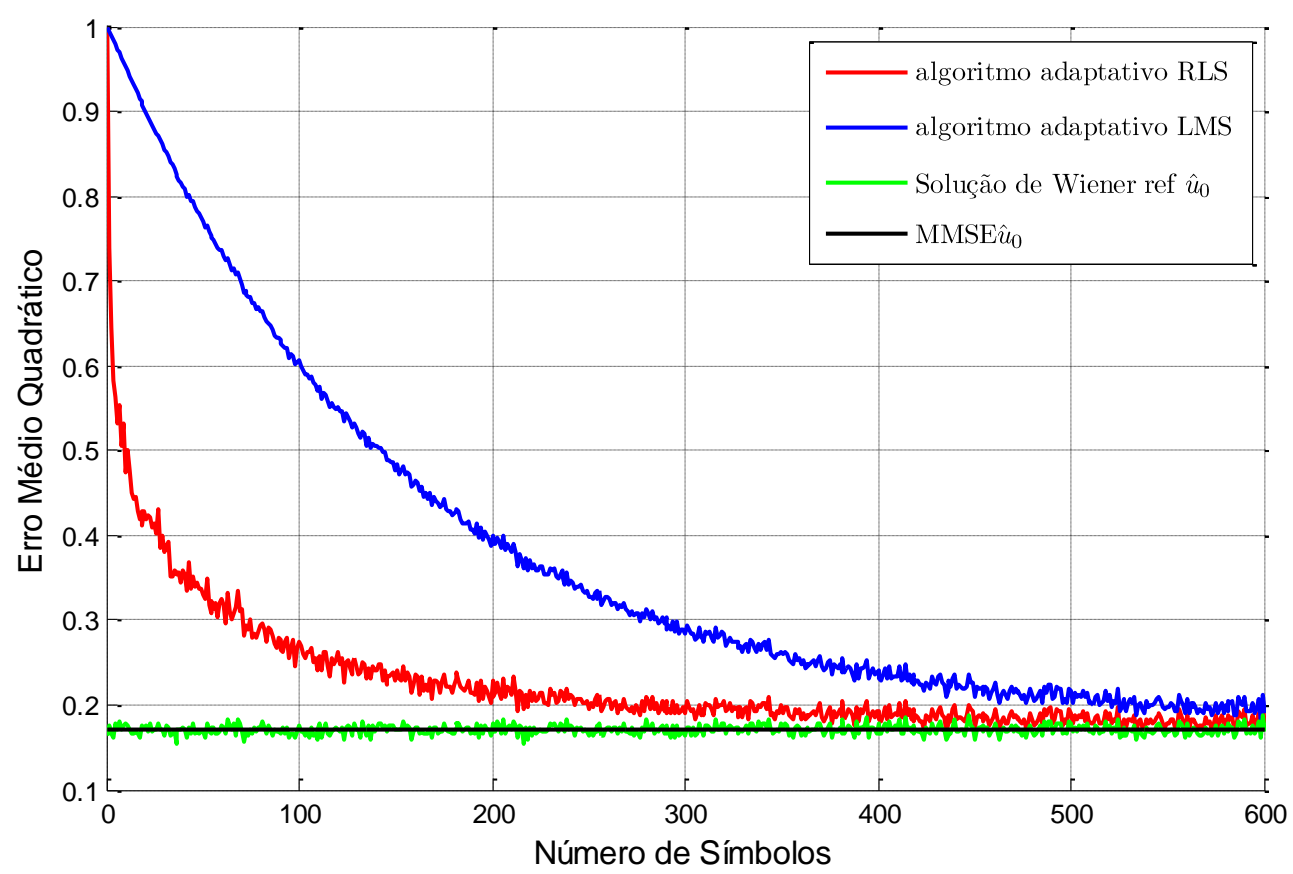

Figura 5.11: Evolução do erro médio quadrático do algoritmo LMS $(\delta=0,0001)$ e do algoritmo RLS $(\lambda=0,9999), K=7$ sensores locais, sistema não homogêneo com SNR $r e f$ $=3 \mathrm{~dB}$ e probabilidades a priori $p_{0}=0,1$ e $p_{1}=0,9$.

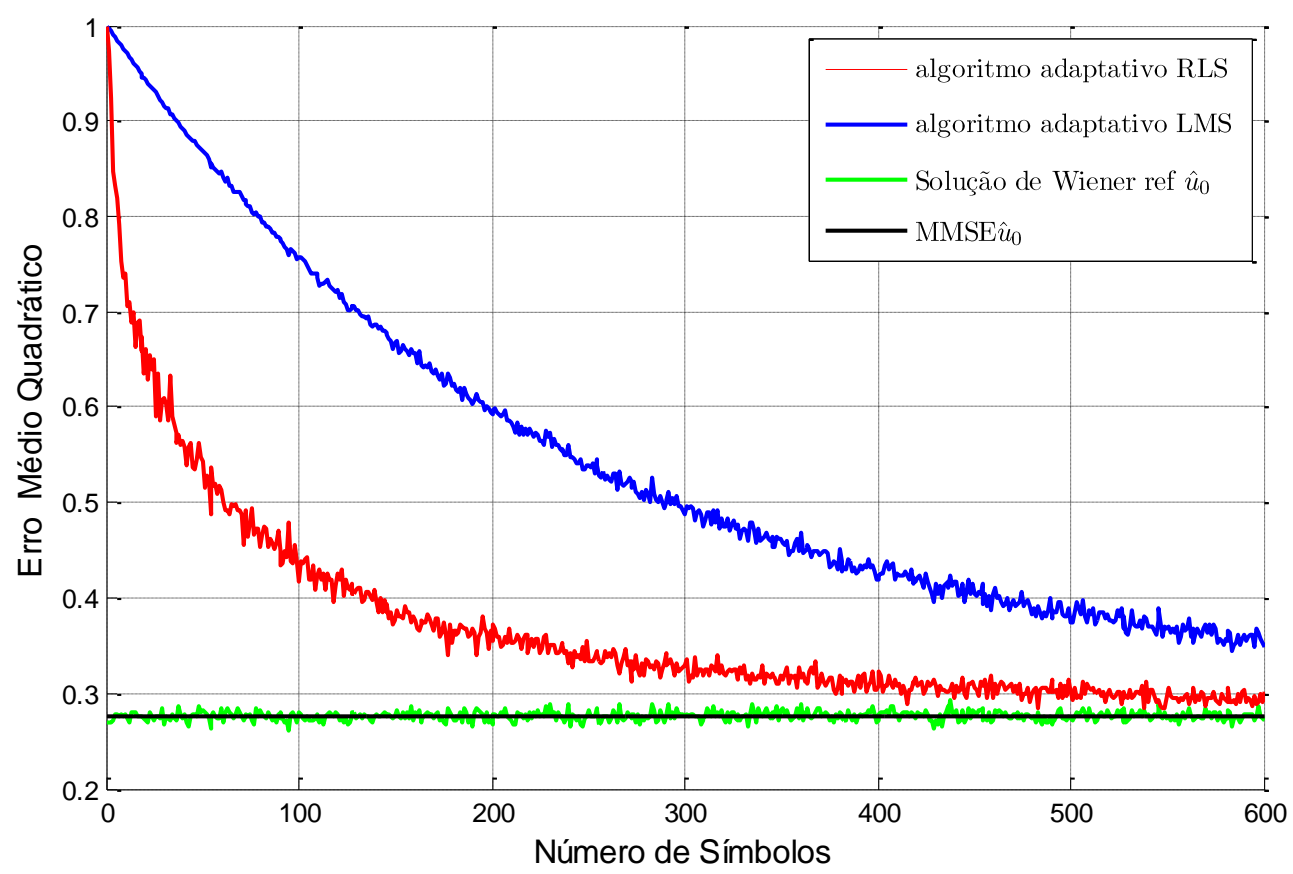

Figura 5.12: Evolução do erro médio quadrático do algoritmo LMS $(\delta=0,0001)$ e do algoritmo RLS $(\lambda=0,9999), K=7$ sensores locais, sistema não homogêneo com $\mathrm{SNR}_{r e f}$ $=-2 \mathrm{~dB}$ e probabilidades a priori $p_{0}=0,1$ e $p_{1}=0,9$.

No sistema não homogêneo, a SNR média do canal e a SNR local variam com o sensores (conforme descrito na Seção 5.3), como consequência há uma menor correlação entre as componentes do vetor de observação $\hat{\mathbf{b}}(i)$. Para uma 
$\mathrm{SNR}_{\text {ref }}=3 \mathrm{~dB}$, o valor do eigenspread médio é de $\boldsymbol{\chi}_{\text {med }}\left(\mathbf{K}_{\hat{\mathbf{b}}}\right)=3,81$. Conforme indicado pela Figura 5.11, ambos os algoritmos convergem para um valor de $\operatorname{MMSE}_{\widehat{u}_{0}}=0,17$ tendo um comportamento de convergência similar (com um erro residual um pouco maior em ambos os algoritmos) ao do sistema homogêneo mostrado na Figura 5.10. Isso ocorre devido a valores de eigenspread próximos, acarretando assim correlações similares para as componentes do vetor de observação $\hat{\mathbf{b}}(i)$ nos dois casos. Para uma SNR ${ }_{r e f}=-2 \mathrm{~dB}$, tem-se que $\chi_{\text {med }}\left(\mathbf{K}_{\hat{\mathbf{b}}}\right)$ $=1,63$, provocando um $\mathrm{MMSE}_{\widehat{u}_{0}}=0,27$. Nesse caso, para um passo de $\delta=0,0001$, o algoritmo LMS apresenta um erro residual de 0,11 em aproximadamente 500 símbolos.

Foi mostrado que no presente problema, o algoritmo RLS converge mais rápido e apresenta um erro residual menor que o algoritmo LMS em relação ao mínimo erro médio quadrático teórico $\mathrm{MMSE}_{\widehat{u}_{0}}$ e que ambos os algoritmos convergem para o $\mathrm{MMSE}_{\widehat{u}_{0}}$ teórico com erro residual tanto maior quanto menor for a SNR local e SNR do canal de cada sensor.

Deve ser levado em consideração que a métrica utilizada pelos algoritmos é a minimização do erro médio quadrático relativo à hipótese verdadeira $\widehat{u}_{0}, \mathrm{MSE}_{\widehat{u}_{0}}$, entre a combinação linear das estimativas das mensagens enviadas pelos nós, $s(i)$, e a estimativa $\hat{u}_{0}$ da hipótese verdadeira $u$. Assim, quanto pior for a qualidade da estimativa $\hat{u}_{0}$, pior será o desempenho do algoritmo no sentido da minimização do erro médio quadrático, MSE, relativo à hipótese verdadeira $u$. Contudo, minimizar $\mathrm{MSE}_{\widehat{u}_{0}}$ é um objetivo intermediário do algoritmo, posto que o objetivo final é minimizar a probabilidade de erro do centro de fusão. Isto é alcançado quando a saída do algoritmo está o mais próximo possível daquela gerada pela regra de fusão ótima.

A próxima seção verifica o efeito da minimização do $\mathrm{MSE}_{\widehat{u}_{0}}$ dos algoritmos na probabilidade de erro de decisão global no centro de fusão.

\section{5}

\section{Avaliação da Probabilidade de Erro de Decisão no Centro de Fusão}

O objetivo final dos algoritmos é a minimização da DER no centro de fusão, porém os algoritmos utilizados tem como métrica a minimização do $\mathrm{MSE}_{\widehat{u}_{0}}$, pois 
são algoritmos tratáveis matematicamente além de muito consolidados na literatura, diferentemente da minimização da probabilidade de erro que na maioria dos casos são intratáveis e muito mais complexos computacionalmente [56-59].

Tendo realizado uma análise do comportamento da convergência dos algoritmos LMS e RLS em relação à minimização do $\mathrm{MSE}_{\widehat{u}_{0}}$ e verificado que ambos convergem para o $\mathrm{MMSE}_{\widehat{u}_{0}}$, com velocidades de convergência e erros residuais diferentes, nesta seção será verificado qual o impacto desta minimização do $\mathrm{MSE}_{\widehat{u}_{0}}$ na probabilidade de erro de decisão do centro de fusão.

\subsection{1}

\section{Análise de Probabilidade de Erro}

A saída do algoritmo, após convergência, é composto pelos pesos $\hat{\mathbf{c}}(i)$ e o limiar $\hat{c}_{0}(i)$ que fazem a combinação linear de $\hat{\mathbf{b}}(i)$, gerando uma saída dada por (5-9) e repetida aqui por conveniência:

$$
s(i)=\hat{\mathbf{c}}(i)^{T} \hat{\mathbf{b}}(i)+\hat{c}_{0}(i)
$$

O centro de fusão, então, realiza uma detecção de polaridade do sinal $s(i)$ gerando a decisão final $\hat{u}(i)$ :

$$
\widehat{u}(i)=\operatorname{sign}[s(i)] .
$$

O erro de decisão é dado por:

$$
e_{d}(i)=u(i)-\hat{u}(i)
$$

A regra ótima de fusão das componentes de $\hat{\mathbf{b}}(i)$, no sentido da minimização da probabilidade de erro de (5-6), é feita pelos pesos ótimos c e o limiar ótimo $c_{0}$. Uma maneira de verificar a qualidade de $\hat{\mathbf{c}}(i)$ e $\hat{c}_{0}(i)$, em relação a minimização da probabilidade de erro, pode ser feita através do coeficiente de correlação entre os vetores $\hat{\mathbf{c}}^{\prime}(i)=\left[\begin{array}{ll}\hat{\mathbf{c}}^{T}(i) & \hat{c}_{0}(i)\end{array}\right]^{T}$ e $\mathbf{c}^{\prime}=\left[\begin{array}{ll}\mathbf{c}^{T} & c_{0}\end{array}\right]^{T}$. Em outras palavras, como as decisões $\hat{u}(i)$ do centro de fusão dependem apenas da 
polaridade de $s(i)$, se o vetor $\hat{\mathbf{c}}^{\prime}(i)$ está na mesma direção de $\mathbf{c}$ é esperado que a saída do centro de fusão tenha seu desempenho maximizado em relação a DER.

A métrica utilizada para medir o coeficiente de correlação é dada por:

$$
\rho_{\mathbf{c}^{\prime} \hat{\mathbf{c}}^{\prime}(i)}=\mathbb{E}\left[\frac{\mathbf{c}^{\prime T} \hat{\mathbf{c}}^{\prime}(i)}{\left\|\mathbf{c}^{\prime}\right\|\left\|\hat{\mathbf{c}}^{\prime}(i)\right\|}\right]
$$

em que $-1<\rho_{\mathrm{c}^{\prime} \hat{\mathrm{c}}^{\prime}(\mathrm{i})}<1$

Pode ser facilmente verificado que:

$$
\mathbb{E}\left[\left\|\frac{\mathbf{c}^{\prime}}{\left\|\mathbf{c}^{\prime}\right\|}-\frac{\hat{\mathbf{c}}^{\prime}(i)}{\left\|\hat{\mathbf{c}}^{\prime}(i)\right\|}\right\|^{2}\right]=2-2 \rho_{\mathbf{c}^{\prime} \hat{\mathbf{c}}^{\prime}(i)}
$$

Deste modo, se $\rho_{\mathbf{c}^{\prime} \hat{\mathbf{c}}^{\prime}(i)} \rightarrow 1$ quando $i \rightarrow \infty \quad$ o desvio médio quadrático dado em (5-32) converge para zero e a versão normalizada de $\hat{\mathbf{c}}^{\prime}(i)$ tende para a versão normalizada de $\mathbf{c}^{\prime}$ no sentido da média quadrática, resultando na mínima DER na saída do centro de fusão adaptativo. Valores mais altos de $\rho_{\mathbf{c}^{\prime} \hat{\mathbf{c}}^{\prime}(i)}$ resultam em uma melhora no desempenho relativo à DER.

A fim de se verificar o comportamento da convergência dos algoritmos LMS e RLS (nesse cenário de observações discretas) em termos de correlação com a regra ótima e, consequentemente, com a probabilidade de erro, foram geradas curvas de coeficiente de correlação ao longo da sequencia de símbolos transmitidos. Estas curvas são comparadas com aquelas correspondentes ao coeficiente de correlação entre $\mathbf{c}^{\prime}$ e o vetor contendo a solução de Wiener com referência $\hat{u}_{0}, \mathbf{c}^{\prime w}=\left[\mathbf{c}^{\boldsymbol{w}}(i) c_{0}^{w}(i)\right]^{T}$. As curvas são comparadas também com as correspondentes ao coeficiente de correlação entre $\mathbf{c}^{\prime}$ e $\mathbf{c}^{\prime o p t}$, onde $\mathbf{c}^{\prime o p t}$ é o vetor contendo a solução de Wiener quando a referência é a própria hipótese $u$ (solução de Wiener ${ }_{u}$ ). Esta solução de Wiener é dada por:

$$
\begin{gathered}
c_{0}^{o p t}=m_{u}-\mathbf{c}^{o p t^{T}} \boldsymbol{m}_{\hat{\mathbf{b}}}, \\
\mathbf{c}^{o p t}=\mathbf{K}_{\hat{\mathbf{b}}}^{-\mathbf{1}} \boldsymbol{p}_{\overline{\mathbf{u}} \overline{\mathbf{b}}}
\end{gathered}
$$

em que 


$$
\begin{gathered}
m_{u}=p_{1}-p_{0} \\
m_{\hat{b}}=\left(1-2 P_{M_{k}}\right) p_{1}+\left(2 P_{F_{k}}-1\right) p_{0}
\end{gathered}
$$

As expressões analíticas para a matriz de covariância $\mathbf{K}_{\hat{\mathbf{b}}}$ e para o vetor de covariância cruzada $\boldsymbol{p}_{\overline{\boldsymbol{u}} \overline{\mathbf{b}}}=\mathbb{E}\left[\left(u(i)-m_{u}\right)\left(\hat{\mathbf{b}}(i)-\boldsymbol{m}_{\hat{\mathbf{b}}}\right)\right]$ são deduzidas no Apêndice B.

Como a solução de Wiener $_{u}$ em (5-33) e (5-34) fornece a melhor estimativa linear possível no sentido da minimização do MSE, ela será usada como Figura de mérito para os algoritmos LMS e RLS.

Foram realizadas simulações nas quais os coeficientes de correlação foram calculados usando os mesmos parâmetros utilizados nas simulações da Seção 4.3 ( $\delta=0,0001$ e $\lambda=0,9999$ ), o mesmo modelamento de canais em cada sensor e utilizados 600 símbolos em cada experimento.

A Figura 5.13 mostra a curva de coeficiente de correlação para o sistema heterogêneo descrito na Seção 5.3, com probabilidades a priori $p_{0}=0,1$ e $p_{1}=$ 0,9 e $\mathrm{SNR}_{r e f}=3 \mathrm{~dB}$. Observa-se que o coeficiente de correlação $\rho_{\mathbf{c}^{\prime} \hat{\mathbf{c}}^{\prime}(i)}$ entre os algoritmos adaptativos e a regra ótima é maior que o coeficiente de correlação $\rho_{\mathbf{c}^{\prime} \mathbf{c}^{\prime} w}$ da solução de Wiener ${\widehat{u_{0}}}_{0}$. Isto evidência que a minimização de $\mathrm{MSE}_{\widehat{u}_{0}}$ não corresponde à minimização da probabilidade de erro no presente problema. Além disso, diferentemente do que ocorre nas curvas de $\mathrm{MSE}_{\widehat{u}_{0}}$ da Figura 5.11, o algoritmo LMS converge mais rápido (para um coeficiente de correlação maior)

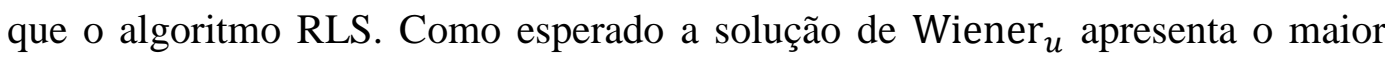
coeficiente de correlação $\left(\rho_{\mathbf{c}^{\prime} \mathbf{c}^{\prime o p t}}\right)$ nesta configuração.

Como a referência da solução de $\operatorname{Wiener}_{\widehat{u}_{0}}, \widehat{u}_{0}(i)$ é uma estimativa de $u$, é razoável supor que quanto pior a estimativa $\hat{u}_{0}(i)$, pior será a o fator de correlação $\rho_{\mathbf{c}^{\prime} \mathbf{c}^{\prime} w}$ entre a solução de Wiener ${\widehat{\widehat{u}_{0}}}$ e a regra ótima. Uma maneira de medir a qualidade da estimativa $\hat{u}_{0}(i)$ é pela correlação entre $\hat{u}_{0}(i)$ e $u(i)$ que é dado por:

$$
\rho_{\widehat{u}_{0} u}=\mathbb{E}\left[\hat{u}_{0}(i) u(i)\right]
$$

em que $\mathbb{E}\left[\hat{u}_{0}(i) u(i)\right]=\left(1-2 P_{M 0}\right) p_{1}+\left(1-2 P_{F 0}\right) p_{0}$ e $P_{F 0}$ e $P_{M 0}$ são as mesmas probabilidades definidas em (5-24). 
No cenário da Figura 5.13 tem-se que $\rho_{\widehat{u}_{0} u}=0,87$, e para este valor obtemse um coeficiente de correlação $\rho_{\mathbf{c}^{\prime} \mathbf{c}^{\prime w}}=0,92$ e $\rho_{\mathbf{c}^{\prime} \mathbf{c}^{\prime o p t}}=0,987$. Os algoritmos RLS e LMS convergem para $\mathbf{c}^{\prime}$, no sentido do $\mathrm{MSE}_{\widehat{u}_{0}}$, com um erro residual. Este erro aparentemente favorece ambos os algoritmos, que convergem para valores de $\rho_{\mathbf{c}^{\prime} \hat{\mathbf{c}}^{\prime}(i)}$ entre 0,92 e 0,987 . É notável que a convergência do coeficiente de correlação do algoritmo LMS ocorra mais rapidamente (100 símbolos) que a do algoritmo RLS (300 símbolos), diferentemente do que ocorre com as curvas de erro médio quadrático da Figura 5.11.

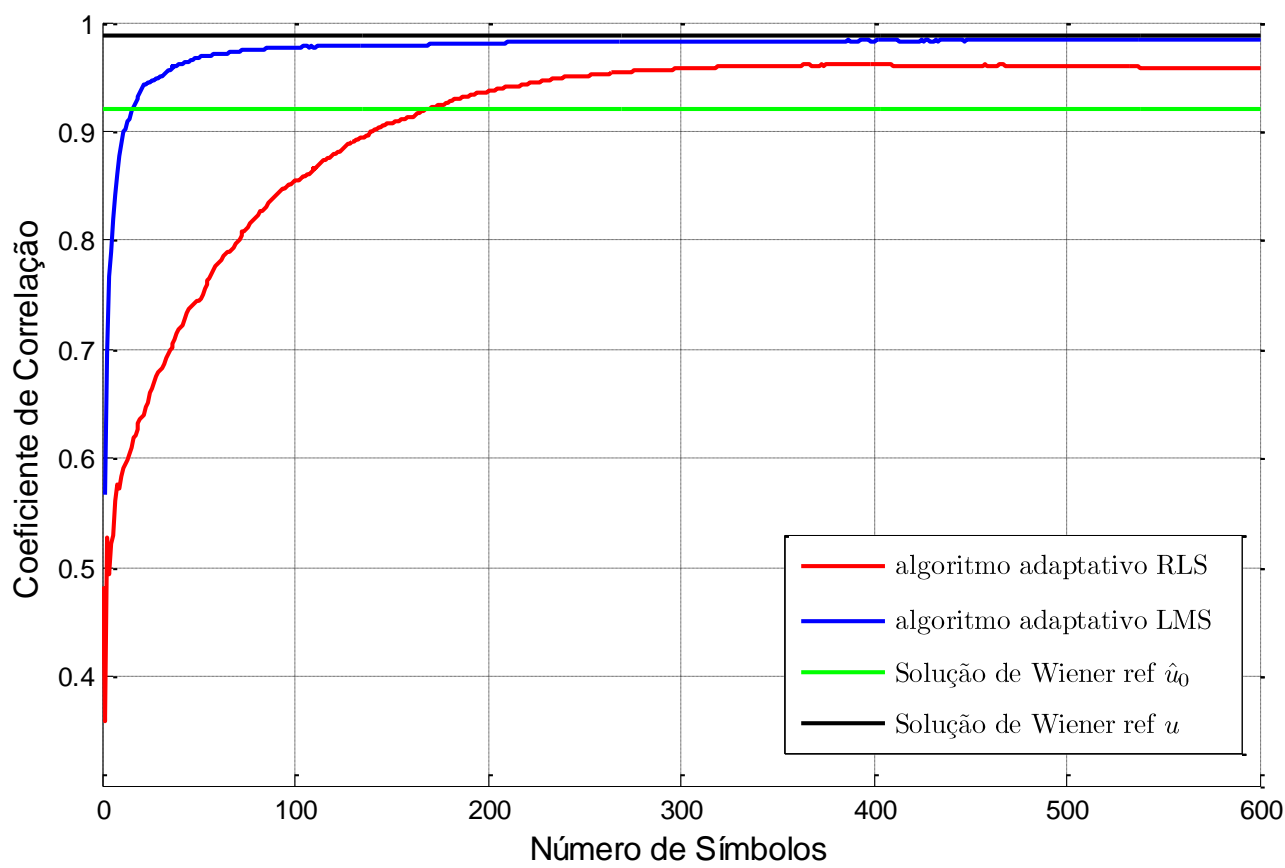

Figura 5.13: Coeficiente de correlação entre a saída do algoritmo LMS $(\delta=0,0001)$ e do algoritmo $\operatorname{RLS}(\lambda=0,9999)$ com a regra ótima, para $K=7$ sensores locais, sistema não homogêneo com $\mathrm{SNR}_{r e f}=3 \mathrm{~dB}$ e probabilidades a priori $p_{0}=0,1$ e $p_{1}=0,9$.

A Figura 5.14 ilustra as curvas de evolução da DER, $P(\hat{u} \neq u)$, em função do número de símbolos transmitidos, para o sistema heterogêneo, com probabilidades a priori $p_{0}=0,1$ e $p_{1}=0,9$ e $\mathrm{SNR}_{\text {ref }}=3 \mathrm{~dB}$. Aqui é observado que a evolução da DER do algoritmo LMS acompanha a evolução do coeficiente de correlação apresentado na Figura 5.18, ou seja, quanto maior o coeficiente de correlação menor a DER. A curva de evolução da DER do algoritmo RLS apresenta valores maiores que as do algoritmo LMS e segue o padrão do comportamento do coeficiente de correlação apresentado na Figura 5.13 inclusive no que diz respeito à velocidade de convergência. O fato da curva de evolução do 
erro da solução de Wiener ${\widehat{u_{0}}}_{0}$ estar acima das curvas dos algoritmos LMS e RLS evidencia o fato de que a métrica de minimização do $\mathrm{MSE}_{\widehat{u}_{0}}$ não corresponde a uma minimização da probabilidade de erro, $P(\hat{u} \neq u)$, corresponderia talvez à minimização de $P\left(\hat{u}_{0} \neq u\right)$ que não é o objetivo dos algoritmos. $\mathrm{O}$ mesmo comportamento é verificado na Figura 5.13, onde coeficiente de correlação $\rho_{\mathbf{c}^{\prime} \mathbf{c}^{\prime} w}$ da solução de Wiener $\widehat{u}_{0}$ é menor (para o número de símbolos utilizados) que os coeficientes de correlação $\rho_{\mathbf{c}^{\prime} \mathbf{c}^{\prime}(i)}$ dos algoritmos LMS e RLS o que resulta em valores de probabilidade de erro de decisão maiores que a dos algoritmos adaptativos. Uma possível explicação para este comportamento dos coeficientes de correlação reside no fato que a estimativa $\hat{u}_{0}(i)$ conter erros em relação à hipótese verdadeira $u$, fazendo com que o vetor $\mathbf{c}^{\prime w}$ associado à solução de Wiener ${\widehat{u_{0}}}_{0}$ não aponte na direção do vetor $\mathbf{c}^{\prime}$ da regra ótima (conforme verificado na Figura 5.13). Como o algoritmo LMS implementado possui um passo pequeno, as flutuações discretas geradas pelo desvio de $\hat{u}_{0}(i)$ em torno da hipótese verdadeira $u$ não são rastreadas (ou pelo menos não conseguem ser rastreadas completamente). Em outras palavras, no algoritmo LMS a referência $\hat{u}_{0}(i)$ (desde que a probabilidade de erro em $\hat{u}_{0}(i)$ e o passo $\delta$ sejam suficientemente pequenos), faz com que a direção média do vetor de saída $\hat{\mathbf{c}}^{\prime}(i)$ seja quase coincidente com a do vetor $\mathbf{c}^{\prime}$ da regra ótima. Já o algoritmo RLS consegue rastrear com mais precisão as flutuações discretas do erro de $\hat{u}_{0}(i)$ e consequentemente seu vetor de saída $\hat{\mathbf{c}}^{\prime}(i)$ tem uma direção mais próxima a do vetor $\mathbf{c}^{\prime w}$ da solução de Wiener $\widehat{u}_{0}$. Como consequência, o vetor de saída $\hat{\mathbf{c}}^{\prime}(i)$ gerado pelo algoritmo LMS resulta em uma menor DER quando comparada a obtida com o algoritmo RLS e com a solução de Wiener $\widehat{u}_{0}$, conforme ilustrados pelos resultados da Figura 5.14. 


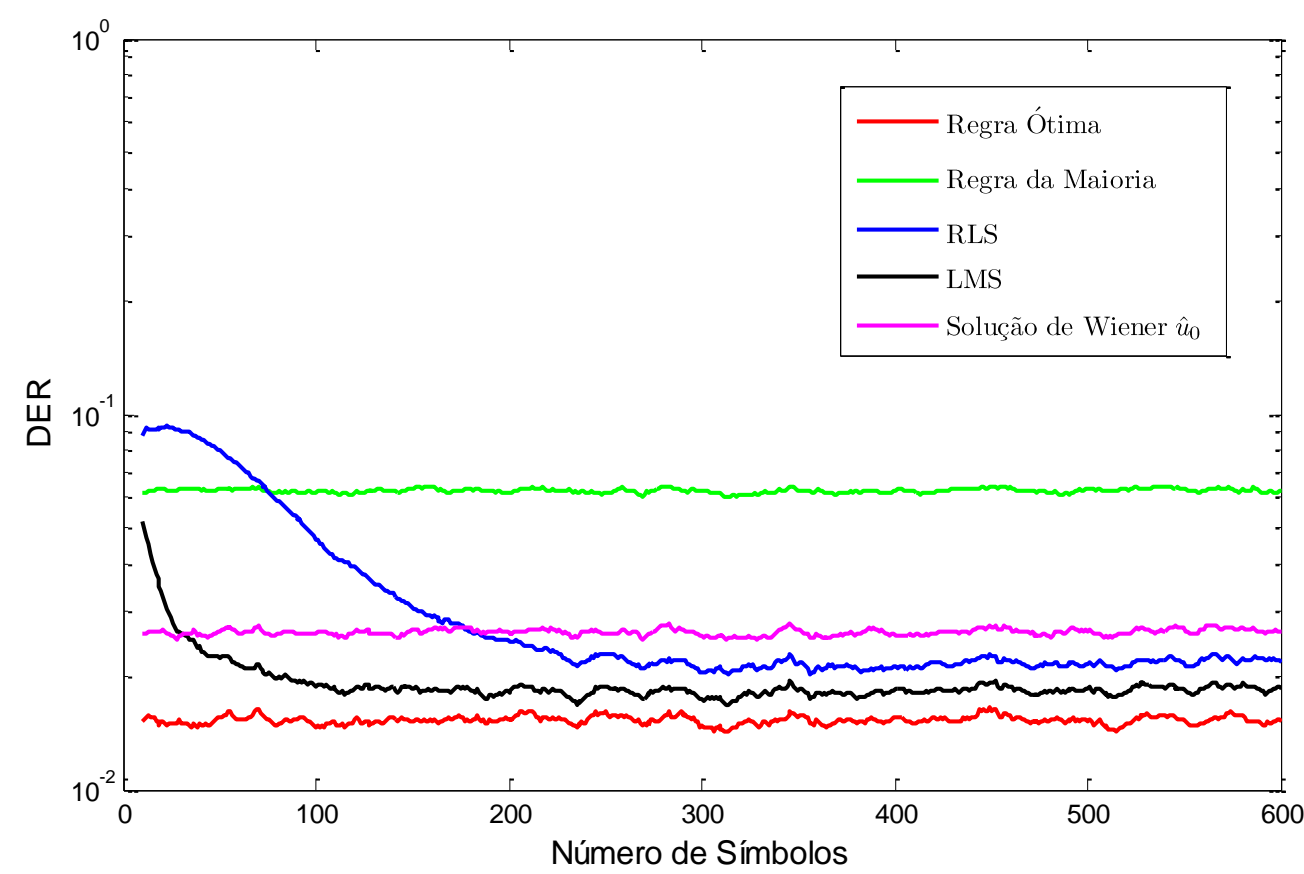

Figura 5.14: Evolução da DER do algoritmo $\operatorname{LMS}(\delta=0,0001)$ e do algoritmo $\operatorname{RLS}(\lambda=$ $0,9999), K=7$ sensores locais, sistema não homogêneo com $\mathrm{SNR}_{r e f}=3 \mathrm{~dB}$ e probabilidades a priori $p_{0}=0,1$ e $p_{1}=0,9$.

A Figura 5.15 ilustra as curvas de evolução da DER em função do número de símbolos, para o sistema heterogêneo, com probabilidades a priori $p_{0}=0,1 \mathrm{e}$ $p_{1}=0,9$ e $\mathrm{SNR}_{r e f}=-2 \mathrm{~dB}$. Neste caso os valores da SNR média dos sensores locais são mais baixos que o da Figura 5.14 e, consequentemente, a referência $\hat{u}_{0}(i)$ é mais errônea que na situação mostrada na Figura 5.14. Especificamente nesse caso a correlação $\rho_{\widehat{u}_{0} u}=0,64$. Consequentemente, a solução de Wiener $\widehat{u}_{0}$ tem um desempenho degradado, praticamente coincidente com o da regra da maioria. Mesmo nessa situação extrema, o algoritmo LMS obtém um desempenho superior em termos de DER, ou seja, o passo é pequeno o suficiente para não acompanhar as flutuações discretas de $\hat{u}_{0}(i)$. O algoritmo RLS possui um desempenho inicial superior ao LMS, porém à medida que o número de símbolos aumenta o algoritmo começa a rastrear os erros de $\hat{u}_{0}(i)$ e o desempenho da DER tende a seguir a da solução de Wiener $\widehat{u}_{0}$.

É interessante notar que o comportamento das curvas de evolução da DER dos algoritmos LMS e RLS é compatível com os das curvas de convergência de coeficiente de correlação ilustradas na Figura 5.16. A curva de evolução do coeficiente de correlação do algoritmo RLS começa a diminuir após um certo 
número de símbolos, aproximando-se da curva da solução de Wiener $\widehat{u}_{0}$, e a curva de DER começa a aumentar com o aumento do número de símbolos transmitidos.

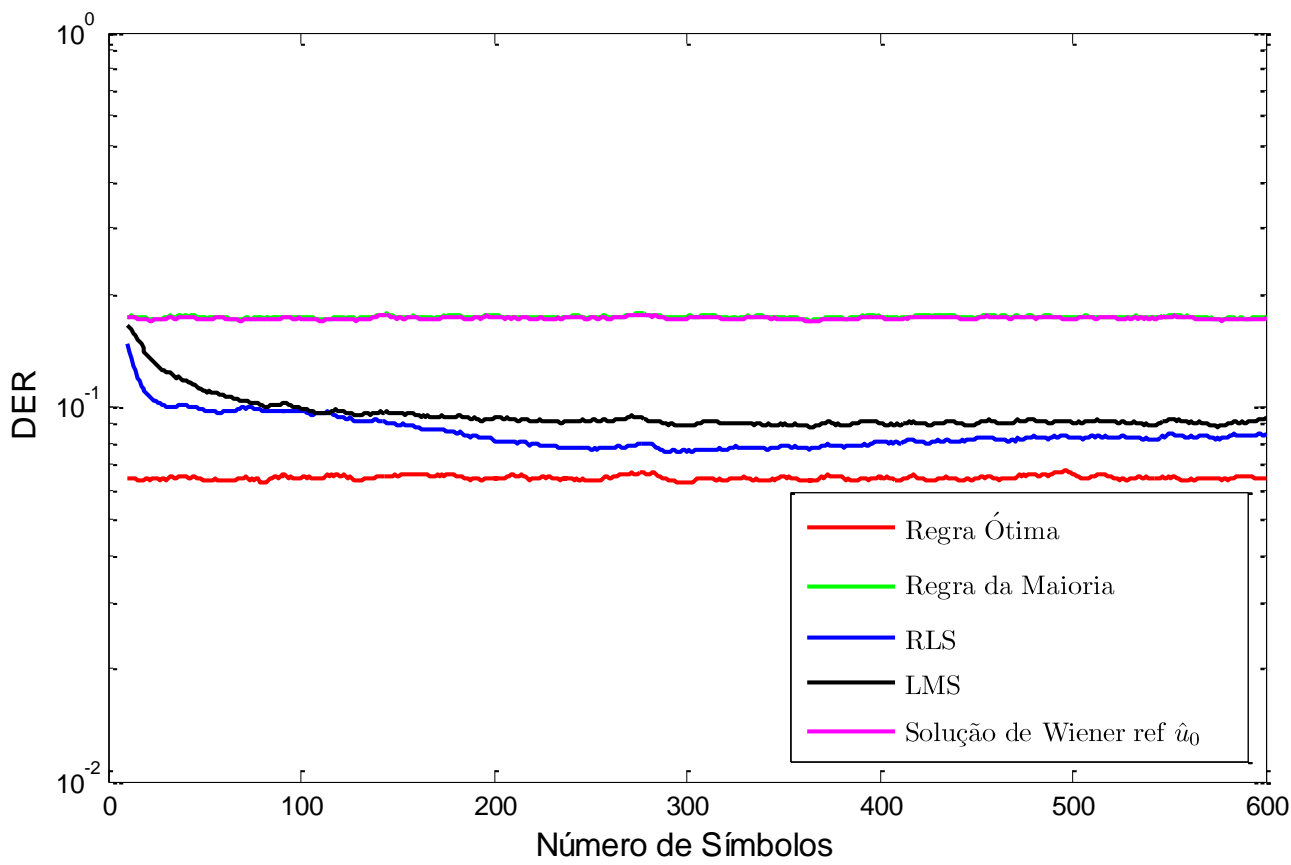

Figura 5.15: Evolução da DER do algoritmo LMS $(\delta=0,0001)$ e do algoritmo $\operatorname{RLS}(\lambda=$ $0,9999), \mathrm{K}=7$ sensores locais, sistema não homogêneo com $\mathrm{SNR}_{r e f}=-2 \mathrm{~dB}$ e probabilidades a priori $p_{0}=0,1$ e $p_{1}=0,9$.

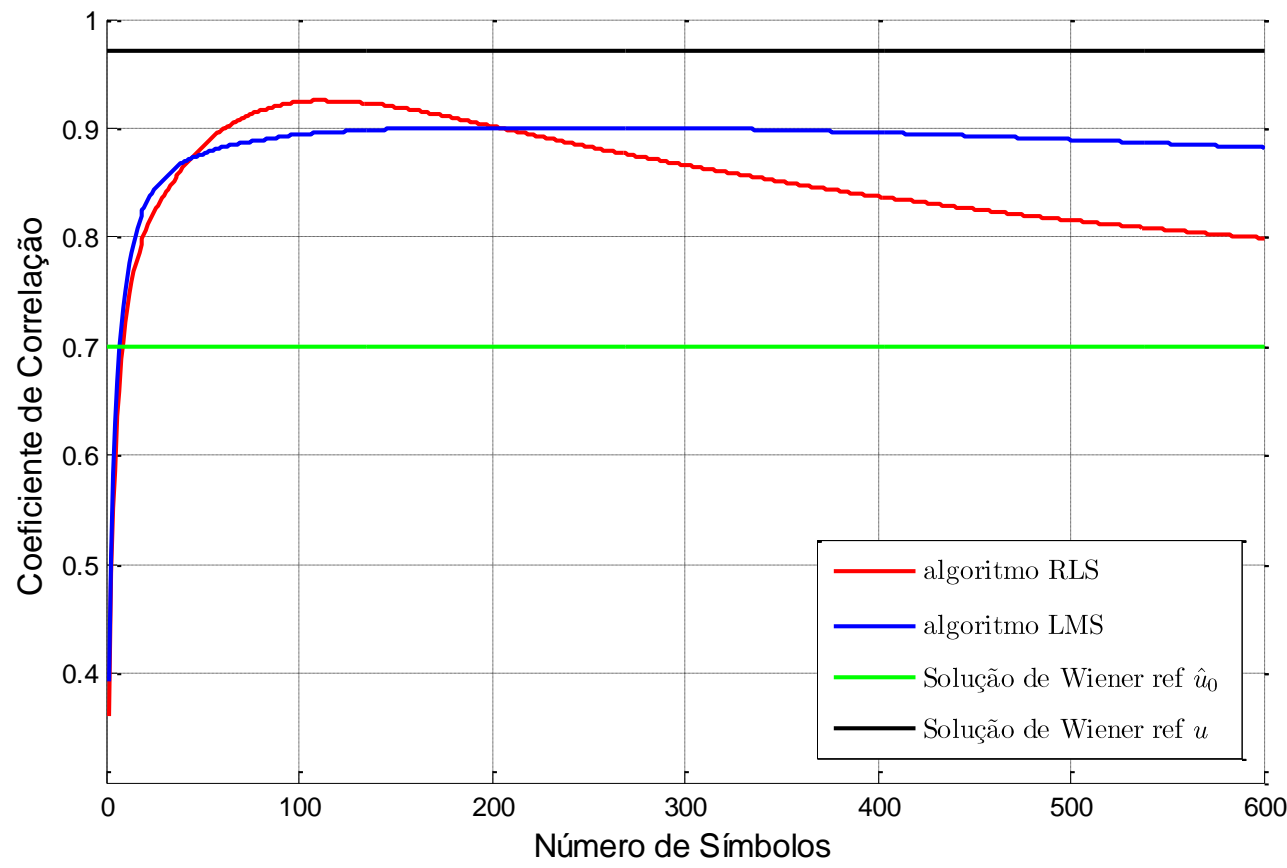

Figura 5.16: Coeficiente de correlação entre a saída do algoritmo LMS $(\delta=0,0001)$ e do algoritmo $\operatorname{RLS}(\lambda=0,9999)$ com a regra ótima, para $K=7$ sensores locais, sistema não homogêneo com $\mathrm{SNR}_{r e f}=-2 \mathrm{~dB}$ e probabilidades a priori $p_{0}=0,1$ e $p_{1}=0,9$. 
As Figuras 5.17 e 5.18 mostram as curvas de evolução da DER do algoritmo RLS e LMS para um sistema homogêneo (SNR média do canal e local iguais para todos os $\mathrm{K}=7$ nós da rede de sensores), SNR média do canal de $8 \mathrm{~dB}$ para todos os sensores e probabilidades a priori $p_{0}=0,1$ e $p_{1}=0,9$ para uma SNR local de $3 \mathrm{~dB}$ e $-2 \mathrm{~dB}$ (para todos os sensores), respectivamente.

Nesse caso, a correlação entre $\widehat{u}_{0}$ e $u$ é $\rho_{\widehat{u}_{0} u}=0,99$ para SNR local de $3 \mathrm{~dB}$ e $\rho_{\widehat{u}_{0} u}=0,88$ para SNR local de $-2 \mathrm{~dB}$. Assim, no primeiro caso a referência $\hat{u}_{0}$ é praticamente igual à hipótese verdadeira $u$. Desse modo, o desempenho da DER dos algoritmos LMS e RLS são muito próximos aos da solução de Wiener $\widehat{\widehat{u}}_{0}$, cujo desempenho, por sua vez, é praticamente idêntico ao da regra ótima. Assim, o vetor $\mathbf{c}^{\prime w}$ e o vetor $\mathbf{c}^{\prime}$ da regra ótima estão praticamente alinhados, o que é evidenciado pelos resultados da Figura 5.19.

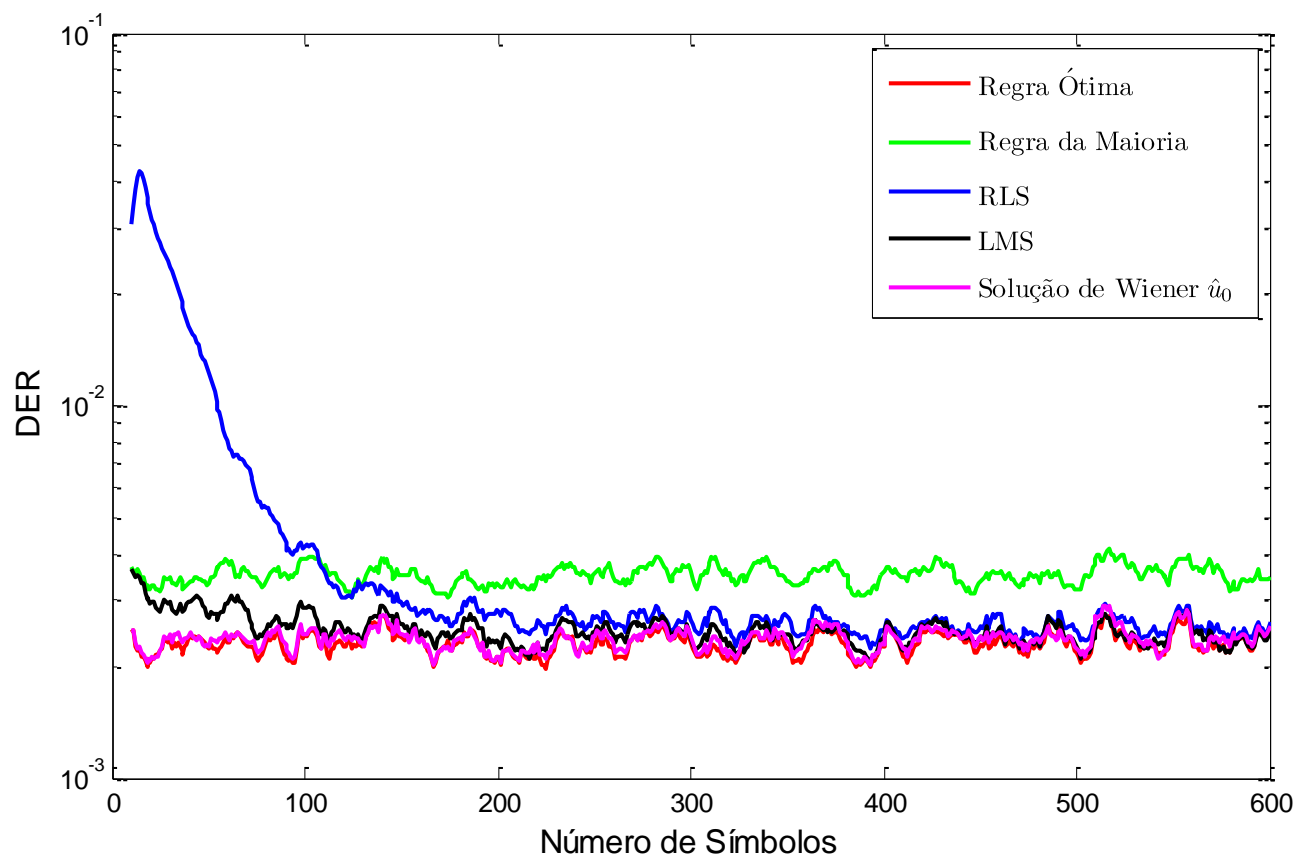

Figura 5.17: Evolução da DER do algoritmo LMS $(\delta=0,0001)$ e do algoritmo $\operatorname{RLS}(\lambda=$ 0,9999), sistema homogêneo, $K=7$ sensores locais, SNR média do canal de 8 dB e SNR local dos sensores iguais a $3 \mathrm{~dB}$ e probabilidades a priori $p_{0}=0,1$ e $p_{1}=0,9$. 


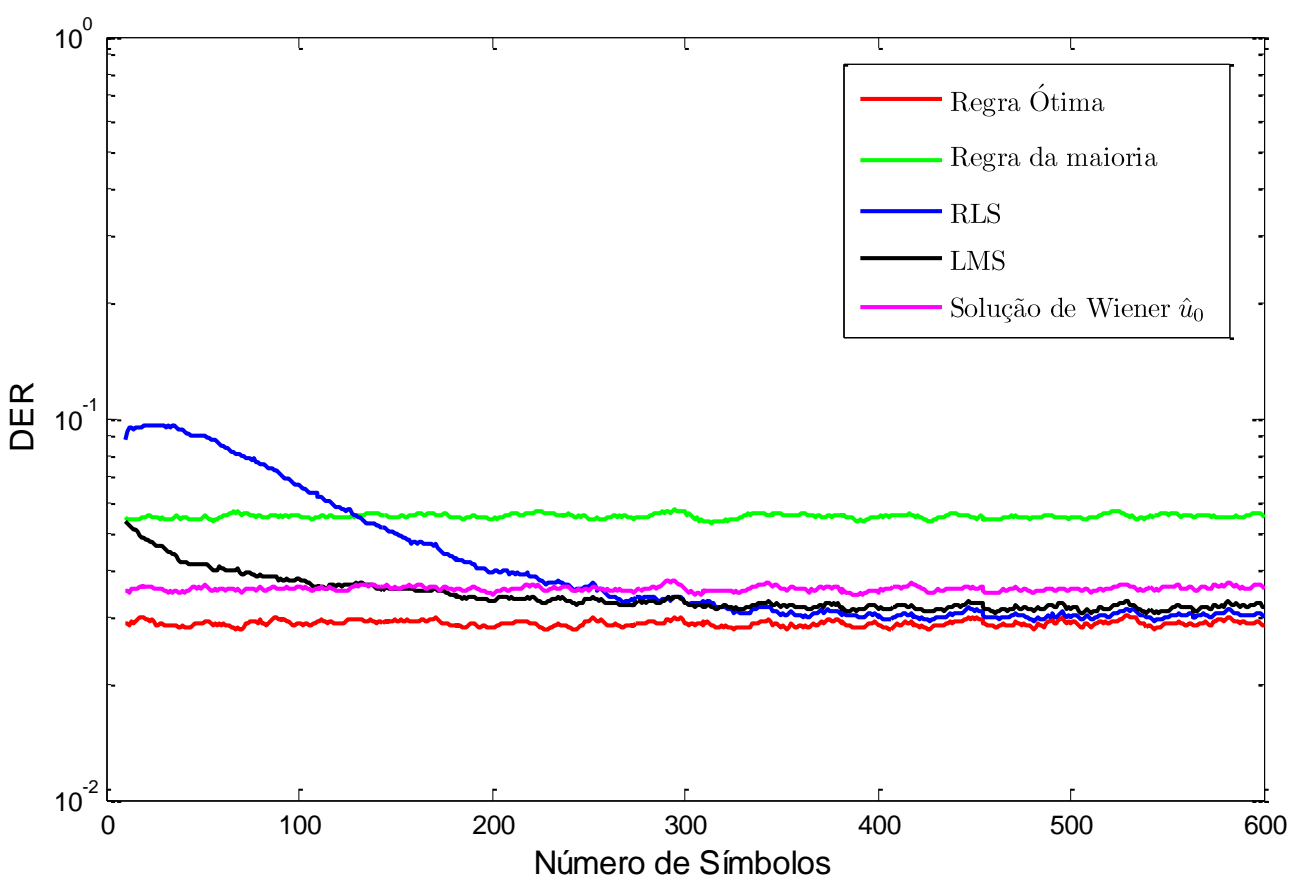

Figura 5.18: Evolução da DER do algoritmo LMS $(\mu=0,0001)$ e do algoritmo $\operatorname{RLS}(\lambda=$ 0,9999 ), sistema homogêneo, $K=7$ sensores locais, SNR média do canal de $8 \mathrm{~dB}$ e SNR local dos sensores iguais a $-2 \mathrm{~dB}$ e probabilidades a priori $p_{0}=0,1$ e $p_{1}=0,9$.

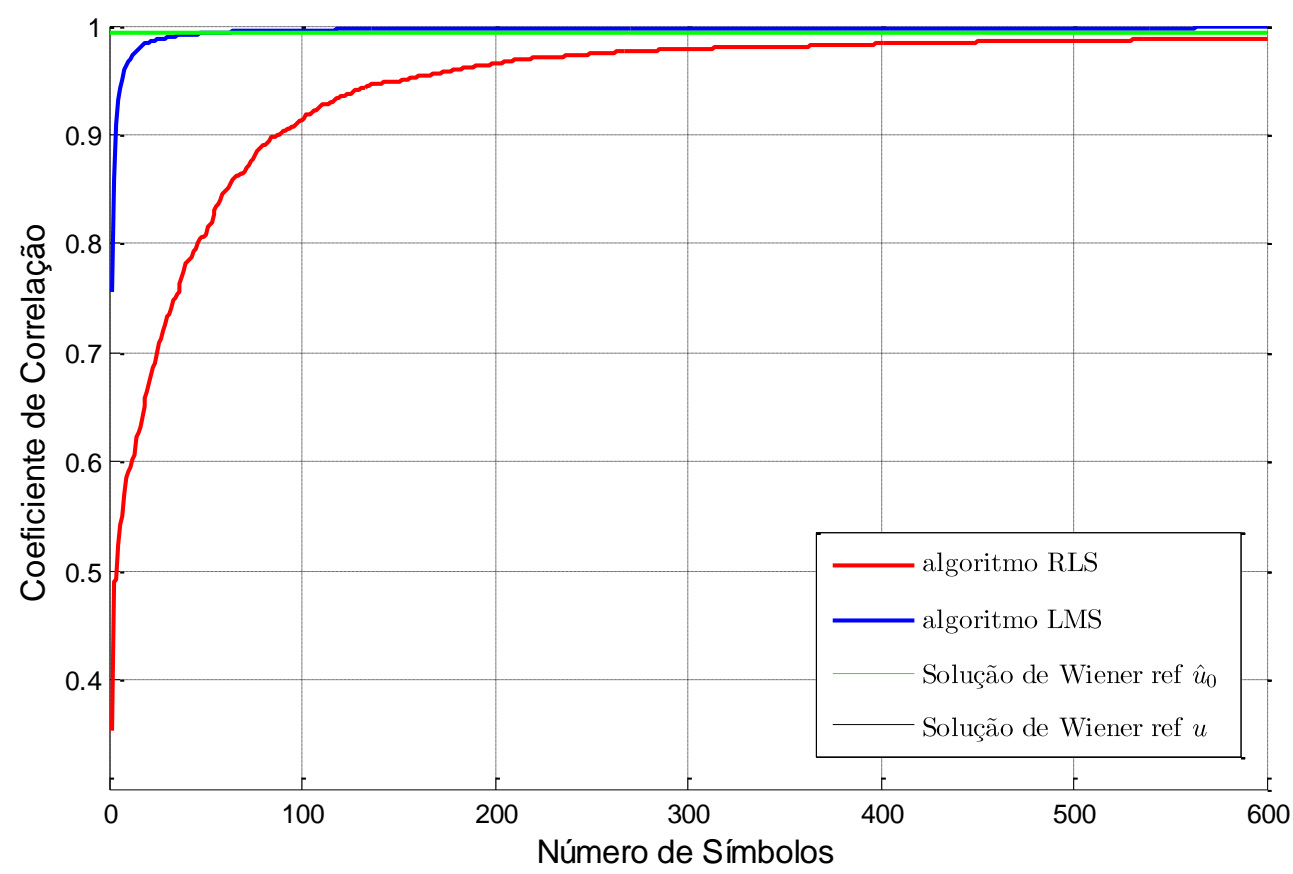

Figura 5.19: Coeficiente de correlação entre a saída do algoritmo LMS $(\delta=0,0001)$ e do algoritmo RLS $(\lambda=0,9999)$, sistema homogêneo, $K=7$ sensores locais, SNR média do canal de $8 \mathrm{~dB}$ e SNR local dos sensores iguais a $3 \mathrm{~dB}$ e probabilidades a priori $p_{0}=0,1$ e $p_{1}=0,9$. 
A Figura 5.18 mostra que o desempenho da solução de Wiener $\widehat{u}_{0}$ é degradado devido à redução do coeficiente de correlação $\rho_{\widehat{u}_{0} u}$ de 0,99 para 0,88 . Nesse caso ambos os algoritmos LMS e RLS tem desempenhos de DER semelhantes.

Foi verificado que o algoritmo LMS possui um desempenho superior ao do algoritmo RLS e ao da solução de Wiener ${\widehat{u_{0}}}$ no que diz respeito à probabilidade de erro. Como já mencionado, esse comportamento contra intuitivo é aparentemente ocasionado pelo fato da referência $\hat{u}_{0}$ ter erros em relação à hipótese $u$. Isto faz com que a referência $\hat{u}_{0}$ se comporte como a hipótese $u$ com flutuações discretas. Com passo de adaptação do algoritmo LMS suficientemente pequeno essas flutuações não são rastreadas pelo algoritmo LMS e, desde que a probabilidade de erros em $\hat{u}_{0}(i)$ seja pequena, ou seja, que o valor de $\hat{u}_{0}(i)$ seja na maior parte do tempo igual à hipótese $u(i)$, o algoritmo efetivamente rastreia a hipótese $u$. Isto pode ser verificado na Figura 5.20 onde é apresentada a curva de convergência do erro médio quadrático do algoritmo LMS em relação à hipótese $u$, o $\mathrm{MMSE}_{\widehat{u}_{0}} \mathrm{e}$ o MMSE teórico em relação à hipótese $u$ desenvolvido no Apêndice B.

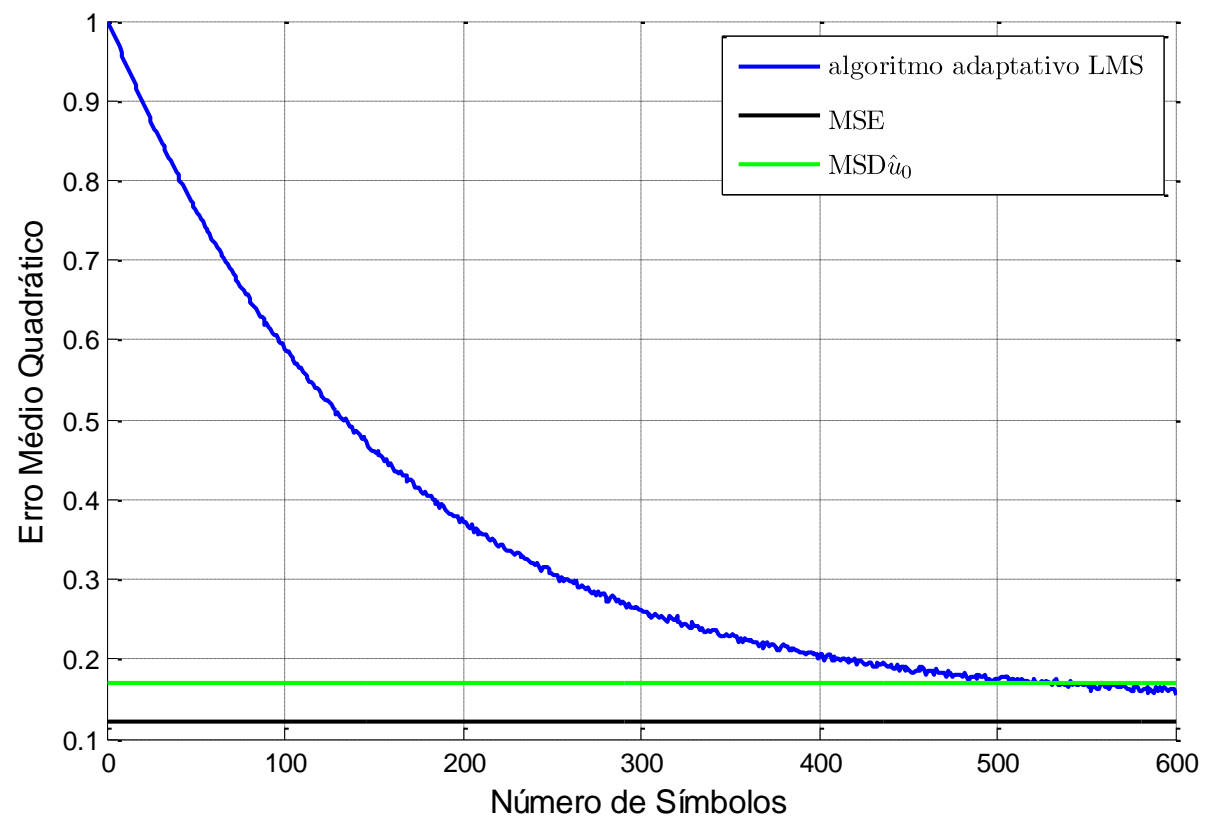

Figura 5.20: Evolução do erro médio quadrático do algoritmo LMS $(\delta=0,0001)$ e do algoritmo RLS $(\lambda=0,9999), K=7$ sensores locais, sistema não homogêneo com SNR $_{r e f}$ $=3 \mathrm{~dB}$ e probabilidades a priori $p_{0}=0,1$ e $p_{1}=0,9$. 
Verifica-se, através da Figura 5.20, que o erro médio quadrático do algoritmo LMS converge para um valor um pouco abaixo do $\mathrm{MMSE}_{\widehat{u}_{0}}$ teórico da solução de Wiener $\widehat{u}_{0}$. Desta forma, o vetor de saída $\hat{\mathbf{c}}^{\prime}(i)$ do algoritmo LMS alcança um coeficiente de correlação $\rho_{\mathbf{c}^{\prime} \mathbf{c}^{\prime}(i)}$ mais alto e consequentemente um desempenho DER próximo ao da regra ótima.

Vale ressaltar que o algoritmo RLS pode ser ajustado de modo que ele se torne lento o suficiente para não rastrear os erros de $\hat{u}_{0}(i)$ e obter um desempenho em termos de DER semelhante ao do algoritmo LMS. Porém, como a complexidade do algoritmo LMS é razoavelmente menor que do algoritmo RLS, o primeiro seria uma escolha natural para o uso na fusão adaptativa proposta nesse trabalho.

\section{6}

\section{Algoritmo de Gradiente para minimização da DER}

Conforme visto na seção anterior, o algoritmo LMS cuja função custo é o $\mathrm{MSE}_{\widehat{u}_{0}}$ possui um desempenho com relação a DER superior ao do algoritmo RLS e da solução de Wiener $\widehat{u}_{0}$, caso seu passo de atualização seja suficientemente pequeno. Nesse caso, o algoritmo LMS possui um erro residual em relação ao $\operatorname{MMSE}_{\widehat{u}_{0}}$ o que aparentemente auxilia o algoritmo a reduzir a DER.

Os algoritmos LMS e RLS com observações Gaussianas normalmente possuem uma relação direta entre minimização da MSE e a minimização da probabilidade de erro. Contudo, nesse trabalho as observações são discretas e, além disso, correlacionadas, pois são resultados das decisões de sensores que observam um mesmo processo estocástico. Assim, é interessante que essa correspondência direta entre minimização do $\mathrm{MSE}_{\widehat{u}_{0}}$ e da DER seja examinada.

A fim de verificar se nessa situação, o algoritmo LMS, cuja função custo é o MSE (ou seja, a referência da função custo é a hipótese $u$ ), promove a minimização da probabilidade de erro, essa sub-seção desenvolve um algoritmo do tipo gradiente que utiliza uma função custo relacionada diretamente com a probabilidade de erro $(P(\hat{u} \neq u))$ e compara seu desempenho com o algoritmo LMS voltado para a minimização do MSE. 
Primeiramente, a probabilidade de erro de decisão do centro de fusão, $P_{e}(i)$, pode ser expressa por:

$$
\begin{aligned}
& \mathbb{E}[\hat{u}(i) u(i)]=P(u(i)=\hat{u}(i))-P(u(i) \neq \hat{u}(i)), \\
&=1-2 P_{e}(i), \\
& P_{e}(i)=\frac{1-\mathbb{E}[\hat{u}(i) u(i)]}{2}=\mathbb{E}\left[\frac{1-\hat{u}(i) u(i)}{2}\right] .
\end{aligned}
$$

Assim, sendo a probabilidade de erro do centro de fusão expressa pelo valor médio dado em (5-39), pode-se utilizar o valor instantâneo:

$$
P_{e}^{i n s t}(i) \triangleq \frac{1-\hat{u}(i) u(i)}{2}
$$

como função de custo do algoritmo de gradiente:

$$
\left[\begin{array}{c}
\hat{\mathbf{c}}(i+1) \\
\hat{c}_{0}(i+1)
\end{array}\right]=\left[\begin{array}{c}
\hat{\mathbf{c}}(i)-\delta \frac{\partial P_{e}^{i n s t}(i)}{\partial \hat{\mathbf{c}}(i)} \\
\hat{c}_{0}(i)-\delta \frac{\partial P_{e}^{i n s t}(i)}{\partial \hat{c}_{0}(i)}
\end{array}\right]
$$

As equações recursivas de (5-41) requerem as derivadas de (5-40) que, por sua vez, pode ser expressa na forma:

$$
P_{e}^{i n s t}(i)=\frac{1-u(i)(\operatorname{sign}[s(i)])}{2}
$$

Entretanto, a presença da função sign[.] torna (5-42) não diferenciável. Aqui a função $\operatorname{sign}[x]$ é aproximada por $\tanh (\mathrm{A} x)$, em que $\tanh ($.$) é a função$ tangente hiperbólica e $A \in \mathbb{Z}$ é uma constante inteira a ser dimensionada.

Com essa aproximação e substituindo $s(i)$ por (5-9) resulta que (5-41) pode ser escrita como: 
$\left[\begin{array}{c}\hat{\mathbf{c}}(i+1) \\ \hat{c}_{0}(i+1)\end{array}\right]=\left[\begin{array}{c}\hat{\mathbf{c}}(i)+\delta \frac{\mathrm{A}}{2}(u(i) \hat{\mathbf{b}}(i)) \operatorname{sech}\left(\mathrm{A}\left(\hat{\mathbf{c}}(i)^{T} \hat{\mathbf{b}}(i)+\hat{c}_{0}(i)\right)\right)^{2} \\ \hat{c}_{0}(i)+\delta \frac{\mathrm{A}}{2}(u(i)) \operatorname{sech}\left(\mathrm{A}\left(\hat{\mathbf{c}}(i)^{T} \hat{\mathbf{b}}(i)+\hat{c}_{0}(i)\right)\right)^{2}\end{array}\right]$

ou por:

$$
\left[\begin{array}{c}
\hat{\mathbf{c}}(i+1) \\
\hat{c}_{0}(i+1)
\end{array}\right]=\left[\begin{array}{c}
\hat{\mathbf{c}}(i)+\delta^{\prime}(u(i) \hat{\mathbf{b}}(i)) \operatorname{sech}\left(\mathrm{A}\left(\hat{\mathbf{c}}(i)^{T} \hat{\mathbf{b}}(i)+\hat{c}_{0}(i)\right)\right)^{2} \\
\hat{c}_{0}(i)+\delta^{\prime}(u(i)) \operatorname{sech}\left(\mathrm{A}\left(\hat{\mathbf{c}}(i)^{T} \hat{\mathbf{b}}(i)+\hat{c}_{0}(i)\right)\right)^{2}
\end{array}\right]
$$

em que $\delta^{\prime}=\delta \frac{\mathrm{A}}{2}$ é o passo de atualização. Assim as equações recursivas em (5-43) fornecem uma aproximação para um algoritmo estocástico assistido de busca iterativa pelo vetor $\mathbf{c}^{\prime}(i)$ que minimiza a probabilidade de erro do centro de fusão.

As Figuras 5.21 e 5.22 ilustram as curvas de evolução da DER em função do número de símbolos, para o sistema heterogêneo, $\mathrm{SNR}_{r e f}=3 \mathrm{~dB}$ com probabilidades a priori $p_{0}=0,1$ e $p_{1}=0,9$ e $p_{0}=p_{1}=0,5$, respectivamente. Aqui o algoritmo de gradiente tem por base a equação (5-43) com uma constante $\mathrm{A}=10$. Para esse valor, a função $\tanh (\mathrm{A} x)$, se assemelha o suficiente à função $\operatorname{sign}[x]$ e ao mesmo tempo sua derivada atende as condições para estabilidade de (5-43). O passo $\delta^{\prime}$ tem o mesmo valor do passo do algoritmo LMS da seção anterior. Entretanto, aqui o algoritmo LMS utiliza como sinal piloto a referência ideal $u(i)$. Conforme ilustrado pelas Figuras 5.21 e 5.22, as curvas de desempenho do algoritmo LMS e do algoritmo de gradiente voltado para minimização da probabilidade de erro são praticamente coincidentes. Isto indica que no presente problema, no qual as observações são discretas e correlacionadas, a busca pela minimização do $\mathrm{MSE}_{u}$ resulta na minimização da DER 


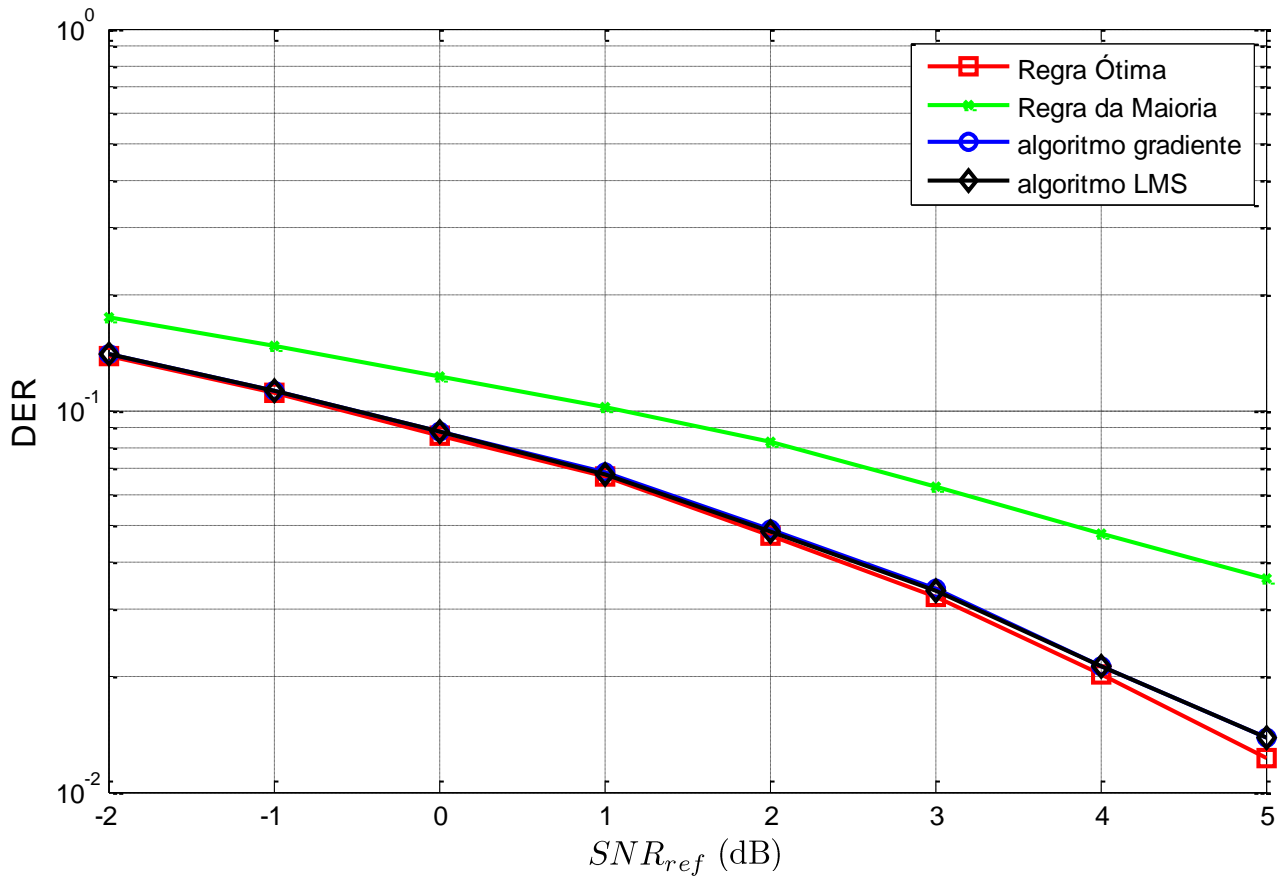

Figura 5.21: DER vs $\mathrm{SNR}_{\text {ref }}$ para os algoritmos LMS e gradiente. $\mathrm{K}=7$ sensores locais, sistema não homogêneo e probabilidades a priori $p_{0}=0,1$ e $p_{1}=0,9$.

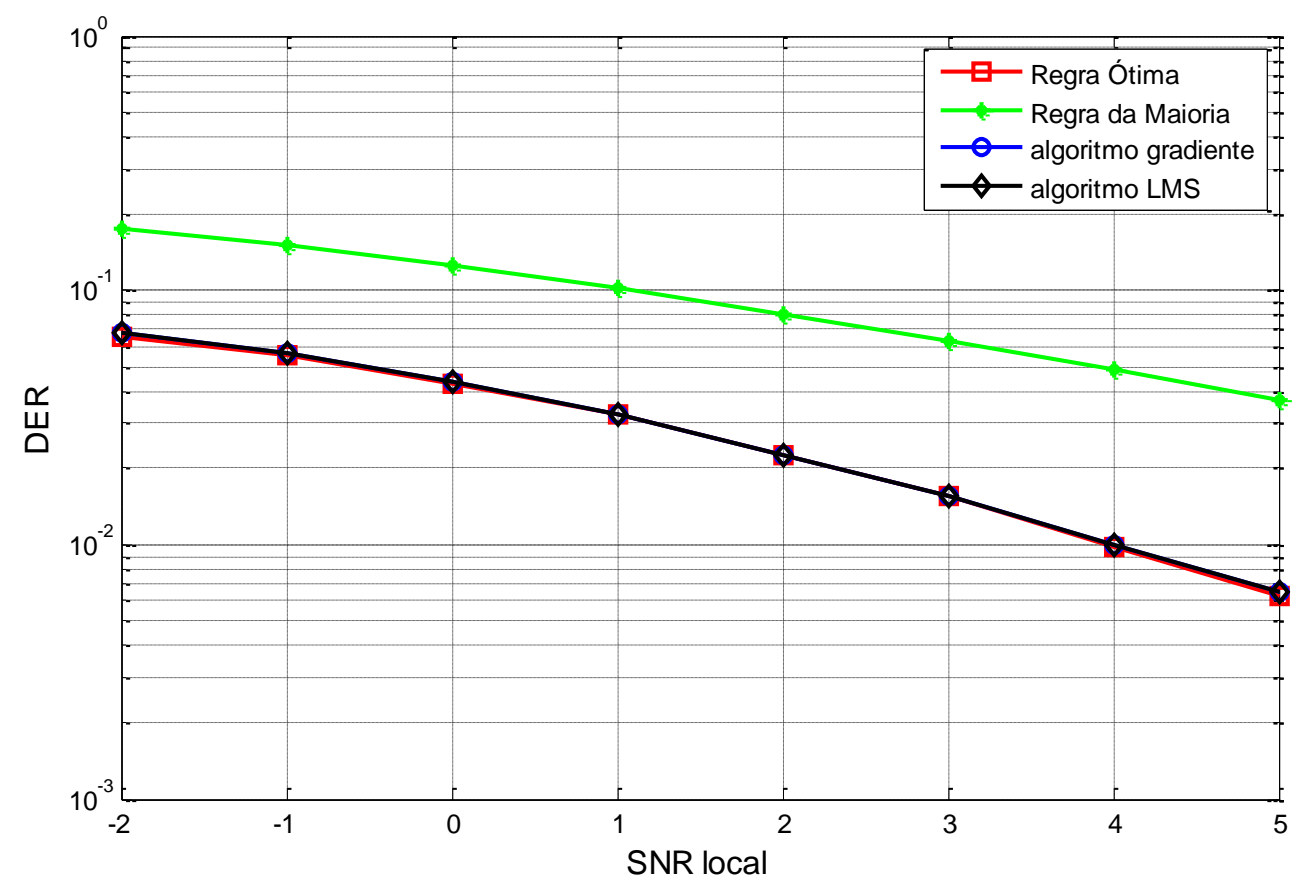

Figura 5.22: DER vs $\mathrm{SNR}_{r e f}$ para os algoritmos LMS e gradiente. $\mathrm{K}=7$ sensores locais, sistema não homogêneo e probabilidades a priori iguais. 


\section{7}

\section{Conclusões}

Este capítulo propôs esquemas de estimação adaptativa conjunta linear dos pesos e do limiar de decisão da regra de fusão ótima para utilização no centro de fusão de rede de sensores. O desempenho dos esquemas propostos foi ilustrado considerando uma rede de sensores CS-CDMA, para a qual os coeficientes da regra de fusão ótima puderam ser obtidos analiticamente.

Os esquemas propostos utilizam algoritmos adaptativos LMS e RLS nos quais sinal de referência é obtido pela regra da maioria aplicada às mensagens detectadas no primeiro estágio do centro de fusão. Desta forma, os algoritmos são considerados cegos (prescindem de sequência de treinamento).

Foi verificado por meio de simulações que os esquemas propostos apresentam um desempenho superior à regra da maioria e muito próximo do desempenho da regra de fusão ótima teórica. 


\section{Conclusões e Trabalhos Futuros}

Essa tese abordou o problema de detecção de hipóteses binárias em sistemas distribuídos com centro de fusão operando em canais seletivos em frequência. O esquema de detecção distribuída utilizado nessa tese é composto por $\mathrm{K}$ nós sensores, sendo que cada nó realiza uma tomada de decisão binária acerca de um fenômeno de observação, independentemente da decisão binária dos outros K-1 sensores. Estas decisões são transmitidas através de um canal seletivo em frequência para um centro de fusão, onde os sinais recebidos são processados para gerar a decisão final sobre o fenômeno observado pelos sensores.

Foi proposto o uso do esquema CS-CDMA para múltiplo acesso em redes de sensores distribuídos em ambientes seletivos em frequência. No esquema CSCDMA proposto, a ortogonalidade entre os sinais transmitidos pelos sensores é preservada no receptor, a despeito da propagação através de canais multipercursos seletivos em frequência. Um procedimento de decisão sub-ótimo de baixa complexidade no qual as mensagens são detectadas isoladamente (primeiro estágio) e, depois, combinadas por meio de uma regra de fusão para gerar a decisão final (segundo estágio) foi proposto. Foi mostrado que seu desempenho é bem próximo do decisor ótimo teórico, que também foi obtido nessa tese. Comparações de desempenho foram feitas com uma rede de sensores utilizando o esquema DS-CDMA e mostrou-se que a rede de sensores com esquema CSCDMA possui complexidade computacional menor e pode operar com maior eficiência espectral e com desempenho superior.

Métodos simples de estimação de canal, um método cego e outro assistido foram propostos para utilização em redes de sensores CS-CDMA. Foi verificado que tais redes equipadas com os métodos propostos mantêm o desempenho superior, com menor complexidade computacional, quando comparadas em redes de sensores DS-CDMA com equalização RLS, tanto em ambientes invariantes quanto variantes no tempo.

A fim de melhorar a detecção das mensagens enviadas pelos sensores no centro de fusão foi proposta uma rede de sensores cooperativa utilizando o esquema de transmissão CS-CDMA. Nesta rede cada sensor é pareado com um 
sensor vizinho formando um sensor cooperativo que transmite sua mensagem e retransmite uma estimativa da mensagem do sensor pareado em um esquema de cooperação detect-and-forward. Resultados numéricos indicaram que a rede de sensores cooperativa possui um melhor desempenho que a rede se sensores nãocooperativa, entretanto, o ganho de desempenho é mais significativo em ambientes com desvanecimento plano. Em ambientes seletivos em frequência a rede de sensores CS-CDMA não-cooperativa já explora eficientemente a diversidade de multipercurso, e o ganho decorrente da diversidade espacial provida pelo uso da cooperação não resulta em uma melhora substancial no desempenho final. Isto indica que o uso de cooperação em redes de sensores utilizando o esquema de transmissão CS-CDMA é mais vantajoso em ambientes com poucos componentes de multipercurso.

As mensagens detectados no primeiro estágio do receptor são combinadas (fusão de dados) no segundo estágio a fim de realizar detecção final do receptor. A regra de fusão ótima teórica necessita do conhecimento das probabilidades de falso alarme e misdetection relacionadas à detecção das mensagens, bem como da probabilidade a priori das hipóteses. Foram propostos dois esquemas para estimação adaptativa conjunta linear dos pesos e do limiar de decisão da regra de fusão ótima e, assim, realizar uma fusão adaptativa no centro de fusão sem a necessidade de qualquer conhecimento prévio das estatísticas dos sensores bem como das estatísticas hipótese observada. O desempenho dos esquemas propostos foi ilustrado considerando uma rede de sensores CS-CDMA, para a qual os coeficientes da regra de fusão ótima puderam ser obtidos analiticamente. Os esquemas propostos utilizam algoritmos adaptativos LMS e RLS cujo sinal de referência é obtido pela regra da maioria aplicada às mensagens detectadas no primeiro estágio do centro de fusão. Desta forma os algoritmos são não-assistidos (prescindem de sequência de treinamento). Foi feito um extenso desenvolvimento teórico (Apêndice B) para obtenção de expressões analíticas para o mínimo erro médio quadrático (MMSE) e para o mínimo erro médio quadrático em relação à $\widehat{u}_{0}\left(\mathrm{MMSE}_{\widehat{u}_{0}}\right)$ associados à solução de Wiener para funções custo cujas referências são, respectivamente, o sinal correspondente as hipóteses verdadeiras (função custo MSE) e o sinal de saída resultante da regra da maioria (função custo $\mathrm{MSE}_{\widehat{u}_{0}}$ ). Essas expressões foram utilizadas como limitantes teóricos na análise de 
convergência dos algoritmos adaptativos propostos. Foi verificado por meio de simulações que os esquemas propostos apresentam um desempenho superior à regra da maioria e muito próximo do desempenho da regra de fusão ótima.

Como sugestões de trabalhos futuros podem-se destacar os seguintes tópicos:

- $\quad$ estimação dos limiares de decisão do primeiro estágio do receptor do centro de fusão, além dos pesos e do limiar de decisão da regra fusão, pelos algoritmos propostos a fim de verificar a possibilidade de melhora no desempenho global.

- Generalização do sistema de detecção distribuído utilizado nesta tese para detecção de hipóteses $m$-árias. Este problema é desafiador tendo em vista que para sistemas $m$-ários a regra de fusão ótima não pode mais ser escrita como uma combinação ponderada das decisões dos sensores. Desta forma os algoritmos devem ser repensados. Uma proposta de prosseguimento seria o uso de separação hierárquica [61-63] das hipótese $m$-árias em hipóteses binárias de forma de algoritmos propostos nesta teste podem ser utilizados. 


\section{Referências bibliográficas}

[1] AKYILDIZ, W.; SANKARASUBRAMANIAM, Y.; CAYIRCI, E. A survey on sensor networks, IEEE Commun. Mag., vol. 40, no. 8, pp. 102-114, August 2002.

[2] KUMAR, S.; ZHAO, F.; SHEPHERD, D. Special issue on collaborative signal and information processing in microsensor networks, IEEE Signal Processing Mag., vol. 19, pp. 13-14, Mar. 2002.

[3] CHONG, C.; KUMAR, S. Sensor networks: Evolution, opportunities, and challenges, Proc. IEEE, vol. 91, pp. 1247-1256, Aug. 2003

[4] VISWANATHAN, R.; VARSHNEY, P.K. Distributed detection with multiple sensors: Part I-fundamentals, Proc. IEEE, vol. 85, no. 1, pp. 54-63, Jan. 1997.

[5] TENNEY, R.R.; SANDELL, N.R. Detection with distributed sensors IEEE Trans. Aerosp. Electron. Syst., vol. 17, no. 4, pp. 501-510, 1981.

[6] HOBALlAH, I.Y.; VARSHNEY, P.K. Distributed Bayesian signal detection, IEEE Trans. Inform. Theory, vol. 35, pp. 995-1000,Sept. 1989.

[7] CHAIR, Z.; VARSHNEY, P.K. Optimal data fusion in multiple sensor detection systems, IEEE Trans. Aerospace Elect. Syst., vol. AES-22, pp. 98-101, Jan. 1986.

[8] TSITSIKLIS, J.N. Decentralized detection, Advs. Statistical Signal Processing, vol. 2, pp. 297-344, 1993.

[9] TSITSIKLIS, J.N. Decentralized detection by a large number of sensors, Math. Control, Signals, Syst., vol. 1, no. 2, pp. 167-182, 1988.

[10] LONGO, M.; LOOKABAUGH, T.D.; GRAY, R.M. Quantization for de centralized hypothesis testing under communication constraints, IEEE Trans. Inf. Theory, vol. 36, no. 2, pp. 241-255, Mar. 1990.

[11] BLUM, R.S.; KASSAM, S.A.; POOR, H.V. Distributed Detection with multiple sensors: Part II - Advanced topics, Proc. of the IEEE, vol. 85, no. 1,pp. 64-79, Jan. 1997.

[12] CHAMBERLAND, J.F.; VEERAVALLI, V.V. Decentralized detection in sensor networks, IEEE Trans. Signal Processing, vol. 51, no. 2, pp. 407-416, Feb. 2003.

[13] SHI, W.; SUN, T.W.; WESEL, R.D. Quasiconvexity and Optimal Binary Fusion for Distributed Detection with Identical Sensors in Generalized Gaussian Noise, IEEE Trans. Information Theory, vol. 47, pp. 446-450, 2001. 
[14] ZHANG, Q.; VARSHNEY, P.K.; WESEL, R.D. Optimal Bi-Level Quantization of i.i.d. Sensor Observations for Binary Hypothesis Testing, IEEE Trans. Information Theory, vol. 48, no. 7, pp. 2105-2111, 2002.

[15] XIAO, J.J.; LUO, Z.Q. Universal decentralized detection in a bandwidth constrained sensor network, IEEE Trans. Signal Processing, vol. 53, no. 8, pp. 2617-2624, Aug. 2005.

[16] LUO, Z.Q. Universal decentralized estimation in a bandwidth constrained sensor network, IEEE Trans. Information Theory, vol. 53, pp. 22102210, 2005.

[17] DAVID, R.P.; MEDINA, C.S; SAMPAIO NETO, R. Comparação entre Esquemas de Detecção Distribuída e Mensagens Quantizadas, XXX Simpósio Brasileiro de Telecomunicações, Brasil, Sep. 2012.

[18] CHEN, B.; TONG, L.; VARSHNEY, P. Channel-aware distributed detection in wireless sensor networks, IEEE Signal Process. Mag., vol. 23, pp. 16-26, Jul. 2006

[19] CHEN, B.; JIANG, R.; KASETKESAM, T.; VARSHNEY, P.K. Channel aware decision fusion in wireless sensor networks, IEEE Trans. Signal Process., vol. 52, no. 12, pp. 3454-3458, Dec. 2004.

[20] BANAVAR, M.K.; SMITH, A.D.; TEPEDELENLIOGLU, C.; SPANIAS, A. Distributed detection over fading MACs with multiple antennas at the fusion center, in Proc. of IEEE International Conference on Acoustics Speech and Signal Processing, pp. 2894-2897, 2010

[21] JAYAWEERA, S. Optimal Bayesian Data Fusion and Low-complexity Approximations for Distributed DS-CDMA Wireless Sensor Networks in Rayleigh Fading, in Proceeding of Intelligent Sensing and Information Processing, Conf.2005, Jan 2005, vol. 2, pp. 19-24.

[22] WEI, S. Spreading sequence-based non-coherent sensor fusion and its resulting large deviation exponents, in Proc. in Acoustic., Speech Signal Processing, 2007, vol. 3, pp.177-180.

[23] ZHOU, S.; GIANNAKIS, G. Chip-Interleaved Block-Spread Code Division Multiple Access, IEEE Trans. Commun., vol. 50, pp. 235-248, February 2002

[24] ARÉVAlO, L.; SAMPAIO NETO, R.; MEDINA, C.S. Brincando com Blocos: Uma Nova Combinação de Transmissão em Blocos com a Técnica de Múltiplo Acesso CDMA, XXX Simpósio Brasileiro de Telecomunicações, Brasil, Set. 2012.

[25] DAVID, R.P.; MEDINA, C.S.; SAMPAIO-NETO, R. Distributed CSCDMA Wireless Sensor Networks in Frequency Selective Channel, International Symposium on Wireless Communication Systems (ISWCS), Aug. 2013. 
[26] BAI, K.; TEPEDELENLIOGLU, C. Distributed Detection in UWB Wireless Sensor Networks, IEEE Transactions on Signal Processing, Vol. 58, No. 2, Feb. 2010.

[27] SEDDIK, K.G.; RAY LIU, K.J.R. On Relay Nodes Deployment for Distributed Detection in Wireless Sensor Networks, IEEE Global Telecommunications Conference, Dec. 2008.

[28] BAIDAS, M.W.; IBRAHIM, A.S.; SEDDIK, K.G.; LIU, K.J.R. On the Impact of Correlation on Distributed Detection in Wireless Sensor Networks with Relays Deployment, IEEE Conference on Communications, June 2009.

[29] DAVID, R.P.; MEDINA, C.S; SAMPAIO-NETO, R. Distributed CSCDMA Cooperative Wireless Sensor Networks, XXXI Simpósio Brasileiro de Telecomunicações, Brasil, Out. 2013.

[30] MIRJALILY, G.; ZHI-QUAN, L.; DAVIDSON, T.N.; BOSSE, E. Blind adaptive decision fusion for distributed detection, IEEE Trans. on Aerospace and Electronic Systems, vol. 39, no. 1, pp. 34, 52, Jan. 2003.

[31] ANSARI, N.; HOU, E.S.H.; ZHU, B.; CHEN, J. Adaptive fusion by reinforcement learning for distributed detection systems, IEEE Transactions on Aerospace and Electronic Systems, vol.32, no. 2, pp. 524-531, April 1996.

[32] ANSARI, N.; CHEN, J.G.; ZHANG, Y.Z. Adaptive decision fusion for unequiprobable sources, IEEE Proc. on Radar, Sonar and Navigation, vol.3, no. 144, pp. 105-111, June 1997.

[33] TANG, H.; WU, H.C; LU, L.; IYENGAR, S.S. Adaptive Cooperative Spectrum Sensing Based on a Novel Robust Detection Algorithm, in IEEE International Conference on Commun., June, 2012

[34] WU, J.Y.; WU, C.W.; WANG, T.Y.; LEE, T.S. Channel-aware decision fusion with unknown local sensor detection probability, IEEE Trans. Signal Process., vol. 58, no. 3, pp. 1457-1463, Mar. 2010

[35] NASR, I.; CHIEF, S. A Novel Adaptive Fusion Scheme For Cooperative Spectrum Sensing, IEEE Vehicular Technology Conference (VTC Fall), September 2012.

[36] CIUONZO, D.; ROMANO, G.; SALVO ROSSI, P. Channel-aware decision fusion in distributed MIMO wireless sensor networks: Decode-andfuse vs. decode-then-fuse, IEEE Trans. Wireless Commun., vol. 11, no. 8, pp. 2976-2985, Aug. 2012.

[37] GIANNAKIS, G.; ANGHEL, P.A.; WANG, Z. Generalized Multicarrier CDMA: Unification and Linear Equalization, EURASIP Journal on Applied Signal Processing, no.5, pp. 743-556, 2005. 
[38] TSATSANIS, M.K.; XU, Z.. Performance analysis of minimum variance CDMA receivers, IEEE Trans. Commun., vol. 46, no. 11, pp. 3014-3022, Nov. 1998.

[39] XU, Z.; TSATSANIS, M.K. Blind adaptive algorithms for minimum variance CDMA receivers, IEEE Trans. Commun., vol. 49, no. 1, pp. 180-194, Jan. 2001.

[40] LIU, H.; LI, K. Low complexity receivers for CDMA communications over frequency-selective channels, Proceedings SPAWC'97, Paris, França, pp. 265-268, Abril 1997.

[41] VINHOZA, T.T.V.; DE LAMARE, R.C.; SAMPAIO-NETO, R. Low Complexity Blind Constrained Data-Reusing Algorithms based on Minimum Variance and Constant Modulus Criteria, IEEE International Conference on Acoustics, Speech and Signal Processing, 2006.

[42] DE LAMARE, R.C.; SAMPAIO-NETO, R. Low-Complexity Variable Step Size Mechanisms for Stochastic Gradient Algorithms in Minimum Variance CDMA Receivers, IEEE Trans. Signal Processing, v. 54, p. 2302-2317, 2006.

[43] DE LAMARE, R.C.; SAMPAIO-NETO, R. Blind adaptive MIMO receivers for space-time block-coded DS-CDMA systems in multipath channels using the constant modulus criterion, IEEE Trans. Communications (Print), v. 58, p. 21-27, 2010.

[44] WANG, L.; YUKAWA, M.; DE LAMARE, R.C. Adaptive Reduced-Rank Constrained Constant Modulus Algorithms Based on Joint Iterative Optimization of Filters for Beamforming. IEEE Trans. Signal Processing, v. 58, p. 2983-2997, 2010.

[45] DE LAMARE, R.C.; SAMPAIO-NETO R. Blind Adaptive MIMO for Receivers Space-Time Block-Coded DS-CDMA Systems in Multipath Channels using the Constant Modulus Criterion, IEEE Trans. Communications, v. 57, p. 45-51, 2009.

[46] de OLIVEIRA, A.; SAMPAIO-NETO, R.; MEDINA, C.S. Blind Detection Techniques for IEEE 802.15.4a Communication System, International Symposium of Wireless Communication Systems (ISWCS), Aug. 2012.

[47] MEYER C. D.. Matrix Analysis and Applied Linear Algebra, SIAM Society for Industrial and Applied Mathematics, Feb. 2001.

[48] LANEMAN J. N.; WORNELL G. W.. Energy-efficient antenna sharing and relaying for wireless networks, in Proc. IEEE Wireless Communications and Networking Conference (WCNC), Sep. 2000.

[49] SKLAR, B.. Rayleigh Fading Channels in Mobile Digital Communications Systems - Part I: Characterization. IEEE Communications Magazine, p.90-100, July 1997. 
[50] SKLAR, B. Rayleigh Fading Channels in Mobile Digital Communications Systems - Part II: Mitigation. IEEE Communications Magazine, p.102-109, July 1997.

[51] KAY, S.M. Fundamentals of Statistical Signal Processing: Detection Theory. Englewood Cliffs, NJ: Prentice-Hall PTR, 1998.

[52] HAYKIN, S. Adaptive Filter Theory, Prentice Hall, 2002, ISBN 0-13048434-2.

[53] DINIZ, P.S.R. Adaptive Filtering: Algorithms and Practical Implementation, Kluwer Academic Publishers, 1997.

[54] SAYED, A.H. Fundamentals of Adaptive Filtering, Wiley, 2003.

[55] FARHANG-BOROUJENY, B. Adaptive Filters: Theory and Applications, Wiley, 1998.

[56] SHAMASH, E.; YAO, K. On the Structure and Performance of a Linear Decision-Feedback Equalizer Based on the Minimum Error Probability Criterion, International Conference on Communications, pp. 25F1-25F5, 1974.

[57] CHEN, V.; CHENG, E.; MUlGREW, B.; GIBSON, G. Minimum-BER Linear-Combiner DFE. International Conference on Communications, pp. 1173-1177, 1996.

[58] PSAROMILIGKOS, I.N.; BATALAMA, S.N.; PADOS, D.A. Adaptive Minimum Probability of Error Linear-Filter Receivers for DS-CDMA channels, Proceedings of Conference on Information Sciences and Systems, pp. 90-94, 1996.

[59] QURESHI, S.U.H. Adaptive Equalization, Proceedings of the IEEE, vol. 73, no.9, pp. 1349-1387, Sep. 1985.

[60] DAVID, R.P.; MEDINA, C.S.; SAMPAIO-NETO, R. A Linear Adaptive Algorithm for Data Fusion in Distributed Detection Systems, International Symposium on Wireless Communication Systems (ISWCS), Aug. 2014.

[61] DEMIRBAS, K. Distributed Sensor Data Fusion with Binary Decision Trees, IEEE Trans. AES, Vol. 33, No. 2, pp. 223-234, Aug. 1993.

[62] ZHU, X.; KAM, M.; RORRES, C. Mary Hypothesis Testing with Binary Local Decisions, Proc. of Conference on Information Science and Systems, Princeton, Mar. 1998.

[63] ZHANG, Q.; VARSHNEY, P.K. Towards the fusion of distributed binary decision tree classifiers, 2nd International Conference on Information Fusion (Fusion'99), July 1999. 


\section{Apêndice A}

\section{Derivação do Algoritmo Adaptativo RLS}

Reescrevendo (5-9) como um somatório de escalares tem-se:

$$
s(i)=\sum_{n=1}^{\mathrm{K}} \hat{c}_{n}(i) \hat{b}_{n}(i)+\hat{c}_{0}(i)
$$

Assim o estimador linear RLS dos pesos $c_{n}(i)$ e do limiar $c_{0}(i)$ são achados substituindo (A-1) em (5-15) e achando a derivada parcial em relação a $c_{0}$ (aqui o índice $i$ é omitido nos termos das equações para conveniência de notação):

$$
\frac{\partial}{\partial \hat{c}_{0}}\left[\sum_{l=0}^{i} \lambda^{i-l}\left(\hat{u}_{0}(l)-\left(\sum_{n=1}^{\mathrm{K}} \hat{c}_{n} \hat{b}_{n}(l)+\hat{c}_{0}\right)\right)^{2}\right]
$$

Derivando e igualando a zero, tem-se:

$$
\begin{aligned}
\sum_{l=0}^{i} \lambda^{i-l} \hat{c}_{0} & =\sum_{l=0}^{i} \lambda^{i-l} \hat{u}_{0}(l)-\left[\sum_{l=1}^{i} \lambda^{i-l} \sum_{n=1}^{\mathrm{K}} \hat{c}_{n} \hat{b}_{n}(l)\right] \\
& =\sum_{l=0}^{i} \lambda^{i-l} \hat{u}_{0}(l)-\hat{\mathbf{c}}^{T}\left[\sum_{l=1}^{i} \lambda^{i-l} \hat{\mathbf{b}}(l)\right]
\end{aligned}
$$

Observando que o primeiro termo da soma e o termo entre parênteses representam uma média ponderada pode-se reescrever (A-4) como: 


$$
\begin{gathered}
\hat{c}_{0}\left(\frac{1-\lambda^{i+1}}{1-\lambda}\right)=\sum_{l=0}^{i} \lambda^{i-l} \hat{u}_{0}(l)-\hat{\mathbf{c}}^{T}\left[\sum_{l=1}^{i} \lambda^{i-l} \hat{\mathbf{b}}(l)\right]= \\
\hat{c}_{0}=\widehat{m}_{\widehat{u}_{0}}-\hat{\mathbf{c}}^{T} \widehat{\boldsymbol{m}}_{\hat{\mathbf{b}}}
\end{gathered}
$$

em que $\quad \widehat{m}_{\widehat{u}_{0}}=\left(\frac{1-\lambda}{1-\lambda^{i+1}}\right) \sum_{l=0}^{i} \lambda^{i-l} \hat{u}_{0}(l)$ e $\quad \widehat{\boldsymbol{m}}_{\hat{\mathbf{b}}}=\left(\frac{1-\lambda}{1-\lambda^{i+1}}\right) \sum_{l=0}^{i} \lambda^{i-l} \hat{\mathbf{b}}(l)$, respectivamente.

Continuando, substituindo (A-5) em (5-15) e achando a derivada parcial em relação aos pesos $\hat{c}_{n}(n=1,2, \ldots, \mathrm{K})$ tem-se:

$$
\frac{\partial}{\partial \hat{c}_{n}}\left[\sum_{l=0}^{i} \lambda^{i-l}\left(\left(\sum_{n=1}^{\mathrm{K}} \hat{c}_{n}\left(\hat{b}_{n}(l)-\widehat{m}_{\hat{b}}\right)-\left(\hat{u}_{0}(l)-\widehat{m}_{\widehat{u}_{0}}\right)\right)\right)^{2}\right] .
$$

Em notação vetorial,

$$
\frac{\partial}{\partial \hat{\mathbf{c}}}\left[\sum_{l=0}^{i} \lambda^{i-l}\left(\left(\hat{\mathbf{c}}^{T}\left(\hat{\mathbf{b}}(l)-\widehat{\boldsymbol{m}}_{\hat{\mathbf{b}}}\right)-\left(\hat{u}_{0}(l)-\widehat{m}_{\widehat{u}_{0}}\right)\right)\right)^{2}\right] .
$$

Desenvolvendo (A-7), temos:

$$
\begin{aligned}
& \frac{\partial}{\partial \hat{\mathbf{c}}}\left[\sum_{l=0}^{i} \lambda^{i-l}\left(\hat{\mathbf{c}}^{T}\left(\hat{\mathbf{b}}(l)-\widehat{\boldsymbol{m}}_{\hat{\mathbf{b}}}\right)\left(\hat{\mathbf{b}}(l)-\widehat{\boldsymbol{m}}_{\hat{\mathbf{b}}}\right)^{T} \hat{\mathbf{c}}\right)\right. \\
& -2 \sum_{l=0}^{i} \lambda^{i-l}\left(\hat{\mathbf{c}}^{T}\left(\hat{\mathbf{b}}(l)-\widehat{\boldsymbol{m}}_{\hat{\mathbf{b}}}\right)\left(\hat{u}_{0}(l)-\widehat{m}_{\widehat{u}_{0}}\right)\right) \\
& \left.+\sum_{l=0}^{i} \lambda^{i-l}\left(\hat{u}_{0}(l)-\widehat{m}_{\widehat{u}_{0}}\right)^{2}\right]=
\end{aligned}
$$




$$
\frac{\partial}{\partial \hat{\mathbf{c}}}\left[\hat{\mathbf{c}}^{T} \widehat{\mathbf{K}}_{\hat{\mathbf{b}}}(i) \hat{\mathbf{c}}-2 \hat{\mathbf{c}}^{T} \widehat{\boldsymbol{p}}_{\bar{u}_{0} \overline{\mathbf{b}}}(i)+\hat{\sigma}_{\widehat{u}_{0}}^{2}(i)\right]
$$

sendo que $\widehat{\mathbf{K}}_{\hat{\mathbf{b}}}(i)$ é a aproximação da matriz covariância de $\hat{\mathbf{b}}(i)$ de dimensão $\mathrm{K} \mathbf{x}$ $\mathrm{K}$ e $\widehat{\boldsymbol{p}}_{\bar{u}_{0} \overline{\mathbf{b}}}(i)$ é a aproximação do vetor de covariância cruzada de dimensão K x $1 \mathrm{e}$ $\hat{\sigma}_{\widehat{u}_{0}}^{2}(i)$ a aproximação da variância de $\hat{u}_{0}(i)$.

Assim, resolvendo (A-9) tem-se:

$$
\frac{\partial J_{\hat{\mathbf{c}}, \hat{c}}}{\partial \hat{\mathbf{c}}}=2\left(\widehat{\mathbf{K}}_{\hat{\mathbf{b}}}(i) \mathbf{c}-\widehat{\boldsymbol{p}}_{\bar{u}_{0} \overline{\mathbf{b}}}(i)\right)
$$

Igualando (A-10) a zero resulta, finalmente, em (retornando com o índice $i$ ):

$$
\hat{\mathbf{c}}(i)=\widehat{\mathbf{K}}_{\hat{\mathbf{b}}}(i)^{-1}(i) \widehat{\boldsymbol{p}}_{\bar{u}_{0} \overline{\mathbf{b}}}(i) .
$$

A inversa de $\widehat{\mathbf{K}}_{\hat{\mathbf{b}}}(i)$ é calculada recursivamente utilizando o lema de inversão de matrizes:

$$
\widehat{\mathbf{K}}_{\hat{\mathbf{b}}}{ }^{-1}(i)=\lambda^{-1} \widehat{\mathbf{K}}_{\hat{\mathbf{b}}}^{-1}(i-1)-\lambda^{-1} \mathbf{K}(i) \hat{\mathbf{b}}_{m}(i)^{T} \widehat{\mathbf{K}}_{\hat{\mathbf{b}}}^{-1}(i-1),
$$

em que $\hat{\mathbf{b}}_{m}(i)=\hat{\mathbf{b}}(i)-\boldsymbol{m}_{\hat{\mathbf{b}}}(i) \mathrm{e}$

$$
\mathbf{K}(i)=\frac{\lambda^{-1} \widehat{\mathbf{K}}_{\hat{\mathbf{b}}}^{-1}(i-1) \hat{\mathbf{b}}_{m}(i)}{1+\lambda^{-1} \hat{\mathbf{b}}_{m}(i)^{T} \widehat{\mathbf{K}}_{\hat{\mathbf{b}}}(i-1)^{-1}(i) \hat{\mathbf{b}}_{m}(i)} .
$$

O vetor $\widehat{\boldsymbol{p}}_{\bar{u}_{0} \overline{\mathbf{b}}}(i)$ é calculado recursivamente através de:

$$
\widehat{\boldsymbol{p}}_{\bar{u}_{0} \overline{\mathbf{b}}}(i)=\lambda \widehat{\boldsymbol{p}}_{\bar{u}_{0} \mathbf{b}}(i-1)+\hat{\mathbf{b}}_{m}(i) \bar{u}_{0 m}(i)
$$

onde $\bar{u}_{0 m}(i)=\hat{u}_{0}(i)-\widehat{m}_{\widehat{u}_{0}}(i)$ 
Assim, utilizando (A-12) e (A-14) em (A-11) e considerando (A-5), temos finalmente, as estimativas, no instante $i$, do vetor de pesos e do limiar obtidas pela formulação RLS:

$$
\begin{gathered}
\hat{c}_{0}=\widehat{m}_{\widehat{u}_{0}}-\hat{\mathbf{c}}^{T} \widehat{\boldsymbol{m}}_{\hat{\mathbf{b}}} \\
\hat{\mathbf{c}}(i)=\hat{\mathbf{c}}(i-1)+\mathbf{K}(i)\left(\bar{u}_{0 m}(i)-\hat{\mathbf{c}}^{T}(i-1) \hat{\mathbf{b}}_{m}(i)\right)
\end{gathered}
$$




\section{Apêndice B}

\section{Derivação da Solução de Wiener}

A fim de calcular a solução de Wiener com referência à hipótese verdadeira $u$, é necessário minimizar a seguinte função custo:

$$
\boldsymbol{J}=\mathbb{E}\left[\left|u(i)-\hat{\mathbf{c}}^{T} \hat{\mathbf{b}}(i)-\hat{c}_{0}\right|^{2}\right]=\mathbb{E}\left[|e(i)|^{2}\right]
$$

$\mathrm{O}$ vetor $\mathbf{c}^{\text {opt }}$ e o escalar $c_{0}^{o p t}$ que minimizam (B-1) são obtidos igualando o seu gradiente a zero. Resolvendo para $\hat{c}_{0}$, tem-se:

$$
c_{0}^{o p t}=m_{u}-\mathbf{c}^{o p t^{T}} \boldsymbol{m}_{\hat{\mathbf{b}}},
$$

onde $m_{u}=\mathbb{E}[u(i)]$ e $m_{\hat{\mathbf{b}}}=\mathbb{E}[\hat{\mathbf{b}}(i)]$. Substituindo (B-2) em (B-1) e minimizando para $\hat{\mathbf{c}}$ tem-se:

$$
\mathbf{c}^{o p t}=\mathbf{K}_{\hat{\mathbf{b}}}^{-1} \boldsymbol{p}_{\bar{u} \overline{\mathbf{b}}}
$$

onde $\quad \mathbf{K}_{\hat{\mathbf{b}}}=\mathbb{E}\left[\left(\hat{\mathbf{b}}(i)-\boldsymbol{m}_{\hat{\mathbf{b}}}\right)\left(\hat{\mathbf{b}}(i)-\boldsymbol{m}_{\hat{\mathbf{b}}}\right)^{T}\right]$ e $\boldsymbol{p}_{\bar{u} \overline{\mathbf{b}}},=\mathbb{E}\left[\left(u(i)-m_{u}\right)(\hat{\mathbf{b}}(i)-\right.$ $\left.\left.\boldsymbol{m}_{\hat{\mathbf{b}}}\right)\right]$.

Expandindo então o vetor de covariância cruzada $\boldsymbol{p}_{\bar{u} \overline{\mathbf{b}}}$ :

$$
\begin{aligned}
\boldsymbol{p}_{\bar{u} \overline{\mathbf{b}}} & =\mathbb{E}[u \hat{\mathbf{b}}]-m_{u} \boldsymbol{m}_{\hat{\mathbf{b}}}-m_{\hat{\mathbf{b}}} m_{u}+\boldsymbol{m}_{\hat{\mathbf{b}}} m_{u}= \\
& =\mathbb{E}[u \hat{\mathbf{b}}]-\boldsymbol{m}_{\hat{\mathbf{b}}} m_{u}
\end{aligned}
$$

onde o índice temporal $i$ é suprimido por conveniência de notação. Calculando então $\mathbb{E}[u \hat{\mathbf{b}}]$ para cada termo $\hat{b}_{k}$ de $\hat{\mathbf{b}}$ tem-se:

$$
\mathbb{E}\left[u \hat{b}_{k}\right]=\sum_{u=-1,1} \sum_{\hat{b}=-1,1} u \hat{b} P\left(\hat{b}_{k} \mid u\right) P(u)
$$




$$
\begin{gathered}
\mathbb{E}\left[u \hat{b}_{k}\right]=P\left(\hat{b}_{k}=1 \mid u=1\right) P(u=1) \\
-P\left(\hat{b}_{k}=-1 \mid u=1\right) P(u=1) \\
-P\left(\hat{b}_{k}=1 \mid u=-1\right) P(u=-1) \\
+P\left(\hat{b}_{k}=-1 \mid u=-1\right) P(u=-1)
\end{gathered}
$$

Substituindo os valores das probabilidades de (B-4) tem-se:

$$
\mathbb{E}\left[u \hat{b}_{k}\right]=\left(1-P_{M_{k}}\right) p_{1}-P_{M_{k}} p_{1}-P_{F_{k}} p_{0}+\left(1-P_{F_{k}}\right) p_{0}
$$

Calculando agora $m_{\hat{b}}$ cada termo $\hat{b}_{k}$ de $\hat{\mathbf{b}}$ tem-se

$$
\begin{gathered}
m_{\widehat{b}}=\mathbb{E}[\hat{b}]=\sum_{i=0,1} \mathbb{E}\left[\widehat{b} \mid H_{i}\right] P\left(H_{i}\right) \\
m_{\hat{b}}=\mathbb{E}\left[\widehat{b} \mid H_{1}\right] P\left(H_{1}\right)+\mathbb{E}\left[\widehat{b} \mid H_{0}\right] P\left(H_{0}\right)
\end{gathered}
$$

Substituindo os valores das médias condicionais em (B-7):

$$
m_{\hat{b}}^{k}=\left(1-2 P_{M_{k}}\right) p_{1}+\left(2 P_{F_{k}}-1\right) p_{0}
$$

Finalmente, $m_{u}$ é calculada:

$$
m_{u}=\mathbb{E}[u]=\mathbb{E}\left[H_{i}\right]=p_{1}-p_{0}
$$

Substituindo então (B-7), (B-8) e (B-9) em (B-4) é obtida a expressão analítica de cada termo de $\boldsymbol{p}_{\bar{u} \overline{\mathbf{b}}}$ :

$$
\begin{gathered}
p_{\bar{u} \bar{b}^{k j}}=\left(1-2 P_{M_{k}}\right) p_{1}+\left(1-2 P_{F_{k}}\right) p_{0} \\
-\left[\left(1-2 P_{M_{k}}\right) p_{1}+\left(2 P_{F_{k}}-1\right) p_{0}\right]\left(p_{1}-p_{0}\right)
\end{gathered}
$$

Agora é calculada a matriz de covariância $\mathbf{K}_{\hat{\mathbf{b}}}$, para isso tem-se: 


$$
\begin{aligned}
\mathbf{K}_{\hat{b}}= & \mathbb{E}\left[\left(\hat{b}_{k}-\boldsymbol{m}_{\hat{b}_{k}}\right)\left(\hat{b}_{j}-\boldsymbol{m}_{\hat{b}_{j}}\right)^{T}\right] \\
= & \mathbb{E}\left[\hat{b}_{k} \hat{b}_{j}\right]-\boldsymbol{m}_{\hat{b}_{k}} \boldsymbol{m}_{\hat{b}_{j}}
\end{aligned}
$$

Temos que a correlação $\mathbb{E}\left[\hat{b}_{k} \hat{b}_{j}\right]$ é obtida através de:

$$
\begin{gathered}
\mathbb{E}\left[\hat{b}_{k} \hat{b}_{j}\right]=\sum_{i=0,1} \mathbb{E}\left[\hat{b}_{k} \hat{b}_{j} \mid H_{i}\right] P\left(H_{i}\right) \\
\mathbb{E}\left[\hat{b}_{k} \hat{b}_{j}\right]=\left\{\begin{array}{l}
\sum_{i=0,1} \mathbb{E}\left[\hat{b}_{k}{ }^{2} \mid H_{i}\right] P\left(H_{i}\right) \quad ; \text { para } k=j \\
\sum_{i=0,1} \mathbb{E}\left[\hat{b}_{k} \mid H_{i}\right] \mathbb{E}\left[\hat{b}_{j} \mid H_{i}\right] P\left(H_{i}\right) ; \text { para } k \neq j
\end{array}\right. \\
=\left\{\begin{aligned}
\left(1-2 P_{M_{k}}\right)\left(1-2 P_{M_{j}}\right) p_{1}+\left(2 P_{M_{k}}-1\right)\left(2 P_{M_{j}}-1\right) p_{0} ; k \neq j \\
1 \quad ; k=j
\end{aligned}\right.
\end{gathered}
$$

Assim, substituindo (B-13) e os valores das médias $\boldsymbol{m}_{\hat{b}_{k}}$ e $\boldsymbol{m}_{\hat{b}_{j}}$, dadas em (B-8), em (B-11) obtemos a expressão final para as componentes de $\mathbf{K}_{\widehat{b}}$ :

$$
\begin{gathered}
\mathrm{K}_{\hat{b}}^{k j}= \\
\left\{\begin{array}{l}
\quad\left(1-2 P_{M_{k}}\right)\left(1-2 P_{M_{j}}\right) p_{1}+\left(2 P_{M_{k}}-1\right)\left(2 P_{M_{j}}-1\right) p_{0}- \\
{\left[\left(1-2 P_{M_{k}}\right) p_{1}+\left(2 P_{F_{k}}-1\right) p_{0}+\left(1-2 P_{M_{j}}\right) p_{1}+\left(2 P_{F_{j}}-1\right) p_{0}\right] ; k \neq j} \\
1-\left[\left(1-2 P_{M_{k}}\right) p_{1}+\left(2 P_{F_{k}}-1\right) p_{0}\right]^{2}
\end{array} ; k=j\right.
\end{gathered}
$$

Substituindo (B-10) e (B-14) nas componentes de $\boldsymbol{p}_{\bar{u} \overline{\mathbf{b}}}$ e $\mathbf{K}_{\hat{\mathbf{b}}}$ respectivamente, é obtida a expressão analítica do filtro de Wiener.

Assim, é possível calcular o mínimo erro médio quadrático (MMSE) para do filtro de Wiener utilizando a expressão clássica para o MMSE [52-53]:

$$
\operatorname{MMSE}=\left(1-m_{u}^{2}\right)-\boldsymbol{p}_{\bar{u} \overline{\mathbf{b}}}^{T} \mathbf{K}_{\overline{\mathbf{b}}}^{-1} \boldsymbol{p}_{\bar{u} \overline{\mathbf{b}}}
$$

Tendo desenvolvido a solução de Wiener, cuja a referência da função custo é a verdadeira da hipótese $u$, será desenvolvido a solução de Wiener, cuja referência é uma estimativa de $u$ dada pela saída da regra da maioria, $\hat{u}_{0}$, 
calculada através das componentes $\mathbf{b}$ conforme mencionado previamente no capítulo 5 .

Nesse caso, a solução de Wiener com referência $\hat{u}_{0}$, é dada por:

$$
\begin{gathered}
c_{0}^{w}=m_{\widehat{u}_{0}}-\mathbf{c}^{w^{T}} \boldsymbol{m}_{\hat{\mathbf{b}}}, \\
\mathbf{c}^{w}=\mathbf{K}_{\hat{\mathbf{b}}}^{-1} \boldsymbol{p}_{\bar{u}_{0} \overline{\mathbf{b}}}
\end{gathered}
$$

onde $\quad m_{\widehat{u}_{0}}=\mathbb{E}\left[\hat{u}_{0}\right], \quad \mathbf{K}_{\hat{\mathbf{b}}}=\mathbb{E}\left[\left(\hat{\mathbf{b}}(i)-\boldsymbol{m}_{\hat{\mathbf{b}}}\right)\left(\hat{\mathbf{b}}(i)-\boldsymbol{m}_{\hat{\mathbf{b}}}\right)^{T}\right] \quad$ e $\quad \boldsymbol{p}_{\bar{u}_{0} \overline{\mathbf{b}}}=$ $\mathbb{E}\left[\left(\hat{u}_{0}(i)-m_{\widehat{u}_{0}}\right)\left(\hat{\mathbf{b}}(i)-\boldsymbol{m}_{\hat{\mathbf{b}}}\right)\right]$.

Conforme observado em (B-16) e (B-17), a matriz de covariância $\mathbf{K}_{\hat{\mathbf{b}}}$ é a mesma que em (B-14) e as componentes do vetor média $\boldsymbol{m}_{\hat{\mathbf{b}}}$ são os mesmos de (B-8). Assim, é necessário calcular $\boldsymbol{p}_{\bar{u}_{0} \overline{\mathbf{b}}}$ e $m_{\widehat{u}_{0}}$ para chegar a expressões analíticas de (B-16) e (B-17).

Nesse contexto, expandindo então o vetor de covariância cruzada $\boldsymbol{p}_{\bar{u}_{0} \overline{\mathbf{b}}}$, tem-se:

$$
\boldsymbol{p}_{\bar{u}_{0} \overline{\mathbf{b}}}=\mathbb{E}\left[\hat{u}_{0} \hat{\mathbf{b}}\right]-\boldsymbol{m}_{\hat{\mathbf{b}}} m_{\widehat{u}_{0}}
$$

Calculando $\mathbb{E}\left[\hat{u}_{0} \hat{\mathbf{b}}\right]$ para cada termo $\hat{b}_{k}$ de $\hat{\mathbf{b}}$, tem-se:

$$
\begin{gathered}
\mathbb{E}\left[\hat{u}_{0} \hat{b}_{k}\right]=\sum_{u=-1,1} \sum_{\hat{b}=-1,1} \hat{u}_{0} \hat{b} P\left(\hat{u}_{0} \mid \hat{b}\right) P(\hat{b})= \\
\mathbb{E}\left[u \hat{b}_{k}\right]=P\left(\hat{u}_{0}=1 \mid \hat{b}_{k}=1\right) P\left(\hat{b}_{k}=1\right) \\
-P\left(\hat{u}_{0}=-1 \mid \hat{b}_{k}=1\right) P\left(\hat{b}_{k}=1\right) \\
-P\left(\hat{u}_{0}=1 \mid \hat{b}_{k}=-1\right) P\left(\hat{b}_{k}=-1\right) \\
+P\left(\hat{u}_{0}=-1 \mid \hat{b}_{k}=-1\right) P\left(\hat{b}_{k}=-1\right)
\end{gathered}
$$

Para desenvolver (B-21) é necessário calcular cada uma das probabilidades do lado direito da equação (B-21). Tem-se, então, que: 


$$
P\left(\hat{u}_{0} \mid \hat{b}_{k}=j\right)=\sum_{\hat{\mathbf{b}}_{i}^{k} \in\{-1,1\}^{\mathrm{K}-1}} \sum_{i=1,0} P\left(\hat{u}_{0}, \hat{\mathbf{b}}_{1}^{k}, H_{i} \mid \hat{b}_{k}=j\right),
$$

em que $\hat{\mathbf{b}}_{1}^{k}=\left[\hat{b}_{1} \hat{b}_{2} \ldots \hat{b}_{k-1} \hat{b}_{k+1} \ldots \hat{b}_{\mathrm{K}}\right]$ dado $\hat{b}_{k}=j, j \in\{-1,1\}$. A equação (B-22) pode ser expressa como:

$$
P\left(\hat{u}_{0} \mid \hat{b}_{k}=j\right)=\sum_{\hat{\mathbf{b}}_{i}^{k} \in\{-1,1\}^{\mathrm{K}-1}} \sum_{i=0,1} P\left(\hat{u}_{0}, \hat{\mathbf{b}}_{1}^{k} \mid H_{i}, \hat{b}_{k}\right) P\left(H_{i} \mid \hat{b}_{k}\right) .
$$

Para $\hat{u}_{0}=1, \hat{b}_{k}=1$ e $H_{1}$ :

$$
P\left(\hat{u}_{0}=1, \hat{\mathbf{b}}_{1}^{k} \mid H_{1}, \hat{b}_{k}=1\right)=P\left(\operatorname{sum}\left(\hat{\mathbf{b}}_{1}^{k}\right)>\mathrm{K}-\left\lfloor\frac{\mathrm{K}}{2}\right\rfloor-1\right),
$$

onde $\operatorname{sum}()=.\sum_{k=1}^{\mathrm{K}} \hat{b}_{k}$ e [. ] é a função floor. Desenvolvendo (B-24) tem-se:

$$
\begin{gathered}
P\left(\hat{u}_{0}=1, \hat{\mathbf{b}}_{1}^{k} \mid H_{1}, \hat{b}_{k}=1\right)= \\
=\sum_{\left.k=\mathrm{K}-\mid \frac{\mathrm{K}}{2}\right]_{-1}} \prod_{S_{k+}^{+}} 1-P_{M_{k}} \prod_{S_{k+}^{-}} P_{M_{k}}
\end{gathered}
$$

em que $S_{k+}^{+}$é o conjunto das $2^{\mathrm{K}-1}$ possíveis combinações das componentes de $\hat{\mathbf{b}}^{k}$ para $\hat{b}_{k}=1$ e $S_{k+}^{-}$é o conjunto das $2^{\mathrm{K}-1}$ combinações das componentes de $\hat{\mathbf{b}}^{k}$ para $\hat{b}_{k}=-1$.

Seguindo, tem-se que:

$$
\begin{gathered}
P\left(H_{1} \mid \hat{b}_{k}=1\right)=\frac{P\left(\hat{b}_{k}=1 \mid H_{1}\right) P\left(H_{1}\right)}{P\left(\hat{b}_{k}=1\right)} \\
P\left(H_{1} \mid \hat{b}_{k}=1\right)=\frac{\left(1-P_{M_{k}}\right) p_{1}}{P\left(\hat{b}_{k}=1 \mid H_{1}\right) P\left(H_{1}\right)+P\left(\hat{b}_{k}=1 \mid H_{0}\right) P\left(H_{0}\right)} \\
P\left(H_{1} \mid \hat{b}_{k}=1\right)=\frac{\left(1-P_{M_{k}}\right) p_{1}}{\left(1-P_{M_{k}}\right) p_{1}+P_{F_{k}} p_{0}}
\end{gathered}
$$


Para $\hat{u}_{0}=1, \hat{b}_{k}=1$ e $H_{0}$ :

$$
\begin{gathered}
P\left(\hat{u}_{0}=1, \hat{\mathbf{b}}_{1}^{k} \mid H_{1}, \hat{b}_{k}=1\right)= \\
\sum_{k=\mathrm{K}-\left\lfloor\frac{\mathrm{K}}{2} \mid-1\right.}^{\mathrm{K}} \prod_{S_{k+}^{+}} P_{F_{k}} \prod_{S_{k+}^{-}} 1-P_{M_{k}} \\
P\left(H_{0} \mid \hat{b}_{k}=1\right)=\frac{P\left(\hat{b}_{k}=1 \mid H_{0}\right) P\left(H_{0}\right)}{P\left(\hat{b}_{k}=1\right)} \\
P\left(H_{0} \mid \hat{b}_{k}=1\right)=\frac{P_{F_{k}} p_{0}}{\left(1-P_{M_{k}}\right) p_{1}+P_{F_{k}} p_{1}}
\end{gathered}
$$

em que $S_{k+}^{+}$é o conjunto das $2^{\mathrm{K}-1}$ combinações das componentes de $\hat{\mathbf{b}}^{k}$ para $\hat{b}_{k}=1$ e $S_{k+}^{-}$é o conjunto das $2^{\mathrm{K}-1}$ combinações das componentes de $\hat{\mathbf{b}}^{k}$ para $\hat{b}_{k}=-1$.

Assim, substituindo (B-24), (B-28), (B-29) e (B-31) em (B-23), tem-se que:

$$
\begin{gathered}
P\left(\hat{u}_{0}=1 \mid \hat{b}_{k}=1\right)= \\
{\left[\sum_{k=\mathrm{K}-\left\lfloor\frac{\mathrm{K}}{2} \mid-1\right.}^{\mathrm{K}} \prod_{S_{k}^{+}} 1-P_{M_{k}} \prod_{S_{k}^{-}} P_{M_{k}}\right]\left[\frac{\left(1-P_{M_{k}}\right) p_{1}}{\left(1-P_{M_{k}}\right) p_{1}+P_{F_{k}} p_{0}}\right]+} \\
{\left[\sum_{k=\mathrm{K}-\left\lfloor\frac{\mathrm{K}}{2}\right\rfloor_{-1}}^{\mathrm{K}} \prod_{S_{k}^{+}} P_{F_{k}} \prod_{S_{k}^{-}} 1-P_{M_{k}}\right]\left[\frac{P_{F_{k}} p_{0}}{\left(1-P_{M_{k}}\right) p_{1}+P_{F_{k}} p_{0}}\right]+}
\end{gathered}
$$

Para $\hat{u}_{0}=-1, \hat{b}_{k}=-1$ e $H_{1}$ :

$$
P\left(\hat{u}_{0}=-1, \hat{\mathbf{b}}_{0}^{k} \mid H_{1}, \hat{b}_{k}=-1\right)=P\left(\operatorname{sum}\left(\hat{\mathbf{b}}_{-1}^{k}\right)<\mathrm{K}-\left\lfloor\frac{\mathrm{K}}{2}\right\rfloor-1\right)
$$




$$
\begin{gathered}
P\left(\hat{u}_{0}=-1, \hat{\mathbf{b}}_{-1}^{k} \mid H_{1}, \hat{b}_{k}=1\right)= \\
=1-\sum_{k=\mathrm{K}-\left[\frac{\mathrm{K}}{2}\right]-1} \prod_{S_{k-}^{+}} 1-P_{M_{k}} \prod_{S_{k-}^{-}} P_{M_{k}}
\end{gathered}
$$

onde $S_{k-}^{+}$é o conjunto das $2^{\mathrm{K}-1}$ possíveis combinações das componentes de $\hat{\mathbf{b}}_{-1}^{k}$ para $\hat{b}_{k}=1$ e $S_{k-}^{-}$é o conjunto das $2^{\mathrm{K}-1}$ possíveis combinações das componentes de $\hat{\mathbf{b}}_{-1}^{k}$ para $\hat{b}_{k}=-1$.

Seguindo, tem-se que:

$$
\begin{gathered}
P\left(H_{1} \mid \hat{b}_{k}=-1\right)=\frac{P\left(\hat{b}_{k}=-1 \mid H_{1}\right) P\left(H_{1}\right)}{P\left(\hat{b}_{k}=-1\right)} \\
=\frac{P_{M_{k}} p_{1}}{P\left(\hat{b}_{k}=-1 \mid H_{0}\right) P\left(H_{0}\right)+P\left(\hat{b}_{k}=-1 \mid H_{0}\right) P\left(H_{0}\right)} \\
P\left(H_{1} \mid \hat{b}_{k}=1\right)=\frac{P_{M_{k}} p_{1}}{P_{M_{k}} p_{1}+\left(1-P_{F_{k}}\right) p_{0}}
\end{gathered}
$$

Para $\hat{u}_{0}=-1, \hat{b}_{k}=-1$ e $H_{0}$ :

$$
\begin{array}{r}
P\left(\hat{u}_{0}=-1, \hat{\mathbf{b}}_{-1}^{k} \mid H_{0}, \hat{b}_{k}=1\right)= \\
1-\sum_{k=\mathrm{K}-\left[\frac{\mathrm{K}}{2}\right]-1} \prod_{S_{k-}^{+}} 1-P_{F_{k}} \prod_{S_{k-}^{-}} P_{F_{k}} \\
P\left(H_{0} \mid \hat{b}_{k}=-1\right)=\frac{P\left(\hat{b}_{k}=-1 \mid H_{0}\right) P\left(H_{0}\right)}{P\left(\hat{b}_{k}=-1\right)} \\
=\frac{\left(1-P_{F_{k}}\right) p_{0}}{P_{M_{k}} p_{1}+\left(1-P_{F_{k}}\right) p_{0}}
\end{array}
$$

Assim, substituindo (B-34), (B-37), (B-38) e (B-40) em (B-23) tem-se que:

$$
P\left(\hat{u}_{0}=-1 \mid \hat{b}_{k}=-1\right)=
$$




$$
\begin{aligned}
& {\left[1-\sum_{k=\mathrm{K}-\left\lfloor\frac{\mathrm{K}}{2}\right\rfloor-1}^{\mathrm{K}} \prod_{S_{k-}^{+}} 1-P_{M_{k}} \prod_{S_{k-}^{-}} P_{M_{k}}\right]\left[\frac{P_{M_{k}} p_{1}}{P_{M_{k}} p_{1}+\left(1-P_{F_{k}}\right) p_{0}}\right]+} \\
& {\left[1-\sum_{k=\mathrm{K}-\left\lfloor\frac{\mathrm{K}}{2}\right\rfloor-1}^{\mathrm{K}} \prod_{S_{k-}^{+}} 1-P_{F_{k}} \prod_{S_{k-}^{-}} P_{F_{k}}\right]\left[\frac{\left(1-P_{F_{k}}\right) p_{0}}{P_{M_{k}} p_{1}+\left(1-P_{F_{k}}\right) p_{0}}\right]+}
\end{aligned}
$$

Finalmente, tem-se que:

$$
\begin{aligned}
& P\left(\hat{u}_{0}=-1 \mid \hat{b}_{k}=1\right)=1-P\left(\hat{u}_{0}=1 \mid \hat{b}_{k}=1\right) \\
& P\left(\hat{u}_{0}=1 \mid \hat{b}_{k}=-1\right)=1-P\left(\hat{u}_{0}=-1 \mid \hat{b}_{k}=-1\right)
\end{aligned}
$$

Tendo calculado as probabilidades condicionais $P\left(\hat{u}_{0} \mid \hat{b}_{k}\right)$, falta então o cálculo de $P\left(\hat{b}_{k}=1\right)$ e $P\left(\hat{b}_{k}=-1\right)$ para obter-se a expressão analítica de (B21). Para isto faz-se:

$$
\begin{gathered}
P\left(\hat{u}_{0}=1\right)=P\left(\hat{u}_{0}=1 \mid H_{1}\right) P\left(H_{1}\right)+P\left(\hat{u}_{0}=1 \mid H_{0}\right) P\left(H_{0}\right) \\
P\left(\hat{u}_{0}=-1\right)=P\left(\hat{u}_{0}=-1 \mid H_{1}\right) P\left(H_{1}\right)+P\left(\hat{u}_{0}=-1 \mid H_{0}\right) P\left(H_{0}\right)
\end{gathered}
$$

Tem-se que $P\left(\hat{u}_{0}=1 \mid H_{0}\right)$ é a probabilidade de que no mínimo $\left\lfloor\frac{\mathrm{K}}{2}\right\rfloor$ estimativas $\hat{b}_{k}$ estejam associados a um falso alarme:

$$
P_{F 0}=P\left(\hat{u}_{0}=1 \mid H_{0}\right)=\sum_{k=\mathrm{K}-\left\lfloor\frac{\mathrm{K}}{2}\right\rfloor}^{\mathrm{K}} \prod_{S_{k}^{+}} P_{F_{k}} \prod_{S_{k}^{-}} 1-P_{F_{k}}
$$

onde $S_{k}^{+}$é o conjunto das $2^{\mathrm{K}-1}$ possíveis combinações das componentes $\hat{\mathbf{b}}$ para $\hat{b}_{k}=1$ e $S_{k}^{-}$é o conjunto das $2^{\mathrm{K}-1}$ possíveis combinações das componentes $\hat{\mathbf{b}}$ para $\hat{b}_{k}=-1$.

Similarmente, $P\left(\hat{u}_{0}=1 \mid H_{1}\right)$ é a probabilidade de que no mínimo $\left\lfloor\frac{\mathrm{K}}{2}\right\rfloor$ estimativas $\widehat{b}_{k}$ sejam iguais a 1 dado que a hipótese $H_{1}$ tenha ocorrido, ou seja: 


$$
P\left(\hat{u}_{0}=1 \mid H_{1}\right)=\sum_{k=\mathrm{K}-\left\lfloor\frac{\mathrm{K}}{2}\right\rfloor} \prod_{S_{k}^{+}} 1-P_{M_{k}} \prod_{S_{k}^{-}} P_{M_{k}}
$$

Finalmente, tem-se:

$$
\begin{array}{r}
P\left(\hat{u}_{0}=-1 \mid H_{0}\right)=1-P\left(\hat{u}_{0}=1 \mid H_{0}\right) \\
P_{M 0}=P\left(\hat{u}_{0}=-1 \mid H_{1}\right)=1-P\left(\hat{u}_{0}=1 \mid H_{1}\right)
\end{array}
$$

Assim substituindo (B-32), (B-41), (B-42), (B-43), (B-46-B-49) em (B-21) obtêm-se a expressão analítica para o vetor de correlação cruzada $\mathbb{E}\left[u \hat{b}_{k}\right]$.

A média $m_{\widehat{u}_{0}}$ pode ser expressa como:

$$
\begin{aligned}
& m_{\widehat{u}_{0}}=\mathbb{E}\left[\hat{u}_{0}\right]=\sum_{i=0,1} \mathbb{E}\left[\hat{u}_{0} \mid H_{i}\right] P\left(H_{i}\right) \\
& m_{\widehat{u}_{0}}=\mathbb{E}\left[\hat{u}_{0} \mid H_{1}\right] P\left(H_{1}\right)+\mathbb{E}\left[\hat{u}_{0} \mid H_{0}\right] P\left(H_{0}\right)
\end{aligned}
$$

Substituindo a probabilidade de falso-alarme de $\hat{u}_{0}, P_{F 0}$ dada por (B-46) e a probabilidade de misdetection de $\hat{u}_{0}, P_{M 0}$ dada por (B-47) e (B-49), de $P_{M 0}$ em (B-51) obtêm-se:

$$
m_{\widehat{u}_{0}}=\left(1-2 P_{M 0}\right) p_{1}+\left(2 P_{F 0}-1\right) p_{0}
$$

Assim, substituindo (B-8), (B-21) e (B-52), obtêm-se as componentes do vetor $\boldsymbol{p}_{\bar{u}_{0} \overline{\mathbf{b}}}$ dado em (B-19). Com (B-14) e (B-19) obtêm-se o filtro de Wiener com referência $\hat{u}_{0}$, dada em (B-16) e (B-17).

O mínimo erro médio quadrático $\left(\mathrm{MMSE}_{\widehat{u}_{0}}\right)$ para a solução de Wiener com referência $\hat{u}_{0}$, dada em (B-16) e (B-17), é calculada por:

$$
\operatorname{MMSE}_{\widehat{u}_{0}}=\left(1-m_{\widehat{u}_{0}}^{2}\right)-\boldsymbol{p}_{\bar{u}_{0} \overline{\mathbf{b}}}^{T} \mathbf{K}_{\hat{\mathbf{b}}}^{-1} \boldsymbol{p}_{\bar{u}_{0} \overline{\mathbf{b}}}
$$

